Bild und Recht - Studien zur Regulierung des Visuellen 8

Franziska Brinkmann

\title{
Satire vor Gericht
}

Eine Auseinandersetzung mit den Politsatire-Plakaten Klaus Staecks aus rechtlicher und kunsthistorischer Perspektive

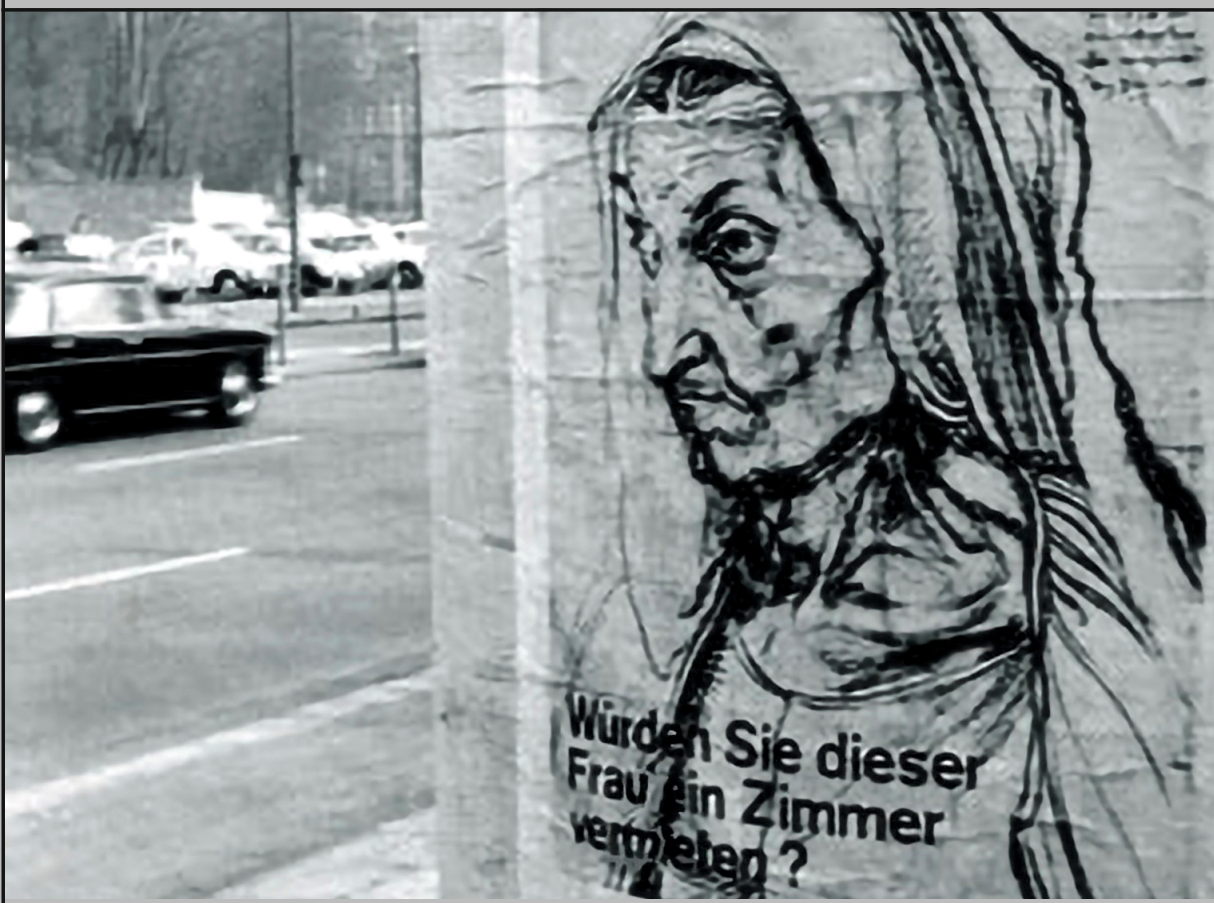


Bild und Recht - Studien zur Regulierung des Visuellen

herausgegeben von

Prof. Dr. Thomas Dreier

PD Dr. Dr. Grischka Petri

Prof. Dr. Wolfgang Ullrich

Prof. Dr. Matthias Weller

Band 8 
Franziska Brinkmann

\section{Satire vor Gericht}

Eine Auseinandersetzung mit den Politsatire-Plakaten Klaus Staecks aus rechtlicher und kunsthistorischer Perspektive

\section{Nomos}


(c) Titelbild: Nürnberger Plakataktion 1971, Klaus Staeck

The book processing charge was funded by the Baden-Württemberg Ministry of Science, Research and Arts in the funding programme Open Access Publishing and the University of Freiburg.

Erstgutachter: $\quad$ Prof. Dr. Thomas Dreier, M.C.J.

Zweitgutachter: Prof. Dr. Thomas Würtenberger

Tag der mündlichen Prüfung: 16.11.2020-18.11.2020

Dekan: $\quad$ Prof. Dr. Jan von Hein

Die Deutsche Nationalbibliothek verzeichnet diese Publikation in der Deutschen Nationalbibliografie; detaillierte bibliografische Daten sind im Internet über http://dnb.d-nb.de abrufbar.

Zugl.: Freiburg i. Br., Univ., Diss., 2020

1. Auflage 2021

(๖) Franziska Brinkmann

Publiziert von

Nomos Verlagsgesellschaft mbH \& Co. KG

Waldseestraße 3-5 | 76530 Baden-Baden

www.nomos.de

Gesamtherstellung:

Nomos Verlagsgesellschaft mbH \& Co. KG

Waldseestraße 3-5 | 76530 Baden-Baden

ISBN (Print): 978-3-8487-7861-4

ISBN (ePDF): 978-3-7489-2265-0

DOI: https://doi.org/10.5771/9783748922650

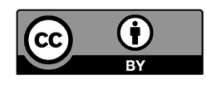

Dieses Werk ist lizensiert unter einer Creative Commons Namensnennung 4.0 International Lizenz. 


\section{Vorwort}

„Deutsche Arbeiter! Die SPD will euch eure Villen im Tessin wegnehmen“

In seinen pointierten Plakaten kommentiert der Künstler und Jurist Klaus Staeck das politische Geschehen und fordert eine Auseinandersetzung mit großen gesellschaftlichen Themen ein - durchaus zum Ärger der Betroffenen. In den zahlreich gegen ihn geführten Rechtsverfahren wird das Spannungsfeld der satirischen Äußerung zwischen Kunst- und Meinungsfreiheit sowie dem Persönlichkeitsrecht der Betroffenen deutlich. Die interdisziplinäre Arbeit beleuchtet die Plakate und die Rechtsverfahren aus rechtlicher und kunsthistorischer Sicht. Sie entstand während meiner Zeit als akademische Mitarbeiterin am Zentrum für Angewandte Rechtswissenschaft, Karlsruher Institut für Technologie.

Mein Dank gilt zunächst Professor Klaus Staeck, der die Bearbeitung des Themas in dieser Form überhaupt erst ermöglichte. Herr Staeck stand nicht nur jederzeit für Fragen zur Verfügung, sondern überließ mir für die Dauer der Dissertation sein privates Archivmaterial zu den Prozessen, deren Auswertung das Herzstück dieser Arbeit bildet. Für dieses große Vertrauen bedanke ich mich sehr.

Meinem Doktorvater Professor Dr. Thomas Dreier danke ich für die Betreuung der Arbeit. Herr Dreier hat mich stets durch wichtige Anregungen und Hinweise unterstützt. Er ermöglichte mir, meine verschiedenen Studiengänge der Kunstgeschichte, Geschichte und Rechtswissenschaften im Rahmen dieser Dissertation zu verbinden. Den Kontakt zu Herr Staeck vermittelte dankenswerterweise Professor Dr. Wolfgang Ullrich. Ihm, meinem Doktorvater, PD Dr. Dr. Grischka Petri sowie Professor Dr. Matthias Weller danke ich für die Aufnahme in die Schriftenreihe „Bild und Recht - Studien zur Regulierung des Visuellen“. Professor Dr. Thomas Würtenberger bin ich für die zügige Erstellung des Zweitgutachtens dankbar. Dr. Marco Ganzhorn und dem Team des Nomos-Verlags danke ich für die Betreuung der Drucklegung.

Bei meinen Freunden und Kollegen am Institut bedanke ich mich für die vielen hilfreichen Gespräche und die freundschaftliche Arbeitsatmosphäre. Der reiche Gedankenaustauch mit Dr. Eva-Maria Bauer hat die Entstehung der Arbeit befördert. 
Alexander danke ich sehr für den unermüdlichen Einsatz, die Motivation und das Durchhaltevermögen. Meinen Eltern danke ich für die Durchsicht des Manuskripts sowie die stete Bestärkung.

Karlsruhe, im Dezember 2020

Franziska Brinkmann 


\section{Inhaltsverzeichnis}

$\begin{array}{ll}\text { Einführung } & 15\end{array}$

A. Einleitungsgedanke $\quad 15$

B. Methodik und Forschungsstand 16

C. Gang der Darstellung $\quad 18$

$\begin{array}{ll}\text { - Erster Teil - } & 19\end{array}$

Erstes Kapitel: Das Plakat $\quad 21$

A. Arten und Formen des Plakats unter Berücksichtigung der historischen Einordnung $\quad 21$

I. Einleitung $\quad 21$

II. Die kunsthistorischen und -soziologischen Vorläufer 22

III. Typologie des Plakats $\quad 26$

1. Das Plakat und seine werbende Funktion 26

2. Das politische Plakat 28

3. Das künstlerische politische Plakat 31

4. Das künstlerische Politsatire-Plakat 35

B. Ein Zwischenfazit 37

Zweites Kapitel: Vom Komischen zum Satirischen. Eine Begriffsannäherung 38

A. Das Komische und das Witzige - der Humor 39

B. Das Ironische, das Sarkastische, das Zynische 41

C. Die Karikatur, die Parodie, der Pastiche und die Persiflage 44

I. Die Karikatur $\quad 44$

II. Die Parodie 45

1. Die etymologische und kunst- und literaturwissenschaftliche Einordnung 45

2. Die rechtliche Einordnung 45

III. Der Pastiche 47

1. Die etymologische und kunst- und literaturwissenschaftliche Einordnung $\quad 47$ 
2. Die rechtliche Einordnung des Begriffs „Pastiche“ 48

IV. Die Persiflage 50

D. Die Satire, das Satirische und die literaturwissenschaftliche Satiretheorie $\quad 50$

I. Einführung in eine Begriffsnäherung 50

II. Die Definitionen der deutschen Autoritäten 53

III. Die konstituierenden Merkmale nach der

Literaturwissenschaft $\quad 54$

1. Einführung 54

2. Die Elemente nach Schönert, Brummack und Zymner 55

3. Die überzeitlichen Merkmale der Satire: Angriff, Indirektheit und Normbezug $\quad 58$

a) Angriff und Aggression $\quad 58$

b) Normbezug $\quad 58$

c) Indirektheit 59

d) Zwischenfazit 60

IV. Die nicht-konstituierenden Merkmale der Satire? $\quad 60$

1. Die Ironie 60

2. Das Lachen: Humor, Witz und Komik 61

V. Funktion, Ziel und Wirkung der Satire 63

1. Die Funktionen der Satire in Bezug auf den Rezipienten 63

2. Die Funktionen der Satire in Bezug auf den Satiriker 66

VI. Bewertung 67

1. Das Problem der Rezipientenabhängigkeit 67

2. Das Problem der Indirektheit und des Angriffs 69

3. Das Problem der Kontextbezogenheit 70

4. Das Problem des Lachens 70

5. Eine Näherung durch Beschreibungen $\quad 71$

E. Ein Zwischenfazit 72

Drittes Kapitel: Das satirische Plakat im rechtlichen Konflikt $\quad 74$

A. Einführung 74

B. Der rechtliche Satirebegriff $\quad 75$

$\begin{array}{ll}\text { I. Der verfassungsrechtliche Satirebegriff } & 75\end{array}$

II. Der rechtliche Satirebegriff in Bezug auf den literatur- bzw. kulturhistorischen Satirebegriff 
C. Der verfassungsrechtliche Schutz der Satire $\quad 80$

I. Die Meinungsfreiheit, Art. 5 Abs. 1 S. 1 GG 80

1. Die Notwendigkeit des Schutzes $\quad 80$

2. Die Meinung 82

3. Meinung und Werbung $\quad 84$

4. Meinung und Satire 84

II. Presse-, Rundfunk- und Filmfreiheit, Art. 5 Abs. 1 S. 2 GG 86

III. Kunstfreiheit, Art. 5 Abs. 3 S. 1 GG 87

1. Der Begriff der Kunst 88

2. Die Satire und die Kunstfreiheit 90

3. Das satirische Plakat in Bezug auf die Kunstfreiheit 91

IV. Das Verhältnis $\quad 92$

1. Einführung 92

2. Verhältnis von Kunst- und Meinungsfreiheit 92

3. Verhältnis zu anderen Grundrechten 93

D. Eingriffe in den Schutzbereich 94

E. Das künstlerische Politsatire-Plakat und seine Grenzen 95

I. Die Schranken und Schranken-Schranken der Satire im Allgemeinen 95

1. Das Zensurverbot des Art. 5 Abs. 1 S. 3 GG 96

2. Die allgemeinen Gesetze und der Ehrschutz nach Art. 5 Abs. 2 GG 96

3. Die Schranken der Kunstfreiheit 98

II. Die absoluten Grenzen 99

1. Schmähkritik und Formalbeleidigungen 99

2. Angriff auf die Menschenwürde 101

III. Die (satirische) Äußerung in Abwägung mit dem

Persönlichkeitsrecht

1. Vermutungsregel bei Beiträgen zur öffentlichen Meinungsbildung $\quad 103$

2. Rede und Gegenrede, das Recht auf Gegenschlag 104

3. Erhöhte Schwelle durch die Idee der Reizüberflutung 106

4. Die Sphärentheorie 106

5. Schritt in die Öffentlichkeit 107

6. Rahmen der Äußerung 108

7. Besonders schützenswerte Personen 108

8. Ergebnis 109 
IV. Die Kriterien für die Auslegung der Satire im Besonderen

1. Auslegungsmethodik der Rechtsprechung: Die Entkleidung der Aussage

2. Kritik und Auslegungsvorschläge der Literatur

a) Kritik an der Ausführung des Gesamtkontextkonzepts

b) Die „erträgliche“ Form

c) Die alleinige Fokussierung auf den Aussagekern

d) Kritik an dem Maßstab des Durchschnittsbetrachters

3. Der Auslegungsmaßstab im Fall des künstlerischen Politsatire-Plakats

V. Die satirische Äußerung in Kollision

1. Die Satire in Kollision mit dem Namensrecht

2. Die Satire in Kollision mit dem Markenrecht

F. Satire im Lichte der EMRK und des EU-Rechts

I. Die Rechtsprechung des EGMR

1. Der Schutz der Satire unter den Kommunikationsfreiheiten

2. Der Schutz der Satire unter der Kunstfreiheit

a) Satire und Sexualmoral

b) Der zeitliche und örtliche Bezug

II. Die Rechtsprechung des EuGH

1. Deckmyn gegen Vandersteen

a) Der Sachverhalt

b) Rechtliche Bewertung: Zwischen Parodie und Satire

c) Zwischen Parodie und Satire im Lichte des Europarechts

2. Das Spannungsverhältnis Persönlichkeitsrecht und Kommunikationsfreiheiten im Europarecht

G.Zwischenfazit

- Zweiter Teil -

Viertes Kapitel: Die Plakate Klaus Staecks

A. Ausgangslage: Der Stand der Plakatkunst in der BRD 133

B. Klaus Staeck 134

$\begin{array}{ll}\text { I. Kurzbiographie } & 134\end{array}$

II. Wichtige künstlerische Stationen 135

1. Intermedia 69 
2. Die Verbindung zu Joseph Beuys 136

C. Die Plakate Klaus Staecks 138

I. Ein Einblick in die frühen Plakataktionen Klaus Staecks 138

$\begin{array}{ll}\text { II. Die Methodik } & 140\end{array}$

1. Die Montage 143

2. Text-Bild-Verhältnisse 143

a) Die bild-linguistische Untersuchung der Plakate im Allgemeinen 145

b) Plakatbeispiele 146

aa) Dominanz und Redundanz 146

bb) Komplementarität 147

cc) Kontradiktion 148

dd) Kontextualität 149

c) Das Satirische in den Plakaten Staecks 149

D. Konflikte und Aktionen nicht juristischer Art 150

I. Der Fall Staeck 150

II. Der sogenannte Bonner Bildersturm 152

E. Kritische Rezeption Staecks 154

F. Zwischenfazit 156

Fünftes Kapitel: Die Prozesse 157

A. Ein Staeckmotiv im Strafprozess 157

$\begin{array}{ll}\text { I. Sachverhalt } & 157\end{array}$

$\begin{array}{lr}\text { II. Entscheidung } & 158\end{array}$

III. Bewertung 158

B. Die zivilrechtlichen Prozesse gegen Arbeiten Klaus Staecks $\quad 160$

I. Plakate mit satirischer Wahlaufforderung zu Lasten der CDU 160

1. „Die Reichen müssen reicher werden. Deshalb CDU“ 160
a) Sachverhalt 160
b) Entscheidung 161
c) Bewertung 162

2. „Die Reichen müssen reicher werden, wählt christdemokratisch" 163

3. BVG Berlin und das Niedersachsenroß 164

4. Zwischenfazit 166

II. „Juso beißt wehrloses Kind“ 167 
III. „Alle reden vom Frieden. Wir nicht“ 169

1. Einstimmung 169

2. Das Plakat 169

3. Der Hintergrund 170

4. Verfahrensverlauf - ein Überblick 171

5. Die Verfahren im Einzelnen 172

a) Die Verfahren in der ersten Instanz 172 aa) Die Anträge 172 bb) Die Beschlüsse 174

b) Die Verfahren in der zweiten Instanz 175 aa) Die Anträge 175

bb) Entscheidungen 176

6. Bewertung 180

a) Die Auseinandersetzung der Gerichte mit der Satire $\quad 180$

b) $\$ 23$ Abs. 1 Nr. KUG 181

7. Nachtrag 182

IV. „Alle reden vom Klima. Wir ruinieren es“

1. Das Plakat 183

2. Der Hintergrund 184

3. Die Verfahren 185

a) Verfahrensverlauf - ein Überblick $\quad 185$

aa) Kali Chemie AG 185

bb) Hoechst AG 186

cc) Zwischenergebnis 187

b) OLG Celle 187

c) OLG Frankfurt am Main 189

d) $\mathrm{BGH} \quad 190$

e) BVerfG 192

aa) Die Verfassungsbeschwerde von Greenpeace 193

bb) Die Verfassungsbeschwerde des Vorstandsvorsitzenden 194

4. Bewertung 195

a) Methodik des satirischen Plakats 195

b) Verpflichtungen der Satire 197

c) „Alle reden vom Klima. Wir ruinieren es“ und „Alle reden vom Frieden. Wir nicht“ - Ein Vergleich 198

V. „Der größte Schwindel seit der Farbe Grün“ 199

1. Plakat und Hintergrund 199

2. Verfahren 200

3. Bewertung 201 
VI. Zwischenfazit zu den zivilrechtlichen Prozessen 201

C. Klaus Staeck als Kläger 202

I. „typisch faschistisch“ 202

II. „Vetternwirtschaft ist für sowas ein noch zu freundlicher Ausdruck“" 205

III. Reaktionen 208

D. Klaus Staeck der rechtsstaatliche Künstler 208

E. Klaus Staeck als Gesamtkunstwerk 211

I. Die Motive 211

1. Der Topos des Prozessrisiko als finanzielles Existenzrisiko

2. Die David-Goliath-Inszenierung 211

3. Die starke mediale Berichterstattung 212

4. Der Künstler ist anwesend 212

5. Der Künstler als eigener Archivar 212

6. Der Künstler als Publizist 214

7. Der Rechtskonflikt als Ausstellungsobjekt 216

8. Gerichtlicher Prozess und die Verfahren als

9. Klaus Staeck, Künstler oder Kämpfer für die Meinungsfreiheit? 218

10.Gerichtsprozess als Katharsis 221

II. Das Gesamtkunstwerk und seine Auswirkungen 222

F. Zwischenfazit 223

- Dritter Teil - 225
2

Sechstes Kapitel: Satirerechtsprechung nach Staeck 227

A. Die Satire in der Satirezeitschrift 227

B. Die Satire-Fernsehshow 229

I. Das „Schmähgedicht“: Die Satire um der Satire willen 229

II. „Nazi-Schlampe“: Die Satire als Argument 231

III. „Darf ich zuspitzen“: Der Kontextbezug 233

C. Zwischenfazit 235 
Siebtes Kapitel: Ausblick: Neue Problemfelder des Plakats und der Satire

A. Die Zukunft des Plakats 237

I. Das Plakat ist tot 237

II. Es lebe das Plakat 238

1. Das Wahlplakat der Satire-Partei 238

2. Adbusting und Street Art in der Tradition Staecks 239

B. Ausblick: politische Satire und politische Manipulation 242

I. Die Satire im Fernsehformat 243

II. Formen der partizipativen Satire 245

III. Satire und „Fake News“ 248

1. Schritt 1: „Fake News“ und „Hate Speech“ 248

2. Schritt 2: Unter dem Deckmantel der Satire 250

3. Schritt 3: Die notwendige Abgrenzung 253

C. Zwischenfazit 256

$\begin{array}{ll}\text { Schlussgedanke } & 257\end{array}$

Anhang 261

A. Rheinmetall AG, Pressemitteilung „Rheinmetall contra Staeck“, 21.12.1981

B. Leserbrief des Bundestagsabgeordneten Wilfried Böhm, Hersfelder Zeitung, 26.5.1976

C. Zeitungsartikel mit Erklärung des CDU-Fraktionsvorsitzenden im Gemeinderat, Dr. Raban von der Malsburg, Rhein-Neckar Zeitung vom 28.3.1994

Abbildungen

Literaturverzeichnis

Abbildungsverzeichnis 


\section{Einführung}

\section{A. Einleitungsgedanke}

„Der Satiriker lebt gefährlich.“1

Voltaire ging ins Exil, Daumier ins Gefängnis und Klaus Staeck vor Gericht.

Satire will und soll angreifen, provozieren, kritisieren, irritieren, verstören, emotionalisieren, verletzen, bewegen, aufstacheln, ausgrenzen. Folglich bergen Satiren ein immenses Konfliktpotenzial und können zu extremen Reaktionen führen. ${ }^{2}$ Die New York Times kündigte beispielsweise im Juni 2019 an, in ihrer internationalen Ausgabe keine Satiren und Karikaturen mehr abzudrucken. ${ }^{3}$ Das ZDF erwog scherzhaft bei einer seiner Satiresendungen den Warnhinweis „Vorsicht Satire!“ zu platzieren. ${ }^{4}$ Satire will und soll aber auch informieren, pointieren, hinterfragen, kontrastieren, aufzeigen, entschlüsseln, aktivieren, unterhalten, amüsieren, vereinigen.

Klaus Staeck, der „Plakat-Polemiker aus Leidenschaft" ${ }^{“ 5}$, prägte mit seinen satirischen Arbeiten seit den 1970er Jahren die Öffentlichkeit der BRD, wie auch die der DDR und des wiedervereinten Deutschlands. Die satirischen Plakate sind bis heute der Kernbestandteil seines künstlerischen Schaffens. Seine Plakate wurden heruntergerissen und rechtlich gegen ihre Verbreitung vorgegangen. Der Satiriker Staeck bewegt sich in dem für die

1 Solms, Warum stehen Satiriker in den 90er Jahren so oft vor Gericht?, in: Folckers/Solms (Hrsg.), Was kostet der Spaß? Wie Staat und Bürger die Satire bekämpfen, 1997, S. 12.

2 Man erinnere sich an den in seiner Heftigkeit erschütternden islamistisch motivierten terroristischen Anschlag auf die französische Satirezeitschrift „Charlie Hebdo“ am 7.1.2015.

3 Lohr, New York Times's Global Edition Is Ending Daily Political Cartoons, New York Times, 10.6.2019, https:/www.nytimes.com/2019/06/10/business/internation al-new-york-times-political-cartoons.html.

4 ZDF, Tweet vom 19.3.2015, 12:32 Uhr („Wir erwägen künftig bei allen @neomagazin-Ausstrahlungen im TV und im ZDI den Warnhinweis „Vorsicht Satire!“ zu platzieren. \#varoufake“). Vgl. auch zu der Aktion „\#varoufake“ Podskalksy, Jan Böhmermann und Die Partei, 2017, S. $7 \mathrm{ff}, 44 \mathrm{ff}$.

5 Castorp, „Nimmt Springer noch am öffentlichen Leben teil?“, Deutsches Allgemeines Sonntagsblatt, 7.3.1976, o. Seitenangabe. 


\section{Einfübrung}

Satire typischen Spannungsfeld zwischen Kritik, Provokation und Witz und nahm dafür den Weg vor Gericht in Kauf. Staeck beschreibt sich selbst als jemanden, der bloßstellt, der klarstellt und richtigstellt. ${ }^{6}$

Ganz allgemein betrachtet, ist es für satirische Arbeiten durchaus charakteristisch, dass es zur Kollision mit geschützten Rechtsgütern kommen kann. Ziel dieser Arbeit ist es nicht, im Rahmen einer umfassenden Gesamtbetrachtung alle rechtlichen Anknüpfungspunkte der Satire zu erörtern oder die Frage nach dem grundrechtlichen Schutz der Satire im Rahmen der Meinungs- oder Kunstfreiheit zu klären. Im Zentrum dieser Arbeit stehen die politischen, satirischen Plakate des Künstlers Klaus Staeck, die Auslöser für rechtliche Konflikte waren. Eine Auswahl der Gerichtsverfahren, die gegen Klaus Staecks Arbeiten geführt wurden, werden hier besprochen, bewertet und eingeordnet. Dabei wird nicht davon ausgegangen, dass das Politsatire-Plakat in einer anderen Form zu beurteilen ist als andere satirische Äußerungen. Vielmehr geht es darum, typische Merkmale des Politsatire-Plakats im Allgemeinen, aber vor allem die des Politsatire-Plakat Staecks, herauszuarbeiten. Dank der bereitgestellten Verfahrensakten und der begleitenden Presseberichte in Verbindung mit den Materialien, die Klaus Staeck zur Vor- und Nachbereitung seiner Plakatentwürfe gesammelt hat, ist eine differenzierte Besprechung und Bewertung der rechtlichen Auseinandersetzungen, aber auch der Politsatire-Plakate selbst möglich.

\section{B. Methodik und Forschungsstand}

Diese Arbeit fußt demnach zu einem großen Teil auf einer Archiv-Recherche und Aufarbeitung von Rechtsverfahren, die anlässlich der Plakate Staecks geführt wurden. ${ }^{7} \mathrm{Zu}$ den von Klaus Staeck archivierten Dokumenten gehören aber nicht nur die Urteile, Beschlüsse und anwaltlichen Schriftsätze, sondern auch Korrespondenzen unterschiedlichster Form, für Glaubhaftmachungen und Beweisführungen in Frage kommendes Materi-

6 Staeck, Demokratie kommt nicht aus der Steckdose, in: Museum Folkwang (Hrsg.), Klaus Staeck. Sand fürs Getriebe, Ausst. Kat. Museum Folkwang, 2018, S. 14.

7 Die Archivalien entstammen aus dem Privatarchiv Klaus Staecks in Heidelberg, die er der Verf. zur Verfügung gestellt hat. Die Überführung des privaten Archivs in ein Archiv im Rahmen der Akademie der Künste Berlin befindet sich in Planung. Um eine Einheitlichkeit zu erreichen, wurden in dieser Arbeit alle Gerichtsentscheidungen, ob in Fachzeitschriften oder in Entscheidungssammlungen veröffentlicht oder nicht, mit Datum und Aktenzeichen versehen. 
al, diverse Schriftstücke und Bilder für die inhaltliche Vorbereitung auf die Prozesse oder für die Gestaltung der Plakate sowie die die Verfahren begleitenden Pressestimmen. Für die vorliegende Untersuchung wurden 14 Archivboxen mit dem Material zu rechtlichen Auseinandersetzungen zwischen 1972 und 1999 ausgewertet. Die Archivlage ist gut und von Klaus Staeck auch mit dem Ziel der Vollständigkeit geführt worden. So sammelte er nicht nur die Dokumente zu den Verfahren, die von ihm oder gegen ihn selbst als Person geführt wurden, sondern auch diejenigen, die gegen „Verwender“ seiner Plakate angestrengt wurden. Bei der Archivierung arbeitete Staeck mit Zeitungsausschnittdiensten zusammen, wodurch ein umfangreicher Überblick über die Besprechungen und Kommentare zu den Verfahren ermöglicht wird. Das Archiv Klaus Staecks wurde im Kontext dieser Arbeit zwischen 2016-2019 gesichtet. Es ist davon auszugehen, dass mangels eines Findbuchs die Prozessakten und die zahlreichen Archivboxen zu der Vielzahl an nicht juristischen Konflikten, die hier thematisch aus dem Untersuchungsgegenstand herausgenommen wurden, nicht in ihrer Vollständigkeit gesichtet und erfasst werden konnten.

Klaus Staeck ist selbst Publizist, er hat zahlreiche Schriften verfasst. Genannt sei hier vor allem das im Jahre 2001 in der zweiten Auflage erschienene Buch „Ohne Auftrag" ${ }^{\text {, }}$, in dem er die eigene künstlerische Tätigkeit in Verbindung mit den Konflikten und Rechtsstreitigkeiten in einem pointierten Stil beschreibt. In zahlreichen Zeitschriftenartikeln und Ausstellungskatalogen sind Interviews mit Klaus Staeck zu finden, denn man lässt Staeck offensichtlich gerne selbst sprechen. ${ }^{9}$ Als Person des öffentlichen Lebens, Verfasser eigener Kolumnen und Auslöser so mancher kleiner Staatsaffäre müssen vor allem Tageszeitungsartikel erwähnt werden, die in dieser Arbeit mittelbar Eingang gefunden haben. Im Gegensatz zu den zahlreichen Eigenpublikationen und der intensiven tagespolitischen Berichterstattung gibt es sowohl in der juristischen als auch in der kunsthistorischen Fachliteratur nur wenige Studien zu dem Werk von Klaus Staeck. ${ }^{10}$

8 Staeck, Ohne Auftrag, ${ }^{2} 2001$.

9 Vgl. unter vielen Staeck, „Demokratie kommt nicht aus der Steckdose“, Monte Packham im Gespräch mit Klaus Staeck, in: Museum Folkwang (Hrsg.), Klaus Staeck. Sand fürs Getriebe, Ausst. Kat. Museum Folkwang, 2018, S. 8-19.

10 Vgl. die Aufsätze in den Katalogen Museum Folkwang (Hrsg.), Klaus Staeck. Sand fürs Getriebe, Ausst. Kat. Museum Folkwang, 2018; Merkert (Hrsg.), Klaus Staeck. Schöne Aussichten. Eine Retrospektive, Ausst. Kat. Berlinische Galerie, 2009; Ullrich, Art 2014/12, S. 52-56. In der juristischen Literatur wird, wenn nur auf 


\section{Einfübrung}

In den Forschungsstand soll kapitelweise gezielt eingeführt werden. Dieses Vorgehen ist mit dem interdisziplinären Ansatz und Aufbau der hier vorgestellten Untersuchung zu begründen. So wurden neben rechtswissenschaftlicher Literatur auch nationale und internationale kunst-, kultur- und literaturwissenschaftliche Quellen sowie sozialwissenschaftliche Forschungsansätze berücksichtigt. ${ }^{11}$

\section{Gang der Darstellung}

Den zentralen Aspekten des Untersuchungsgegenstands folgend ist diese Arbeit in drei Teile gegliedert.

Zunächst gilt es im ersten Teil den allgemeinen Rahmen, in welchem sich Politsatire-Plakate bewegen, begrifflich und inhaltlich abzustecken. Insofern wird im ersten Kapitel das Plakat als das grundlegende Medium unter historischen und kulturhistorischen Gesichtspunkten knapp besprochen. Im zweiten Kapitel folgt die Auseinandersetzung mit dem Begriff des Satirischen an und für sich aus einer literatur- bzw. kulturwissenschaftlichen Perspektive. Im dritten Kapitel wird das Phänomen der Satire aus einer rein rechtlichen Perspektive behandelt.

Der zweite Teil, das Herzstück der Arbeit, beschäftigt sich mit den künstlerischen Politsatire-Plakaten Klaus Staecks. Der kunsthistorischen und historischen Einordnung und Untersuchung, der das vierte Kapitel gewidmet ist, folgt die Besprechung und Bewertung der Gerichtsverfahren im fünften Kapitel.

Im dritten Teil werden zunächst im sechsten Kapitel ausgewählte politisch-satirische Werke in anderen Medien besprochen, die auch Gerichtsverfahren nach sich zogen. Im Vergleich können die Besonderheiten der Plakate Klaus Staecks noch deutlicher herausgearbeitet werden. Das siebte Kapitel untersucht in Form eines Ausblicks den Einfluss der digitalen Medien auf die Satire und ihre traditionellen Formate.

einzelne Verfahren Bezug genommen. Vgl. dazu dann die Anmerkungen im fünften Kapitel zu den entsprechenden Verfahren, S. $137 \mathrm{ff}$.

11 Da die Arbeit interdisziplinär, somit zum Teil auch historisch angelegt ist, wurde im Sinne einer erleichterten Zuordnung der Quellen in die einzelnen Disziplinen auf eine Kurzangabe der Quellen in den Fußnoten verzichtet und zusätzlich das Erscheinungsjahr als Orientierungshilfe angefügt. Auf eine Nennung der Namen der abgebildeten oder sonst in den Arbeiten Staecks besprochenen Personen wurde verzichtet, sofern es sich nicht um Personen handelt, die politische Ämter bekleiden oder in der Vergangenheit solche innehatten. 
- Erster Teil - 


\section{Erstes Kapitel: Das Plakat}

\section{A. Arten und Formen des Plakats unter Berücksichtigung der historischen Einordnung}

\section{Einleitung}

Das Plakat ${ }^{12}$ ist ein grafisches Medium der visuellen Kommunikation, das sich in der Regel an die Öffentlichkeit richtet und sich grundsätzlich der Verbindung zweier Zeichensysteme bedient: Schrift und Bild. ${ }^{13}$ Als Hauptgattungen können zwischen dem politischen Plakat, dem Warenplakat und dem Veranstaltungsplakat unterschieden werden. In der Intensität der deutschsprachigen wissenschaftlichen Auseinandersetzung mit dem Plakat lassen sich starke Unterschiede ausmachen. Ein Höhepunkt dieser Forschung lässt sich in den späten 1960er- bis in die Mitte der 1980er Jahre festmachen. In diesem Zeitraum sind Grundlagenwerke entstanden, die inzwischen zum Teil mehrere Neuauflagen erlebt haben. In Bezug auf das deutsche Plakat der Zeit nach dem Zweiten Weltkrieg muss auch zwischen einer west- und ostdeutschen Betrachtung unterschieden werden. ${ }^{14} \mathrm{Zu}$ nennen wäre zunächst die dreisprachige Arbeit des Schweizer Grafikers Josef Müller Brockmann und der Künstlerin Shizuko Müller-Brockmann aus dem Jahr 1971, die auf die Erforschung des Mediums Plakat bis heute einen großen Einfluss ausübt. ${ }^{15}$ Bezüglich des geschichtlichen Abrisses des

12 Der Begriff Plakat ist etymologisch abzuleiten aus niederländisch „plakaat“ bzw. französisch „placard“ und wird im niederdeutschen Sprachraum seit dem 16. Jh. zur Bezeichnung öffentlicher Anschläge verwendet. Deiters, „Plakat“, in: Ueding (Hrsg.), Historisches Wörterbuch der Rhetorik, Bd. 6, Must-Pop, 2003, Sp. 1230. Der französische Begriff „Affiche“ ist mittlerweile veraltet und wird im Deutschen, außer in der Schweiz, Österreich und als Terminus der Werbesprache und Kunstgeschichte, nicht mehr verwendet. Das englische Wort „Poster“ wurde hingegen gänzlich in der deutschen Sprache aufgenommen.

13 Deiters, ebd., Sp. 1230-1239.

14 Mit der Teilung Deutschlands entstand auch ein erhöhtes Interesse an der Untersuchung des sowjetischen Plakats oder an einer komparativen Untersuchung. So z.B. bei Kämpfer, „Der rote Keil““. Das politische Plakat. Theorie und Geschichte, 1985.

15 Müller-Brockmann/Müller-Brockmann, Geschichte des Plakats, 1971. 
Plakats ist die Monographie Ursula Zellers ${ }^{16}$ zu erwähnen, die sich mit der Geschichte des Plakats von 1848 bis 1918 auseinandersetzt und damit auch ein Grundlagenwerk für das deutsche politische Plakat geschaffen hat. Abhandlungen zur politischen Kunst im Allgemeinen, also ohne die Beschränkung auf einen einzelnen Künstler, sind naturgemäß zahlreich und können an dieser Stelle nicht ausführlich bewertet werden. Ein sehr hilfreiches allgemeines Bild zur politischen Kunst der 1990er Jahre mit einem Schwerpunkt auf einer differenzierenden Begriffsbestimmung des Phänomens liefert jedoch die Dissertation von Holger Kube Ventura. ${ }^{17}$

\section{Die kunsthistorischen und -soziologischen Vorläufer}

Werbende oder aufklärende Plakate haben eine tausendjährige Geschichte. In der einschlägigen Literatur zur Erforschung der Plakatgeschichte wird regelmäßig auf die Tatsache verwiesen, dass Vorläufer bzw. Ursprünge des Plakats in der europäischen Antike zu verorten sind. Verwiesen werden kann hier etwa auf die öffentlichen Bekanntmachungen der Athener Agora oder auf dem römischen Forum sowie die politische Wahlwerbung, die sich in den Ruinen Pompejis - unmittelbar auf den Putz und die Wandfarbe der Außenwände der Häuser aufgetragen - zahlreich erhalten haben. ${ }^{18}$ Ganz unumstritten war aber schon bei den antiken Zeitgenossen diese Form der Werbung im öffentlichen Raum nicht, wie eine erhaltene Aufschrift mit den Worten „Ein Wunder ist es, o Mauer, dass du nicht eingefallen bist, da du so viel ekelhaftes Gekritzel ertragen musst." zeigt. ${ }^{19}$ Ein gravierender Unterschied, weswegen diese Außenwerbung nur als ein Vorläufer angesprochen werden kann, liegt in der Tatsache begründet, dass diese Bekanntmachungen direkt auf der Wandfläche angebracht wurde und sich somit ganz wesentlich vom Plakat unterscheidet, das einen beweglichen Schrift- und Bildträger nutzt. Werbende Warenplakate, die

16 Zeller, Die Frühzeit des politischen Bildplakats in Deutschland (1848-1918), 1988.

17 Kube Ventura, Politische Kunst Begriffe, 2002.

18 Im Allgemeinen wurden neben politischen Wahlaufrufen auch Bekanntmachungen und Anzeigen zu Theaterfestspielen, Gladiatorenkämpfen oder ähnlichen, die Gesellschaft betreffenden, Unterhaltungs- bzw. Spielprogrammen gefunden.

19 Admiror, paries, te non cecidisse ruinis/ qui tot scriptorum taedia sustineas, siehe dazu Voegtle, Graffiti und Karikaturen als Medien der Kommunikation im städtischen Raum, in: v. Mundt, Felix (Hrsg.), Kommunikationsräume im kaiserzeitlichen Rom, 2012, S. 105-121. 
Schrift und Bild miteinander verbinden und auf Papier vergleichsweise einfach reproduzierbar waren, sind viele Jahrhunderte jünger und haben darüber hinaus mehr mit Flugblättern gemein als mit antiker europäischer Wandwerbung. Denn diese machen sich ab einem gewissen Zeitpunkt druckgrafische Verfahren zunutze, wie es im ausgehenden Mittelalter durch den Holzschnitt und dann später durch das Buchdruckverfahren ermöglicht wurde..$^{20}$ Die ersten gedruckten Plakate datieren in das 16. und 17. Jahrhundert und bewarben Tierschauen, Gaukler, Zauberkünstler, Akrobaten und andere Schausteller, die sich vor allem durch ihre Kuriosität und damit ihren Unterhaltungswert auszeichneten. ${ }^{21}$ In den europäischen Metropolen der Neuzeit, wie Paris und London, hat die Plakatwerbung ein solches Ausmaß angenommen, dass von einer regelrechten „Affichomanie“ oder „Poster Boom“ gesprochen werden konnte. Plakate wurden zum Gegenstand von Spott und Karikaturen und der Akt des Plakatierens wurde schließlich in der Form einer detaillierten Gesetzgebung stark reglementiert. ${ }^{22}$ Diese Regulierung und eine Institutionalisierung führten aber auch zu einer Professionalisierung der in der Plakatgestaltung tätigen Berufsgruppen. Große Gestalter in den frühen Jahren der Plakatkunst, die sich nicht nur durch ihre Pionierarbeit, sondern auch künstlerische Feinheit auszeichneten, waren im französisch-sprachigen Raum unter anderem Jules Chéret (1836-1932) ${ }^{23}$ und Henri de Toulouse-Lautrec (1864-1901) ${ }^{24}$

20 Bild-Text-Druckverfahren in Form des Holzschnitts werden um 1400 datiert. Der Buchdruck in der weiterentwickelten und dadurch revolutionierten Form von Johannes von Gutenberg ist aus der Mitte des 15. Jahrhunderts.

21 Vgl. dazu: Schindler, Monografie des Plakats. Entwicklung, Stil, Design, 1972, S. 22.

$22 \mathrm{Zu}$ einer solchen strengen Reglementierung kam es bei den Pariser Plakatklebern, die durch einen Erlass von 1722 gewisse Qualifikationen vorweisen und Genehmigungen einholen mussten sowie in der Zahl begrenzt waren. Das Entstehen des sogenannten Pariser Plakatkleberbunds 1772 führte dann auch zu einer Institutionalisierung. Siehe Faulstich, Die bürgerliche Mediengesellschaft, 1700-1830, 2002, S. 48. In London wurde das Anschlagen von Plakaten 1839 geregelt und mit einer Gesellschaft für die öffentliche Plakatierung institutionalisiert, Schindler, Monografie des Plakats. Entwicklung, Stil, Design, 1972, S. 36. In Deutschland folgte eine solche Form des Berufsverbands erst im Mai 1919 mit dem Bund der Deutschen Gebrauchsgrafiker (heute Berufsverband der deutschen Kommunikationsdesigner).

23 Jules Chéret war gelernter und innovativer Lithograph mit zunächst eigener Druckerei, die er dann verkaufte, um sich als freischaffender Künstler gänzlich auf die Plakatkunst zu konzentrieren.

24 Henri de Toulouse-Lautrec war besonders bekannt für seine feierliche Darstellung des Unterhaltungs- und Nachtlebens im Pariser Montmartre, die im Gegen- 
sowie Théophile Steinlein (1859-1923) ${ }^{25}$. Für diese Druckprodukte, besonders aber für die künstlerischen Entwürfe, gab es, neben dem werbenden Zweck für die sie geschaffen wurden, auch einen Kunstmarkt, auf dem sie gehandelt und gesammelt wurden. Als starken Einfluss auf den Jugendstil im Allgemeinen und die Plakatkunst des Jugendstils im Besonderen muss der japanische Farbholzschnitt hervorgehoben werden. ${ }^{26}$ In diesem Zusammenhang sind die Drucke Kitagawa Utamaros (1753-1806) und Katsushika Hokusais (1760-1849) zu sehen, die in Europa gefragte Sammlerobjekte darstellten. Diese Arbeiten hinterließen eben nicht nur tiefe Eindrücke bei Künstlern wie Paul Gauguin (1848-1903) oder Vincent Van Gogh (1853-1890), sondern auch bei den künstlerischen Werbegrafikern des Impressionismus und Post-Impressionismus. ${ }^{27}$

In London, der Welthauptstadt des 19. Jahrhunderts, überwog für das Plakat als Werbeträger - im Unterschied zu Frankreich - ein grafischer Stil, der sich durch einen stärker ausgeprägten Schrift-Teil und klare, grobe Farbflächen auszeichnete. ${ }^{28}$ Kurioserweise lässt sich dieser Stil nicht mit künstlerischen Intentionen erklären, sondern vielmehr mit der Tatsache, dass die verpestete Luft einer Weltstadt, die unter den Konsequenzen einer zunehmenden Industrialisierung zu leiden hatte, die Wahrnehmung des Auges stark beeinträchtigte: Im englischen Nebel und im durchziehenden

satz zu den jungen naiven Frauen Chérets charaktervoller dargestellt wurden. Sein CEuvre umfasst lediglich rund 30 Plakate.

25 Die Plakate mit den Katzen von Paris (Tournée du chat noir) gehören zu seinen berühmtesten Arbeiten, auch wenn der gebürtige Schweizer, der auch als der "Gerhart Hauptmann des Plakats" bezeichnet wurde, sich vor allem sich mit sozialen Fragen durch Darstellung des einfachen Arbeiters beschäftigte.

26 Dies erfolgt hier demonstrativ, da es in der Plakatkunstgeschichte wissenschaftliche Arbeiten ohne diesen Bezug gibt. So z.B. bei Döring, Plakatkunst. Von Toulouse-Lautrec bis Benetton, Ausst. Kat. Museum für Kunst und Gewerbe Hamburg, 1994; Schindler, Monografie des Plakats. Entwicklung, Stil, Design, 1972, angesprochen bei Müller-Brockmann/Müller-Brockmann, Geschichte des Plakats, 1971, S. 31.

27 Josef und Shizuko Müller-Brockmann machen deutlich, dass gerade die dezidierte Erotik dieser Holzschnitte Werbegrafiker und Plakatkünstler beeinflussten ihre (Produktwerbe-)Plakate sexueller aufzuladen. Auch wenn die tanzenden Frauen eines Chérets oder Toulouse-Lautrec sicherlich nicht mit der gar pornografischen Erotik des Schnitts „Der Traum der Fischersfrau“ mithalten können.

28 Vgl. dazu die Ausführungen zu Dudley Hardy in: Schindler, Monografie des Plakats. Entwicklung, Stil, Design, 1972, S.72. Auf die wenigen Ausnahmen, wie den Illustrator der Bücher Oscar Wildes Vincent Aubrey Beardsley, sei hier verzichtet. 
Rauch des industriellen Fortschritts konnten sich detaillierte Feinheiten in den öffentlichen Räumen nicht durchsetzen. ${ }^{29}$

Zwar waren mit unterschiedlichen Holzschnitttechniken und spätestens mit dem Buchdruck Guttenbergs die technischen Voraussetzungen für den Plakatdruck bereits erfüllt. Meilensteine für das Plakat lagen aber in der Erfindung der Lithografie durch Alois Senefelder (1771-1834) um $1800^{30}$ und in der Weiterführung als Farblithographie, die Godefroy Engelmann (1788-1839) unter dem Namen „Chromolithographie“ im Jahre 1837 patentieren ließ. Durch dieses Verfahren konnten Lithografien mit bis zu 25 unterschiedlichen Farben hergestellt werden. Mit der Einführung der Steindruck-Schnellpresse 1871 konnte auch dieses bis dato teure Verfahren durch die Möglichkeit der Produktion hoher Auflagen erheblich kosteneffizienter ausgestaltet werden. Da das Plakat als ein Medium des öffentlichen Raumes häufig der Witterung ausgesetzt ist, musste neben dem drucktechnischen Fortschritt auch das Papier zu einem wetterfesten Material gemacht werden (Affichenpapier). Der Offsetdruck, erfunden in den USA 1904 als eine ganz wesentliche Weiterentwicklung der Lithographie, wurde schließlich die maßgebliche Drucktechnik des 20. Jahrhunderts und erlaubt zum ersten Mal die Vervielfältigung eines unbearbeiteten fotografischen Bildes. Mit der Zeit setzten sich auch einheitliche Formate in der Plakatkunst durch, wie beispielsweise das noch heute gängige DIN A1-Format $(84,1 \times 59,4 \mathrm{~cm}){ }^{31}$

Für eine Darstellung der frühen US-amerikanischen Plakate bietet die vorliegende Arbeit nicht den nötigen Raum, wobei damit die Bedeutung der US-amerikanischen Werbegrafik nicht geleugnet werden soll, auch wenn aus europäischer Sicht häufig behauptet wurde, dass das US-amerikanische Plakat in künstlerischer Hinsicht weit abgeschlagen hinter dem

29 Vgl. ferner Schindler, ebd.

30 Die Begründung der Lithografie im Allgemeinen wird dem Münchner Alois Senefelder zugeschrieben, der bereits vor 1800 laut einer Anekdote zufällig bei einem Spaziergang den chemischen Steindruck erfand und sein Wissen später sehr aufwendig in einem Lehrbuch veröffentlichte. Senefelder, Vollständiges Lehrbuch der Steindruckerey. enthaltend eine richtige und deutliche Anweisung zu den verschiedenen Manipulations-Arten derselben in allen ihren Zweigen und Manieren belegt mit den nöthigen Musterblättern nebst einer vorangehenden ausführlichen Geschichte dieser Kunst von ihrem Entstehen bis auf gegenwärtige Zeit, 1818.

31 Solche Einheitsgrößen setzten sich selbstverständlich auch in anderen Ländern oder Regionen durch. In der Schweiz das F4 Weltformat und F 200 Cityformat, in den USA liegt das häufigste Format bei gerundet 61 x $\left.91 \mathrm{~cm} \mathrm{(24"x} 36^{\prime \prime}\right)$ und in Frankreich bei 120 x $160 \mathrm{~cm}$. 
französischen bleibe. ${ }^{32}$ Auch auf eine eigenständige Historie des Plakats des 20. Jahrhunderts muss in diesem Rahmen verzichtet werden.

Dass für die nun folgende Unterteilung der Plakatkunst (III. Typologie des Plakats) und so auch für die Plakate Klaus Staecks eine mittelbare geschichtliche Verortung unvermeidbar ist, ist jedoch evident.

\section{Typologie des Plakats}

\section{Das Plakat und seine werbende Funktion}

Genuine Warenplakate, die vor allem auf Verkaufsförderung ausgerichtet waren, kamen erst im 19. Jahrhundert im Zuge der industriellen Revolution auf, wurden aber dann stetig relevanter ${ }^{33}$ und verdrängten letztlich auch die in erster Linie künstlerischen Plakate. Gerade das besonders künstlerische Plakat, wie es die oben genannten französischen Grafiker wie Chéret oder Toulouse-Lautrec geschaffen haben, entfaltete nicht unbedingt eine Wirkung als Werbeplakat.

Als öffentlich angebrachter Träger einer Nachricht oder Information stellt das Plakat ein Medium der Massenkommunikation moderner Konsum- und Informationsgesellschaften dar, das konstitutiv auf rhetorische Wirkung hin angelegt ist. ${ }^{34}$ Dabei ist das Plakat aggressiv, denn es wirkt im öffentlichen Raum. Es existiert nicht in einer Aura, der sich der KunstInteressierte willentlich hingibt, sondern es „attackiert“ den Passanten,

32 Charles B. Cochran bezeichnete die amerikanischen Plakate schlichtweg als Gräuel. Justus Brinckmann differenzierte anlässlich der ersten Plakatausstellung in Deutschland 1893 in der vorgestellten Art, zit. nach Spielmann, Kunsthistorische Aspekte des frühen Plakats in England und den Vereinigten Staaten, in: Malhotra/Thon et.al., Das frühe Plakat in Europa und den USA, Bd. 1, 1973, S. 15 f., bis heute unter vielen in Döring, Plakatkunst. Von Toulouse-Lautrec bis Benetton, Ausst. Kat. Museum für Kunst und Gewerbe Hamburg, Heidelberg 1994, S. 14. Mit Will H. Bradley, 1868-1962, gab es jedoch auch um die Jahrhundertwende in den USA einen gefeierten Vertreter des Jugendstils, der in seinen Plakaten sowohl technisch als auch ästhetisch den europäischen Kollegen nicht nachstand.

33 Vgl. ausführliche Darstellung bei: Zeller, Die Frühzeit des politischen Bildplakats in Deutschland, 1988, S. 1-23.

34 Vgl. dazu auch Luhmann: „Die Werbung sucht zu manipulieren, sie arbeitet unaufrichtig und setzt voraus, dass das vorausgesetzt wird. Sie nimmt gleichsam die Todsünde der Massenmedien auf sich." Luhmann, Die Realität der Massenmedien, 1996, S. 85. 
den Wartenden, den Bürger, der sich im öffentlichen Raum bewegt. Da das Plakat - ob kommerzielles Werbe-, Kunst- oder Wahlplakat - mittlerweile selbstverständlicher Teil des öffentlichen Lebensraumes ist, könnte allein schon der Faktor der Gewöhnung seine Aggressivität relativieren. Doch führen allein die Masse und Gewöhnung nicht zum Verlust der medialen Rhetorik. ${ }^{35}$ Es ist gerade die Stärke des Plakats, dass es trotz einer intensiven medialen Überflutung in den wenigen Sekunden der beiläufigen Wahrnehmung des Menschen wirkt. Das Plakat kann bis heute mit dem Werbewirkungsprinzip der AIDA-Formel, die von Elmo Lewis bereits 1898 entwickelt wurde, in seiner Pragmatik beschrieben werden. Die vier Wirkungsstufen, die sich in dem namensgebenden Akronym wiederfinden, stehen für Attention (das Erwecken von Aufmerksamkeit), Interest (Erregen des Interesses), Desire (Hervorrufen eines auch wenn nur vermeintlichen Bedürfnisses) und Action (Anreizen zu einer angestrebten Handlung). ${ }^{36}$

Alle Plakate - ganz allgemein betrachtet - verbindet ihre Materialität und Funktion, sie unterscheiden sich aber in ihrer Wirkung. Damit lässt sich keine einheitliche Methodik der Interpretation definieren. Eine typologische Unterscheidung zwischen beispielsweise politischen Plakaten, Wirtschafts-, Film-, Veranstaltungs-, Fremdenverkehrs-, Verkehrsmittelund Kunstplakaten ${ }^{37}$ oder Ähnlichem ${ }^{38}$ wurde in dieser Differenziertheit nicht gewählt. Im Rahmen dieses Definitionsversuches soll auch gerade nicht auf das Künstlerplakat, wie es im Expressionismus oder dann später mit den Arbeiten von Georges Braque (1882-1963), Fernand Léger (18811955), Marc Chagall (1887-1985), Pablo Picasso (1881-1973) oder Henri Matisse (1869-1954) zu finden ist, eingegangen werden. Es geht nicht um Plakate, die für den Sammler geschaffen werden und daher sofort in Mappen oder generell unter dem Schutz der heimischen Sammlung, dem Museum oder der Ausstellungsfläche stehen.

35 Vgl. dazu medientheoretische Ausführungen zur Rhetorik des Plakats bei Deiters, Bilder ohne Rahmen - Zur Rhetorik des Plakats, in: Knape (Hrsg.), Medienrhetorik, 2005, S. 81-112.

36 Riedl, „AIDA-Formel“, in: Ueding (Hrsg.), Historisches Wörterbuch der Rhetorik, Bd. 1, A-Bib, 1992, Sp. 285-295.

37 Diese Unterscheidung trifft Schindler, Monografie des Plakats. Entwicklung, Stil, Design, 1972, S. 231-251.

38 Zwischen dem illustrativen Plakat, dem sachlich-informativen Plakat, dem konstruktiven, dem experimentellen Plakat und dem Serie-Plakat unterscheidet Müller-Brockmann/Müller-Brockmann, Geschichte des Plakats, 1971. 
Das Plakat besitzt - abgesehen von seinen technischen und publizistischen Mechanismen - ästhetische und künstlerische Qualitäten sowie nicht zuletzt auch politische und historische Relevanz. Die Voraussetzungen für die Analyse und Entschlüsselung eines Plakats sind folglich komplexer Natur. So ist die Analyse der vielfältigen, über den unmittelbaren Kontext hinausgehenden Bezüge notwendig. Aus diesen Gründen versucht die vorliegende Arbeit in einem ersten Schritt, die verschiedenen Mechanismen und Bezüge getrennt darzustellen: Mit dem politischen Plakat beginnend (2.) wird anschließend das künstlerische, ästhetische Plakat (3.) behandelt, um schließlich die Kategorie des künstlerischen Politsatire-Plakats (4.) in vertiefter Form zu erörtern. Da sich die Plakate des Klaus Staeck durch diese hier vorgestellten Dimensionen auszeichnen, ist es weder hilfreich noch sinnvoll eine Typologie nach dem beworbenen Sujet vorzunehmen.

\section{Das politische Plakat}

Im Gegensatz zum Warenwerbeplakat ist das politische Plakat nicht der Träger einer Verkaufsbotschaft von Waren, sondern von Ideen, geistigen Konzepten und Visionen. Damit hat das politische Plakat neben seiner Funktion als Wahlplakat - gerade in der deutschen Geschichte - Einfluss auf den öffentlichen Diskurs. Dies wird besonders in Zeiten politischer Umstürze deutlich: unmittelbar vor und während eines Krieges, in Friedensphasen nach einem Krieg, in der Phase eines drohenden potenziellen Kriegs, (wie beispielsweise während des sogenannten Kalten Krieges in der Zeit nach dem Zweiten Weltkrieg), oder auch - in den Phasen der durch Krieg geteilten Nationen - die Auseinandersetzung um eine Wiedervereinigung und schließlich die Bewertung ihrer Umsetzung.

Die Entstehung des politischen Plakats beruht auf drei Voraussetzungen: Neben der technischen Möglichkeit, die für jede Form des Plakats als Massenmedium erst im 19. Jahrhundert ermöglicht wurde, musste es auch einen Bedarf für politische Wahlwerbung geben und diese musste wiederum auch rechtlich zulässig sein. Deswegen geht Ursula Zeller in ihrer umfänglichen Analyse zum frühen politischen Plakat davon aus, dass es erst einer politischen Wahlwerbung bedarf, wenn die regierende Macht sich auf eine demokratische Legitimationskette berufen muss. Denn wenn das Volk keine Entscheidungsgewalt hat, dann müsse es auch von nichts und niemandem beworben werden. Aus diesen Gründen schlägt Zeller 
1848 als Entstehungsjahr des politischen Bildplakats vor. ${ }^{39}$ Denn die Revolutionsjahre 1848/49, in denen auch für Grundrechte und eine Verfassung gekämpft wurde, führten nicht nur zu Wahlen und zu einem Parlament, sondern auch zu einer gewissen Presse-, Meinungs- und Versammlungsfreiheit. Denn erst mit dieser Revolution kann von einer entscheidungsrelevanten Masse von Bürgern gesprochen werden, die es galt für politische Ziele zu überzeugen. Gerade die Entstehung eines Mehrparteiensystems wird demnach maßgeblich für den Aufschwung des politischen Plakats angesehen. Bis heute greifen Parteien, die ihr Wahlprogramm, Grundeinstellungen und Kandidaten bewerben wollen, auf das Medium des Plakats zurück. Nach Zeller stellt die Paulskirchenverfassung von 1849 die erste gesamtdeutsche und demokratische Verfassung dar, die in ihrer Entstehungszeit auch die faktischen und rechtlichen Voraussetzungen für das politische Plakat erfüllt. ${ }^{40}$ Damit sind die Voraussetzungen für die Geburtsstunde des politischen Plakats gegeben, wenn man die Tatsache, dass die Presse-, Meinungs- und Versammlungsfreiheiten in der deutschen Geschichte immer wieder erheblich eingeschränkt wurden und auch die Paulskirchenverfassung nie in Kraft getreten ist, übergeht. Von einer ansatzweise freien politischen Plakatierung konnte letztlich in Deutschland bis 1918 durch die strengen Gesetze im Rahmen des Presserechts nicht gesprochen werden.

Das mit dem Plakat eng verwandte politische Flugblatt, welches dem Namen entsprechend als fliegendes Blatt darauf ausgelegt ist, aktiv verteilt zu werden, statt statisch an einer Wand angeschlagen zu sein, ließe sich früher als das Plakat datieren. Denn das Flugblatt ist als Informationsmedium aus dem 19. Jahrhundert nicht wegzudenken ist, da es staatlich schwer zu kontrollieren und gleichzeitig einfach herzustellen ist. ${ }^{41}$

Politische Plakate können in Bezug auf ihre Botschaft unterschieden werden: Horvat-Pintarić differenziert zwischen Plakaten, in denen der Status quo erhalten bleiben soll und Plakaten, in denen der Status quo kritisiert wird, wie Protest- und Aktionsplakate. ${ }^{42}$

Die Plakate, die sich für die Erhaltung des Bestehenden einsetzen, sollen klassische politische Plakate sein, die statt Waren Wahlkandidaten, Partei-

39 Zeller, Die Frühzeit des politischen Bildplakats in Deutschland, 1988, S. 16-23.

40 Zeller, ebd.

41 Vgl. zur Geschichte des Flugblatts: Heesen, Das illustrierte Flugblatt als Wissensmedium der Frühen Neuzeit, 2011.

42 Horvat-Pintarić, Das politische Plakat, in: Feuchtinger, Plakatkunst des 19. und 20. Jahrhunderts, 1977, S. 99. 
en oder Ideologien anpreisen. Natürlich können diese wiederum weiter differenziert werden. Es kann sich um politische Propaganda handeln, in der einseitig bestimmte Ideologien an eine Gesellschaft, die in ihrer politischen Meinungsbildung eingeschränkt wird, verkauft werden. Diese Form der Ideenverbreitung entspricht in seinem modernen Verständnis dem Begriff der politischen Propaganda, der seit dem Reichsministerium für Volksaufklärung und Propaganda - einer der zentralen Institutionen des Nationalsozialismus - nur noch mit negativer Konnotation verwendet werden kann.

Aber auch wenn die Ideen gegeneinander konkurrieren und für einen kritischen Diskurs zugänglich sind, wie es mit dem heutigen Mehrparteiensystem auf staatlich politischer Ebene der Fall ist, kann es sich um Plakate handeln, die den Status quo erhalten wollen. Die Form des Plakats als freies Wahlplakat folgt in seiner Erscheinungsform seit dem Ende des Zweiten Weltkriegs ${ }^{43}$ einem gängigen Muster und besteht aus einem reduzierten Wahlspruch in Kombination mit dem Parteienkürzel und unter Umständen einem Bild des Kandidaten. ${ }^{44}$

Eine ausführliche Untersuchung der Strategien politischer Werbung für die Jahre 1919-1972 findet sich bei Gerd Müller ${ }^{45}$, der auch die Reduktion auf kurze Slogans und Schlagworte zur Vermittlung des politischen Programms im Laufe dieser Geschichte der Wahlplakate aufzeigt. ${ }^{46}$

In der Reihe der Protest- und Aktionsplakate, die nicht aus ästhetischen Gesichtspunkten interessant sind, sei die Pariser Studentenbewegung 1968 genannt, die aus zeithistorischer Perspektive das Plakat besonders wirkungsvoll einsetzten. Diese Form der politischen Plakate, die hier Protestund Aktionsplakate genannt werden, haben gemein, dass sie eine politische Handlung über die Teilhabe an einer Wahl einfordern. Sie können an den Staat, eine Obrigkeit oder an die Gesellschaft im Abstrakten oder den Menschen im Konkreten gerichtet sein.

Mittelbar wurde schon gezeigt, welche Ungenauigkeit bzw. Widersprüchlichkeit mit der Unterteilung von Horvat-Pintarić einhergeht. Poli-

43 Bis zur Wiedervereinigung nur in der BRD.

44 Diese Form der Personalisierung ist inhaltlich sicherlich nicht das Interessanteste, führt aber zu einer Vermenschlichung abstrakter politischer Ziele.

45 Müller, Das Wahlplakat - Pragmatische Untersuchungen zur Sprache in der Politik am Beispiel von Wahlplakaten aus der Weimarer Republik und der Bundesrepublik, 1978.

46 Gekürzt wurden mit der Zeit also selektive Anreden, meist eine direkte Thematisierung des Gegners sowie in entscheidendem Ausmaß der Informationsgehalt. In der Zusammenfassung Müller, ebd., S. $252 \mathrm{f}$. 
tische Propaganda und politisches (Wahl-)Plakat in einem freiheitlich-demokratischen System sind grundverschieden. Die Zusammenführung in die Hauptgruppe Plakate, die sich für den Status quo einsetzen, unterschätzt die manipulative Wirkung des Propaganda-Plakats und deklassiert das politische Plakat in der Abgrenzung zum Protest- und Aktionsplakat zu einem der Propaganda entsprechenden, unkritischen Führungsmittel. Basierend auf der Nomenklatur von Horvat-Pintarić wird hier eine dreifache Differenzierung des weiten Felds politischer Plakate vorgeschlagen: Propaganda-Plakate durch und von einer einseitig gesteuerten und kontrollierten Institution, in der Gegenpositionen nicht zugelassen werden; politische Plakate von Institutionen, die staatlich, kirchlich oder bürgerlich organisiert sind und in einem freien Konkurrenzverhältnis stehen; sowie Plakate nicht institutionalisierter Einzelpersonen oder Gruppen.

\section{Das künstlerische politische Plakat}

Die Verbindung zwischen Kunst und Politik ist längst nicht auf das Plakat begrenzt. Die politische Kunst steht, über die unterschiedlichen Medien und Techniken hinweg, in einem gewissen Spannungsverhältnis zwischen ästhetischem Anspruch und politischer Aussagekraft.

Ein kursorischer Blick über die politische Kunst der letzten Jahre zeigt eine thematische Konvergenz zwischen diesen Arbeiten und den gesellschaftlichen Diskussionen. Eine Flut an politischer Kunst unterschiedlicher Medien behandelt gesamtgesellschaftlich diskutierte Themen. Dazu gehören beispielsweise: der Abtreibungsparagraphen $\$ 218 \mathrm{StGB}$, die als Isolationsfolter bezeichnete Inhaftierung von mutmaßlichen Terroristen, eine kapitalistische Machtkonzentration oder gar Monopolstellung von global agierenden Konzernen, Atomenergie, nukleare Rüstung, Gentechnologie, Klimawandel, Netzneutralität, globale Spionage und Abhörtätigkeiten, Nepotismus und Korruption hoher staatlicher oder kirchlicher Amtsträger.

Die Künstlerin und politisch aktive Pazifistin Käthe Kollwitz (18671945) sei im Folgenden als eine besondere politische Plakatkünstlerin hervorgehoben. Ein Jahr nach dem Deutschen Krieg von 1866 geboren, erlebte sie als Kleinkind den Deutsch-Französischen Krieg, als Mutter mit gefallenem Sohn den Ersten Weltkrieg und als Schöpferin von sogenannter entarteter Kunst die Schreckensherrschaft der Nationalsozialisten und den Zweiten Weltkrieg, bis sie wenige Tage vor Ende des Krieges verstarb. Das Plakat „Nie wieder Krieg“ für den mitteldeutschen Jugendtag in Leip- 
zig (2.-4. August 1924) oder das ebenfalls 1924 von ihr für die Kommunistische Partei Deutschlands (KPD) gestaltete Plakat „Nieder mit den Abtreibungsparagraphen!“ sind Lithografien, die ihre Botschaft außerordentlich eindrücklich vermittelt. Sie schaffte es, mit den vergleichsweise begrenzten Mitteln des Plakats nicht nur Mitleid und Betroffenheit zu zeigen und hervorzurufen, sondern auch einen wahrhaftigen kämpferischen Einsatz zu verkörpern und auch vom Betrachter einzufordern.

Das Werk eines Künstlers, das sich - in welcher Form auch immer politisch, sozial und gesellschaftskritisch engagiert, galt und gilt zuweilen noch heute als „illegitime Verfolgung eines außerkünstlerischen Zwecks, die eine Minderung des ästhetischen Gehalts und damit Qualität des Kunstwerks zur Folge hat." 47 Ein politisches Plakat - sei es also noch so künstlerisch - wird niemals zweckfrei sein. Auch Käthe Kollwitz setzt sich mit dem Anspruch des reinen künstlerischen Zwecks auseinander, wenn sie - fast wie eine Rechtfertigung - erklärt, dass „reine Kunst in dem Sinne [sei] meine nicht. Aber Kunst doch. Jeder arbeitet, wie er kann. Ich bin einverstanden damit, dass meine Kunst Zwecke hat." 48

In der aktuellen Forschung herrscht so auch weitgehend Einigkeit, dass die Forderung nach einer zweckfreien und damit auch unpolitischen Kunst sowohl im gegenwärtigen wie auch vergangenen Kunstschaffen ganz selbstverständlich nicht haltbar ist. Vielmehr hat sich als comunis opinio etabliert, dass jedes Kunstwerk zwangsläufig eine politische Konnotation in sich birgt. Sicherlich gibt es dabei Werke, in denen die politische Dimension leichter zu erkennen ist als in anderen. $\mathrm{Zu}$ denken sei dabei zunächst an die Werke der Historienmalerei, an Jacques-Louis Davids „Der Tod des Marats“ von 1793, an Auguste Delacroix“ „Die Freiheit führt das Volk“ von 1830, an vordergründig politisch angelegte Karikaturen wie jene von Charles Philipon (1800-1861) oder an die künstlerisch sehr aufwendigen Lithografien des Honoré Daumier (1808-1879). Davon zu unterscheiden sind selbstredend Werke, die per se keinen vordergründig politischen Anspruch erheben, jedoch aus machtpolitischen Gründen und durch eine von Ideologien gesteuerte Pseudokritik als dekadent verbrämt wurden („Entartete Kunst“).49

47 Knies, Schranken der Kunstfreiheit als verfassungsrechtliches Problem, 1967, S. 21.

48 Kollwitz, Bekenntnisse, ${ }^{3} 1987$, S. 55.

49 Ein prägendes Beispiel dafür ist die Aneignung der Nationalsozialisten während des NS-Regimes von Kunst, die der nationalsozialistischen Vorstellung nicht entsprach und in der Ausstellung „Entartete Kunst“ in München 1937 gezeigt wurde. 
Edwin Lüthy, der sich eingehend mit künstlerisch politischen Plakaten in der Schweiz auseinandergesetzt hat, beschreibt 1920 den Zweck des künstlerischen politischen Plakats: Es soll ,jeden auf der Straße gedankenlos Vorüberbummelnden oder gedankenschwer Vorbeihastenden mit telepathischen Griffe fesseln [...] und kann, sein Gehirn durch ein kurz orientierendes Schlagwort in die gewollte politische Richtung drängen, sein Herz durch die Schönheit und Anmut eines Bildes gewinnen, sein Interesse durch den Witz satirischer Verstellung erhaschen, den Abscheu vor der ,anderen' Richtung durch illustrative Darstellung und Konsequenzen gegnerischer Gedankengänge und der Schwächen ihrer bisherigen Taten und Persönlichkeiten erregen, oder durch das dekorative und symbolische Glorifizierung der besonderen politischen Ideen die Sympathie für die eigene Sache gewinnen und bestärken." ${ }^{00}$

Lüthy benennt bestimmte Mechanismen des künstlerischen politischen Plakats: Vom Vorgang der Diffamierung, bei der eigene Stärken hervorgehoben werden, indem der Gegner lächerlich gemacht oder in anderer Weise herabgewürdigt wird, über die Überhöhung der eigenen Stärken bis hin zu den Mitteln des Witzes und der Satire.

Hier wird sich in inhaltlicher Hinsicht auf das politisch engagierte, künstlerische Plakat konzentriert. Es wird gegen den Sonderfall des künstlerischen politischen Werbeplakats abgegrenzt. Die berühmtesten Beispiele für politische kommerzielle Werbeplakate sind von dem Fotografen Oliviero Toscani für das italienische Modeunternehmen Benetton, die mit dem Begriff der sogenannten Benetton-Schock-Werbung über Jahre sowohl die Medien als auch die Gerichte beschäftigten.

Ein blutverschmiertes Hemd mit Einschussloch und eine ebenso verschmierte Hose mit einem zerschnittenen Gürtel liegen auf weißen Grund im Querformat. An der links-unteren Bildecke steht in weißen Lettern auf einem grünen Rechteck der Name der Firma: UNITED COLORS OF BENETTON. Die Kleidungstücke gehörten dem im Bosnienkrieg erschossenen Kroaten Marinko Grago. Der Deutsche Werberat verurteilt dieses Werbeplakat mit den Worten: „Zynisch, schamlos und grässlich!“51 Toscani hingegen erklärt: „Wenn mich die Leute fragen, was denn der Krieg

50 Lüthy, Das künstlerische politische Plakat in der Schweiz. Mit Äußerungen plakatschaffender Künstler und 32 originalgetreuen Wiedergaben, 1920, S. 2; auch abgedruckt in: Malhotra, Künstler und politisches Plakat, in: Bohrmann (Hrsg.), Politische Plakate, 1984, S. 11.

51 Zitat des Sprechers des Deutschen Werberats Volker Nickel, zit. nach N.N., Pullover und Krieg, Der Spiegel, 1994/8, S. 79, abrufbar unter: http://magazin.spi egel.de/EpubDelivery/spiegel/pdf/13684629. 
in Ex-Jugoslawien, Aids oder aktuelles Zeitgeschehen mit Pullovern zu tun haben, antworte ich, sie hätten gar nichts miteinander zu tun (...) Ich nutze die Möglichkeiten, die Wirkungskraft und die Gelegenheiten zur Präsentation einer unausgeschöpften und verachteten Kunst, nämlich der Werbung. Ich kratze die öffentliche Meinung dort, wo sie juckt." ${ }^{52}$ Toscanis Werbefotografien waren auch Gegenstand von zahlreichen gerichtlichen Verfahren vor nationalen als auch ausländischen Gerichten. ${ }^{53}$

$\mathrm{Ob}$ das künstlerische Plakat in Abgrenzung zu dem reinen Werbeplakat - und nur sofern man diese Abgrenzung noch ziehen kann - von der Wirkung her eindrücklicher ist, kann generell wohl nicht beantwortet werden. Doch kann davon ausgegangen werden, dass ein geschickt auf werbeund wahrnehmungspsychologischen Effekten und Aspekten aufbauendes Plakat in seiner Wirksamkeit erfolgreicher sein wird als ein rein künstlerisches Plakat, welches Gefahr läuft nur von Kunstinteressierten, also zumindest nur von einem begrenzten Teil der Gesellschaft, wahrgenommen zu werden.

Das politisch engagierte künstlerische Plakat ist darauf angewiesen, dass es von der Gesellschaft verstanden wird. Denn wenn diese politisch engagierte Kunst „eine kritische Reflexion gesellschaftlicher und sozialer Missstände [ist], die mit bildnerischen Mitteln die Veränderung dieser Missstände anstrebt oder gesellschaftliche Umwälzungen begleitet bzw. mitträgt ${ }^{\text {" } 54}$, dann ist eine Öffentlichkeit für diese absolut notwendig. Beispiele für den politisch engagierten Künstler sind zum einen Joseph Beuys (1921-1986), der die Verbindung von Kunst und Politik perfekt in einer Identität verbindet, auch wenn eine eindeutige politische Agenda in der Form nicht erkennbar ist. Es wird später gezeigt, dass auch Klaus Staeck zu den Künstlern, die politisch engagierte Kunst schaffen, gehört. Doch zunächst soll das Medium des Plakats weiter spezifiziert werden.

52 Toscani, Die Werbung ist ein lächelndes Aas, ${ }^{7} 1997$, Klappentext.

53 Vgl. BVerfG, 12.12.2000, 1 BvR 1762/95, 1 BvR 1787/95, GRUR 2001, S. 170 - Benetton-Werbung I; BVerfG, 11.3.2003, 1 BvR 426/02, GRUR 2003, S. 442 - Benetton-Werbung II.

54 Schweinebraden, Kunst und Politik, in: Staatliche Museen Preußischer Kulturbesitz (Hrsg.), 1945-1985. Kunst in der Bundesrepublik, Ausst. Kat. Nationalgalerie Berlin, 1985, S. 300. 
4. Das künstlerische Politsatire-Plakat

In Europa entwickelte sich die Geschichte des Plakats hauptsächlich in Paris und London, so dass es nach der Aussage von Zeitgenossen im Jahre 1895 schwierig gewesen sei über die deutsche Plakatkunst zu sprechen, weil sie einfach nicht existiere. ${ }^{55}$ Das änderte sich schlagartig im darauffolgenden Jahr, aber nicht durch das Aufkommen einer deutschen eklektischen Plakatkunst nach dem Vorbild der Nachbarländer, sondern vornehmlich durch Vorbilder aus anderen Medien. Ein Beispiel dafür war die neue Zeitschrift Simplicissimus, die sich neben zahlreicher berühmter Schriftsteller auch durch ihre Illustratoren wie Thomas Theodor Heine $(1867-1948)^{56}$ auszeichnete. Die deutsche Plakatkunst war damit von Beginn an nicht in erster Linie auf eine feine künstlerische Gestaltung ausgerichtet, sondern arbeitete mit Ironie, Witz, Satire und Spott. Das Satirische ist so das Künstlerische in diesen Plakaten. Die Zeit-, Gesellschafts- und Politikkritik brachte den Leser zum Lachen. ${ }^{57}$ Die bissige, von ihrer Kette befreite, rot-leuchtende Bulldogge, die mit ihrem scharfen, direkten Blick den Betrachter fixiert, war der Coup des Illustrators Heine. Er brachte damit den beißenden satirischen Inhalt, der als „Witzblatt" ${ }^{* 58}$ bezeichneten Wochenzeitschrift Simplicissimus mit einem Bild auf den Punkt.

Man kann fast sagen, dass sich die ganze Geschichte Deutschlands ab der Jahrhundertwende in den satirischen künstlerischen und politischen Medien widerspiegelt. Das beginnt mit den berühmten Satirezeitungen, wie dem Simplicissimus, geht aber über die Pardon zur heutigen Titanic und ist thematisch eng verwandt mit dem politischen Kabarett und dem Karneval.

Nach dem Zweiten Weltkrieg gehörte in der BRD eine humorvolle Satire politischen Inhalts nahezu zum guten Ton und gerade Kabaretts erfreuten sich großer Beliebtheit. Politiker und ihre Entscheidungen wur-

55 Das sei der Ausruf des französischen Germanisten Henri Albert zit. nach: Schindler, Monografie des Plakats. Entwicklung, Stil, Design, 1972, S. 93.

56 Thomas Theodor Heine arbeitete aber längst nicht nur an Illustrationen für den Simplicissimus oder als Karikaturist für die fliegenden Blätter, sondern auch an rein kommerziellen Produktwerbeplakaten oder Veranstaltungsplakaten.

57 Es soll aber nicht davon ausgegangen werden, dass Deutschland keine klassischen Werbeplakate kannte. Ganz im Gegenteil führten die Städte München und Berlin ab 1900 die europäische Plakatkunst an. Vgl. dazu Schindler, Monografie des Plakats. Entwicklung, Stil, Design, 1972, S. 118.

58 Thomas Mann nannte es „das beste Witzblatt der Welt“. Vgl. dazu Heißerer, Das „beste Witzblatt der Welt“: Thomas Mann und der „Simplicissimus“, 2005. 
den freundlich und zurückhaltend humorvoll kritisiert. Diese Form der Zurückhaltung äußerste sich in einem großen Respekt vor hauptsächlich sittlichen und religiösen Gefühlen, aber auch gesellschaftlichen Konventionen und Tabus. Die Kabarettistin Lore Lorentz beschrieb dies rückblickend mit den Worten: "Wir waren das frivole Feigenblatt der Nation“.59 Auch wenn diese Zurückhaltung aus der Perspektive des 21. Jahrhunderts lähmend langweilig gelten mag, so muss damals schon allein die Tatsache, dass ein Politiker Gegenstand eines öffentlichen Witzes war, für eine gewisse Spannung gesorgt haben. Es mag daher kaum überraschen, dass diese Formen der Satire im weiteren Sinne kaum zu Konflikten oder gar rechtlichen Auseinandersetzungen führten. Dies änderte sich aber mit den Studentenprotestbewegungen der 1968er Jahre. Während die Gesellschaft politischer wurde, wurde der politische Witz auch radikaler und aggressiver. Mit der zunehmenden Aggressivität wurde so auch die Satire beliebter und durchzog alle Medien des politischen Meinungskampfes und Protestes. Altbewährte und bekannte Ausdrucksformen wie das Kabarett, die Demonstration und das Plakat im öffentlichen Raum bedienten sich satirischer und damals unkonventioneller Mittel. 1969 fand ein grundsätzlicher politischer Wandel durch die Regierungsübernahme der sozialliberalen Koalition statt, die jahrelang regierende Union (CDU/CSU) bildete zum ersten Mal die Opposition. Die sozialliberale Reformpolitik und die neue Ostpolitik wurden zum Dreh- und Angelpunkt erbittert umkämpfter politischer Auseinandersetzungen, in denen Franz Josef Strauß eine zentrale Gestalt ${ }^{60}$ und damit auch ein beliebtes Ziel der satirischen Kritik darstellte. Neben zahlreichen anderen Karikaturen ist das schwarz-rot-weiße Plakat Rainer Hachfelds (geb. 1939) von 1980, auf welchem der Politiker mit seinen Armen und Beinen in der Form des Hakenkreuzes abgebildet ist, ein berühmtes Beispiel. ${ }^{61}$

59 Kosthorst, „In lustiger Gesellschaft?“ Politischer Humor als Spiegel der Zeit, in: Stiftung Haus der Geschichte der Bundesrepublik Deutschland (Hrsg.), Spaß beiseite - Politik und Humor in Deutschland, Ausst. Begleitbuch Zeitgeschichtliches Forum Leipzig der Stiftung Haus der Geschichte der Bundesrepublik Deutschland, im Haus der Geschichte der Bundesrepublik Deutschland, Bonn, 2010, S. $11 \mathrm{f}$.

60 Kosthorst, ebd.

61 Franz Joseph Strauß ging 1970-1971 gegen Rainer Hachfeld vor. Er hatte aber nie gegen Klaus Staeck geklagt. 


\section{B. Ein Zwischenfazit}

Welche Erkenntnis lässt sich nun aus diesem Überblick zu den Arten des Plakats gewinnen?

Es zeigt sich, dass das Plakat kunsthistorisch und historisch als eigenständiges Medium verankert ist. In seiner Art, Gestaltung oder Funktion kann das Plakat durchaus unterschiedlich sein. Wie die angeführte Typologie zeigt, ist aber auch eine Koppelung bzw. Vermischung unterschiedlicher Funktionen nicht nur möglich, sondern kann auch bewusst gesucht werden und ist infolgedessen üblich, so dass diese in die Bewertung mit einbezogen werden müssen. Das Künstlerische in einem Politsatire-Plakat liegt gerade in der Kunstform der Satire. Das künstlerische Politsatire-Plakat Klaus Staecks wird Gegenstand des vierten Kapitels. Was aber unter dem Begriff der Satire zu verstehen ist, ist Thema des folgenden Kapitels. 


\section{Zweites Kapitel: Vom Komischen zum Satirischen. Eine Begriffsannäherung}

Nach der einführenden Betrachtung des Plakats in seinen unterschiedlichen Ausführungen als politisches Plakat, als künstlerisches und Politsatire-Plakat soll in diesem Kapitel eine nähere Auseinandersetzung mit dem Satirischen, dem Komischen, dem Parodistischen, dem Witzigen, dem Ironischen und verwandten Begriffen folgen. All diese genannten Begriffe haben gemein, dass sie zum einen ein alltägliches Phänomen sind und zum anderen häufig als Stilmittel bezeichnet werden. Ihre Alltäglichkeit darf aber nicht darüber hinwegtäuschen, dass ein tieferes Verständnis dieser Mittel bei künstlerischen Arbeiten, die sich ihrer bedienen, für ihre Nutzung und so auch für die rechtliche Bewertung vonnöten sind. Denn es handelt sich dabei gerade nicht um pauschalisierte Alltagsbegriffe, die sich durch eine unspezifische Verwendung auszeichnen, sondern um komplexe Wahrnehmungsphänomene mit unterschiedlich scherzhaften ReizReaktionssystemen. ${ }^{62}$ Aufgrund ihrer begriffsgeschichtlichen Ähnlichkeit werden die genannten Begriffe in der literatur-, kunst- und kulturhistorischen Forschung im Kontext und in Relation zueinander untersucht und voneinander abgegrenzt. Es soll nicht verschwiegen werden, dass die Satire sowie die ihr verwandten Begriffe vorrangig in der Literaturwissenschaft und dort anhand konkreter literarischer Werke verhandelt werden. Eine begriffliche Abgrenzung muss hier ohne Untersuchung literarischer Arbeiten auskommen.

In diesem Kapitel werden die oben genannten Begriffe zunächst hergeleitet und eingeordnet, bevor es gilt, sie voneinander abzugrenzen. Die Untersuchung und Bestimmung des Begriffs der Satire schließt aber auch eine Betrachtung der anderen Begriffe mit ein. Dass dabei der Satire in dieser Arbeit ein besonderer Stellenwert zukommt, liegt inhaltlich an den Plakaten Staecks und an der besonderen Stellung der Satire im Recht.

$\mathrm{Zu}$ Beginn soll sich den Begriffspaaren Komik und Witz sowie der Ironie, der Parodie und des Pastiches genähert werden. $\mathrm{Zu}$ letzteren darf auch eine rechtliche Einordnung freilich nicht fehlen, wobei entsprechend

62 Vgl. Schwind, „Komisch“, in: Barck/Fontius/et al. (Hrsg.), Ästhetische Grundbegriffe, 2001, S. $332 \mathrm{f}$. 
der Schwerpunktsetzung dieser Arbeit auf die rechtliche Einordnung der Satire im dritten Kapitel gesondert eingegangen wird.

\section{A. Das Komische und das Witzige - der Humor}

Der Witz ist neben seinen Erscheinungsformen als Wortwitz, Wortspiel oder einer sehr kurzen Geschichte mit einem überraschenden pointierten Ende auch „die verstandesmäßige Fähigkeit zum überraschenden Einfall“, für die sich mittlerweile zur besseren Unterscheidungskraft die Begriffe Gewitztheit oder Witzigkeit herausgebildet haben. ${ }^{63}$ Der Witz will in den Worten Freuds „Ähnlichkeiten zwischen Unähnlichem“ sog. „versteckte Ähnlichkeiten "64 aufzeigen. ${ }^{65}$ Die meisten Witze funktionieren so, dass zunächst eine Assoziation und Erwartung aufgebaut und diese dann durch eine unerwartete Pointe aufgelöst wird.

Insbesondere das Wortspiel zeichnet sich durch die Doppeldeutigkeit aus. Wenn Klaus Staeck auf seinem Plakat von 2014 in der Eigenschreibweise des Automobil-Vereins ADAC in schwarz auf gelben Grund ADE AC statt ADAC schreibt, dann spielt er mit der Aussprache des „D“ als „De“, das dem vorangestellten "A“ dem Abschiedsgruß Ade gleichkommt. Der Technik des Witzes ist hier die leichte Modifikation, die dann zu diesem „Doppelsinn“ und damit dem Wortspiel führt. ${ }^{66}$ Der Witz oder das Witzige sind eng verwandt mit dem Humor und dem Begriff des Komischen.

Mit dem knappen Satz „Komisch ist das, worüber ich lache“ fasst Robert Gernhardt das Komische zusammen. ${ }^{67}$ Dieses Zitat zeigt die große Gemeinsamkeit der gängigen Komik: Das Komische hat ein Lachen oder zumindest ein Lächeln zu bewirken. ${ }^{68}$ Das Lachen ist somit ein Erken-

63 Willer, „Witz“, in: Wirth (Hrsg.), Komik. Ein interdisziplinäres Handbuch, 2017, S. 11.

64 Freud, Der Witz und seine Beziehung zum Unbewussten, 1905, S. 3.

65 Jean Paul beschreibt dies mit den Worten „Der Witz ist der verkleidete Priester, der jedes Paar kopuliert." Paul, Vorschule der Ästhetik nebst einigen Vorlesungen in Leipzig über die Parteien der Zeit, in: Pfotenhauer/Hunfeld (Hrsg.), Jean Paul Werke. Historisch-Kritische Ausgabe, Bd. 2, Berlin, 2015, \$41, Z. $23-24$.

66 Vgl. zur Technik des Witzes, Freud, Der Witz und seine Beziehung zum Unbewussten, 1905, S. 8-72.

67 Gernhardt, Was gibt es denn da zu lachen?, 1988, S. 465.

68 Winkler, „Komik“, in: Ueding (Hrsg.), Historisches Wörterbuch der Rhetorik, Bd. 4, Hu-K, 1998, Sp. 1166. 
nungsmerkmal, wobei gerade das Lachen aufgrund der Belustigung nicht durch die Komik hervorgerufen werden muss. Das liegt daran, dass die Komik sich zu einem Oberbegriff etabliert hat für unterschiedliche Formen der Belustigung. ${ }^{69}$ Das Komische beinhaltet per se aber zwei Wortbedeutungen, das Lustige und das Seltsame. Etwas kann sowohl komisch im Sinne von seltsam als auch immer komisch im Sinne von lustig sein und so beide Wortbedeutungen gleichzeitig erfüllen. Doch geht es hier maßgeblich um das Lachen hervorrufende Komische im Sinne der Komik. Der deutsche Phänomenologe Theodor Lipps ${ }^{70}$ beschreibt in seiner viel beachteten Schrift zu Komik und Humor, dass die Komik zu den Gefühlen der Lust gehört. ${ }^{71}$ Gernhardt sieht in dem hervorgerufenen Lachen aber nicht nur ein Gefühl, sondern gleichzeitig für den Lachenden eine Art Kontrollverlust über sich selbst. ${ }^{72}$ Die Komik wird ferner neben einem (Lust-) Gefühl oder einem Kontrollverlust als eine Methode beschrieben, die ernstzunehmende Aussagen subversiv durch das Komische verständlich machen soll. Es wird dabei der Komik zugesprochen, eine ins Lächerliche verzerrte Realität aufzuzeigen, die Heiterkeit auslösen soll. ${ }^{73}$

Im Gegensatz zum Witz, der eigentlich ähnlich konstruiert ist, jedoch eine Erwartung aufbaut und diese mit einer Pointe auflöst, sind die Erscheinungsformen der Komik nicht nur vielfältig, sondern auch einer subjektiven Wahrnehmung unterworfen. Die Vielfältigkeit liegt beispielsweise darin, dass eine Person, ein Gegenstand, eine Aussage oder eine Handlung unbeabsichtigt komisch sein kann, eine Tatsache, die sich in den Begriffen „unfreiwillige Komik“ und „Situationskomik“ niederschlägt.

Geht man davon aus, dass etwas nur komisch (im Sinne von lustig) ist, wenn es sein Ziel des Lachens erfüllt, dann erhält etwas erst das Adjektiv komisch, wenn es beim Rezipienten die bezweckte Belustigung hervorruft. So könnte man konstatieren, dass es für die Komik des Humors bedarf. Der Humor ist dann lediglich die Eigenschaft einer Person, dem Komi-

69 Kindt, „Komik“, in: Wirth (Hrsg.), Komik. Ein interdisziplinäres Handbuch, 2017, S. 2.

70 Theodor Lipps (1851-1914) war ein einflussreicher Philosoph und Psychologe des 19. Jahrhunderts und Begründer des psychologischen Instituts der Universität München.

71 Lipps, Komik und Humor. Eine psychologisch-ästhetische Untersuchung, 1898, S. 215.

72 Gernhardt, Was gibt es denn da zu lachen?, S. 460.

73 Schwind, „Komisch“, in: Barck/Fontius/et al. (Hrsg.), Ästhetische Grundbegriffe 2001, S. 340. 
schen gegenüber aufgeschlossen zu sein. ${ }^{74}$ Sigmund Freud beschreibt das Wesen des Humors dahingehend, „dass man sich die Affekte erspart, zu denen die Situation Anlass gäbe, und sich mit einem Scherz über die Möglichkeit solcher Gefühlsäußerungen hinaussetzt ${ }^{675}$. Wobei letztlich für ihn der Humor der „Triumph des Narzissmus“ darstellt. ${ }^{76}$ Thorsten Sindermann geht für den Humor maßgeblich von einem Perspektivwechsel aus: „Wer Humor hat, hat die Fähigkeit, seiner Perspektive eines skandalonartigen Ernstes eine alternative Perspektive korrektiv zur Seite zu stellen, um jene als zu ernste zu erkennen, und in eins damit die korrektive Perspektive anzuerkennen als die bessere und angemessenere, die dann zu seiner leitenden Sicht wird, so lange er diesbezüglich Humor hat." ${ }^{\text {"77 Dieser Ansatz }}$ fußt letztlich auch auf der für die Humorforschung grundlegenden Inkongruenztheorie. So beschreibt Arthur Schopenhauer, dass ein Lachen „aus der plötzlich wahrgenommenen Inkongruenz zwischen einem Begriff und den realen Objekten, die durch ihn, in irgendeiner Beziehung, gedacht worden waren, “78 entsteht. Folglich ist das Lachen dann eben nur der Ausdruck dieser Inkongruenz. ${ }^{79}$

Vielleicht bleibt festzuhalten, dass die Komik erst eintritt, sofern der Rezipient (ausgestattet mit dem nötigen Humor) das Komische erkennt und der emotionale Reflex des Lachens ausgelöst wird. Gemein haben folglich das Komische und der Witz, dass beide der auf das Lachen des Rezipienten abzielen, wohingegen sich der Witz - im Unterschied zur Komik - durch einen typischen Bauplan, nämlich einer Pointe, die eine zuvor aufgebaute Erwartung in völlig unerwarteter Form auflöst, auszeichnet.

\section{B. Das Ironische, das Sarkastische, das Zynische}

Ironie liegt vor, wenn das Gegenteil des Gemeinten geäußert wird. Das ist die einfache und grundlegende Definition der Ironie, die sich wider-

74 Kindt, „Humor“, in: Wirth (Hrsg.), Komik. Ein interdisziplinäres Handbuch, 2017, S. 7.

75 Freud, Gesammelte Werke. Chronologisch geordnet, hrsg. v. Freud, Anna, Bd. 6, 1999, S. 254.

76 Freud, ebd.

77 Sindermann, Über praktischen Humor, 2009, S. 219; vgl. auch Kindt, „Humor“, in: Wirth (Hrsg.), Komik. Ein interdisziplinäres Handbuch, 2017, S. 9.

78 Schopenhauer, Wille und Vorstellung, Bd. 1, ${ }^{4} 1873$, S. 70.

79 Schopenhauer, ebd. 
spruchsfrei in der einschlägigen Literatur findet. ${ }^{80}$ Diese Auslegung entspricht bereits dem Verständnis der antiken europäischen Philosophie. So zeichnet sich beispielsweise für Aristoteles (384-322 v. Chr.) „Ironie“ durch das „Un-Wahrhafte“ aus. ${ }^{81}$ Für Aristoteles ist Ironie darüber hinaus ein Mittel, den Gegner lächerlich zu machen ${ }^{82}$. Diesen Gedanken greift der deutsche Philosoph Friedrich Hegel (1770-1831) auf, der Ironie jetzt als die „absolute Negativität“ bewertet und in einer ironischen Lebenshaltung sogar die "allseitige Vernichtungskunst“ sieht. Hegel ist überzeugt, dass sich der Ironiker, der alles auf sich selbst bezieht, den Anderen abwertet. 83

Für den menschlichen Intellekt ist es bekanntlich schwierig, Ironie zu decodieren. Das zeigen beispielhaft die zahlreichen aktuellen ethologischen Forschungsansätze zum Ironie-Verständnis von Kindern, wonach ihnen überhaupt erst ab einem Alter von acht Jahren ein Verständnis von Ironie zugesprochen wird. ${ }^{84}$ Zum Erkennen der Ironie gibt es bestimmte „Kontextualisierungsmittel“, die in ihrer Wahl von unterschiedlichen Faktoren wie dem Kulturkreis des Produzenten, der Sprache, des sozialen Milieus und der Gattung (Gespräch, Text, Text-Bild) abhängig sind ${ }^{85} \mathrm{Be}-$ sonders schwierig ist es im Schriftlichen Ironie zu vermitteln, da es keine mimischen, gestischen und prosodische Ironiesignale gibt, sofern man von grafischen Hilfen in der Gegenwartssprache, wie den Emoticons - meist dem sogenannten Zwinkersmiley;-) - absieht. Ein hilfreiches Zeichen ist das Auseinanderfallen zwischen dem Erzählten und der auf Fakten beru-

80 Behler, „Ironie“, in: Ueding (Hrsg.): Historisches Wörterbuch der Rhetorik, Bd. 4, Hu-K, 1998, Sp. 599; Gernhardt, Robert, zit. nach: Eilers, Robert Gernhardt: Theorie und Lyrik. Erfolgreiche komische Literatur in ihrem gesellschaftlichen und medialen Kontext, 2011, S. 191.

81 „Bzgl. der Wahrheit soll, wer die Mitte einnimmt, wahrhaft und die Mitte Wahrhaftigkeit heißen. Ihre Entstellung nach Seiten des Zuviel heiße Prahlerei, und wem sie eigen ist prahlerisch, die nach Seiten des Zuwenig Ironie oder verstellte Unwissenheit, die Person ironisch.“ Aristoteles, Nikomachische Ethik, hrsg. v. Bien, Günther, übers. auf Grundlage v. Rolfes, Eugen, 1985, S. 39.

82 Dies macht Aristoteles im Rahmen seiner Rhetorik deutlich. Vgl. Aristoteles, Rhetorik, übers. v. Heinrich Huebel, Stuttgart 1838, S. 275.

83 Hegel, Vorlesungen über die Ästhetik Erster Teil, ${ }^{2} 1842$, S. 201.

84 Vgl. dazu ferner Creusere, A Developmental Test of Theoretical Perspectives on the Understanding of Verbal Irony: Children's Recognition of Allusion and Pragmatic Insincerity. in: Gibbs./Colston (Hrsg.), Irony in Language and Thought. A Cognitive Science Reader, 2007, S. 409-424.

85 Moroni, Ironie und Intonation im privaten Gespräch, in: Amann/Hackl (Hrsg.), Satire - Ironie - Parodie. Aspekte des Komischen in der deutschen Sprache und Literatur, 2016, S. 169. 
henden Realität, sofern dieses erkannt wird. Produzent und Rezipient verlangen nach einem ähnlichen moralischen Verständnis, schließen eine Art moralischen Pakt. ${ }^{86}$ Es muss demnach Einigkeit herrschen, wie bestimmte Ereignisse, Personen, Zustände zu bewerten sind. Umso schwieriger kann die Verwendung von Ironie demnach im Rahmen einer politischen Kommunikation sein.

Ähnlich schwierig zu erkennen sind der Sarkasmus oder der ironische Sarkasmus. Der Sarkasmus kann sich des Mittels der Ironie bedienen, zeichnet sich aber dadurch aus, dass er bissig respektive spöttisch ist. Er wird auch umschrieben als der „Hohn, den jemand mit verbissenen Lippen ausspricht. " 87 Der Sarkasmus kann sich der Ironie, d.h. einer Umkehrung des Gemeinten durch das Gesagte, bedienen oder auch die Form der direkten Aussage wählen. Der ironische Sarkasmus kann insofern erkannt werden, wenn die Inkongruenz zwischen Gesagten und Gemeinten, die spöttisch aufgeladen ist, gesehen wird. Sonst sind für das Verständnis der implizierten Aussage, bedient sie sich nicht der Ironie, noch einmal mehr kontextuelle oder situative Signale relevant. Als Redefigur hat der Sarkasmus im Gegensatz zur Ironie durch das Spöttische ein stark wertendes Element. Mag man den Sarkasmus als Spott in einen eher negativ konnotierten Bereich verschieben, haben Studien aus der Kognitionspsychologie gezeigt, dass im Gegensatz zu einer direkten Kritik, der Sarkasmus als indirekte Form auch als eine höflichere Form der Kritik verwendet wird, auch wenn das Lächerlichmachen weiterhin im Vordergrund steht. ${ }^{88}$

Unter Zynismus wird nicht ein Stilmittel verstanden, sondern eine spezifische Lebensanschauung. Diese ist geprägt von der bis zur Vernichtung reichenden Verspottung moralischer Wertvorstellungen, gesellschaftlicher Konventionen oder persönlicher Gefühle. ${ }^{89}$

86 Siehe dazu Amann, Ironie im Dienste politischer Agitation. Walthers von der Vogelweide „Opferstock“-Strophe und das Spottgedicht auf Kaiser Ludwig den Bayern (1346/47), in: ders./Hackl (Hrsg.), Satire - Ironie - Parodie. Aspekte des Komischen in der deutschen Sprache und Literatur, 2016, S. 95.

87 Vgl. dazu Meyers Konversationslexikon, „Sarkasmus“, http://www.woerterbuchn etz.de/Meyers?lemma=sarkasmus.

88 Meyer-Sickendieck, „Sarkasmus“, in: Ueding (Hrsg.), Historisches Wörterbuch der Rhetorik, Bd. 8, Rhet-St, 2007, Sp. 447.

89 Vgl. dazu Duden, „Zynisch“, https://www.duden.de/rechtschreibung/zynisch. 
C. Die Karikatur, die Parodie, der Pastiche und die Persiflage

Als eng verwandt mit der Ironie, dem Sarkastischen und dem Zynischen gelten die Darstellungsformen der Karikatur, Parodie, Pastiche und Persiflage.

\section{Die Karikatur}

Die Karikatur wird landläufig als ein absichtlich verzerrtes und dadurch lächerlich gemachtes, aber noch erkennbares Bild einer Person, Sache oder Geschehen zur Belustigung des Rezipienten verstanden. ${ }^{90}$ Der Begriff kann auf rein bildliche Darstellungen begrenzt werden, auch wenn er beispielsweise für die Literatur in Form der literarischen Karikatur in Anspruch genommen wird. ${ }^{91}$ Die Karikatur ist häufig, aber nicht zwingend politisch ${ }^{92}$ und wird als eng verwandt mit der Satire angesehen ${ }^{93}$, so dass auch für die Karikatur zuweilen der Begriff der „Bildsatire“ verwendet wird. ${ }^{94}$ Hier wird von einer Trennung der Begrifflichkeiten ausgegangen, wobei aber die Existenz von satirischen Karikaturen nicht angezweifelt wird. Was unter dem Satirischen zu verstehen ist, ist hier ausschlaggebend und daher getrennt zu beleuchten.

90 So oder ähnlich bei Duden, „Karikatur“, https://www.duden.de/rechtschreibung/ Karikatur; Meyers Konversationslexikon, „Karikatur“, http://www.woerterbuchne tz.de/Meyers?lemma=karikatur; Brockhaus, „Karikatur“, https://brockhaus.de/ecs/ julex/article/karikatur-bildende-kunst.

91 Rösch, „Karikatur“, in: Fricke (Hrsg.), Reallexikon der deutschen Literaturwissenschaft. Bd. II H-O, 2007, S. 234.

92 Auf das Politische abstellend Brockhaus, „Karikatur“, https://brockhaus.de/ecs/jul ex/article/karikatur-bildende-kunst.

93 Vgl. m.w.N. zur Abgrenzung Cueni, Schutz von Satire im Rahmen der Meinungsfreiheit, 2019, S. 54-58.

94 Siehe dazu Gärtner, Was die Satire darf, 2009, S. 36; Heller/Goldbeck, ZUM 2007, S. 628; Kassing, Ehrverletzende Personalsatire, 2004, S. 31. 
II. Die Parodie

1. Die etymologische und kunst- und literaturwissenschaftliche Einordnung

Die Parodie wird landläufig als eine komisch-satirische Nachahmung oder Umbildung eines meist künstlerischen oder literarischen Werkes betrachtet. ${ }^{95}$ Ausgehend von der Etymologie und dem antiken Verständnis muss die Parodie nicht komisch sein. Dies spiegelt sich in der sogenannten Parodia seria, die in der frühen Neuzeit vermehrt aufzufinden ist. Diese lässt, wie der Name schon nahelegt, jegliche Komik vermissen. ${ }^{96}$ In der literaturwissenschaftlichen Parodieforschung haben sich unterschiedliche Meinungen gebildet, die von einem Schwerpunkt in der Komik bis hin zu denjenigen reichen, die einen Schwerpunkt in der Aggression sehen oder letztlich gar keine Komik als Merkmal anerkennen wollen. ${ }^{97}$ Nachhaltig rezipiert wurde die Definition von Margaret Rose, für die die Parodie die „Nachahmung und komische Umfunktionierung einer präformierten Vorlage" darstellt. ${ }^{98}$

In der Geschichte der Parodieforschung wurde vermehrt darauf eingegangen, dass die Parodie entweder ein „Hauptwerkzeug“ der Satire oder die Parodie eine besondere Art der Satire sei. ${ }^{99}$ Will man die Parodie als ein „literarisches Instrument der Ideologiekritik“100 verstehen, dann bleibt man eine Antwort bzw. einen Einordnungsvorschlag auf die Masse an rein belustigenden Beispielen der Parodie schuldig. ${ }^{101}$

\section{Die rechtliche Einordnung}

Da es der Parodie phänomenologisch eigen ist, mit einer Vorlage zu arbeiten, ist der Begriff der Parodie im Rechtlichen besonders in dem Rechts-

95 Duden, „Parodie“, https://www.duden.de/rechtschreibung/Parodie.

96 Vgl. Wirth, „Parodie“, in: Wirth (Hrsg.), Komik. Ein interdisziplinäres Handbuch, 2017, S. 26.

97 Vgl. dazu m.w.N. Brinkmann, Formen der Kopie, in: Dreier/Jehle (Hrsg.), Original - Kopie - Fälschung, 2020, S. 68-70.

98 Rose, Parodie, Intertextualität, Interbildlichkeit, 2006, S. 7.

99 In Berufung auf Karl Friedrich Flögel und Johann Joachim Eschenburg, Freund, Die literarische Parodie, 1981, S. 2 f.

100 Freund, Die literarische Parodie, 1981, S. 13.

101 Vgl. dazu beispielsweise das Internetphänomen des Memes. 
gebiet virulent, das vor Übernahmen schützt - namentlich dem Urheberrecht. In diesem Sinne kommt es häufig zu Übernahmen zum Zwecke der Parodie von urheberrechtlich geschütztem Material. Das deutsche Urheberrecht kannte den Begriff der Parodie jedoch lange nicht. Zuerst die Infosoc-Richtlinie sieht in dem Art. 5 Abs. 3 lit. k RL 2001/29/EG die Möglichkeit vor, dass die Mitgliedstaaten Ausnahmen oder Beschränkungen für die Nutzung zum Zwecke von Karikaturen, Parodien oder Pastiches schaffen können. Eine eigene Parodie-Schranke wurde auch nach dieser Richtlinie nicht im deutschen Urheberrecht geschaffen, vielmehr richtete sich bislang die Parodie im deutschen Urheberrecht nach den Maßstäben der Regelung zur freien Benutzung im $\$ 24$ Abs. 1 UrhG. Der EuGH hat aber in seiner Deckmyn-Entscheidung zur Parodie festgestellt, dass der Begriff der Parodie ein eigenständiger Begriff des Unionsrechts ist. ${ }^{102}$

Auf die Schlussanträge des Generalanwalts und den allgemeinsprachlichen Gebrauch des Begriffes rekurrierend, sieht der EuGH die wesentlichen Merkmale der Parodie darin, dass zwar an ein bestehendes Werk erinnert wird, gleichzeitig aber gegenüber der Vorlage wahrnehmbare Unterschiede vorhanden sind, und die Parodie sich durch Humor und Verspottung vom Vorlagewerk signifikant absetzt. ${ }^{103}$

Deutlich wurde in dieser Entscheidung durch die zweite Vorlagefrage aber vor allem, welche Voraussetzungen die Parodie gerade nicht erfüllen muss. Das Vorlagegericht fragte nach den wesentlichen Merkmalen der Parodie: Erstens ob ein eigener ursprünglicher Charakter und damit Originalität vorliegt, in der Form, dass die Parodie nicht vernünftigerweise dem Urheber des ursprünglichen Werkes zugeschrieben werden könnte; zweitens ob die in der Verspottung versteckte geäußerten Kritik sich gegen das ursprüngliche Werk oder eine andere Sache oder Person zu richten hat; sowie drittens ob das parodierte Werk zu nennen sei. ${ }^{104}$

In eindrücklicher Deutlichkeit macht das Gericht klar, dass es keiner antithematischen Auseinandersetzung mit dem Ursprungswerk bedarf und es auch nicht zu den Voraussetzungen der Parodie gehört, dass sie vernünftigerweise dem Urheber des ursprünglichen Werkes zugeschrieben werden könnte. ${ }^{105}$ Damit wurde dem Parodie-Begriff ein weiter Anwendungsbereich zugesprochen. Diesem Parodie-Verständnis folgt nach der

102 EuGH, 3.9.2014, C-201/13, GRUR 2014, S. 972, 973, Rn. 15, 17 - Deckmyn.

103 EuGH, ebd., Rn. 20.

104 EuGH, ebd., S. 973.

105 Vgl. EuGH, ebd., S. 974, Rn. 33. 
EuGH-Entscheidung aber auch die Einengung durch die grundrechtliche Abwägung. 106

Mit dem Gesetzesentwurf zur Anpassung des Urheberrechts an die Erfordernisse des digitalen Binnenmarkts wird jedoch in $\$ 51$ a UrhG-E eine eigene Schranke für Karikaturen, Pastiches und eben Parodien eingeführt. Ausweislich des Regierungsentwurfs war Anlass für diese Schranke sowohl die Entscheidung des EuGH zu Pelham (Metall auf Metall) ${ }^{107}$ als auch der Art. 17 Abs. 7 UAbs. 2 lit. b DSM-Richtlinie, der voraussetzt, dass die Nutzung zum Zwecke von Karikaturen, Parodien, Pastiches für Nutzer von Upload-Plattformen erlaubt sind. ${ }^{108}$

\section{Der Pastiche}

1. Die etymologische und kunst- und literaturwissenschaftliche Einordnung

Das aus dem Französischen entlehnte Wort „Pastiche“ bedeutet ursprünglich nicht mehr als eine bestimmte Form der (Stil-)Übernahme oder Nachahmung. ${ }^{109}$ Der Begriff ist - im Gegensatz zum deutschen Sprachraum - im englischen Sprachraum weit verbreitet. ${ }^{110}$ Pastiche meint - neben der Nachahmung oder Übernahme - ein künstlerisches Werk, das aus ver-

106 EuGH, ebd., S. 974, Rn. 27, 34.

107 EuGH, 28.7.19, C-476/17, GRUR 2019, S. 932, Rn. 56 ff - Pelham.

108 RegE, Entwurf eines Gesetzes zur Anpassung des Urheberrechts an die Erfordernisse des digitalen Binnenmarkts, 3.2.2021, S. 102 f., https:/www.bmjv.de/Share dDocs/Gesetzgebungsverfahren/Dokumente/RegE_Gesetz_Anpassung_Urheber recht_digitaler_Binnenmarkt.pdf;jsessionid=F714760A218A5C6431A156C75CE D7AĀ5.1_cid334?_blob=publicationFile $\& v=4$.

109 "En Peinture, on appelle Pastiches, des tableaux où un peintre a mêlé la manière d'un autre à la sienne, a emprunté son goût, son coloris, ses formes favorites" Le Dictionnaire de l'Académie françoise, Bd. 3, Paris ${ }^{3} 1740$, S. 265 . Vom italienischen Pasticcio (deutsch: Pastete) ins Französische übernommen, wurde der Begriff des Pastiches im späten 19. Jahrhundert sowohl in der französischen als auch in der englischen Sprache verwendet. "Mot emprunté des Italiens, et signifiant, dans la langue des Arts, Mélange, Composition mêlée [...] En Musique, on appelle Pastiche, un opéra composé de morceaux de différents Maîtres" Le Dictionnaire de l'Académie françoise, ebd.

110 Siehe dazu die ausführlichen Auseinandersetzungen von: Dyer, Pastiche, 2007; Hoesterey, Pastiche. Cultural Memory in Art, Film, Literature, 2001; Jameson, The Political Unconscious, 1991; Kellner, Media Culture. Cultural studies, Identity and Politics between the Modern and the Postmodern, 1995. Gerade im 
schiedenen anderen Werken und/oder Werkteilen zusammengesetzt ist. ${ }^{111}$ Folglich ist der Pastiche mit der Kunstform der Collage oder der Parodie verwandt, auch wenn für die Collage das Zusammenführen unterschiedlicher Vorlagen und bei der Parodie das Komische im Vordergrund steht. Im englischen Sprachraum wird „Pastiche“ schließlich zum Oberbegriff unterschiedlichster Formen der Übernahme, Ähnlichkeit und Zusammenstellung. Im Bereich des Films wird das Wort darüber hinaus als ein Synonym für „Hommage“ verwendet. ${ }^{112}$

\section{Die rechtliche Einordnung des Begriffs „Pastiche“}

Ebenso lässt sich der Begriff Pastiche im rechtlichen Kontext wiederfinden. In der deutschen Rechtssprache ist dieser - überraschenderweise - eng verwandt mit den Begriffen der Parodie und Karikatur. Als Rechtsbegriff stammt dieser wie die Parodie aus dem Europarecht, namentlich der Infosoc-Richtlinie und später der DSM-Richtlinie. In der zumindest deutschen rechtswissenschaftlichen Literatur fristete der Pastiche-Begriff trotz seiner der Parodie in Art. 5 Abs. 3, lit. k Infosoc-Richtlinie gleichgestellten Einordnung ein Schattendasein. ${ }^{113}$ Mit der neuen Schranke nach $\ 51$ a UrhGE wird sich dies wohl ändern.

Für eine Abgrenzung wurde bisher auch schon vorgeschlagen die Karikatur der Kunst, die Parodie der Musik und den Pastiche der Literatur zuzuordnen und so eine Abgrenzung nach Werkgattungen zu vollziehen. ${ }^{114}$ Mag die Karikatur in Bezug auf die Kunst noch nachvollziehbar eingeordnet sein, ist eine Einordnung der Parodie zur Musik und des Pastiche zur Literatur nicht überzeugend. Weder vom allgemeinen Sprachgebrauch noch etymologisch lässt sich eine solche Einordnung rechtfertigen. Spätestens mit der Deckmyn-Entscheidung muss klar werden, dass die Parodie

Rahmen der Filmkritik und -theorie ist der Pastiche ein viel verwendeter Oberbegriff.

111 „Pastiche: 1) a literary, artistic, musical, or architectural work that imitates the style of previous work. 2) a musical, literary, or artistic composition made up of selections from different works." https:/www.merriam-webster.com/dictionary/ hodgepodge.

112 Vgl. dazu ferner Dyer, Pastiche, 2007, S. 7 f.

113 Die Dissertation Vlahs führt den Pastiche-Begriff leicht irreführend im Titel, doch geht auf diesen inhaltlich nicht nennenswert ein. Vlah, Parodie, Pastiche und Karikatur - Urheberrechte und ihre Grenzen, 2015, S. 48 f.

114 Vlah, ebd., S. 49. 
sich nicht auf die Musik beschränkt. Der Bericht des UK Intellectual Property Office sieht z.B. gerade den Pastiche als eine eher der Musik zugehörigen Erscheinung. ${ }^{115}$ Bei einem so unterschiedlichen Verständnis lässt sich folglich nur festhalten, dass eine gattungsbezogene Trennung nicht zielführend ist.

Der Generalanwalt der Deckmyn-Entscheidung geht in seinen Schlussanträgen auf eine Unterscheidung der drei in der Richtlinie genannten Begriffe nicht ein, da für ihn alle diese Begriffe dieselbe Wirkung - die Ausnahme vom Recht des Urhebers des ursprünglichen Werkes - haben. ${ }^{116}$

Die Karikatur und die Parodie verbinden eine humorvolle, meist auch verspottende, sarkastische Absicht. Dies unterscheidet sie aber von dem Pastiche, die wie oben gezeigt, zunächst nur eine Übernahme voraussetzt. Rein systematisch ließe sich daher vertreten, dass der Pastiche in der Aneinanderreihung mit Karikatur und Parodie ebenfalls eine dieser Begriffe entsprechenden Absicht benötige. Versteht man den Pastiche hingegen als eine Form der Stilübernahme, dann erweitert sich der Anwendungsbereich. ${ }^{117}$

Der Regierungsentwurf folgt in Abgrenzung zur Karikatur und Parodie diesem weiteren Verständnis und will gerade Praktiken wie Remix, Meme, GIF, Mashup, Fan Art, Fan Fiction oder Sampling erfassen. ${ }^{118}$

115 „Pastiche is musical or other composition made up of selections from various sources or one that imitates the style of another artist or period" Intellectual Property Office, Exceptions to Copyright: Guidances for creators and copyright owners, Oktober 2014, https://assets.publishing.service.gov.uk/government/uplo ads/system/uploads/attachment_data/file/448274/Exceptions_to_copyright_-_Gu idance_for_creators_and_copyright_owners.pdf.

116 GA Cruz Villalón, Schlussanträge, 22.5.2014, C-201/13, Rn. 46 - Deckmyn.

117 In diesem Sinne wurde schon vor dem Regierungsentwurf vertreten, dass beispielsweise die sogenannte Fan Fiction unter den Pastiche-Begriff fallen soll, vgl. Stieper, AfP 2015, S. 305; kritisch dazu: Maier, Remixe auf Hostingplattformen, 2018, S. 62. Oder der Begriff wurde für das Phänomen des Samplings fruchtbar gemacht, vgl. Ohly, GRUR 2017, S. 964, 968 f.

118 RegE, Entwurf eines Gesetzes zur Anpassung des Urheberrechts an die Erfordernisse des digitalen Binnenmarkts, 3.2.2021, S. 105, https:/www.bmjv.de/Shared Docs/Gesetzgebungsverfahren/Dokumente/RegE_Gesetz_Anpassung_Urheberr echt_digitaler_Binnenmarkt.pdf;jsessionid=F714760A218A5C6431A156C75CE D7AA5.1_cid334?_blob=publicationFile\&v=4. 
IV. Die Persiflage

Die Definition des Dudens und des Brockhaus - „Persiflage ist eine feine, geistreiche Verspottung durch übertreibende oder ironisierende Darstellung bzw. Nachahmung"119 - zeigt wiederum die Nähe zu den bisher schon vorgestellten Begriffen. Der Aspekt der Nachahmung ist mit der Parodie und dem Pastiche verwandt, das Spöttische lässt sich in dem Begriff des Sarkasmus bereits wiederfinden. Bei einer direkten Gegenüberstellung fällt nur auf, dass der Persiflage eine besondere Feinsinnigkeit und Esprit zugesprochen wird.

\section{Die Satire, das Satirische und die literaturwissenschaftliche Satiretheorie}

\section{Einführung in eine Begriffsnäherung}

„Satire muss, auch wenn sie noch so überzeichnet, verfremdet und übertreibt, immer auf Wahrheit beruhen. ${ }^{\text {"120 }}$ Mit diesen Worten umreißt Klaus Staeck sein Satireverständnis. Sie beinhaltet zwei Elemente, die sich durch das Satireverständnis - sei es der Literatur, der Politik oder Rechtswissenschaft - mehr oder weniger durchzieht: Die Übertreibung und der Anspruch der Wahrheit. Das entspricht schon dem antiken europäischen Verständnis des römischen Dichters Horaz (65 v.Chr.-8 n.Chr.), für den die Satire - „ridentem dicere verum“ - lachend die Wahrheit sagt. ${ }^{121}$ Auch der deutsche Philosoph Hans-Georg Gadamer (1900-2002) sieht eine der Grundaufgaben der Satire in der „Aufdeckung der moralischen Heuchelei, d.h. der Unwahrheit der seinsollenden Welt." ${ }^{122}$ Doch bevor sich diesem integren Ziel genähert wird, welches auch nicht im Rahmen einer begrifflichen Bestimmung vergessen werden sollte, lohnt es sich einen Blick auf die Etymologie und die historischen Ursprünge der Satire zu werfen. Historisch betrachtet wird davon ausgegangen, dass die Satire im

119 Duden, „Persiflage“, https://www.duden.de/rechtschreibung/Persiflage; Brockhaus, „Persiflage“, https://brockhaus.de/ecs/enzy/article/persiflage.

120 Staeck, Plakate, 1998, S. 44.

121 Albrecht, Horaz, in: Adamietz (Hrsg.), Die römische Satire, 1986, S. 169.

122 Gadamer, Die verkehrte Welt, in: ders. (Hrsg.), Hegel-Tage Royaumont 1964: Beiträge zur Deutung der Phänomenologie des Geistes, Nachdruck, 2016, S. 149. 
Sinne einer „verbalen Aggression“ 123 kulturübergreifend auf Riten zurückzuführen ist. ${ }^{124}$ Weitaus konkreter lässt sich bestimmen, dass die Satire in ihrer Form der Satiredichtung ihren Ursprung in der griechischen und römischen Antike hat. Vor allem die römischen Autoren Lucilius (180-103 v.Chr.), der bereits zitierte Horaz und Iuvenal (um 60- um 130 n.Chr.) seien in diesem Kontext genannt. Der Satirebegriff selbst festigte sich ausgehend von der Gedichtsammlung mit dem Namen Satura, die der römische Dichter Ennius (239-169 v.Chr.) um 200 vor Christus verfasste. ${ }^{125}$ Die römische Satire lässt sich längst nicht mit dem heutigen weitreichenden Satireverständnis, auf das gleich genauer eingegangen werden soll, gleichsetzen. Unter Satire wurde eine Kunstform mit festen Regeln und Gesetzmäßigkeiten verstanden, die einen festen Platz in der antiken Dichtung und Theater hatte. ${ }^{126}$ Der Satirebegriff der modernen Literaturwissenschaft ist jedoch viel weiter gefasst. Jörg Schönert beispielsweise sieht in der Satire keine fest umrissene literarische Form, sondern ein Formprinzip mit lediglich „festen Formtraditionen und Funktionen im literarischen Leben “. ${ }^{27}$ Nach heutigem Sprachverständnis kann mit dem Adjektiv „satirisch“ sehr flexibel gearbeitet werden. So lässt sich von einem satirischen Roman, satirischen Lied oder eben einem satirischen Plakat sprechen.

In einem kurzen historischen Abriss sei zunächst auf die Einordnung der Satire eingegangen. Wurde in der Antike zwischen der Tragödie, dem Satyrspiel und der Komödie unterschieden, entspricht dies dann auch der Differenzierung im 14. Jahrhundert zwischen den Stilarten der Tragödie, dem erhabenen Stil, der Satire, dem mittleren Stil und der Komödie, dem niederen Stil. ${ }^{128}$ Thomas Hobbes grenzt im 16. Jahrhundert zwischen Hof,

123 Der Begriff der verbalen Aggression übersetzt und übernommen von Test, Satire, 1991, v.a. S. 100.

124 Dieser Ansatz lässt sich vor allem in der englischsprachigen Satireforschung wiederfinden. Test, Satire, 1991, v.a. S. 100, vgl. auch Cueni, Schutz von Satire im Rahmen der Meinungsfreiheit, 2019, S. 16 m.w.N.

125 Dementsprechend kommt der Begriff etymologisch von der satura (zu dt. die mit Diversem gefüllte Schale) und gerade nicht von dem Satyrspiel, dem letzten Stück im Rahmen der achttägigen Dionysien. Etymologisch ist der Begriff „Satire" auf lanx satura - eine mit Früchten und Nüssen gefüllte Schale - und nicht, wie es naheliegend erscheinen mag, auf die mythologische Figur des Satyrs zurückzuführen. hM vgl. nur Greenberg, The Cambridge Introduction to Satire, 2018, S. 11.

126 Vgl. dazu Knoche, Die römische Satire, Göttingen ${ }^{4} 1982$, S. 3 ff.

127 Schönert, Roman und Satire im 18. Jahrhundert, 1969, S. 8.

128 Vgl. dazu die Ausführungen bei Brummack, DVjs 45, S. 278. 
Stadt und Land ab. Der Hof steht dabei entsprechend für die heroische Dichtung mit den Gattungen Epos und Tragödie, die Stadt für die skommatische Dichtung mit der Satire und der Komödie, das Land für die Pastoraldichtung mit den Gattungen Bukolik und Schäferspiel. ${ }^{129}$ All diese Differenzierungen haben gemein, dass sie eine Hierarchisierung antiken Ursprungs und Verständnisses übernehmen und die Satire dabei an eher mittlerer bzw. unterer Stelle eingeordnet wird. Bezieht man sich auf das Merkmal der Verspottung und beachtet man die sogenannte Ständesatire und damit eine Satire vor der Zeit der Aufklärung, dann wird deutlich, dass die Satire häufig nur Teil von Predigten und Sittenlehren wird und so die Verspottung dann lediglich in der „Androhung höllischer Strafen“ besteht. ${ }^{130}$

Viel rezipierte Auseinandersetzungen mit der Satire in theoretischer Hinsicht folgen bei den Schriftstellern Friedrich Schiller und Jean Paul. Schiller unterscheidet entsprechend seiner Vorstellung der sentimentalischen Dichtung im Rahmen von Idee und Wirklichkeit zwischen Satire, Elegie und Idylle, wobei er die weiterführende Unterscheidung der Satire zwischen der strafenden und der lachenden Satire aus der Antike aufgenommen hat. ${ }^{131}$ Die strafende Satire erlangt nach Schiller eine poetische Freiheit, indem sie ins Erhabene übergeht, wohingegen die lachende Satire poetischen Gehalt erhält, indem sie ihren Gegenstand mit Schönheit behandelt. ${ }^{132}$ Die Grunddefinition der Satire sieht Schiller letztlich darin, dass „in der Satire die Wirklichkeit als Mangel, dem Ideal als der höchsten Realität gegenüber gestellt wird“. ${ }^{133}$

Die Satire wird in den unterschiedlichen Epochen zumindest leicht unterschiedlich verstanden, auch wenn sich die definitorischen Merkmale häufig ähneln. In der Forschung des späten 20. und 21. Jahrhunderts lässt sich daher das Motiv der Undefinierbarkeit der Satire häufiger wiederfinden, das auch die Rechtswissenschaft übernommen hat. ${ }^{134}$ Bevor jedoch

129 Brummack, DVjs 45, S. 279.

130 Arntzen, Satirischer Stil, ${ }^{3} 1983$, S. 6.

131 Schiller, Über naive und sentimentalische Dichtung, 2013, S. 22 f., 27 f., 38 f.; vgl. ferner Brummack, DVjs 45, S. 279.

132 Schiller, ebd., S. $22 \mathrm{f}$.

133 Schiller, ebd., S. 22; 27. Auf diese Definition aus der Rechtswissenschaft zum Teil rekurrierend Brauneck, ZUM 2000, S. 137 f.

134 Arntzen, Satirischer Stil zur Satire Robert Musils im „Mann ohne Eigenschaften", ${ }^{3}$ 1983; Brummack, DVjs 45, 330 f.; Elliott, The Power of Satire, 1960, S. 22 f.; aus der Rechtswissenschaft u.a. Cueni, Schutz von Satire im Rahmen der Meinungsfreiheit, 2019, S. 58. 
gleich von einer allumfassenden Undefinierbarkeit ausgegangen wird, soll eine Auswahl an unterschiedlichen Definitionsversuchen vorgestellt werden. Schon dabei wird dann deutlich, dass die einleitend von Klaus Staeck beschriebene Funktion der Satire, die Wahrheit aufzuzeigen, ein in unterschiedlichen Ausprägungen wiederkehrender Topos ist.

\section{Die Definitionen der deutschen Autoritäten}

Die Autoritätsquellen der deutschen Sprache und des Begriffsverständnisses weisen unterschiedliche Definitionen auf. Drei der gängigen Quellen seien hier vorgestellt:

1. Für den Duden ist die Satire eine „Kunstgattung (Literatur, Karikatur, Film), die durch Übertreibung, Ironie und (beißenden) Spott an Personen, Ereignissen Kritik übt, sie der Lächerlichkeit preisgibt, Zustände anprangert, mit scharfem Witz geißelt." ${ }^{135}$

2. Die Brockhaus Enzyklopädie sieht in der Satire eine „mit Ironie und scharfem Spott menschliche Schwächen und Laster geißelnde Darstellung literarisch-künstlerischer Art" ${ }^{\text {“ }}{ }^{36}$

3. Meyers Konversationslexikon geht einer Definition aus dem Wege, indem es die Satire als eine "Grundform der subjektiven ästhetischen Auffassung" bezeichnet, „die sich in allen Künsten, vor allem aber in der Poesie, und in dieser in allen Gattungen (Epos, Roman, Novelle, Lyrik, Drama) geltend machen kann; insbesondere aber versteht man unter Satiren diejenigen (bald umfangreicheren, bald knapper gefassten) Gedichte, in denen die negierende, tadelnde Beschreibung von Eigenschaften und Zuständen der Einzelnen oder bestimmter engerer oder weiterer Gemeinschaftsgruppen vorwaltet". ${ }^{137}$

Die aufgezeigten Definitionen zeigen die begriffliche Nähe zu beispielsweise der Ironie und dem Sarkasmus, steht doch der Spott in den ersten beiden Definitionen im Vordergrund. Die letzte Definition versperrt sich zunächst eines handhabaren Umgangs, da sie von Beispielen statt einer Gemeingültigkeit ausgeht. Die Definitionen haben jeweils aber große Gemeinsamkeiten: Es wird zum einen das Künstlerische hervorgehoben und zum anderen das zu Tadelnde mit unterschiedlichen Methoden kritisiert.

135 Duden, „Satire“, http://www.duden.de/rechtschreibung/Satire.

136 Brockhaus, „Satire“, https://brockhaus.de/ecs/enzy/article/satire-20.

137 Meyers Konversationslexikon, „Satire“, http://www.woerterbuchnetz.de/Meyers? lemma=satire. 
Darin liegt zum Teil aber auch schon die Problematik dieser Definitionen. Der Bezug auf die Kunstgattung mit den Ausprägungen in Literatur, Karikatur und Film, den der Duden formuliert, ist zu eng. Das zeigt schon das satirische Plakat. Ob Ironie und Spott, wie es die Brockhaus Enzyklopädie vorschlägt, die einzigen Mittel sind, wird wie die Frage, ob es für die Satire einen „scharfen Witz“ braucht, unter anderem anschließend besprochen.

\section{Die konstituierenden Merkmale nach der Literaturwissenschaft}

\section{Einführung}

Eine Definition der literarischen Satire wird im deutschsprachigen Raum meist aus drei Kernmerkmalen gebildet, nämlich Aggressivität, Normativität und Indirektheit. An diese Kategorien eines literaturwissenschaftlichen Satirebegriffs knüpft die juristische Forschung an. ${ }^{138} \mathrm{Im}$ Folgenden sollen daher unterschiedliche Ansätze für die konstituierenden Merkmale gezeigt werden, die über die deutschen Autoren hinausgehen, um eine weiterreichende Differenzierung der Begrifflichkeit anzustreben.

Gemein haben diese Ansätze, dass die Satire - entgegen dem antiken Verständnis - nicht an eine bestimmte Gattung gebunden ist. Der Theaterwissenschaftler Klaus Lazarowicz (1920-2013), der mit seiner Habilitationsschrift aus den 1960er Jahren ein grundlegendes Werk zur literarischen Satire im deutschsprachigen Raum verfasst hat, stellt treffend fest, dass die Satire nicht aufgrund äußerer Merkmale identifiziert werden kann, sondern dass der Satiriker vielmehr jede beliebige Ausdrucksform zum Mittel und Medium seines spezifischen Gestaltungswillen machen kann. ${ }^{139}$ Ein häufig anzutreffender Topos der deutschen Satireforschung liegt daher auch in einem Vergleich der Satire mit Proteus, einem Gott der griechischen Mythologie, der sich - genau wie die Satire - in alle denkbaren Gestalten verwandeln kann. ${ }^{140}$ Dieses Bild wird bemüht, um hervorzuheben, dass es eben neben einem satirischen Text auch satirische

138 Vgl. unter vielen beispielsweise Klass, AfP 2016, S. 477-495; Kassing, Ehrverletzende Personalsatire, 2004, S. 24 f.

139 Lazarowicz, Verkehrte Welt. Vorstudien zu einer Geschichte der deutschen Satire, 1963, S. XI.

140 Beispiele unter vielen: Gaier, Satire, 1967, S. 329 f.; Knight, Comparative Literature 1992, S. 22; Schmitz, Das Satirische in Juvenals Satiren, 2000, S. 5 m.w.N.; Worcester, The Art of Satire, 1960, S.3-10; Zehrer, Dialektik der Satire, 2002, S. 58 . 
Musik oder satirische Bilder geben kann. Aus der Wandelbarkeit der Satire folgt auch, dass die satirischen Elemente unterschiedlich stark ausgeprägt sein können. Lazarowicz unterscheidet beispielsweise zwischen Fällen, in denen das Satirische nur akzident und solchen, in denen es dominant auftritt. ${ }^{141}$ Das führt dazu, dass Teile eines zusammenhängenden Werkes satirisch sein können, aber dieses insgesamt nicht als eine Satire anerkannt oder verstanden wird. Im Rahmen dieser Arbeit wird daher unter der Satire oder dem Satirischen jede Form der satirischen Äußerung in all ihren Facetten und Stärken verstanden, ohne dabei die Satire zu einem Stilmittel des Satirischen selbst verengen zu wollen.

Meilensteine in der Satiretheorie sowohl aus der englischsprachigen als auch der deutschsprachigen Literatur stammen aus den späten 50er und 60er Jahren des 20. Jahrhunderts. Grundlegende Theorieentwürfe des Satire-Begriffs in der deutschsprachigen Literaturwissenschaft, auf die sich auch schon die juristische Wissenschaft stützt, ${ }^{142}$ lassen sich in dem Forschungsbericht des Literaturwissenschaftlers Jürgen Brummack mit dem Titel „Zu Begriff und Theorie der Satire“ von $1971^{143}$ und in Jörg Schönerts Beitrag „Roman und Satire im 18. Jahrhundert“ von $1969^{144}$ wiederfinden. Im Folgenden seien einzelne Theorien vor allem der genannten Autoren vorgestellt.

\section{Die Elemente nach Schönert, Brummack und Zymner}

Für Schönert ist die Satire ein „Instrument literarisches Erkennen von Wirklichkeit“ ${ }^{145}$ und darauf gerichtet, keine einzelnen Missstände, son-

141 In seiner literaturwissenschaftlichen Untersuchung führt Lazarowicz aus: „Die Dominanz des satirischen Elements erzwingt vielmehr eine Art- oder Gattungsverkehrung, die zwar die Kontur der Arten und Gattungen nicht antastet, sie aber gleichsam von innen substantiell verkehrt. Wo dieses Element nur als Akzidenz in Erscheinung tritt, haben wir es etwa mit einem satirischen Enkomion, einer satirischen Legende oder einem satirischen Epos zu tun; tritt es dagegen beherrschend auf, dann wird es angemessen sein [...], von einer enkomiastischen, einer legendaren oder einer epischen Satire zu sprechen." Lazarowicz, Verkehrte Welt. Vorstudien zu einer Geschichte der deutschen Satire, 1963, S. 312 .

142 So beispielsweise Gärtner, Was die Satire darf, 2009; Senn, Satire und Persönlichkeitsschutz, 1998.

143 Brummack, DVjs 45, S. 275-377.

144 Schönert, Roman und Satire im 18. Jahrhundert, 1969.

145 Schönert, ebd., S. 10. 
dern größere Zusammenhänge aufzuzeigen. Schönert arbeitet begrifflich weniger mit Merkmalen, sondern spürt zunächst Tendenzen auf. Die erste liegt in ihrer „strafenden Absicht“. ${ }^{146}$ Mit der Verfremdung bzw. dem Befremdungseffekt - als weitere Tendenz - wird durch eine neue ungewohnte Perspektive der erwünschte Erkenntnisvorgang ausgelöst. Der Satiriker „verfremdet das Vertraute“ 147 , „in der verzerrten Form wird das Charakteristische entdeckt und analysiert“. ${ }^{148}$ Er führt den Begriff der „satirischen Situation" ein: In der satirischen Situation kommt neben dem Satiriker und seinem Gegenstand dem angesprochenen Publikum und seinen Beziehungen zum Satiriker und Objekt eine entscheidende Bedeutung zu. ${ }^{149}$

Die drei konstitutiven Merkmale nach Brummack liegen im individuellen, sozialen und ästhetischen Element. ${ }^{150}$ Unter dem ersten wird der Hass, Wut bzw. Aggression des Satirikers verstanden, unter dem zweiten sein Wille auf einen Missstand mit dem Ziel der Besserung aufmerksam zu machen. Das ästhetische Element kann sich in unterschiedlichen rhetorischstilistischen Mitteln äußern. Für Brummack ist mit einem Schwerpunkt auf den ersten beiden Elementen Satire daher „sozialisierte Aggression“. 151

Die Merkmale einer Satire nach Rüdiger Zymner liegen in der Verstellung, „dissimulatio“, der Verspottung, „illusio“, und in der Entrüstung, „indignatio“. ${ }^{152}$ Zymner nähert sich damit dem Satirebegriff über typische rhetorisch-stilistische Mittel. Er verkennt aber nicht, dass dies sicherlich keine abschließende Aufzählung sein kann und erweitert diese um den Sarkasmus, die „scharfsinnig-witzige Stichelrede des Asteismus“, die Hyperbel, „die pauschal-gruppencharakterisierende Ethopoeia“, die „pauschal-einzelcharakterisierende Prosopopoeia“, die Andeutung, das Wortspiel und die Parodie. ${ }^{153}$

Diese Ansammlung möglicher, aber nicht notwendiger stilistischer Erscheinungsformen wie es Zymner vorschlägt, ist eine gängige Herangehensweise an eine Definition der Satire ${ }^{154}$ sowohl in der internationalen

146 Schönert, ebd.

147 Schönert, ebd., S. 15.

148 Schönert, ebd., S. 14.

149 Schönert, ebd., S. 28.

150 Brummack, DVjs 45, S. 282.

151 Brummack, ebd, S. 282.

152 Zymner, „Satire“, in: Wirth (Hrsg.), Komik. Ein interdisziplinäres Handbuch, 2017, S. 22.

153 Zymner, ebd., S. 22.

154 Definitionen, die mit solchen Beispielen arbeiten angreifend: Declercq, Journal of Aesthetics and Art Criticism 2018, S. 319-330. 
Satireforschung ${ }^{155}$ als auch in der deutschen Rechtswissenschaft ${ }^{156}$. Sie entspricht dem bestehenden Konsens der Proteushaftigkeit der Satire.

Schönerts und Brummacks Definitionen ähneln sich. In den Jahren 1969 und 1971 erschienen, kommen sie nicht nur aus der gleichen Zeit und literaturwissenschaftlichen Strömung, sondern beziehen sich auch auf die gleichen Grundlagen, wie Klaus Lazarowicz ${ }^{157}$, Helmut Arntzen ${ }^{158}$ oder die US-Amerikaner Leonard Feinberg ${ }^{159}$ und Robert C. Elliot ${ }^{160}$. Es überrascht nicht, dass der Ansatz Brummacks in der deutschen Rechtswissenschaft die größte Resonanz erfahren hat, da er klare und handliche Merkmale herausgearbeitet hat, die sich gerade durch das Ästhetische in der „sozialisierten Aggression“ nicht nur auf das Literarische beziehen. Das Merkmal der Aggression, wie es bei Brummack im individuellen Element eingeordnet wird, findet sich bei vielen anderen Theorien und Autoren wieder, auf die sich Brummack bezieht, oder die auf Brummack verweisen. ${ }^{161}$ Die knapp und verkürzend formulierte Beschreibung der Satire als „ästhetisch sozialisierte Aggression“ wird auf ihre Schlüssigkeit hin immer wieder überprüft und thematisiert. ${ }^{162}$ Auch wenn die Trias Angriff, Indirektheit und Normbezug nicht von Brummack geschaffen wurde, er selbst sie schon vielmehr als „überzeitliche Merkmale“ verstanden hat, ist es doch er, der mit diesen in Verbindung gebracht und rezipiert wird. ${ }^{163}$

155 Condren, Satire and Definition, Humor 2012, S.375, v.a. 386. Demgegenüber äußerst kritisch: Declercq, Journal of Aesthetics and Art Criticism 2018, S. 319330.

156 So z.B. Cueni, Schutz von Satire im Rahmen der Meinungsfreiheit, 2019, v.a. S. 58 .

157 Lazarowicz, Verkehrte Welt, 1963.

158 Arntzen, Satirischer Stil zur Satire Robert Musils im „Mann ohne Eigenschaften“, ${ }^{3} 1983$; ders., Deutsche Satire im 20. Jahrhundert, 1964.

159 Feinberg, The Satirist, 1963.

160 Elliot, The Power of Satire, 1960.

161 Beispielsweise bei Schwind, Satire in funktionalen Kontexten, 1988, S. 63 f.

162 Vgl. beispielsweise Lanius, sic 4/2019, S. 239-244.

163 So schon Brummack, DVjs 45, S. 332; darauf rekurrierend u.a. Podskalsky, Jan Böhmermann und Die Partei, 2017, S. 15. 
3. Die überzeitlichen Merkmale der Satire: Angriff, Indirektheit und Normbezug

a) Angriff und Aggression

Der Angriff, die Aggression oder das aggressive Element beschreibt die verbale, visuelle, auditive Attacke oder - weiter gefasst - die nicht-körperliche Gewalt gegen jemanden oder gegen etwas. Mit dem Merkmal des Angriffs oder der Aggression soll der für die Satire typische „Überschuss an feindlicher Energie" 164 umrissen werden. Der Angriff kann eindeutig und plump oder versteckt und subtil erfolgen. Ziel eines Angriffs können per se erstmal Personen, Institutionen, Gruppierungen, aber auch allgemein Wertvorstellungen oder gesellschaftliche Narrative sein. Im Rahmen der politischen Satire überwiegt der Angriff gegen Politiker, politische Parteien, weltliche oder religiöse Würdenträger, Unternehmen oder in der Öffentlichkeit stehende (private) Entscheidungsträger.

Teilweise wird auch der Angriff mit dem Begriff der Kritik gleichgesetzt. ${ }^{165}$ Das kann jedoch, wenn man dem Begriffsverständnis Brummacks folgt, problematisch sein. Für ihn kann die Kritik nämlich unsachlich und ungerecht sein, der satirische Angriff hingegen muss nach seinem Verständnis zwar nicht per se gerecht aber dennoch gerechtfertigt sein. ${ }^{166}$

\section{b) Normbezug}

Dieses Angriffsverständnis bereitet das zweite Kriterium des Normbezugs vor. Der Angriff muss sich folglich auf eine Norm beziehen. Eine Norm setzt gleichfalls Normabweichungen voraus, weswegen nach Brummack ein Moment des Strafens oder Korrigierens in diesem Merkmal vorliegt. ${ }^{167}$ Demnach ist der Angriff auf dasjenige gerichtet, was nach dem subjektiven Verständnis des Satirikers einen Missstand in Form einer Abweichung von einer Norm darstellt. Brummack weist darauf hin, dass dieses Merkmal unglücklich gewählt ist, da der Begriff der Norm eine allgemein anerkann-

164 Brummack, DVjs 45, S. 333.

165 So beispielsweise bei Cueni, Schutz von Satire im Rahmen der Meinungsfreiheit, 2019, S. 21.

166 Brummack, DVjs 45, S. 333.

167 Brummack, ebd. 
te, als verbindlich geltende Regel voraussetzt. ${ }^{168}$ Umso verwunderlicher ist es, dass auch gerade dieses Merkmal in der rechtswissenschaftlichen Satireforschung übernommen wurde, ${ }^{169}$ setzt doch gerade eine Norm im rechtlichen Verständnis grundsätzlich einen Tatbestand und eine Folge voraus. Der Normbezug wird als Begriff in der literaturwissenschaftlichen Satiretheorie folglich weniger präzise verwendet.

Dieses Merkmal öffnet - auch gerade in der Rezeption durch die rechtswissenschaftliche Lehre - den Raum für eine Bewertung. Der Normbezug soll nach einer nicht unerheblich stark vertretenen Meinung sicherstellen, dass „die Satire konstruktiv“ ist. ${ }^{170}$

\section{c) Indirektheit}

Mag sich die Indirektheit in der Literaturwissenschaft als Oberbegriff herausgebildet haben, vereint er letztlich als ästhetisches Element die Vielzahl an Mitteln und Möglichkeiten, um den Normbezug im Angriff zu demonstrieren und gleichzeitig zu „verschlüsseln“171. Für Lazarowicz ist die Satire nur dort anzuwenden, wo „der künstlerische Aufbau einer verkehrten Welt angestrebt und wenigstens ansatzweise (auf jeden Fall aber: deutlich erkennbar) geleistet worden ist." 172 Damit ist für ihn, der das Künstlerische der Satire maßgeblich hervorhebt, die Indirektheit, nicht wie bei Brummack ein eigenes Merkmal, sondern das grundlegende Prinzip der Satire.

Eine Verschlüsselung kann durch Disproportionalität in Form von Über- oder Untertreibung, Verharmlosung, Banalisierung oder Weglassung entstehen. ${ }^{173}$ Beschrieben werden diese Stilmittel vereinfacht auch als Verfremdung, Verzerrung oder Verformung. So spricht beispielsweise

168 Brummack, ebd.

169 So bei Becker, GRUR 2004, S.908; Cueni, Schutz von Satire im Rahmen der Meinungsfreiheit, 2019, S. 24-29; Erhardt, Kunstfreiheit und Strafrecht 1989, S. 143 f.; Gärtner, Was die Satire darf, 2009, S. 24; Kassing, Ehrverletzende Personalsatire, 2004, S. 25 f.; Klaas, AfP 2016, S. 478; Levin, Die lauterkeitsrechtlichen Möglichkeiten und Grenzen der humorvollen und satirischen vergleichenden Werbung 2013, S. 44; Oechsler, NJW 2017, S. 759; Senn, Satire und Persönlichkeitsschutz, 1998, S. 22-28.

170 Klaas, ebd. auf Wetzel, Communicatio Socialis 2012, S. 279 und Gärtner, ebd., S. 29 rekurrierend.

171 Schönert, Roman und Satire im 18. Jahrhundert, 1969, S. 31.

172 Lazarowicz, Verkehrte Welt, 1963, S. 312.

173 Schönert, Roman und Satire im 18. Jahrhundert, 1969, S. 13 f. 
der Literaturwissenschaftler Ulrich Gaier von „sprachlichen Verzerrungsprozessen “. ${ }^{174}$ Eine Verfremdung kann beispielsweise in einer Karikatur liegen oder sich durch Mittel der Antithese, des Paradoxons, der Metapher, der Anspielung, der Rekontextualisierung oder durch viele andere Formen erzielen lassen. Irreführend an dem Merkmal ist die Verkürzung auf die Verfremdung oder verfremdende Stilmittel. Auch wenn sie ein gängiges Beispiel für die satiretypische Verschlüsselung sein mag, sind auch Verschlüsselungen, die ohne jegliche Verfremdung auskommen, denkbar. So kann beispielsweise die Gegenüberstellung kontradiktorischer Aussagen genutzt werden, um Widersprüchlichkeit aufzuzeigen und anzugreifen.

\section{d) Zwischenfazit}

Die Elemente bei Brummack (aggressiv, sozial und ästhetisch) oder die Merkmale (Angriff, Norm und Indirektheit) suggerieren trotz ihrer jeweiligen Bedingtheit eine klare Trennung und Handlichkeit.

IV. Die nicht-konstituierenden Merkmale der Satire?

\section{Die Ironie}

Bei der Ironie als rhetorische Figur entspricht das Gesagte nicht dem Gemeinten, wobei dies durch gewisse übliche Signale ${ }^{175}$ nach außen erkennbar ist, und nicht auf eine Täuschung und damit eine Lüge ausgerichtet ist. Auch die Ironie kann falsch oder missverstanden werden. Doch lässt sich die Ironie, auch wenn sie als Form und nicht bloß als reine rhetorische Figur vorliegt und sich so als ein Mittel der Indirektheit zeigt, mit dem Adjektiv „selbstgenügsam“ beschreiben. ${ }^{176}$ Damit ist gemeint, dass im Ge-

174 Gaier, Satire. Studien zu Neidhart, Wittenwiler, Brant und zur satirischen Schreibart, 1967, S. 394.

175 Im Gesprochenen können Mimik, Betonung, auch in Kombination die Gestik von Anführungszeichen (synchrones Strecken und Beugen) oder ähnlicher non-verbaler Kommunikationsmittel Aufschluss geben. Im Geschriebenen sind Ironiesignale versteckter und ergeben sich meist aus dem Kontext. vgl. dazu $\mathrm{Ne}$ kula, Ironiesignal. Beschreibung der Ironie in Handlung und Text, in: Brünner Beiträge zu Germanistik und Nordistik, 1996, S. 41-53.

176 Schönert, Roman und Satire im 18. Jahrhundert, 1969, S. 19. 
gensatz zur Satire die Ironie auf kein weiterführendes Ziel ausgerichtet sein muss. Sie genügt sich folglich selbst.

\section{Das Lachen: Humor, Witz und Komik}

Entgegen der Beschreibung von Horaz, dass die Satire - „ridentem dicere verum" - lachend die Wahrheit sagt ${ }^{177}$ ist sich die deutsche Satireforschung über unterschiedliche Schulen und Strömungen hinweg in der Theorie einig, dass der Humor, der Witz, die Komik oder generell das Hervorrufen des Lachens für den Satirebegriff nicht notwendig sei. ${ }^{178}$ Diese Bewertung hat die rechtswissenschaftliche Lehre übernommen. ${ }^{179}$ Es wird dabei nicht geleugnet, dass das Komische, das Lachen hervorrufende durchaus eine große Rolle in der Satire spielen kann. Aber das Witzige und Humoristische bzw. das dadurch hervorgerufene Lachen wird als ein Nebeneffekt ${ }^{180}$ bezeichnet, das als „ästhetisches Signal“ die Satire lediglich befördere. ${ }^{181}$

In der englischsprachigen Forschung hingegen wird das Lachen, der Humor, das Witzige als elementares Merkmal der Satire verstanden. Dies geht soweit, dass die Satire als eine spezielle Form des Humors angesehen wird. ${ }^{182} \mathrm{Zu}$ einer näheren Beleuchtung dieses Ansatzes gilt es die Entwicklung und Strömungen in der englischsprachigen Satireforschung zu betrachten. Northrop Fryes trennt zwei Kriterien, nämlich „fantasy“ und „moral standard“183, Rosenheim unterscheidet zwischen drei Elementen, „attack“, „a manifest fiction“ und ein Verweis auf „historical particulars“, ${ }^{184}$ wohingegen Gilbert Highet fünf Merkmale „topicality, exaggera-

177 Albrecht, Horaz, in: Adamietz (Hrsg.), Die römische Satire, 1986, S. 169.

178 Wetzel, Communicatio Socialis 2012, S. 280; Zymner, „Satire“, in: Wirth (Hrsg.), Komik. Ein interdisziplinäres Handbuch, 2017, S. 22.

179 Gärtner, Was die Satire darf, 2009, S. 33; Senn, Satire und Persönlichkeitsschutz, 1998, S. 25.

180 Vgl. Schönert, Roman und Satire im 18. Jahrhundert, 1969, S. 12; Senn, Satire und Persönlichkeitsschutz, 1998, S. 25.

181 Schönert, ebd., S. 11.

182 „It should be noted that satire is a distinct type of humor." Huntington, Affect and effect of Internet memes, 2017, S. 34; vgl. auch Simpson, On the Discourse of Satire, 2003, S 1; und bereits Feinberg, Introduction to Satire, 1967, S. 101.

183 Frye, Anatomy of Criticism, 1957, S. 224; vgl. im Allgemeinen Greenberg, The Cambridge Introduction to Satire, S. $12 \mathrm{ff}$.

184 Rosenheim, Swift and the Satirist's Art, 1963, S. 31; Greenberg, ebd. 
tion, shock, informality, dark or grotesque humor" erkennt. ${ }^{185}$ Eine Weiterführung von Frye findet sich bei George Test mit seinen vier Elementen: „aggression“, „judgment“, „play“ und „laughter", ${ }^{186}$ die er als "soziale Verhaltensformen" 187 versteht. Dustin H. Griffin entscheidet sich für eine offene Definition, arbeitet aber die Merkmale "inquiry", "provocation" and "playfulness" heraus. ${ }^{188}$ Bei den beiden letztgenannten Autoren, aber auch anderen Bearbeitern, nimmt das Lachen in den 1990er Jahren den Stellenwert ein, den es bis heute in der englischsprachigen Forschung innehat. David Hume will 2007 ganze neun Merkmale sehen: ,attack, humor or wit, self-display, exaggeration, moral or existential truth, mockery, inquiry, a moral idea, reformative aim“. ${ }^{189}$

Die letztgenannten Ansätze haben trotz der Vielzahl der Merkmale die Gemeinsamkeit der Elemente des Humors und der Moral. In der neueren Forschung - für die englischsprachige Forschung sei hier vor allem Jonathan Greenberg genannt - wird sich jedoch gegen das Merkmal der Moral ausgesprochen. Die Moral schränke unnötigerweise den Begriff der Satire ein, denn nicht jeder satirische Gegenstand oder Angriff muss ein moralischer sein, d.h. im Gegenzug auch, dass es einen satirischen Angriff geben kann, der weder moralisch noch immoralisch ist. ${ }^{190}$ Darin liegt genau der Vorteil des weiter gefassten Merkmals der Norm.

Der Humor oder die verwandten Kategorien wie Witz, Lachen, Spiel („play“) oder Verspottung („mockery“) werden nach der neueren englischsprachigen Satireforschung als der Kernpunkt der Satire angesehen, denn der satirische Witz ermögliche eine Befreiung von der Autorität, einschließlich der Autoritäten von Vernunft und Moral. ${ }^{191}$ Der Ansatz geht soweit, die Moral, die Norm oder wie oben genannt das ,judgment“ als bloßes Mittel zur Inszenierung des Witzes zu verstehen. ${ }^{192}$

185 Highet, The Anatomy of Satire, 1962, S. 21; vgl. Greenberg, ebd.

186 Test, Satire. Spirit and Art, 1991, S. 15-36; vgl. Greenberg, ebd.

187 Test, ebd., S. 31; vgl. Greenberg, ebd.

188 Griffin, Satire. A Critical Reintroduction, 1993, S. 35-94; 186. Der Vorteil des Merkmals „inquiry“ sieht Griffin darin, dass das für die Satire typische Vergnügen, herauszubekommen wie die Satire gemeint und zu verstehen ist, eingeschlossen ist; vgl. Greenberg, ebd.

189 Hume, Modern Philology 2007, S. 305; vgl. Greenberg, ebd.

190 Greenberg, The Cambridge Introduction to Satire, S. 15, 20. "ugliness, clumsiness, foolishness, bad taste, stupidity' are generally not thought to be forms of immorality“ Knight, zit. nach Greenberg, ebd. S. 15.

191 Greenberg, ebd., S. 20.

192 Greenberg, ebd. 
Tritt der Witz immer mehr in den Vordergrund, ließe sich annehmen, dass es einer Abgrenzung zum Nonsens bedürfe. Die Trennung zwischen dem Nonsens und der Satire mit der damit verbundenen Gefahr einer Verwechslung ist in Deutschland vor allem der Frankfurter Schule, besonders Robert Gernhardt, und der von den Vertretern der Frankfurter Schule gegründeten Satirezeitschrift Titanic geschuldet. Unter dem Nonsens versteht Gernhardt die „systematisch betriebene Sinnverweigerung“193. Dem Nonsens wird Nihilismus und Zynismus vorgeworfen, ${ }^{194}$ weswegen sich Satire und Nonsens ausschließen sollen.

\section{Funktion, Ziel und Wirkung der Satire}

Die Definition der Satire bzw. eine Annäherung an diese ist, wie in der begrifflichen Abgrenzung schon sichtbar wurde, eng verwoben mit der Frage nach der Funktion, dem Ziel und der Wirkung der Satire. Im Folgenden wird die Funktion als Oberbegriff und damit das Ziel und die Wirkung einschließend verstanden. Es lohnt sich die unterschiedlichen Funktionen, die sich in der Satiretheorie über die Zeit etabliert haben, dezidiert getrennt von den begrifflichen Merkmalen zu besprechen, da sich längst nicht jede Funktion in der Begriffsdefinition widerspiegelt. Für diese Besprechung wird zwischen der Perspektive des Rezipienten (1.) und der des Satirikers (2.) unterschieden.

\section{Die Funktionen der Satire in Bezug auf den Rezipienten}

Ist es für Staeck absolut maßgeblich, dass die Satire auf der Wahrheit beruht, ${ }^{195}$ dann ließe sich daraus auch ableiten, dass es letztlich gilt, die Wahrheit aufzuzeigen. Über diese Wahrheit - mag sie in Vergessenheit geraten, unbekannt oder verdrängt worden sein - sei der Rezipient durch Satire zu informieren. Diese Informations- bzw. Aufdeckungsfunktion ist ein gemeinsamer Nenner unterschiedlichster Satiretheorien und lässt sich

193 Gernhardt, Was gibt's denn da zu lachen?, 1988, S. 232.

194 Podskalsky, Jan Böhmermann und Die Partei, 2017, S. 21; Sloterdijk, Kritik der zynischen Vernunft, 1983, S. 950.

195 Vgl. Staeck, Plakate, 1998, S. 44. 
disziplin- und länderübergreifend wiederfinden. ${ }^{196}$ Der Satire wird so zugesprochen, dass sie desillusioniere, im übertragenen Sinne „Vorhänge wegreiß[e], hinter denen sich eine unangenehme Wahrheit verbirgt“ ${ }^{197}$ Das Aufdecken der Wahrheit beinhaltet konsequenterweise eine Form der Kritik, auch wenn sie nur darin liegt, dass die Wahrheit aufgedeckt werden musste.

Die Kritik ist eine gängige und herrschende Funktion der Satire, die als Merkmal in nahezu allen Definitionen Eingang gefunden hat. Schon für das Reichsgericht geht es der Satire darum, Missstände zu rügen und zu geißeln. ${ }^{198}$ Die Autoritätsquellen sprechen entweder von „Kritik üben“, „geißeln“ oder „tadeln“. ${ }^{199}$ Es sei aber deutlich gemacht, dass in dieser Kritik längst kein austariertes Urteil stehen muss, sondern auch eine höchst einseitige Meinungsäußerung möglich sein kann. Der Moderator der Satiresendung „Extra 3“, Jesko Friedrich, erklärte der ARD beispielsweise, die Satire, die er mache, „will - nach Möglichkeit unterhaltsam - informieren, aber vor allem eine klare und kritische Meinung äußern und deutlich Stellung zu aktuellen Ereignissen beziehen. " ${ }^{200}$ Dies zeigt deutlich, dass es ihm in der Satire nicht um eine Äußerung, die austariert das ganze Spektrum unterschiedlicher Meinungen umfasst, sondern um eine deutliche Stellungnahme geht. Diese kann einseitig, parteiisch, beschränkt, unsachlich und zuweilen tendenziös sein. Die Satire müsste in ihrer Einseitigkeit für ihre Informations- und Kritikfunktion auch nicht aus dieser heraus motiviert sein, sondern könnte auch die genannten Funktionen erfüllen, obwohl die Satire aus einer reinen persönlichen Antipathie herrührt. ${ }^{201}$

Die Satire soll beim Rezipienten auch eine Reaktion bewirken. Diese kann in einer Empörung oder Wut über das Aufgezeigte, in einer Bestäti-

196 In Bezug zur Aufdeckungsfunktion Schönert, Roman und Satire im 18. Jahrhundert, 1969, S. 10 f.; Cueni, Schutz von Satire im Rahmen der Meinungsfreiheit, 2019, S. 60 m.w.N.

197 Fetscher in Bezug auf die Unterscheidung zwischen scharfer Kritik und Satire anhand eines Zitats von Hermann Peter Piwitt: Fetscher, Politische Satire in der Bundesrepublik Deutschland - Anmerkungen eines Sozialwissenschaftlers, in: Münkler/Saage (Hg,), Kultur und Politik. Brechungen der Fortschrittsperspektive heute, 1990, S. 26.

198 RG, 5.6.1928, I 288/28, RGSt 62, S. 183.

199 Siehe dazu Kap. 2 D. II.

200 Friedrich, ARD-Jahrbuch 09, S. 76.

201 Sie soll aber nicht mit der Polemik verwechselt werden, der ein unsachlicher, verunglimpfender Angriff, der persönlich anfeinden soll, zugrunde liegt. Stauffer, „Polemik“, in Historisches Wörterbuch der Rhetorik, Bd. 6, Must-Pop, 2003, Sp. 1403. 
gung seiner politischen Meinung liegen oder generell als ein Anstoß zum Nachdenken verstanden werden. Die der Satire zugrundeliegende Kritik wird so als ein Mittel angesehen, um ein Verhalten oder eine Einstellung in die entsprechende Richtung zu bestärken oder zu ändern. Die Satire verbündet Gleichgesinnte und bestätigt diese in ihrer Ansicht. Diejenigen, die aber Gegenstand der Satire sind, sollen beschämt ihre Einstellung oder ihr Handeln ändern. ${ }^{202}$ Die Stimmen, die diese Funktion - sei sie Korrektur- oder Änderungsfunktion genannt - als Definitionsmerkmal der Satire sehen, gehen häufig davon aus, dass die Satire die Änderung mit einem „positiven Lösungsvorschlag“203 aufzeigt. Das überzeugt wenig. Empirisch gesehen wird wohl in den meisten Satiren durch die Aufdeckung beim Angesprochenen Scham oder Ärger hervorgerufen, der auch nur rein destruktiv wirken kann. Eine Anklage beinhaltet keinen Lösungsvorschlag. Ein Beispiel für einen positiven Lösungsvorschlag mag im Rahmen der politischen Satire liegen, wenn sie in zeitlichem und inhaltlichem Bezug zu demokratischen Wahlen steht und die Satire bezwecken will, die Meinung des Rezipienten zu ändern bzw. ihn so zu überzeugen, dass er entsprechend wählt. ${ }^{204}$

Dies soll aber nicht darüber hinwegtäuschen, dass der Satire auch eine Partizipationsfunktion zukommt. Inwieweit die politische Satire politische Teilhabe beeinflusst oder fördert, ist ein umstrittenes Thema in der Kommunikationsforschung. Zu einem wurde bzgl. politisch-satirischer Fernsehformate bereits prognostiziert, dass diese zu einem zynischen Politikverständnis führen können und so gerade eine Partizipation verhindern. ${ }^{205}$ Es wurde zum anderen herausgearbeitet, dass die Satire nur dann eine politische Beteiligung fördert, wenn die Satire zu einer negativen emotionalen Erregung wie Wut geführt hat. Das Ausmaß ist dann abhängig davon, inwieweit das in der Satire aufgearbeitete Thema für den Rezipienten persönlich bedeutend ist. ${ }^{206}$

202 Vgl. „Readers or viewers of satire discern vice or folly in others and are roused to indignation, brought into alliance with the satirist against a common target. Or if readers see themselves in the target of the satire, they are shamed into reform." Greenberg, The Cambridge Introduction to Satire, 2018, S. 13.

203 Cueni, Schutz von Satire im Rahmen der Meinungsfreiheit, 2019, S. 63 m.w.N.

204 Vgl. zu diesem Beispiel die Arbeiten Staecks und damit hier vor allem Kap. 4.

205 Baumgartner/Morris, The Daily Show Effect, American Politics Research, 34 (3), S. $362,363$.

206 Chen/Gan/Sun, International Journal of Communication, 2017, S.3011-3029, v.a. S. 3023. 
Diejenigen, die den Ansatz der Änderungsfunktion der Satire verfolgen, sehen die Satire zuweilen auch als Hoffnungsträger. ${ }^{207}$ Die Satire ermöglicht demnach durch ihre zugrundeliegende Information und der angestrebten Veränderung ein Vertrauen in eine positiv verlaufende Zukunft. Dies mag aber nicht nur auf Seiten des Rezipienten das angestrebte Ziel sein, sondern sich auch auf den Satiriker selbst auswirken.

Nicht zu unterschätzen ist aber eine Vereinigungs- und Ausgrenzungsfunktion. Diese liegt vor, wenn das gemeinsame Lachen den Satiriker und seinen Rezipienten vereint und gegen den anderen - das Angriffsziel - abgrenzt. Diese Vereinigung fußt darauf, dass der oder das durch die Satire Angegriffene herabgesetzt wird und sich so Satiriker und Rezipient gemeinsam über diesen erheben können. Es lässt sich mit den Worten „im gemeinsamen Lachen von Satiriker und Publikum wird [...] der Gegenstand bekämpft und ,bestraft"“208 zusammenfassen, doch soll dies nicht darüber hinwegtäuschen, dass eine Vereinigungsfunktion immer auch eine Ausgrenzung beinhaltet.

\section{Die Funktionen der Satire in Bezug auf den Satiriker}

Der Satiriker wurde von Kurt Tucholsky (1890-1935) in einem berühmten Statement als gekränkter Idealist bezeichnet, der die Welt gut haben will, aber da sie nun einmal schlecht ist, gegen das Schlechte anrennt. ${ }^{209}$ Der Satire kommt nach diesem Verständnis ein moralischer Anspruch zu. Dieser ist von Grund auf positiv und längst nicht nihilistisch ${ }^{210}$ oder misanthro-

207 „Satiren sind stets auch Ausdruck einer verzweifelten Hoffnung, einer Hoffnung trotz alledem" Fetscher, Politische Satire in der Bundesrepublik Deutschland - Anmerkungen eines Sozialwissenschaftlers, in: Münkler/Saage ( $\mathrm{Hg}$,), Kultur und Politik. Brechungen der Fortschrittsperspektive heute, 1990, S. 31 hier in Bezug auf den Roman „Die Rättin“ von Günter Grass.

208 Schönert, Roman und Satire im 18. Jahrhundert, 1969, S. 10 f.

209 Kurt Tucholsky als Ignaz Wrobel, Was darf die Satire?, Berliner Tagblatt Nr.36, 27.1.1919, abgedr. in Gerold-Tucholsky, Mary/Raddatz, Fritz J. (Hrsg), Kurt Tucholsky. Gesammelte Werke in 10 Bänden, Bd. 2, Hamburg 1960.

210 „Satiriker sind Moralisten, auch wenn man sie oft - zu Unrecht - für Nihilisten hält. Die Wirklichkeit übertreibend, verzerrend, ja deformierend, wollen sie sichtbar machen, was böse, schlecht, inhuman ist und zu dessen Überwindung aufrufen. Satiriker sind aus Menschenliebe böse. Sie greifen an, weil sie ergriffen sind. Sie machen sich Luft, indem sie übertreibend Distanz schaffen von einer überwältigenden Wirklichkeit. Aber diese kritisch-ironisch-aggressive Distanz ist nicht ihr letztes Wort. Nichts wäre ihnen lieber, als wenn 
pisch angelegt. Folgt man Tucholsky, braucht der Satiriker als gekränkter Idealist die Satire, um den Gegenstand seiner Kritik zu verarbeiten. Damit dient die Satire als persönliches Ventil des Satirikers. Diese wird auch als Möglichkeit des Abbaus von Aggressionen frei von körperlicher Gewalt verstanden. ${ }^{211}$ Die Ventilfunktion ermöglicht so auch dem Satiriker zuversichtlich an einen positiven Ausgang oder an ein positives Ergebnis zu glauben und nicht in ein Gefühl der Machtlosigkeit zu verfallen. Somit hat die Satire neben der Ventilwirkung auch für den Satiriker eine Hoffnungsfunktion. Ein eher psychologischer Ansatz versteht die Ventilfunktion ganz anders. Nach diesem projiziert der Satiriker seine eigenen Schwächen oder Widersprüchlichkeiten auf das durch seine Satire angegriffene Gegenüber. Er bestraft sich mit der Satire quasi selbst, um dadurch die eigenen Fehler zu verarbeiten. ${ }^{212}$ Die oben herausgearbeitete Änderungs- und Korrekturfunktion der Satire ist dann freilich durch einen gewissen Narzissmus zu relativieren.

\section{Bewertung}

\section{Das Problem der Rezipientenabhängigkeit}

Die gezeigten Funktionen der Satire verdeutlichen noch einmal mehr wie abhängig die Satire von ihrer Rezeption ist. Dieses Verhältnis ist damit ausschlaggebend für die Funktion und damit auch für die definitorischen Merkmale. Die Satire muss verstanden und vom Rezipienten vervollständigt werden, da der Satiriker die Thematik meist nur anreißt. Das führt aber auch dazu, dass Satiriker und Rezipient sich in nicht zu unterschätzendem Ausmaß ähneln müssen. Zum Verständnis und zu der erfolgreichen und gewünschten Wirkung der Satire bedarf es eine ähnliche moralische und ethische Grundhaltung und Wertvorstellung, eine übereinstimmende Vorkenntnis der verarbeiteten Umstände oder einen ähnlichen Sinn für den Humor oder Witz. Es ist demnach eindeutig, dass derje-

daraus das Engagement von Menschen würde, die jene Wirklichkeit, die sie satirisch angeprangert haben, verändern wollen." Fetscher, Politische Satire in der Bundesrepublik Deutschland - Anmerkungen eines Sozialwissenschaftlers, in: Münkler/Saage (Hg,), Kultur und Politik. Brechungen der Fortschrittsperspektive heute, 1990, S. 21.

211 Cueni, Schutz von Satire im Rahmen der Meinungsfreiheit, 2019, S. 68 f.

212 Greenberg, The Cambridge Introduction to Satire, 2018, S. 17; Burke, Attitudes Towards History, 1987, S. 49. 
nige, der sich von der Satire angegriffen fühlt, sich der Satire gegenüber anders verhält als derjenige, der sich mit dem Angreifer identifiziert. Aus dieser Rezipientenabhängigkeit ließe sich vertreten, dass gerade ein klarer gesellschaftlicher bzw. politischer Konsens - nicht nur in Hinsicht der Verbreitung - für die Satire positiv ist. ${ }^{213}$ Auf der anderen Seite wird aber auch behauptet, dass Zeiten der politischen Polarisierung und des Konflikts Blütezeiten der Satire sind ${ }^{214}$ oder die Zensur gar als Triebfeder der Satire anzusehen ist. ${ }^{215}$ Dementsprechend wird der Satiriker von den einen als progressiver Querulant und den anderen als konservativ angesehen. ${ }^{216}$ Mögen sich die einen darauf einigen, dass der gesellschaftliche Rahmen keinen Einfluss auf die Qualität oder Quantität der Satire hat ${ }^{217}$ bleibt letztlich festzuhalten, dass die Satire in den unterschiedlichsten Zeiten und Ausgangslagen zu finden ist. Von der Qualität und Quantität unabhängig ist jedoch, dass in Zeiten nicht verbindlicher Normen und in „einer Welt voller Gegensätze und Widersprüchlichkeiten“218, das Merkmal des Normbezugs durchaus an seine Grenzen stoßen kann. Ferner lässt sich vertreten, dass die Rezipientenabhängigkeit dazu führt, dass jeweils für unterschiedliche gesellschaftliche Gruppierungen mit ihren unterschiedlichen Wert- und Normvorstellungen entsprechende Satiren geschaffen werden, so dass letztlich nur noch von einer „Klientelsatire“219 gesprochen werden kann. ${ }^{220}$

213 „Satire flourishes in a homogeneous society where satirist and audience share the same views as to how normal people can be expected to behave, and in times of relative stability and contentment." W.H. Auden, zit. nach Greenberg, The Cambridge Introduction to Satire, 2018, S. 13.

214 z.B. Klobusch, ZUM-RD 2017, S. 631; Greenberg, ebd., S. 17.

215 Siehe Griffin, Satire. A Critical Reintroduction, 1993, S. 134 f.

216 Vgl. Greenberg, „The enforcement of stable moral norms makes satire culturally conservative, as the satirist speaks on behalf of age-old truths in the face of a decadent modern world." Greenberg, The Cambridge Introduction to Satire, 2018, S. 13.

217 Cueni, Schutz von Satire im Rahmen der Meinungsfreiheit, 2019, S.28f. m.w.N.

218 Köhler, Der Rabe 50 1997, S. 181.

219 Zehrer, Dialektik der Satire, 2002, S. 100.

220 Dies beschreibt Theodor Adorno in seiner Exilschrift „Minima Moralia“ in Reaktion auf den unbeschreiblichen Terror des Nationalsozialismus als die „Antinomie der Satire“. Er führt aus: „Schuld an der Unmöglichkeit von Satire heute hat nicht, wie Sentimentalität es will, der Relativismus der Werte, die Abwesenheit verbindlicher Normen. Sondern Einverständnis selber, das formale Apriori der Ironie, ist zum inhaltlich universalen Einverständnis geworden.“ Adorno, Minima Moralia, 2003, S. 135. 
Der Normbezug lässt sich auch aus einem ganz anderen Gesichtspunkt kritisieren. So könnte man sich auch für die These aussprechen, dass es mangels strenger Normen in einer liberal-pluralistischen Gesellschaft immer schwieriger wird, Grenzen und Tabus zu überschreiten und so überhaupt anzugreifen. ${ }^{221}$ In der Satireforschung wurde die Ansicht vertreten, dass es einen notwendigen Grund dafür gibt, dass die große Zeit der Satire immer dann anzutreffen ist, wenn „universalistische, dem einzelnen übergeordnete und allgemein akzeptierte Weltbilder" ${ }^{\text {“222 }}$ gelten. Dementsprechend verliert die Satire an Bedeutung je mehr das Individuum in den Vordergrund rückt und so ein solch strenges Weltbild ins Wanken bringt. Das Ideal wird zum Anknüpfungspunkt für die auf das Individuum angelegte Gesellschaft. Dementsprechend bleibt der Satire in Bezug auf den Normbezug - will man dieses Merkmal retten - ein „ontologisches Wertbewusstsein" 223 .

\section{Das Problem der Indirektheit und des Angriffs}

Die Indirektheit - mag man es der englischen Forschung entsprechend Überzeichnung oder Verfremdung nennen - und der Angriff scheitern als konstituierende Merkmale dann, wenn gar keine Überzeichnung oder eine andere Form der Indirektheit und mangels dessen dann auch keine Aggressivität vorliegen. Dies ist mehr als ein Gedankenspiel, wenn man an den Fall denkt, in dem die Realität schon so satirisch ist oder wirkt, dass es einer weiteren Überzeichnung nicht bedarf. Wenn dann nur die Realität abgebildet wird, dann kann schwerlich eine Aggressivität gefunden werden. Es ließe sich argumentieren, dass dies dann entweder keine Satire darstellen könne oder der Begriff der Realsatire dies einzufangen wisse. Will man die Satire in solchen Fällen verneinen, bleibt man einer Antwort auf die Frage, was dann das Satirische ist, trotzdem schuldig. Ähnlich angelegt ist die Überlegung, dass keine Überzeichnung mehr möglich ist, da alle Möglichkeiten der Überzeichnung bereits real oder aber zumindest vorstellbar geworden sind. ${ }^{224}$ Dieser Ansatz entspringt der Überlegung, dass es mit den unbeschreiblichen Gräueltaten in der Menschheitsgeschichte gera-

221 Podskalsky, Jan Böhmermann und Die Partei, 2017, S. 23 f., 32.

222 Freund, Die literarische Parodie, 1981, S. 18.

223 Freund, ebd. S. 19. Freund versteht dies als grundlegenden Unterschied zur Parodie, die gerade kein „ontologisches Wertbewusstsein“ braucht.

224 Vgl. Podskalsky, Jan Böhmermann und Die Partei, 2017, S. 23. 
de wegen der Unbeschreiblichkeit keine Überzeichnung mehr vorstellbar ist. $^{225}$

\section{Das Problem der Kontextbezogenheit}

Es ist für die Satire - nicht nur, aber besonders auch für die politische Satire - bezeichnend, dass ihr Verständnis kontextabhängig ist und so je nach Thematik mehr oder weniger zeitlich und örtlich beschränkt ist. Das liegt primär daran, dass die Satire immer einen realen Bezug aufweist. Eine reine Fiktion schließt daher begriffsnotwendig die Satire aus. Bezieht sich die Satire, wie so häufig, auf aktuelle Geschehnisse oder Personen öffentlichen Interesses, kann im Laufe der Zeit das Verständnis schwieriger werden. Diese Kontextabhängigkeit führt letztlich auch dazu, dass die Satire abhängig von der Zeit unterschiedlich aufgefasst und interpretiert werden kann. Dieser Wirklichkeitsbezug, d. h. die Abhängigkeit von der Aktualität, soll begrifflich in dem sogenannten überzeitlichen Merkmal des Angriffs eingeschlossen sein. ${ }^{226}$ Das mag aber nur in Grenzen überzeugen. Je mehr sich die Satire von der Wirklichkeit entfernt, desto mehr steigt der Anteil der Indirektheit. Dies führt aber nicht dazu, dass das Element des Angriffs dadurch weniger stark vertreten ist, viel mehr wird in vielen Fällen mit ansteigender Überzeichnung sowohl die Indirektheit als auch die Aggressivität zunehmen.

\section{Das Problem des Lachens}

Kritisch lässt sich auch die Ablehnung des Elements des Lachens sehen. Dieses findet in der Trias von Angriff, Indirektheit und Norm nur Eingang, sobald aus dem Lachen als Nebeneffekt ein Lachen im Sinne eines Verlachens, wird. Denn dann kann das Lachen als eine Form des aggressiven Angriffs angesehen und so Teil des konstitutiven Merkmals des Angriffs werden. ${ }^{227}$ Das Lachen vermag genauso zu provozieren wie es

225 Dabei stellen sich die Frage nach der Satire nach dem Nationalsozialismus nach der These Adornos mit „Alle Kultur nach Ausschwitz, samt der dringlichen Kritik daran, ist Müll“ Adorno, Negative Dialektik, 1973, S. 359.

226 Brummack, DVjs 45, S. 333.

227 Schönert, Roman und Satire im 18. Jahrhundert, 1969, S. 13. 
aber eben auch beschwichtigend und vereinigend wirken kann ${ }^{228}$ und so muss es nicht Teil des Angriffs sein. Das Lachen stellt auch ein greifbares Merkmal in der Abgrenzung zur Schmähung dar, denn im Rahmen dieser tritt das Humorvolle bis zur Unkenntlichkeit bzw. Nicht-Existenz in den Hintergrund, wohingegen der Angriff so stark vertreten ist, dass auch der Normbezug überschattet wird. Noch hilfreicher wäre ein Merkmal des Lachens in Abgrenzung zur reinen Gesellschaftskritik, auf die der Angriff inklusive des Aktualitätsbezugs und des Normbezugs vollständig passt, doch bei der das Lachen gänzlich fehlt. ${ }^{229}$

\section{Eine Näherung durch Beschreibungen}

Statt der starren Trias von Angriff, Norm und Indirektheit wird hier eine offenere Begriffsbestimmung bevorzugt, um so vor allem dem Komischen, dem Humoristischen und Witzigen Platz zu schaffen, d.h. aber nicht, dass die Satire letztlich irgendwo zwischen Komik und Schmähung anzusiedeln ist. ${ }^{230}$ Für die Satire ist es typisch nach den eigenen Vorstellungen auch mit einer Vielzahl von stilistischen Möglichkeiten so zu provozieren, Tatsächliches zu kritisieren oder ein Ungleichgewicht anzugreifen, dass diese auch Elemente des Humoristischen beinhalten.

Greenberg schlägt vor, dass sich die Satire zwischen Fantasie und Realität, zwischen Zeitgemäßem und Zeitlosigkeit, zwischen Beschränkung und Freiraum, zwischen Stabilität und Instabilität sowie Engagement und Distanzierung bewegt. ${ }^{231}$ Greenberg will so die unterschiedlichen Arten von Satire über Spannungen auflösen. Mit der Fantasie können die Formen der Überzeichnung, die sich in der Indirektheit wiederfinden, eingeordnet werden. In der Realität spiegelt sich dann teilweise der Wahrheitsund Normbezug wider. Die Spannung zwischen Zeitgemäßem und Zeitlosigkeit übernimmt den Aktualitätsbezug, ermöglicht aber eine Erweiterung auf zeitlose Themen. Da die Satire vom Kontext ihrer Entstehung und vor allem von ihrem Rezipienten abhängig ist, kann sich ihre Bedeu-

228 Test, Satire. Spirit and Art, 1991, S. 26.

229 Vgl. zur Abgrenzung zur Gesellschaftskritik Test, ebd., S. 34.

230 Cueni sieht die Satire „als eine Form zwischen Komik und Beleidigung respektive Schmähung“, Cueni, Schutz von Satire im Rahmen der Meinungsfreiheit, 2019, S. 47.

231 Greenberg unterscheidet zwischen „fantasy and realism, timely and timeless, restraint and licence, stability and instability, engagement and detachment", Greenberg, The Cambridge Introduction to Satire, 2018, S. 23 f. 
tung und Interpretation einfach verschieben. Dies soll über die Spannung zwischen Stabilität und Instabilität aufgefangen werden. ${ }^{232}$ Die Varianz im „Ton“ der Satire soll über die Spannung von Engagement und Distanziertheit beschrieben werden. ${ }^{233}$ Satire kann in ihrer Bissigkeit, Provokation und Aggression engagiert oder durch Belustigung und Resignation distanziert sein. Der Vorteil einer solchen Beschreibung der Spannungen im Rahmen dieser Arbeit liegt schon darin, dass sie zeigen, wie schwer es ist die Satire über feste Tatbestandsmerkmale zu fassen.

\section{E. Ein Zwischenfazit}

In diesem Kapitel wurde gezeigt, wie sich die Satire über typische Merkmale ein- und von anderen verwandten Form abgrenzen lässt. Dabei galt es nicht die Satire als Gattung zu untersuchen, sondern sich dem Satirischen zu nähern, als Beschreibung einer über die Literatur hinausgehenden Erscheinungsform. Die Fragen nach der Intention des Satirikers, der Funktion und Wirkung der Satire wurden davon unabhängig untersucht. Eine Bewertung zwischen "guter" und „schlechter" Satire wurde vermieden, wohingegen es durchaus gilt, zwischen Satirischem und Nicht-Satirischem zu unterscheiden. Diese wertende Unterscheidung - mag sie noch so trivial klingen - ist nicht zu unterschätzen, grenzt sie doch Satirisches und Nicht-Satirisches, namentlich die Comedy, den Nonsense, den Witz, die Parodie oder die Persiflage ab.

Knapp zusammengefasst wurde im zweiten Kapitel herausgearbeitet:

Die oft rezipierte Trias von Angriff, Norm und Indirektheit weist wesentliche Schwächen auf. Nur wenn man die Besonderheiten der Satire, die sonst unproblematisch eigene und zwar gleichwertige Merkmale oder Elemente bilden können und zum Teil müssten, dieser unterordnet und so versucht, Erscheinungsformen oder Tendenzen starr einzugliedern, kann mit dieser Trias gearbeitet werden. Die Lösung über das ästhetische, soziale und aggressive Element kann allenfalls helfen, eine solchermaßen vereinfachte Aufteilung vorzunehmen. Das Merkmal des Humoristischen wird innerhalb dieser Kriterien keine bzw. nur unerhebliche Bedeutung zugesprochen, was nach der hier vertretenen Ansicht zumindest zu einem Ungleichgewicht zwischen Humor und Angriff führt.

232 Greenberg, ebd., S. 24.

233 Greenberg, ebd., S. 24 f. 
Entgegen der Trias wird sich hier für eine offenere und das Witzige, Humoristische, Komische bzw. das Lachen mit einbeziehende Begriffsbestimmung ausgesprochen. Für eine Begriffsbestimmung der Satire reicht es nicht, nur die Voraussetzungen zu benennen, vielmehr müssen auch die Mittel, Ziele und Funktionen Teil der Bestimmung werden. Die Satire bewegt sich insofern im hiesigen Verständnis in dem Bereich der Provokation, Aggression oder Kritik in Bezug auf ein für den Satiriker tatsächlich bestehendes Ungleichgewicht. Dieses kann, wenn auch nicht zwingend, mit der Hilfe einer Vielzahl von stilistischen Möglichkeiten, wie der Übertreibung, auf ein Lachen - teilweise auch bedrücktes - beim Rezipienten ausgelegt sein und dabei ein weiterführendes Ziel verfolgen. Die Einordnung als Satire sowie Bewertung dieser wird im Wege des Wahrnehmungsprozesses durch den Rezipienten immer neu verhandelt.

Schon aus der Begriffsnäherung der Satire wird das juristisch relevante Spannungsfeld zwischen Kritik, Komik und Rechtsverletzung ersichtlich, auf das im folgenden Kapitel im Abstrakten und im fünften Kapitel zu den Prozessen Staecks im Konkreten das Hauptaugenmerk gelegt wird. 


\section{Drittes Kapitel: Das satirische Plakat im rechtlichen Konflikt}

\section{A. Einfübrung}

In diesem Kapitel wird das künstlerische Politsatire-Plakat auf seine rechtliche Bewertung im Allgemeinen untersucht. Dafür gilt es zunächst die Satire generell in ihrem rechtlichen Verständnis und Spannungsfeld darzustellen. Zunächst steht hierbei der rechtliche Satirebegriff im Vordergrund. Anschließend wird der Schutzbereich, Eingriff und die Schranken - der Gesetzessystematik des Grundgesetzes folgend - sowie abschließend die Abwägung zwischen kollidierenden Verfassungsgütern untersucht. Nach welchen Maßstäben eine solche Abwägung vorgenommen wird, folgt dann in der Auseinandersetzung mit den Kriterien der Auslegung und Wahrnehmung der Satire. Inwiefern auch das im zweiten Kapitel thematisierte Begriffsverständnis sich auch im rechtlichen Kontext widerspiegelt, soll hier thematisiert werden.

$\mathrm{Zu}$ der Satire im rechtlichen Spannungsfeld allgemein sind über die ca. letzten 40 Jahre neben meist anlassgebundenen Aufsätzen ${ }^{234}$, die sich unmittelbar auf Gerichtsentscheidungen beziehen, mehrere Dissertationsschriften erschienen. Elmar Ehrhardt setzte sich 1989 mit satirischen Ehrverletzungen in Bezug auf das Strafrecht auseinander, 2015 beleuchtete Gregor Oppermann diese Thematik. ${ }^{235}$ Die von Sebastian Gärtner 2009 erschienene Arbeit schafft einen generellen Überblick über die rechtlichen Grenzen und spricht so neben verfassungs-, und zivil- und strafrechtlichen Fragen auch andere Gebiete wie das Marken-, Urheber- und Lauterkeitsrecht an. ${ }^{236}$ Zum schweizerischen Recht mit teilweise auch Bezügen zum

234 Becker, GRUR 2004, S. 908-913; Brauneck, ZUM 2000, S. 137-142; anlässlich des Gedichts „Schmähkritik“ von Böhmermann beispielsweise Fabl, NStZ 2016, S. 313-318; Klass, AfP 2016, S. 477-495; Christoph, JuS 2016, S. 599-603; Oechsler, NJW 2017, S. 757-763; Faßbender, NJW 2019, S. 705-710.

235 Erhardt, Kunstfreiheit und Strafrecht, 1989; Oppermann, Ehrensache Satire, 2015; zu diesem Thema siehe bereits Würtenberger, NJW 1982, S. 610-616; NJW 1983, S. 1144-1151 mit Antwort von Zechlin, NJW 1984, S. 1091-1093.

236 Gärtner, Was die Satire darf, 2009. Ferner kann noch eine Arbeit von 1996 mit einem Schwerpunkt auf die deutsche Rechtsprechung im Vergleich mit Frankreich, England und den USA genannt werden, da sie Staeck zumindest erwähnt: Wolf, Spötter vor Gericht, 1996. Einen Schwerpunkt auf das Lauterkeitsrecht 
deutschen Recht sind die Arbeit von Mischa Senn von 1998 und die ausführliche Schrift von Raphaela Cueni von 2019 zu nennen. ${ }^{237}$

In diesem Kapitel soll der rechtliche Rahmen - anders als in den genannten Dissertationen - nur abgesteckt werden, bevor in den folgenden Kapiteln eine genauere Untersuchung der Fälle und Plakate Staecks mit anschließender Bewertung erfolgt. Eine Besprechung der für die Satire einschlägigen Rechtsprechung mit einer kritischen Untersuchung der Literatur und eben auch der zuvor genannten Schriften darf trotzdem nicht ausbleiben. Zwangsläufig wird in Bezug auf die Prozesse Staecks, die von den 1970er bis in die späten 1990er Jahre reichen, und der hier zu besprechenden Leitlinien der Rechtsprechung ein gewisser Anachronismus vorliegen, da im Rahmen dieses Kapitels auch auf Entscheidungen eingegangen wird, die zeitlich nach Staecks Prozessen getroffen wurden. Dies ist aber notwendig; einerseits, um einen Überblick $\mathrm{zu}$ erhalten und so die Fälle Staecks einordnen zu können, und andererseits um im letzten Kapitel, als Abschluss dieser Arbeit, einen Ausblick zu wagen.

\section{B. Der rechtliche Satirebegriff}

\section{Der verfassungsrechtliche Satirebegriff}

Die Frage, was das BVerfG unter dem Begriff der Satire versteht, kann zunächst maßgeblich mit Hilfe von sieben Entscheidungen, die sich von 1987-2005 erstrecken, beantwortet werden. Als eine generelle Form der Abgrenzung wird der Begriff der Satire in weiteren Entscheidungen genannt, ohne jedoch genauer auf die Satire einzugehen. ${ }^{238}$ Das unterstreicht den Eindruck, dass diesen ein grundsätzliches Verständnis, was Satire ist, zugrunde liegt.

findet sich bei Levin, Die lauterkeitsrechtlichen Möglichkeiten und Grenzen der humorvollen und satirischen vergleichenden Werbung, 2013.

237 Senn, Satire und Persönlichkeitsschutz, 1998; Cueni, Schutz von Satire im Rahmen der Meinungsfreiheit, 2019. Ferner beschäftigt sich Kassing rechtsvergleichend mit der Satire in Deutschland, Schweiz, Österreich und England Kassing, Ehrverletzende Personalsatire, 2004.

238 So z.B. bei BVerfG, 26.4.2001, 1 BvR 758/97, NJW 2001, S. 1921 - Prinz August von Hannover oder bzgl. der Verunglimpfung der Bundesflagge durch künstlerische Darstellung, BVerfG, 7.3.1990, 1 BvR 266/86, 1 BvR 913/87, NJW 1990, S. 1982. 
Es soll dabei aber betont werden, dass das BVerfG im Rahmen der ersten Entscheidung, ${ }^{239}$ die als ein Präzedenz-Fall der Satire-Rechtsprechung bezeichnet wird, 240 sich begrifflich auf ein Urteil des Reichsgerichts aus dem Jahre $1928^{241}$ bezieht. In diesem erklärte das Reichsgericht grundlegend:

„Es ist der Satire wesenseigen, dass sie, mehr oder weniger stark, übertreibt, d.h. dem Gedanken, den sie ausdrücken will, einen scheinbaren Inhalt gibt, der über den wirklich gemeinten hinausgeht, jedoch in einer Weise, dass der des Wesens der Satire kundige Leser oder Beschauer den geäußerten Inhalt auf den ihm entweder bekannten oder erkennbaren tatsächlich gemeinten Gehalt zurückzuführen vermag, also erkennt, dass tatsächlich nicht mehr als dieser geringere Inhalt gemeint ist. Die Satire und die Karikatur ziehen oft, wenn sie Missstände rügen oder geißeln wollen, in jener übertreibenden, verzerrenden Weise die letzten Folgerungen aus dem Bestehen des Missstandes, um diesen, mag er selbst auch keineswegs in einer so starken Form aufgetreten sein, recht handgreiflich und darum eindrucksvoll als solchen zu kennzeichnen."242

In dem Beschluss zu den Strauß-Karikaturen von Rainer Hachfeld betont das BVerfG 1987 dem Reichsgericht entsprechend, dass es der Kunstgattung Satire wesenseigen ist, mit Übertreibungen, Verzerrungen und Verfremdungen zu arbeiten. ${ }^{243}$ Damit ist die Verfremdung für das BVerfG das strukturtypische Merkmal der Satire im Rahmen dieser Entscheidung. ${ }^{244}$ Gerade von diesen Formen der Verfremdung muss die Satire für die rechtliche Bewertung gelöst werden, da, wie im zweiten Kapitel herausgearbeitet wurde, eine Verfremdung der Satire nicht notwendig ist. $^{245}$ Begrifflich ist hier festzuhalten, dass das BVerfG in dieser Entscheidung weder einen Satirebegriff definiert, unter den subsumiert wird, noch auf weitere Merkmale der Satire eingeht.

In der Entscheidung zu den Hitler-Satiren und in dem DeutschlandliedBeschluss wird lediglich festgestellt, dass es sich bei dem streitgegenständli-

239 BVerfG, 3.6.1987, 1 BvR 313/85, NJW 1987, S. 2661 - Strauß-Karikaturen.

240 Gärtner, Was die Satire darf, 2009, S. 31.

241 RG, 5.6.1928, I 288/28, RGSt 62, S. 183.

242 RG, ebd.

243 BVerfG, 3.6.1987, 1 BvR 313/85, NJW 1987, S. 2661 - Strauß-Karikaturen.

244 BVerfG, ebd., S. 2662.

245 Vgl. dazu zusammenfassend Kap. 2, E. 
chen Deutschlandlied erkennbar um Satire handelt und moniert, dass das Instanzgericht sich damit nicht auseinandergesetzt hat. ${ }^{246}$

Weitaus grundlegender ist die Entscheidung zu einem Artikel und Leserbrief in dem Satiremagazin Titanic, in welchem ein querschnittsgelähmter junger Mann zu dem siebtpeinlichsten Mann des Monats März deklariert wird, weil er viel in Bewegung gesetzt hatte, trotz seiner schweren körperlichen Behinderung an einer Bundeswehrübung für Reserveoffiziere teilnehmen zu können. Er wird mit vollem Vor- und Zunamen sowie dem Zusatz „geb. Mörder“ bezeichnet. ${ }^{247}$ Das Gericht geht auf die Argumente der Parteien ein, indem es die Beschreibung der Satire durch den Beschwerdegegner wiederholt. Danach sei Satire eine „Kunstform, in der sich der an einer Norm orientierte Spott über Erscheinungen der Wirklichkeit nicht direkt, sondern indirekt, durch die ästhetische Nachahmung eben dieser Wirklichkeit ausdrücke. " ${ }^{248}$ Diese Umschreibung ist weitaus näher an der literatur- und kulturwissenschaftlichen Satiredefinition als die der vorherigen bereits genannten BVerfG-Entscheidungen. In der tatsächlichen Begründung der Verfassungsbeschwerde wird dann aber wieder nur auf die Verfremdung, Verzerrung und Übertreibung eingegangen. ${ }^{249}$ Das Verfremdungsmerkmal wird dann jedoch um die Funktion der Satire, beim Rezipienten ein Lachen hervorzurufen, erweitert. ${ }^{250}$

Der Sachverhalt der Entscheidung mit dem Namen Satirische Fotomontagen $^{251}$ bezieht sich nicht darauf, dass die Fotografie des Kopfes eines Vorstandsvorsitzenden der Deutschen Telekom AG auf den Körper eines Mannes gesetzt wurde, sondern darauf, dass die Abbildung des Kopfes mit Hilfe technischer Mittel subtil, aber dennoch merklich verändert wurde. Das Ausmaß der Bearbeitung ist nicht abschließend aufgeklärt worden, mit Sicherheit steht nur fest, dass der Kopf um $5 \%$ gestreckt wurde. ${ }^{252}$ Für das BVerfG ist relevant, dass die Veränderung nicht als eine für satirische

246 BVerfG, 7.3.1990, 1 BvR 1215/87, NJW 1990, S. 1985 - Deutschlandlied-Beschluss; BVerfG, 3.4.1990, 1 BvR 680, 681/86, NJW 1990, S. 2541 - Hitler-Satiren.

247 BVerfG, 25.3.1992, 1 BvR 514/90, GRUR 1992, S. 471 - geb. Mörder.

248 BVerfG, ebd., S. 472.

249 BVerfG, ebd., S. 473.

250 BVerfG, ebd., S. 473 sowie bestätigend bei BVerfG, 12.11.1997, 1 BvR 2000/96, NJW 1998, S. 1386, 1387 - Münzen-Erna; BVerfG, 10.7.2002, 1 BvR 354/98, NJW 2002, S. 3768 - Bonnbons.

251 BVerfG, 14.2.2005, 1 BvR 240/04, GRUR 2005, S. 500 - Satirische Fotomontage.

252 BVerfG, ebd. 
Darstellungen typische Verfremdung oder Verzerrung einzuordnen ist, da die Veränderung für den Betrachter nicht erkennbar ist.

Das Gericht setzt solche Veränderungen mit einer unwahren Aussage gleich, die sich auf die Reichweite des Schutzes der Meinungsfreiheit auswirkt. ${ }^{253}$ Mag diese Entscheidung vom Ergebnis her in Bezug auf Bildmanipulationen begrüßenswert und gerade im Hinblick auf mit Hilfe von künstlicher Intelligenz hergestellter Deep Fakes sehr vorausschauend sein, handelt es sich hierbei jedoch gerade nicht allein um eine reine Manipulation: Durch die Technik der Fotomontage ist für den Betrachter erkennbar, dass es sich im Ganzen um ein verändertes Bild handelt. Insofern kann das Ergebnis des BVerfG zu der Bildmanipulation im Rahmen einer Fotomontage doch verwundern.

Die Differenziertheit und die Genauigkeit des Satirebegriffs des Reichsgerichts, auch wenn auf diesen immer wieder rekurriert wird, wurde seitdem nicht mehr erreicht, da letztlich der Schwerpunkt nur auf die Verfremdung gelegt wird. In der Entscheidung zu der satirischen Fotomontage wurde ferner deutlich, dass es darüber hinaus einer erkennbaren Verfremdung bedarf. Der besondere Bezug auf die Verfremdung lässt sich aber auch über eine Satire-Rechtsprechung hinaus beobachten. In der Entscheidung zum Roman „Esra“ geht das BVerfG in seiner ,je-desto“-Formel davon aus, dass je stärker die Fiktionalität ausgeprägt sei, desto eher das Grundrecht der Kunstfreiheit überwiege. ${ }^{254}$

II. Der rechtliche Satirebegriff in Bezug auf den literatur- bzw. kulturhistorischen Satirebegriff

Es ist offensichtlich, dass die Definition des Verfassungsrechts unspezifischer ist als diejenige, die sich aus der Literatur- und Kulturwissenschaft herausgebildet hat. Die Satire und auch die Karikatur können also lediglich als Oberbegriffe, unter die sich Formen verfremdeter Darstellungen subsumieren lassen, verstanden werden. ${ }^{255}$ Schon im Beschluss zu den

253 BVerfG, ebd., S. 502.

254 „Je stärker Abbild und Urbild übereinstimmen, desto schwerer wiegt die Beeinträchtigung des Persönlichkeitsrechts. Je mehr die künstlerische Darstellung die besonders geschützten Dimensionen des Persönlichkeitsrechts berührt, desto stärker muss die Fiktionalisierung sein, um eine Persönlichkeitsrechtsverletzung auszuschließen.“ BVerfG, 13.06. 2007, 1 BvR 1783/05, GRUR 2007, S. 1089, Rn. 90 - Esra; vgl. in Bezug auf die Satire Oechsler, NJW 2017, S. 757, 758.

255 Gärtner, Was die Satire darf, 2009, S. 35. 
Strauß-Karikaturen werden die Begriffe als gleichwertige Kategorien nebeneinander gestellt. ${ }^{256}$ Was das Verhältnis von Collage und Satire angeht, zieht das BVerfG die Schlussfolgerung, dass „eine Collage in eine Satire eingebettet“ 257 sein kann, wohingegen die Collage auch „als Karikatur, also als satirische Darstellung, einzuordnen“ ist. ${ }^{258}$

Die Literaturwissenschaft wird von der Rechtsprechung als die definierende Disziplin angesehen und in Urteilen thematisiert, auch wenn dies wohl teilweise nur zu mehr Verwirrung führt. Als Beispiel sei eine frühe Entscheidung des OLG Karlsruhe aus dem Jahr 1985 herangezogen. Das Gericht stellt fest, dass der Begriff der Satire „unter Berücksichtigung

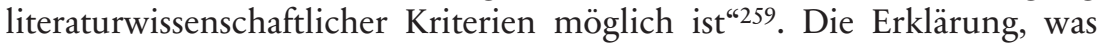
diese literaturwissenschaftlichen Kriterien sein sollen, bleiben die Richter schuldig. Vielmehr erkennen sie die „Verfremdung der Aussage mit dem Stilmittel der Satire“, um nur wenige Zeilen später die Verfremdung gerade zum „wesentlichen Stilelement der Satire“ zu erklären. ${ }^{260}$ Was nun in welcher Beziehung zu was das Stilmittel darstellen soll, bleibt im Zuge dieser Kontradiktion wohl unbeantwortet.

Es wurde schon vermehrt kritisiert, dass die Rechtsprechung für den Satirebegriff häufig Sarkasmus, einen gewissen Witz, Komik oder Humor voraussetzt. $^{261}$ Darin manifestiert sich sicherlich einer der Hauptkritikpunkte der rechtswissenschaftlichen Literatur. Die Literatur mahnt an, dass die Gerichte fälschlicherweise auf einen Witz oder das Lachen abstellen, denn für sie kann das Lachen nur ein „Nebeneffekt“ sein. ${ }^{262}$ Sie sehen die Gefahr, dass nur eine gewitzte, witzige und humorvolle Satire unter den Satirebegriff fällt und so der Begriff verengt wird. Es sei angemerkt, dass nach diesem Verständnis der rechtliche Begriff weiter ist, da kein künstlerischer oder ästhetischer Aspekt vorausgesetzt wird. Im Rahmen der hiesigen Arbeit wird ein anderer Ansatz gewählt. Das Element des Humors spielt nach dem hier vertretenen Satireverständnis eine elemen-

256 BVerfG, 3.6.1987, 1 BvR 313/85, BVerfGE 75, 369, NJW 1987, S. 2661 - StraußKarikaturen.

257 BVerfG, 7.3.1990, 1 BvR 266/86, 1 BvR 913/87, NJW 1990, S. 1982, 1983.

258 BVerfG, ebd. S. 1984.

259 OLG Karlsruhe, 17.10.1985, 2 Ss 58/85, NStZ 1986, S. 363, 364.

260 OLG Karlsruhe, ebd., S. $364 \mathrm{f}$.

261 Gärtner, Was die Satire darf, 2009, S. 32 f.; Klass, AfP 2016, S. 477, 479.

262 Anscheinend nahezu hM in der Literatur vgl. Kassing, Ehrverletzende Personalsatire, 2004, S. 14 f.; Senn, Satire und Persönlichkeitsschutz, 1998, S. 25; ohne direkte Positionierung Gärtner, Was die Satire darf, 2009, S. 33-36. 
tare Rolle, da gerade dieser die Balance zu der Schärfe der Kritik hält. Deswegen läuft zumindest hier dieser Kritikpunkt der Literatur ins Leere.

Die Kritikpunkte der Literatur zur Satire-Rechtsprechung beziehen sich aber nicht nur auf den zugrunde gelegten Satirebegriff, sondern vor allem auf den Umgang und die Bewertung der Satire. Der Vorwurf der Literatur reicht dann unter anderem von der vollkommenen Missachtung satirischer Ausdrucksformen oder dem Verkennen einer Mehrdeutigkeit der satirischen Äußerung bis hin zu einer unzulänglichen Berücksichtigung des Kontextes. ${ }^{263}$ Bevor auf die Kritik jedoch angemessen eingegangen wird, soll zunächst der verfassungsrechtliche Schutz der Satire sowie der Umgang und die Bewertung der Satire im Kollisionsfalle genauer abgesteckt werden.

\section{Der verfassungsrechtliche Schutz der Satire}

Die Satire wird nicht in einem speziellen einfachrechtlichen Gesetz geschützt oder in irgendeiner Form verpflichtet. Vielmehr ergibt sich der Schutz der Satire aus dem Verfassungsrecht. An vorderster Stelle steht dabei die Meinungsfreiheit aus Art. 5 Abs. 1 S. 1 GG, da sie nach der SatireRechtsprechung des BVerfG als eine Form der „Minimalgewährleistung“ dient. ${ }^{264}$ Unter Umständen je nach Verbreitungsform kann die Presse-, Rundfunk-, und Filmfreiheit aus Art. 5 Abs. 1 S. 2 GG einschlägig sein. Der Schutzbereich der Kunstfreiheit nach Art. 5 Abs. 3 GG kann ebenso bei satirischer Kunst eröffnet sein. Im Folgenden sollen diese drei Grundrechte in Bezug auf die Satire genauer beleuchtet werden. Ein Schwerpunkt wird dabei aber folgerichtig wieder auf das satirische Plakat gelegt.

I. Die Meinungsfreiheit, Art. 5 Abs. 1 S. 1 GG

\section{Die Notwendigkeit des Schutzes}

Es ist ein Bedürfnis des Menschen als sozialem Wesen zu kommunizieren. Die Meinungsäußerung ist als eine unverzichtbare Bedingung der menschlichen Existenz zu werten. Das BVerfG hat schon im Lüth-Urteil betont: „Das Grundrecht auf freie Meinungsäußerung ist als unmittelbars-

263 Kassing, ebd., 2004, S. 12.

264 Gärtner, Was die Satire darf, 2009, S. 40. 
ter Ausdruck der menschlichen Persönlichkeit in der Gesellschaft eines der vornehmsten Menschenrechte überhaupt“".265

Das Grundgesetz schützt die Meinungsfreiheit sowohl im Interesse der Persönlichkeitsentfaltung des Einzelnen als auch im Interesse des demokratischen Prozesses, für den sie konstitutive Bedeutung hat. ${ }^{266}$ Das Grundrecht der Meinungsfreiheit will von seinem Grundgedanken nicht nur die Ermittlung der Wahrheit, sondern schafft die Gewährleistung, dass jeder frei sagen kann, was er denkt, auch wenn er keine nachprüfbaren Gründe für seine Aussage angibt oder angeben kann. ${ }^{267}$ Das bedeutet, dass das Grundrecht mit der individuellen Persönlichkeitsentfaltung durch Äußerungen eine subjektive Komponente und mit dem Schutz der öffentlichen Meinungsbildung als Grundlage der Demokratie eine objektive Komponente besitzt, die es gilt in der Ermittlung des Schutzbereichs in Einklang zu bringen. Gerade im Rahmen des Art. 5 Abs. 1 S. 1 GG entbrannte in der verfassungsrechtlichen Wissenschaft ein Streit über das Verhältnis des Grundrechts als subjektives Freiheitsrecht und das Grundrecht als eines mit einer konstituierenden und damit objektiven Wirkung. Dass beide Komponenten - individuelle Kommunikation und Demokratiegrundlage - in Art. 5 Abs. 1 S. 1 GG verankert sind, ist unumstritten. Das Verhältnis und die Folgen der Auslegung werden jedoch kontrovers diskutiert. ${ }^{268}$ Denn die objektive Komponente zeigt, dass nur mit der Beteiligung des Menschen am Kommunikationsprozess eine politische Willensbildung des Volkes zu einer Herrschaft des Staatsvolkes und damit zur Legitimation der Demokratie führt. ${ }^{269}$ Aus diesem ließe sich im Extremen ableiten, dass nur eine für das Staatsvolk produktive, bekräftigende, fördernde Kommunikationsteilhabe von Art. 5 Abs. 1 S. 1 GG erfasst sei. Von dem anfänglich beschriebenen subjektiven Freiheitsrecht würde dann kaum noch etwas zurückbleiben und der Schutzbereich liefe leer. ${ }^{270}$ Diese Weiterführung ad

265 BVerfG, 15.1.1958, 1 BvR 400/51, NJW 1958, S. 257 f. - Lüth; auf das genannte Urteil rekurrierend Isensee/Kirchhof/Schmidt-Jortzig, HStR VII, $\mathbb{\$} 162, \mathrm{Rn} .1$.

266 BeckOK GG/Schemmer, Art. 5, Rn. 1; BVerfG, 15.1.1958, 1 BvR 400/51, NJW 1958, S. 257 f. - Lüth.

267 BVerfG, 11.5.1976, 1 BvR 163/72, NJW 1976, S. 1680, 1681.

268 Vgl. dazu grundlegend die Beschreibung bei Isensee/Kirchhof/Schmidt-Jortzig, HStR VII, $\mathbb{1} 162$, Rn. 3-12, v.a. 4, 8.

269 Art. 20 Abs. 2 S. 1, Art. 21 Abs. 1 S. 1 GG.

270 Dies wäre dann auch nicht mehr weit entfernt von der Auslegung der Meinungsfreiheit im deutschen Kaiserreich als eine „Bestätigung und Konkretisierung des allgemeinen rechtsstaatlichen Grundsatzes der Gesetzmäßigkeit der Verwaltung“, zit. nach Merten/Papier/Jestaedt, HGR IV, 2011, $\$ 102$, Rn. 1. 
absurdum zeigt abstrakt schon die Möglichkeit der engen Begrenzung des Schutzbereichs der Meinungsfreiheit und eine Leugnung der objektiven Komponente demonstriert die endlose Öffnung des Grundrechts. Die hier angerissene uneinheitliche Schwerpunktsetzung in Bezug auf die subjektiven und objektiven Komponenten mit all ihren Folgen wird im Rahmen der allgemeinen Satire-Diskussion und im Besonderen in den Fällen Klaus Staecks immer wieder mittelbar aufzugreifen sein.

\section{Die Meinung}

Die definierenden Merkmale des zentralen Begriffs Meinung sind von der Stellungnahme, dem Dafürhalten, der Beurteilung und einer Form der geistigen Auseinandersetzung geprägt. Der Kern der Meinungsäußerung besteht darin, eine "geistige Wirkung auf die Umwelt“ $\mathrm{zu}$ erzielen, und dabei meinungsbildend und überzeugend zu wirken. ${ }^{271}$ Abzugrenzen ist sie nach herrschender Grundrechtsdogmatik von Tatsachenbehauptungen, deren Wahrheitsgehalt bewiesen werden kann. Der grundlegende Unterschied, dass eine Tatsache belegbar wahr bzw. unwahr sein kann, führt dazu, dass ihr ein besonderer Wert und Kraft in einer Argumentation zu Teil wird. ${ }^{272}$ Mag es im Einzelfall schwierig sein, zwischen Tatsachenbehauptungen und Meinungen zu trennen, so ändert das erst einmal nichts an dieser Unterscheidung selbst, aus der auch entsprechend unterschiedlich zu folgern ist. Gegen diese Differenzierung spricht jedoch das Argument, dass sich streng genommen schon in der Auswahl der Wiedergabe eines Faktums eine wertende Stellungnahme und damit eine Meinung versteckt. ${ }^{273}$

Tatsachenbehauptungen werden dabei nach der Rechtsprechung des BVerfG nicht dem grundrechtlichen Schutz entzogen, sondern vielmehr als Grundkern für die Meinungsbildung, als meinungsbezogene Tatsa-

271 BVerfG, 22.6.1982, 1 BvR 1376/79, NJW 1983, S. 1415 - CSU NPD Europas.

272 Vgl. dazu: BVerfG, 3.6.1980, 1 BvR 797/78; NJW 1980, 2072, 2073 - Böll; Gärtner, Was die Satire darf, 2009, S. 42.

273 Dies oder in inhaltlich vergleichbarer Form ist das Kernargument in der verfassungsrechtlichen Rechtsprechung bei BVerfG, 22.6.1982, 1 BvR 1376/79, NJW 1983, S. 1415 - CSU NPD Europas in der Literatur u.a. bei Gärtner, Was die Satire darf, 2009, S. 43; Isensee/Kirchhof/Schmidt-Jortzig, HStR VII, $\$ 162$, Rn. 21; Maunz/Dürig/Grabenwarter, Art. 5 Abs. 1, 2, Rn. 58 stellt auf die Schwierigkeit der Trennbarkeit ab. 
chen, dem grundrechtlichen Schutz unterstellt, da es sonst zu einer untragbaren Verkürzung des Grundrechtsschutzes kommen könnte. ${ }^{274}$

Für den Schutz des Grundrechts wird die Meinung auch keinem Werturteil unterzogen, d.h. es kommt nicht darauf an, ob sie begründet oder grundlos, überlegt oder unbedacht, emotional oder rational ist, als wertvoll oder wertlos, gefährlich oder harmlos, sachlich oder unsachlich eingeschätzt wird. ${ }^{275}$ Unabhängig davon, dass eine Qualitätskontrolle wohl schwerlich in einer freien Gesellschaft möglich wäre, sind auch gerade Meinungen, die von einer herrschenden Ansicht und Vorstellung abweichen, schutzwürdig. ${ }^{276}$ Die Meinungsfreiheit ist - wie bereits betont wurde - im politischen Meinungsbildungsprozess und damit für eine freiheitlichdemokratisch verfasste Gesellschaft von höchster Wichtigkeit, auch wenn sie selbst natürlich nicht im engeren Sinne politisch sein muss. Beleidigungen, Schmähungen oder ähnliches werden erst auf der Schranken-Ebene in die grundrechtliche Prüfung aufgenommen und ändern insofern zunächst nichts an dem Schutzbereich der Meinungsfreiheit. ${ }^{277}$ Letztlich folgt daraus, dass - nach der Rechtsprechung des BVerfG - sich von dem Schutzbereich nur die bewusste Lüge oder die bewusste Verbreitung von unwahren Tatsachenbehauptungen herausnehmen lässt. ${ }^{278}$ Das überzeugt, da mangels einer Qualitätskontrolle irrige oder fahrlässig recherchierte Aussagen zuzulassen sind, da sie so sehr unter die subjektive Komponente fallen, dass die objektive Komponente zurückzutreten hat. Die bewusste Lüge basiert aber auf einer Manipulationsabsicht, die mit der objektiven Komponente und damit mit dem Interesse an unverfälschter politischer Meinungsbildung als Grundlage für die freiheitliche Demokratie nicht vereinbar ist. Starke Stimmen in der Literatur sehen die verfassungsrechtliche

274 Vgl. dazu BVerfG, 13.4.1994, 1 BvR 23/94, NJW 1994, S. 1779 - Leugnung der Judenverfolgung; BVerfG, 22.6.1982, 1 BvR 1376/79, NJW 1983, S. 1415 - CSU NPD Europas; BVerfG, 9.10.1991, 1 BvR 1555/88, NJW 1992, S. 1439, 1440 Bayer-Aktionäre.

275 Ständige Rechtsprechung, vgl. beispielsweise BVerfG, 14.3.1972, 2 BvR 41/71, NJW 1972, S. 811, 813 - Strafgefangene; BVerfG 13.4.1994, 1 BvR 23/94, NJW 1994, S. 1779 - Ausschwitzlüge.

276 BVerfG, 14.3.1972, 2 BvR 41/71, NJW 1972, S. 811, 813 - Strafgefangene.

277 Ständige Rechtsprechung vgl. nur: BVerfG, 10.10.1995, 1 BvR 1476/91, 1 BvR 1980/91, 1 BvR 102/92, 1 BvR 221/92, NJW 1995, S. 3303, 3304 - Soldaten sind Mörder; BVerfG, 19.4.1990, 1 BvR 40/86, 42/86, NJW 1990, S.1980, 1981 postmortale Schmähkritik.

278 Tatsachenbehauptungen, die sich nachträglich als unwahr herausstellen, sind davon ausgenommen. BVerfG 10.11.1998, 1 BvR 1531/96, NJW 1999, S.1322, 1324 - Fall Helnwein. 
Rechtsprechung insofern kritisch, da sie eine Gefahr darin sehen, wenn der Schutzbereich zu stark eingeengt wird. Deswegen wird erst in der Abwägung mit kollidierenden Grundrechten Dritter diesen unwahren Tatsachenbehauptungen ein gegen Null tendierendes Gewicht beigemessen. ${ }^{279}$ Es soll aber auch nicht verschwiegen werden, dass eine solche Form der Begrenzung des Schutzbereichs für die politisch gefährlichen Fälle der bewussten Lüge, wie der Ausschwitzlüge, aus moralisch-ethischen Gründen durchaus zu akzeptieren ist.

\section{Meinung und Werbung}

Werbende Plakate oder die Werbung im Allgemeinen können auch unter Art. 5 Abs. 1 S. 1 GG fallen, „wenn die Werbung einen wertenden, meinungsbildenden Inhalt hat oder Angaben erhält, die der Meinungsbildung dienen“. ${ }^{280}$ Dass im Rahmen der Wirtschaftswerbung die Meinung dem Zweck des wirtschaftlichen Vorteils und Wachstums für den Anwerbenden untersteht, ändert nach verfassungsrechtlicher Rechtsprechung und der herrschenden Meinung nichts an der Einordnung. ${ }^{281}$

\section{Meinung und Satire}

Es sei darauf hingewiesen, dass die Meinungsfreiheit jede Form der Verkörperlichung von Meinung schützt. In Bezug auf die Satire und das satirische Plakat ist damit - wie es der Wortlaut des Grundrechts schon vorgibt - die mündliche, die textliche oder die bildliche Satire ${ }^{282}$ umfasst. Das BVerfG machte in Bezug auf Bilder nochmal deutlich, dass diese „jedenfalls dann Meinungsäußerungen sind, wenn in ihnen ein Werturteil, eine

279 Isensee/Kirchhof/Schmidt-Jortzig, HStR VII, $\mathbb{1} 162$, Rn. 22.

280 BVerfG, 22.1.1997, 2 BvR 1915/91, NJW 1997, S. 2871 - Tabakwarnhinweise; BVerfG, 19.11.1985, 1 BvR 934/82, NJW 1986, S. 1533, 1534 - Arztwerbung.

281 Mangoldt/Klein/Starck/Starck/Paulus, GG, Art. 5, Rn. 79; Isensee/Kirchhof/ Schmidt-Jortzig, HStR VII, $\mathbb{1} 162$, Rn. 23.

282 Der Wortlaut des Art. 5 Abs. 1 S. 1 GG wird wohl an dieser Stelle nicht abschlieBend zu verstehen sein, somit wäre auch eine satirische Geste oder vergleichbare Handlung als Meinungsäußerung denkbar, vgl. im Allgemeinen Isensee/Kirchhof/Schmidt-Jortzig, HStR VII, $\$ 162$, Rn. 25. 
Ansicht oder Anschauung bestimmter Art zum Ausdruck kommen. “283 Die Satire wird immer ein Werturteil sein und damit begriffsnotwendig immer als eine geistige Auseinandersetzung in den Schutzbereich der Meinungsfreiheit fallen, selbst wenn sie sich dadurch auszeichnet, dass sie zwar eine Tatsache wiedergibt, diese aber durch das Satirische - also beispielsweise nur durch die Verfremdung - wieder zu einer Meinung im Sinne einer Stellungnahme wird. Schwieriger zu prüfen sind die Fälle, in denen im Rahmen der Satire mit Zitaten - sei es zur argumentativen Untermauerung oder zur reinen Bloßstellung des Zitierten - gearbeitet wird. Das Zitat ist grundsätzlich dem Beweis zugänglich, auch wenn das Zitierte selbst inhaltlich eine Meinung im Sinne des Grundrechts darstellt. Durch die Nachprüfbarkeit stellt sich die Frage, ob auch unrichtige Zitate geschützt werden. Das BVerfG macht deutlich, dass „demjenigen, der eine Äußerung wiedergibt, [...] keine wesentlichen oder gar unzumutbaren Erschwerungen oder Risiken auferlegt [werden], wenn er verpflichtet wird, korrekt zu zitieren". ${ }^{284}$ Insofern ist es überzeugend, dass das bewusst unrichtige Zitat letztlich genauso wie die anderen Fälle der bewussten Lüge mit dem Schutzzweck des Grundrechts nicht vereinbar ist. ${ }^{285}$ In der Satire kann aber auch ein Zitat satirisch verfremdet bzw. aufgeladen werden - sei es durch Verkürzung, Re-Kontextualisierung oder ähnlichem. Wenn Klaus Staeck auf einem Plakat, in dem eine Wurst in der Schale einer Banane steckt mit dem Satz "Jetzt wächst zusammen, was zusammen gehört“ verbindet, dann verfremdet er das berühmte Zitat des populären Alt-Kanzlers Willy Brandt anlässlich des Mauerfalls am 09. November 1989.286 Dass das Zitat erkennbar ist, ohne dass die üblichen Ausdrucksformen der direkten und indirekten Rede verwendet werden müssen und die Quelle angegeben

283 BVerfG, 23.3.1971, 1 BvL 25/61, 3/62, NJW 1971, S. 1555, 1558 - Jugendgefährdende Schriften.

284 BVerfG, 3.6.1980, 1 BvR 797/78, NJW 1980, S. 2072 - Böll.

285 Vgl. BVerfG, 3.6.1980, 1 BvR 797/78, NJW 1980, S. 2072 - Böll; Gärtner, Was die Satire darf, 2009, S. 43.

286 Dieses Zitat stammt nicht - wie lange angenommen - aus der großen feierlichen Rede vor dem Schöneberger Rathaus vom 10.11.1989, sondern aus zwei Interviews, die in diesem Zeitraum stattfanden, wie Historiker belegten. So verwundert es sogar noch mehr, dass eine solche eilige, nur flüchtige zusammentreffende und wenig vorbereitete Begebenheit nicht nur zu einem der berühmtesten Leitsprüche dieses historischen Moments wurde, sondern sich gar zu einem geflügelten Wort entwickelte. Vgl. dazu: Rother, „Jetzt wächst zusammen, was zusammengehört" Oder: Warum Historiker Rundfunkarchive nutzen sollten, in: Bundeskanzler-Willy-Brandt-Stiftung (Hrsg.), Wächst zusammen, was zusammengehört?, 2001, S. 25-30 sowie die Dokumentation S. 31-50. 
werden muss, liegt daran, dass für den Rezipienten dieses Zitat als geflügeltes Wort und auch dessen Autor erkennbar sind.

Letztlich müssen Zitate schon begriffsnotwendig richtig wiedergegeben werden. Die gänzlich falsche Zuschreibung muss aber wiederum von der Meinungsfreiheit gedeckt sein, wenn gerade diese als solche erkennbar ist und, aber nicht notwendigerweise, darin gerade die für die Satire typische Verzerrung liegt.

\section{Presse-, Rundfunk- und Filmfreiheit, Art. 5 Abs. 1 S. 2 GG}

Die Pressefreiheit ist ein subjektives Grundrecht für die im Pressewesen tätigen Personen, das seinen Trägern Freiheit gegenüber staatlichem Zwang verbürgt. ${ }^{287}$ Für diesen persönlichen Schutzbereich ist letztlich ausschlaggebend, ob eine Tätigkeit ausgeübt wird, die in engem Funktionszusammenhang mit der Ausübung freier Pressetätigkeiten steht. ${ }^{288}$ Die Funktion des Grundrechts liegt darin, eine staatlich nicht reglementierte, offene Kommunikation zu gewährleisten. ${ }^{289}$ Diese Funktion erfüllend ist ein Presseerzeugnis, in Abgrenzung zur Rundfunk- und Filmfreiheit, ein zur Verbreitung geeignetes und bestimmtes Druckerzeugnis, das in geeigneter und bestimmter Form am Kommunikationsprozess teilnimmt, und nicht zwingend allgemein zugänglich sein muss. ${ }^{290}$ Das hier grundlegende künstlerische Politsatire-Plakat erfüllt diese Definition zweifellos. Auch ein Blick in die (verfassungsrechtliche) Rechtsprechung zur Satire zeigt, dass der Hauptteil der Fälle Druckerzeugnisse in diesem Verständnis oder im Fernsehen ausgestrahlte Formate, die unter die Rundfunkfreiheit fallen, tangieren. Man denke neben allen Verfahren zu Klaus Staeck auch an das Satiremagazin Titanic ${ }^{291}$ und in Bezug auf die Rundfunkfreiheit an die Entscheidungen Münzen-Erna ${ }^{292}$ oder an das Neo-Magazin-Royale mit Jan Böhmermann ${ }^{293}$. Umso mehr mag also überraschen, dass Art. 5 Abs. 1 S. 2 GG ein fast zu vernachlässigendes Schattendasein in der Satire-Rechtsprechung führt.

287 BVerfG, 5.8.1966, 1BvR 586/62, 610/63, 512/64, NJW 1966, S.1603, 1604 Spiegel-Teilurteil.

288 Maunz/Dürig/Grabenwarter, Art. 5 I, II, Rn. 222.

289 BVerfG, 8.10.1996, 1 BvR 1183/90, NJW 1997, S. 386, 387 - Werkszeitungen.

290 Vgl. BVerfG, ebd.

291 Vgl. dazu Kap. 6, A., I.

292 BVerfG 12.11.1997, 1 BvR 2000/96, NJW 1998, S. 1386 - Münzen-Erna.

293 Vgl. dazu Kap. 6, A., II., 1. 
Wie bei der Meinungsfreiheit ist auch in der Pressefreiheit die Äußerung jeglicher Meinung, auch wenn sie noch so wertlos erscheinen mag, geschützt. Die Grenze liegt abermals bei der Verbreitung bewusst falscher Nachrichten, offensichtlich unwahrer Tatsachenbehauptungen und bewusst falscher Zitate, die aus dem Schutzbereich herausgenommen werden. ${ }^{294}$ Auch im Rahmen der Pressefreiheit mag es zu einer notwendigen Unterscheidung zwischen einer bewusst falschen Mitteilung und einer satirischen Mitteilung kommen. Schon begrifflich können die Fälle der Satire oder auch des Scherzes, wie es in Form des Aprilscherzes auch in den journalistischen Bereich Einzug gefunden hat, von bewussten Falschmeldungen in Form von Lügen unterschieden werden. Sind ersteres darauf gerichtet und auch im Ergebnis darauf angewiesen, richtig verstanden zu werden, will die Lüge unerkannt bleiben. Wie mit den Fällen umzugehen ist, in denen eine Lüge oder bewusste Falschmeldung sich als Satire ausgibt und wie diese beiden Bereiche voneinander zu trennen sind, wird im Einzelnen erst im Anschluss zu den Staeck-Verfahren im siebten Kapitel thematisiert.

Für die satirische und gleichzeitig pressefreiheitsrechtlich relevante Äußerung stellt sich die Frage nach der Abgrenzung zwischen Meinungsfreiheit und Pressefreiheit. Das Spezifikum des Schutzbereichs der Pressefreiheit liegt in dem institutionell-organisatorischen Rahmen, d.h. der Herstellung und Verbreitung von Presseerzeugnissen, wohingegen die Meinungsfreiheit Form und Inhalt der Äußerung schützt, auch wenn sie in Form eines Druckerzeugnisses verbreitet wird. ${ }^{295}$ Insofern ist in Bezug auf eine satirische Äußerung das Schattendasein in der Satire-Rechtsprechung durchaus begründet, da die Pressefreiheit eben nur den Rahmen und nicht den Inhalt schützt und so das relevante Grundrecht die Meinungsfreiheit nach Art. 5 Abs. 1 GG darstellt.

\section{Kunstfreiheit, Art. 5 Abs. 3 S. 1 GG}

Schon nach dem ersten Kapitel mit der Geschichte und Typologie des Plakats und den Ausführungen wird unverkennbar klar, dass die Kunstfreiheit aus Art. 5 Abs. 3 S. 1 GG für das künstlerische Politsatire-Plakat naheliegt. Der Begriff der Kunst wird nicht nur im Allgemeinen zur Satire relevant, sondern gerade in Bezug auf Klaus Staeck. Für die folgenden

294 Siehe nur Mangoldt/Klein/Starck/Starck/Paulus, GG, Art. 5, Rn. 139 f.

295 Maunz/Dürig/Grabenwarter, Art. 5, Rn. 319 m.w.N. 
Kapitel - wie dem vierten Kapitel zu den Plakaten Klaus Staecks oder dem fünften Kapitel zu den geführten Prozessen - ist ein grundlegendes Verständnis für das vorbehaltlos gewährte Grundrecht relevant. Deswegen soll hier zunächst der Schutzbereich der Kunstfreiheit auch mit dem begrifflichen Verständnis von Kunst skizziert werden, um dann die Satire und im Speziellen das satirische Plakat unter dem Aspekt des Grundrechts zu untersuchen.

\section{Der Begriff der Kunst}

Der Begriff der Kunst ist grundsätzlich weit auszulegen. Das legt schon der Schutzzweck der grundrechtlichen Garantie nahe. Der von der verfassungsrechtlichen Rechtsprechung geprägte Kunstbegriff ist unter Heranziehung der viel rezipierten Mephisto-Entscheidung ${ }^{296}$ und der Entscheidung zum Anachronistischen Zug ${ }^{297}$ aufzuzeigen. Es sei aber schon von Anfang an betont, dass jeder Versuch einer Definition zu dem unlösbaren Konflikt zwischen begrifflicher Begrenzung und freiheitlicher Gewährleistung führt. Wie das BVerfG aufzeigt, entbindet „die Unmöglichkeit, Kunst generell zu definieren, [...] indessen nicht von der verfassungsrechtlichen Pflicht, die Freiheit des Lebensbereichs Kunst zu schützen, also bei der konkreten Rechtsanwendung zu entscheiden, ob die Voraussetzungen der Kunstfreiheit vorliegen. “298 Deswegen bestehen mehrere Definitionen, die sich meist - ausgehend von der Rezeption in den benannten Entscheidungen - auf drei Begriffe herunterbrechen lassen können: der materielle Kunstbegriff, der formale und der offene (auch kommunikationstheoretische ${ }^{299}$ ) Kunstbegriff. Mit dem Mephisto-Beschluss statuiert das BVerfG, dass "das Wesentliche der künstlerischen Betätigung die freie schöpferische Gestaltung [ist], in der Eindrücke, Erfahrungen, Erlebnisse des Künstlers durch das Medium einer bestimmten Formensprache zu unmittelbarer Anschauung gebracht werden. Alle künstlerische Tätigkeit ist ein Ineinander von bewussten und unbewussten Vorgängen, das rational nicht aufzulösen ist. Beim künstlerischen Schaffen wirken Intuition, Phantasie und Kunstverstand zusammen; es ist primär nicht Mitteilung, sondern Ausdruck, und zwar unmittelbarster Ausdruck der individuellen

296 BVerfG, 24.2.1971, 1 BvR 435/68, GRUR 1971, S. 461 - Mephisto.

297 BVerfG, 17.7.1984, 1 BvR 816/82, NJW 1985, S. 261 - Anachronistischer Zug.

298 BVerfG, ebd., S. 262.

299 So bei Mangoldt/Klein/Starck/Starck/Paulus, GG, Art. 5, Rn. 423. 
Persönlichkeit des Künstlers“. ${ }^{300}$ Diese als materieller Kunstbegriff in die Literatur eingegangene Definition lässt mit den Worten „freie schöpferische Gestaltung“, „Intuition“, „Phantasie“ und „Kunstverstand“ einen offenen Spielraum. Dass diese freie schöpferische Gestaltung sich in einer „bestimmten Formensprache“ auszudrücken hat, lässt an den sogenannten formalen Kunstbegriff erinnern. Danach ist eine formale, typologische Betrachtung des Kunstwerks angebracht, wonach Gattungsanforderungen eines bestimmten Werktyps erfüllt sein müssen. ${ }^{301}$ Dieser knüpft entsprechend an die seit der europäischen Antike bestehenden Gattungen der Malerei, Bildhauerei und Dichtung an. Mit seiner Gattungsgebundenheit versperrt sich der Begriff selbst neuen Kunstarten bzw. in der Sprache des Gerichts Werktypen. Dieses Verständnis ist in dieser Form zu eng, so dass dieser Kunstbegriff nahezu völlig obsolet ist.

In dem Beschluss zum Anachronistischen Zug geht das BVerfG von einem offenen Kunstbegriff aus. Das Gericht sieht „das kennzeichnende Merkmal einer künstlerischen Äußerung darin, dass es wegen der Mannigfaltigkeit ihres Aussagegehalts möglich ist, der Darstellung im Wege einer fortgesetzten Interpretation immer weiterreichende Bedeutungen zu entnehmen, so dass sich eine praktisch unerschöpfliche, vielstufige Informationsvermittlung ergibt“. 302

Trotz aller offensichtlichen Unterschiede haben diese Begriffe gemein, dass keine staatliche Qualitätskontrolle von Kunst durchgeführt wird. Bei jeder Auslegung im Rahmen des Art. 5 Abs. 3 GG hat damit das Prädikat Kunst als eine wertoffene Zuordnung zu erfolgen. Diese Freiheit von staatlicher Kontrolle meint die Freiheit von staatlicher Beurteilung, Freiheit von staatlichen Regeln der Kunstausübung sowie auch die Freiheit von einer staatlichen Identifikation mit bestimmten Kunstrichtungen, -stilen, -schulen oder Gattungen. Dabei wird das künstlerische Schaffen sowohl in Bezug auf den Werkbereich - die Tätigkeit und das Kunstobjekt wie auch den Wirkbereich gesichert. Unter dem Wirkbereich versteht das BVerfG die Darbietung und Verbreitung, also den Bereich ,in dem der Öffentlichkeit Zugang zu dem Kunstwerk verschafft wird“303. Dazu

300 BVerfG, 24.2.1971, 1 BvR 435/68, GRUR 1971, S. 461, 463 - Mephisto.

301 Aufgeführt und seither in folgenden Entscheidungen rezipiert bei BVerfG, 17.7.1984, 1 BvR 816/82, NJW 1985, S. 261, 262 - Anachronistischer Zug.

302 BVerfG, ebd.

303 BVerfG, 24.2.1971, 1 BvR 435/68, GRUR 1971, S. 461, 463 - Mephisto; BVerfG, 17.7.1984, 1 BvR 816/82, NJW 1985, S. 261, 262 - Anachronistischer Zug. 
zählen auch die Personen, die eine unentbehrliche Mittlerfunktion zwischen Künstler und Publikum durch Vervielfältigung, Verbreitung und Veröffentlichung ausüben, wie die Medien ${ }^{304}$ oder die Personen, die das Kunstwerk geschäftsmäßig vertreiben. ${ }^{305}$

Letztlich darf auch bei aller Offenheit und Kommunikationsbezug des Kunstbegriffs dieser nicht endlos ausgeweitet werden. Vor allem sollte die Deutungshoheit nicht beim Künstler selbst liegen, da das sonst letztlich zu einem Gleichlaufen von allgemeiner Handlungsfreiheit und Kunstfreiheit führen würde, auch wenn dies der Beuys'schen Entgrenzung - „Alles ist Kunst, jeder ist Künstler" - entgegenläuft. Hervorzuheben und für die Plakate von Klaus Staeck von großer Relevanz ist die explizite Betonung des BVerfG, dass eine vordergründige und eindeutige politische Absicht die Bewertung nicht verändern kann, wenn das in Frage stehende Werk in den Schutzbereich des Art. 5 Abs. 3 S. 1 GG fällt. ${ }^{306}$

Grenzen der Rechtsprechung zum Straßentheater des anachronistischen Zugs liegen in den neuen Formen einer engagierten Kunst, die sich vor allem durch Partizipation auszeichnet. Zeigen die Richter, dass mit der Form des Straßentheaters eine Distanz zum Zuschauer hervorgerufen wird, die die Rollenverteilung zwischen Schauspielern und Betrachtern klar verdeutlicht, ließe sich schon die Frage nach einem Kunstbegriff stellen, der die performative und gleichzeitig partizipatorische Kunst einschließt. ${ }^{307}$

\section{Die Satire und die Kunstfreiheit}

Im zweiten Kapitel dieser Arbeit wurde die Trias des Angriffs, des Normbezugs und der Indirektheit und dementsprechend das aggressive, soziale und ästhetische Element der Satire inklusiver der Schwächen einer solchen Dreiteilung aufgezeigt. ${ }^{308}$ Unabhängig von der hier geäußerten Kritik wird

304 BVerfG, 3.11.1987, 1 BvR 1257/84, NJW 1988, S. 325, 326 - Herrnburger Bericht.

305 BVerfG, 7.3.1990, 1 BvR 266/86, 1 BvR 913/ 87, NJW 1990, S. 1982, 1983 Verunglimpfung der Bundesflagge.

306 BVerfG, 3.6.1987, 1 BvR 313/85, NJW 1987, S. 2661 - Strauß-Karikaturen, hM vgl. m.w.N. auch zur veralteten Gegenansicht Stern/Stern/Sachs/Dietlein, StaatsR IV/2, $\mathbb{1 1 4}$, S. 106.

307 Vgl. BVerfG, 17.7.1984, 1 BvR 816/82, NJW 1985, S. 261, 262 - Anachronistischer Zug.

308 Siehe dazu Kap. 2, D., III-E. 
unbestritten angenommen, dass die Satire charakteristischerweise ein ästhetisches Element aufweist, weswegen eine Einordnung dieser unter den Begriff der Kunst und das entsprechenden Freiheitsrecht naheliegt.

Bei der Satire - wie auch in anderen Kunstformen - müssen „werkgerechte Maßstäbe“"309 angewendet werden. Unter diesem Aspekt soll die Satire in Bezug auf die unterschiedlichen Kunstbegriffe untersucht werden. Für den formalen Kunstbegriff sind die Gattungsanforderungen zu erfüllen. Eine satirische Äußerung kann sich selbstredend in Form eines Gedichts, einer Zeichnung oder eines Gemäldes ausdrücken, doch wird damit sicherlich nicht der mannigfaltigen Erscheinungsform der Satire Rechnung getragen.

Kernelement des materiellen Kunstbegriffs lag in der „freien schöpferischen Gestaltung“ mit „Intuition“ und „Phantasie“. Satiren zeichnen sich gerade dadurch aus, dass sie in ihrer Form der Verfremdung einen Spielraum unterschiedlicher Möglichkeiten offenlegen. Die Satire entfernt sich durch das Stilmittel der Verfremdung den realen Umständen - auch wenn ein Realitätsbezug bestehen bleibt. Aber genau der notwendige Realitätsbezug, der für den Zweck der Satire - nämlich den Erkenntnisgewinn - vonnöten ist, ließe sich als Argument anführen, dass Kunst und Satire sich ausschließen: In der Literaturtheorie wird diesbezüglich auch die Auffassung vertreten, dass die Satire wegen ihrer Kontextbezogenheit ${ }^{310}$ zwar die primitivste aller Künste, aber letztlich dennoch Kunst sei. ${ }^{311}$

\section{Das satirische Plakat in Bezug auf die Kunstfreiheit}

Die Kunstfreiheit schützt aber nicht nur als Freiheitsrecht den einzelnen Künstler, sondern gewährleistet zum einen objektiv-rechtlich die Kunst als autonomen und eigengesetzlichen Lebensbereich und zum anderen eine grundgesetzlich verankerte Kulturstaatlichkeit. Dies mag zwar nicht ganz klar aus dem kargen Wortlaut des Art. 5 Abs. 3 S. 1 GG direkt herauszulesen sein, doch mit Hilfe der Rechtsprechung des BVerfG und einfachrechtlicher Gesetzgebung ist diese Gewährleistung als objektive

309 BVerfG, 3.6.1987, 1 BvR 313/85, NJW 1987, S. 2661 - Strauß-Karikaturen.

310 Vgl. dazu auch Kap. 2, D., VI.

311 „Because satire usually has a vital connection with a specific cultural context, in fact, can hardly exist without such a context, it remains the most primitive of arts." Test, Satire. Spirit and Art, 1991, S. 31, s.a. S. 35. 
Wertentscheidung deutlich geworden. ${ }^{312}$ Denn, wie das BVerfG statuiert, „als objektive Wertentscheidung für die Freiheit der Kunst stellt sie dem modernen Staat, der sich im Sinne einer Staatszielbestimmung auch als Kulturstaat versteht, zugleich die Aufgabe, ein freiheitliches Kunstleben zu erhalten und zu fördern. “313

\section{Das Verhältnis}

\section{Einführung}

Das Verhältnis der besprochenen Grundrechte untereinander ist gerade in Bezug auf das satirische künstlerische politische Plakat von besonderer Relevanz. In Bezug auf andere hier nicht besprochene Freiheitsrechte, wie der allgemeinen Handlungsfreiheit aus Art. 2 Abs. 1 GG, sei auf den allgemeinen Spezialitätsgrundsatz verwiesen, wonach Art. 2 Abs. 1 GG hinter den spezielleren Grundrechten wie aus Art. 5 Abs. 1 und 3 GG zurücktritt.

2. Verhältnis von Kunst- und Meinungsfreiheit

„Satire kann Kunst sein; nicht jede Satire ist jedoch Kunst.“314 Fast zum Mantra der Satire-Rechtsprechung hat sich diese Aussage des BVerfG entwickelt. Das Gericht macht damit deutlich, dass sich Kunst und Meinungsäußerung nicht ausschließen. Es ist evident, dass die Aussage des BVerfG zur Einordnung der Satire als Kunst oder Meinung nicht hilft.

Eine Meinung kann - wie es bei der engagierten Kunst üblich ist durchaus in der Form künstlerischer Betätigung kundgegeben werden. ${ }^{315}$ Die Kunst wird so lediglich als „Beiwerk“ der geäußerten Meinung ver-

312 Vgl. neben den bereits zitierten Entscheidungen, die Gesetzgebung zum KunstUrhG, dem Kulturgüterschutzgesetz, die Normen zur Förderung Kulturförderung in Bundes- und Landesgesetzen. Die Kunstförderung ist auch in der gängigen Kommentarliteratur als gewährleistete Garantie anerkannt, vgl. nur Maunz/ Dürig/Scholz, GG, Art. 5 Abs. 3, Rn. 16.

313 BVerfG 5.3.1974, 1 BvR 712/68, NJW 1974, S. 689 - Schallplattenumsatz.

314 BVerfG, 25.3.1992, 1 BvR 514/90, GRUR 1992, S. 471, 473 - geb. Mörder; BVerfG, 10.7.2002, 1 BvR 354/98, NJW 2002, S. 3767 - Bonnbons.

315 BVerfG, 3.6.1987, 1 BvR 313/85, NJW 1987, S. 2661- Strauß-Karikaturen. 
standen. ${ }^{316}$ Maßgebliches Grundrecht bleibt somit die Meinungsfreiheit als spezielleres Grundrecht. Das entspricht dem Leitgedanken, dass zunächst erst einmal jede Meinung unabhängig von ihrer Ausdrucksform geschützt wird.

Anders liegt der Fall, wenn - wie im Deutschlandlied-Beschluss klargestellt - berücksichtigt werden muss, dass es dem Künstler darum ging, mit dem durch das Kunstwerk verkörperten Gegenstand die Freiheit zur Vermittlung des Kunstwerks zu erkämpfen. Benutzt der satirische Künstler das Kunstwerk zur Verfolgung des genannten Ziels, dient auch dieses Handeln dazu, es dem Publikum zugänglich zu machen. Wenn sich aber dann staatliche Maßnahmen gezielt und ausschließlich gegen das so verbreitete Kunstwerk richten, tritt die Meinungsäußerungsfreiheit hinter der Kunstfreiheit zurück. ${ }^{317}$

Die Aussage - „Satire kann Kunst sein; nicht jede Satire ist jedoch Kunst“"318 - zeigt aber auch, dass für den grundrechtlichen Schutz der Satire die Frage nach der Verortung als Kunst oder nur Meinung nicht die entscheidende ist. Eine satirische Äußerung lässt sich im Rahmen der Meinungsfreiheit eben gerade als Äußerung verhandeln, auch wenn man die Satire als eine Kunstform anerkennt. ${ }^{319}$ Im Ergebnis wird so auf der Ebene der Rechtfertigung und ebenso bei der Prüfung, ob der Grundrechtseingriff verfassungsrechtlich gerechtfertigt ist, wohl in den meisten Fällen der gleiche Maßstab angelegt, unabhängig davon, ob es sich um eine Beschränkung der Kunst- oder Meinungsfreiheit handelt. ${ }^{320}$

\section{Verhältnis zu anderen Grundrechten}

Gerade in Bezug auf das politische Plakat, das nicht zuletzt auch im Rahmen von Demonstrationen Verwendung findet, ist das Verhältnis zwischen Art. 5 Abs. 1 GG und der Versammlungsfreiheit aus Art. 8 GG zu thematisieren. Die Grundrechte haben ähnliche, aber doch verschiedene

316 So bei BVerfG, 07.03.90, 1 BvR 1215/87, NJW 1990, S. 1985 - DeutschlandliedBeschluss.

317 BVerfG, ebd.

318 BVerfG, 25.3.1992, 1 BvR 514/90, GRUR 1992, S. 471, 473 - geb. Mörder; BVerfG, 10.7.2002, 1 BvR 354/98, NJW 2002, S. 3767 - Bonnbons.

319 Ganz hM siehe Gärtner, Was die Satire darf, 2009, S. 41f.; Brauneck, ZUM 2000, 138; Cueni, Schutz von Satire im Rahmen der Meinungsfreiheit, 2019, S. 221 jeweils mwN.

320 Faßbender, NJW 2019, S. 705, 707. 
Schutzrichtungen. Geht es bei Art. 5 Abs. 1 GG neben der objektiven Komponente als subjektives Freiheitsrecht um die individuelle Teilhabe am Kommunikationsprozess durch eine Meinungsäußerung, schützt Art. 8 Abs. 2 GG hingegen das örtliche Zusammenkommen zu einer „gemeinschaftlichen, auf die Teilhabe an der öffentlichen Meinungsbildung gerichteten Erörterung oder Kundgebung“.321 Nach der herrschenden Meinung wird davon ausgegangen, dass beide Grundrechte nebeneinander anwendbar sind. ${ }^{322}$ Auch wenn das BVerfG zum Teil davon spricht, dass „ergänzend zu Art. 8 GG auch das Grundrecht der Meinungsfreiheit als Prüfungsmaßstab herangezogen werden könnte“, ${ }^{323}$ sollte dies nicht als ein Spezialitätsverhältnis missverstanden werden. ${ }^{324}$

Es darf auch nicht der Schutzbereich des Art. 5 Abs. 3 GG so erweitert werden, dass es zu einem faktischen Leerlaufen des ersten Absatzes kommt, denn „die normale und übliche Kommunikation zwischen den Menschen in Form von Wort, Schrift und Bild ist weder Kunst noch Wissenschaft.“325

\section{Eingriffe in den Schutzbereich}

Die Eingriffsmöglichkeiten in die genannten Schutzbereiche sind mannigfaltig. Aber auch beim satirischen, künstlerischen, politischen Plakat treffen den Staat Schutzpflichten. In Bezug auf die Kunstfreiheit hat der Staat Kunst und Künstler gegen Eingriffe - in Form von beispielsweise Beschädigungen, Zerstörungen oder Gefährdungen - durch Dritte zu schützen. Beschädigungen und Zerstörungen können sich auf das Kunstwerk selbst beziehen oder möglicherweise auf den Werkraum des Künstlers. Bei der Erfüllung der Schutzpflicht hat der Gesetzgeber oder die vollziehende

321 BVerfG, 23.6.2004, 1 BvQ 19/04, NJW 2004, S. 2814, 2815 - Synagogenbau; BVerfG, 24.10.2001, 1 BvR 1190/90, NJW 2002, S. 1031, 1032 - Strafbarkeit von Blockadeaktionen.

322 BVerfG, 26.6.1990, 1 BvR 776/84, NJW 1991, S.91, 92 - Fall Schubart; so in der Literatur auch bei BeckOK GG/Schneider, Art. 8, Rn. 38; Isensee/Kirchhof/Schmidt-Jortzig, HStR VII, $\mathbb{1 6 2}$, Rn. 47, der von einer „Idealkonkurrenz“ spricht.

323 BVerfG, 14.5.1985, 1 BvR 233/81, 1 BvR 341/81, NJW 1985, S. 2395 - Brokdorf; ähnlich auch bei BVerfG, 26.6.1990, 1 BvR 776/84, NJW 1991, S.91, 92 - Fall Schubart.

324 So die Meinung des BVerfG darstellend Isensee/Kirchhof/Schmidt-Jortzig, HStR VII, $\mathbb{1} 162, \mathrm{Rn} .47$.

325 Mangoldt/Klein/Starck/Starck/Paulus, GG, Art. 5, Rn. 412. 
Gewalt einen weiten Einschätzungs-, und Wertungs- und Gestaltungsspielraum, welcher die Berücksichtigung konkurrierender öffentlicher und privater Interessen erlaubt. ${ }^{326}$ Der grundrechtliche Anspruch auf eine solche Schutzpflicht ist unter Berücksichtigung des genannten Gestaltungsspielraums nur verletzt, wenn überhaupt keine Schutzvorkehrungen getroffen wurden oder die Maßnahmen gänzlich ungeeignet oder unzulänglich sind. ${ }^{327}$

\section{E. Das künstlerische Politsatire-Plakat und seine Grenzen}

Dass auch gerade das satirische Plakat nicht grenzenlos geschützt wird, ist leicht ersichtlich. Schon die angeführten Grundrechte bestehen nicht grenzenlos. Daher sollen zunächst die Beschränkungen der im Schutzbereich bereits besprochenen Grundrechte und anschließend die Abwägung der kollidierenden Rechtsgüter im Allgemeinen und in Bezug auf die Satire angerissen werden, bevor letztlich die herausgearbeiteten Kriterien zur Auslegung der Satire zusammengefasst werden. Der grundlegende Anknüpfungspunkt für diese Ausführungen bleibt - wie zu den Fragen des Schutzbereichs - die verfassungsrechtliche Rechtsprechung.

\section{Die Schranken und Schranken-Schranken der Satire im Allgemeinen}

Die im Schutzbereich schon besprochenen Grundrechte bestehen längst nicht schrankenlos: Das Kommunikationsgrundrecht findet seine Schranken in der sogenannten Schrankentrias des Art. 5 Abs. 2 GG bestehend aus den allgemeinen Gesetzen, den Bestimmungen zum Jugendschutz und aus dem Schutz der persönlichen Ehre. Darüber hinaus regelt der Art. 5 Abs. 1 S. 3 GG als Schranken-Schranke das Zensurverbot.

326 BVerfG, 29.10.1987, 2 BvR 624/83, NJW 1988, S. 1651, 1653 - Lagerung chemischer Waffen.

327 BVerfG, ebd. 


\section{Das Zensurverbot des Art. 5 Abs. 1 S. 3 GG}

Mit Art. 5 Abs. 1 S. 3 GG sieht das Grundgesetz als Schranken-Schranke 328 das absolute Verbot eine Zensur vor. Die Verfassung geht bei ihrem Zensur-Verständnis von einer präventiven Zensur aus. Darunter werden Handlungen verstanden, die in der Form zensierend wirken, indem sie Herstellung oder Verbreitung eines Geisteswerkes, insbesondere durch behördliche Vorprüfung und Genehmigung seines Inhalts, beschränken. ${ }^{329}$ In der gesellschaftlichen Diskussion wird häufig bei jeglichen Formen von Beschränkungen der Vorwurf der Zensur erhoben. ${ }^{330}$ Die „Nachzensur ist hingegen durchaus möglich und lässt sich im Rahmen des gerichtlichen Verfahrens überprüfen. Mit anderen Worten wird damit ein präventives Polizeiregime durch ein repressives Gerichtsregime ersetzt. " ${ }^{331}$ Das verfassungsrechtliche Zensurverbot richtet sich jedoch nur gegen die staatliche Gewalt und entfaltet gerade keine Drittwirkung gegenüber Privatpersonen. ${ }^{332} \mathrm{Da}$ es ein absolutes Zensurverbot ist, kann es auch keine Ausnahmen über die allgemeinen Gesetze oder die Gesetze zum Schutze der Jugend und der Ehre des Art. 5 Abs. 2 GG geben.

\section{Die allgemeinen Gesetze und der Ehrschutz nach Art. 5 Abs. 2 GG}

Die allgemeinen Gesetze nach Art. 5 Abs. 2 GG meinen alle Gesetze, die nicht im Speziellen darauf gerichtet sind, eine Meinung als solche zu verbieten oder sich gegen die Äußerung einer Meinung zu richten. ${ }^{333}$ „Die gegenseitige Beziehung zwischen Grundrecht und ,allgemeinem Gesetz ${ }^{6}$ ist also nicht als einseitige Beschränkung der Geltungskraft des Grundrechts durch die ,allgemeinen Gesetze' aufzufassen; es findet vielmehr eine Wechselwirkung in dem Sinne statt, dass die ,allgemeinen Gesetze ${ }^{6}$ zwar dem Wortlaut nach dem Grundrecht Schranken setzen, ihrerseits aber aus der Erkenntnis der wertsetzenden Bedeutung dieses Grundrechts im freiheit-

328 Auf den dogmatischen Streit, ob es sich bei Art. 5 Abs. 1 S. 3 GG um eine Schranken-Schranke oder ein eigenständiges Grundrecht handeln soll, wird mangels inhaltlicher Relevanz im Rahmen dieser Arbeit verzichtet.

329 BVerfG, 25.4.1972, 1 BvL 13/67, NJW 1972, S. 1934, 1937 - Zensur.

330 So auch von Klaus Staeck selbst, siehe dazu Kap. 5, E., I, 10.

331 Mangoldt/Klein/Starck/Starck/Paulus, GG, Art. 5, Rn. 261.

332 hM vgl. nur BeckOK GG/Schemmer, Art. 5, Rn. 117.

333 Konstante verfassungsrechtliche Rechtsprechung vgl. grundlegend BVerfG, 15.1.1958, 1 BvR 400/51, NJW 1958, S. 257, 258 - Lüth. 
lichen demokratischen Staat ausgelegt und so in ihrer, das Grundrecht begrenzenden Wirkung selbst wieder eingeschränkt werden müssen. “334 Dieser als Wechselwirkungslehre benannte Grundsatz ist ein besonderer Ausdruck des Verhältnismäßigkeitsgrundsatzes. ${ }^{335}$

Das BVerfG hat deutlich gemacht, dass den Schranken des Ehren- und Jugendschutzes keine eigenständige Bedeutung zukommt, da sie in den allgemeinen Gesetzen aufgehen. ${ }^{336}$ Auch unter Bezugnahme historischer Argumente legt das Gericht dar, dass mit dem Jugend- und Ehrenschutz lediglich sichergestellt werden sollte, „dass solche Vorschriften weiterhin zulässig sind." ${ }^{337}$ Der Begriff der persönlichen Ehre ist schwer zugänglich und es fehlt eine eingängige Definition. Das BVerfG sieht die persönliche Ehre jedoch als ein Schutzgut des allgemeinen Persönlichkeitsrechts. ${ }^{338}$

Mit dem Erfordernis des Gesetzesvorbehalts für Eingriffe in die persönliche Ehre lässt sich der Begriff der persönlichen Ehre mittelbar durch einfachgesetzliche Ausgestaltung im Straf- und Zivilrecht mit der entsprechenden Rechtsprechung etwas abstecken. ${ }^{339}$

Die typischen einfachrechtlichen Grenzen der Satire liegen im strafrechtlichen Ehrschutz, der in den Beleidigungsdelikten der $\$ \$ 185 \mathrm{ff}$. StGB geregelt ist, in der Volksverhetzung nach $\$ 130$ StGB, der Religionsbeschimpfung nach $\mathbb{1} 166 \mathrm{StGB}$, der Verunglimpfung des Staates und seiner Symbole ( $\mathbb{S} 90$ a StGB) oder im Verwenden von Kennzeichen verfassungswidriger Organisationen ( $\$ 86$ a StGB). ${ }^{340}$ Eine Grenze findet sich auch im allgemeinen Persönlichkeitsrechts (Art. 2 Abs. 1, Art. 1 Abs. 1 GG), das als sonstiges Recht im Sinne des $₫ 823$ I BGB (i.V.m. $\$ 1004$ BGB) auch eine zivilrechtliche Absicherung findet. Eine sondergesetzliche Normierung des allgemeinen Persönlichkeitsrechts findet sich im Recht am eigenen Bild als ein besonderes Persönlichkeitsrecht in den $\$ \mathbb{\$} 22,23$ KUG. ${ }^{341}$

334 Seit BVerfG, ebd. ständige Rechtsprechung. Sich gegen die Wechselwirkungstheorie wegen überflüssiger Wiederholung der im Grundgesetz sowieso schon angelegten Garantien des BVerfG aussprechend Isensee/Kirchhof/Schmidt-Jort$z i g$, HStR VII, $\$ 162$, Rn. 54.

335 Maunz/Dürig/Grabenwarter, GG, Art. 5, Rn. 139. Auf die Kritik bzgl. der Wechselwirkungslehre wird hier verzichtet siehe dazu m.w.N. Maunz/Dürig/Grabenwarter, GG, Art. 5, Rn. 147.

336 Vgl. BVerfG, 4.11.2009, 1 BvR 2150/08, NJW 2010, S. 47, 51, Rn. 63 - Wunsiedel mwN.; Maunz/Dürig/Grabenwarter, GG, Art. 5, Rn. 195 m.w.N.

337 BVerfG, ebd.

338 BVerfG, 25.10.2005, 1 BvR 1696/98, NJW 2006, S. 207, 208 - Stolpe m.w.N.

339 Maunz/Dürig/Grabenwarter, GG, Art. 5, Rn. 199 m.w.N.

340 Siehe dazu ausführlich Gärtner, Was die Satire darf, 2009, S. 196-262.

341 Dazu ausführlicher unter Kap. 5, B., III, 5, Exkurs. 
Da sich das Erfordernis der Allgemeinheit meinungsbeschränkender Gesetze auch auf die Bestimmungen zum Ehrenschutz erstreckt, ${ }^{342}$ sind auch für die straf- und zivilrechtlichen Vorschriften die Wechselwirkungen mit dem eingeschränkten Grundrecht der Meinungsfreiheit sowohl auf der Ebene der Auslegung als auch der Anwendung zu beachten. ${ }^{343}$

\section{Die Schranken der Kunstfreiheit}

Für die Kunstfreiheit verbietet sich aus zwingend systematischen sowie entstehungsgeschichtlichen Gründen eine direkte oder analoge Anwendung der Schranken aus Art. 5 Abs. 2 GG oder sonstiger Schrankenregelungen anderer Verfassungsbestimmungen. ${ }^{344}$ Diese vorbehaltlose Stellung der Wissenschaft, Forschung und Kunst im dritten Absatz ist auch historisch zu erklären. Es liegt an der in ihrer Grausamkeit alleinstehenden Vergangenheit der Deutschen zur Zeit des Nationalsozialismus, dass die Verfassung von 1949 bewusst politisch-ideologische Abhängigkeiten vermeiden wollte. Deshalb sind auch Kunst und Künstler in ihrer Freiheit besonders zu schützen. Damit ist aber insofern keine schrankenlose Gewährleistung zu verstehen, vielmehr ist „ein im Rahmen der Kunstfreiheitsgarantie zu berücksichtigender Konflikt [...] nach Maßgabe der grundgesetzlichen Wertordnung und unter Berücksichtigung der Einheit dieses grundlegenden Wertsystems durch Verfassungsauslegung zu lösen. “" ${ }^{435}$ Der für die Satire typische Fall der Kollision zwischen Meinungsfreiheit und dem Persönlichkeitsschutz ergibt sich ebenso in Bezug auf die Kunstfreiheitsgarantie. Im Rahmen der Abwägung im Einzelfall bedarf es jedoch der Berücksichtigung des Kunstspezifischen. ${ }^{346}$

342 BVerfG, 4.11.2009, 1 BvR 2150/08, NJW 2010, S. 47, 51, Rn. 63 - Wunsiedel.

343 Maunz/Dürig/Grabenwarter, GG, Art. 5, Rn. 199 m.w.N.

$344 \mathrm{hM}$ und ständige Rechtsprechung vgl. dazu ausführlich BVerfG, 24.2.1971, 1 BvR 435/68, GRUR 1971, S. 461, 464 - Mephisto.

345 BVerfG, ebd.

346 BVerfG, ebd., S. 461, 465 - Mephisto. 


\section{Die absoluten Grenzen}

\section{Schmähkritik und Formalbeleidigungen}

Das aus Art. 2 Abs. 1 i.V.m. Art. 1 Abs. 1 GG abgeleitete allgemeine Persönlichkeitsrecht zeigt bereits in seiner dogmatischen Herleitung ganz deutlich, wann die Meinungsfreiheit spätestens zurückstecken muss: bei der Würde des Menschen. Hinzunehmen sind dementsprechend durchaus der Sachverhalt von Polemik, von zugespitzter Äußerung und - sicherlich auch bis zu einem gewissen Grad - von Beleidigung. Eine Ausprägung der Grenze lässt sich in der Schmähkritik und Formalbeleidigung finden. ${ }^{347}$

Eine Schmähkritik liegt vor, wenn die Äußerung, sei sie satirisch, künstlerisch oder nicht, den tiefsten Kern des Persönlichkeitsschutzes, namentlich die Menschenwürde verletzt. Das Persönlichkeitsrecht basiert grundrechtlich auf dem sogenannten, mittlerweile unstrittig anerkannten, allgemeinen Persönlichkeitsrecht, welches dogmatisch aus Art. 2 Abs. 1 i.V.m. Art. 1 Abs. 1 GG hergeleitet wird. Es sei angemerkt, dass nicht nur das allgemeine Persönlichkeitsrecht, sondern alle Grundrechte auf dem Prinzip der Menschenwürde fußen und dieses konkretisieren. Doch durch seine grundlegende Nähe zum vorbehaltlos gewährten Recht auf Menschenwürde, dem „Höchstwert des Verfassungsrechts“348, stellt jeder Angriff, der diesen Kern berührt, die Grenze der zulässigen Äußerung dar. Es bedarf damit immer „einer sorgfältigen Begründung, wenn angenommen werden soll, dass der Gebrauch eines Grundrechts auf die unantastbare Menschenwürde durchschlägt. “349 Äußerungen, die die Qualität eines Angriffs auf den unantastbaren Kern der Menschenwürde haben, werden dann unter den Begriffen der Schmähkritik und der Formalbeleidigung gefasst.

Bezeichnendes Merkmal der Formalbeleidigung ist es, wenn ein sachliches Anliegen völlig in den Hintergrund tritt, wohingegen die persönliche Kränkung in den Vordergrund tritt und sie sich so durch Gehässigkeit

347 BVerfG, 25.2.1993, 1 BvR 151/93, NJW 1993, S. 1462 - Böll; BVerfG, 16.6.1990, 1 BvR 1165/89, NJW 1991, S.95, 96 - postmortale Schmähkritik; BVerfG, 10.10.1995, 1 BvR 1476/91, 1 BvR 1980/91, 1 BvR 102/92, 1 BvR 221/92, NJW 1995, S. 3303, 3304 - Soldaten sind Mörder; BVerfG, 29.7.2003, 1 BvR 2145/02, NJW 2003, S.3760; BVerfG, 8.2.2017, 1 BvR 2973/14, NJW 2017, S. 1460 f. Obergauleiter der SA-Horden.

348 Di Fabio, JZ 2004, S. 1, 5.

349 BVerfG, 10.10.1995, 1 BvR 1476/91, 1 BvR 1980/91, 1 BvR 102/92, 1 BvR 221/92, NJW 1995, S. 3303, 3304 - Soldaten sind Mörder. 
und Böswilligkeit auszeichnet. ${ }^{350}$ Unter den Begriff der Formalbeleidigung fallen alle Schimpfwörter, beleidigende Vergleiche oder vergleichbare Äußerungen, bei denen auch jedes sachliche Anliegen in den Hintergrund rückt, doch im Gegensatz zur Schmähkritik äußert sich das sogar so offensichtlich, dass sich die Frage des Sachbezugs gar nicht ernsthaft stellt. ${ }^{351}$ In diesem Sinne gibt es keinen darüber hinausgehenden Grund zwischen Schmähkritik und Formalbeleidigung zu unterscheiden.

Rechtsdogmatisch ist teilweise umstritten, ob die Schmähkritik überhaupt vom Schutzbereich der Meinungsfreiheit erfasst wird. Damit stellt sich die Frage, ob es sich um eine Begrenzung des Schutzbereichs handelt oder ob die Schmähkritik erst im Rahmen der Abwägung kollidierender Verfassungsgüter relevant wird. Eindeutig ist zunächst nur, dass die Schmähkritik eine Ausnahme darstellt und damit eng auszulegen ist. ${ }^{352}$ Bei Äußerungen, die als eine Schmähkritik einzuordnen sind, tritt nach einer häufig vertretenen Meinung in der Literatur der Ehr- und Persönlichkeitsschutz vor die Meinungsfreiheit. ${ }^{353}$ Dies ließe sich so verstehen, dass es zu dieser Regelwirkung eine Ausnahme gäbe, so dass es letztlich doch zu einer Abwägung zwischen Persönlichkeitsrecht und Meinungsfreiheit kommen könnte. Das BVerfG macht deutlich, dass die Qualifikation einer Äußerung als Schmähkritik auf jeden Fall zu einem Verzicht auf eine Abwägung zwischen Meinungsfreiheit und Ehrschutz führt. ${ }^{354}$ Wegen der eindeutigen und heftigen Folge einer solchen Qualifikation gilt es regelmäßig den Anlass und den Kontext der Äußerung zu berücksichtigen. ${ }^{355}$ Die Diffamierung muss dann im Vordergrund stehen.

350 BVerfG, 28.7.2014, 1 BvR 482/13, ZUM 2014, S. 965, 966.

351 Vgl. Gärtner, Was die Satire darf, 2009, S. 210. Als insofern demütigend wird der Begriff „Krüppel“ vom BVerfG verstanden, BVerfG, 25.3.1992, 1 BvR 514/90, GRUR 1992, S. 471, 472 - geb. Mörder.

352 BVerfG, 14.6.2019, 1 BvR 2433/17, NJW 2019, 2600, Rn.18; BVerfG, 10.10.1995, 1 BvR 1476/91, 1 BvR 1980/91, 1 BvR 102/92, 1 BvR 221/92, NJW 1995, S. 3303 - Soldaten sind Mörder.

353 Maunz/Dürig/Grabenwarter, Art. 5, Rn. 163; Müller-Riemenschneider, Pressefreiheit und Persönlichkeitsschutz, 2013, S. 81; Rühl, Tatsachen - Interpretationen - Wertungen: Grundfragen einer anwendungsorientierten Grundrechtsdogmatik, 1998, S. 318.

354 Vgl. m.w.N. BVerfG, 14.6.2019, 1 BvR 2433/17, NJW 2019, S. 2600.

355 BVerfG, 14.6.2019, 1 BvR 2433/17, NJW 2019, S. 2600, Rn. 18; BVerfG, 23.8.2005, 1 BvR 1917/04, NJW 2005, S. 3274 - Anspielung auf NS-Zeit; BVerfG, 10.10.1995, 1 BvR 1476/91, 1 BvR 1980/91, 1 BvR 102/92, 1 BvR 221/92, NJW 1995, S. 3303 - Soldaten sind Mörder. 
Ein zum Teil schon selbst im Beschwerdeverfahren revidierter Beschluss des Landgerichts Berlin von 2019 in Bezug auf die Grünen-Politikerin Renate Künast führte - milde ausgedrückt - zu großer Verwunderung. Danach wurden offensichtlich entwürdigende Äußerungen nicht als Formalbeleidigungen oder Schmähkritik verstanden, da sie für die Berliner Richter in einem unmittelbaren Zusammenhang mit einer Äußerung der Politikerin standen, die im Rahmen einer Pädophilie-Debatte von 1986 erfolgt war. ${ }^{356}$

In Bezug auf die Satire oder gar das satirische Plakat gäbe es in der Rechtspraxis - so wird es zuweilen konstatiert - kaum Fälle der reinen Schmähkritik und Formalbeleidigung. ${ }^{357}$ Der Fall des Satirikers Jan Böhmermann zu seinem sogenannten „Schmähgedicht" über den türkischen Präsidenten Erdoğan mag dazu eine Ausnahme darstellen. ${ }^{358}$

\section{Angriff auf die Menschenwürde}

Unabhängig von den Fällen der Schmähkritik und der Formalbeleidigung sind auch Fälle denkbar, in denen in sonstiger Weise die Menschenwürde durch Äußerungen angegriffen wird. Nach ständiger Rechtsprechung und herrschender Meinung wird die Objektformel verwendet. Danach widerspricht es der menschlichen Würde, den Menschen zum bloßen Objekt zu machen, ${ }^{359}$ d.h. der Mensch ist vor Angriffen der Würde wie Erniedrigung, Brandmarkung, Verfolgung, Ächtung usw. zu schützen. ${ }^{360}$ Zum Kern der privaten Lebensführung gehört als Teil des Intimlebens die Darstellung sexuellen Verhaltens, wenn diese geeignet ist, den Betroffenen in seiner Person zu entwerten und ihm so die Würde als Mensch abzusprechen. ${ }^{361}$ So begründete das Gericht 1987 die Entscheidung zu einer Karikatur Rainer Hachfelds, die den damaligen CSU-Politiker Franz Josef Strauß als ein

$356 \mathrm{Zu}$ den Äußerungen, die nicht beanstandet wurden, gehörten „Stück Scheisse“, „Krank im Kopf“", „altes grünes Drecksschwein“, „Geisteskrank“, „kranke Frau“, „Schlampe“, „Gehirn Amputiert“, „Drecks Fotze“, „Sondermüll“, „Alte perverse Dreckssau“, „hohle Nuss“. LG Berlin, 9.9.2019, 27 AR 17/19, MMR 2019, S. 754.

357 Gounalakis, NJW 1995, S. 809, 816; Kassing, Ehrverletzende Personalsatire, 2004, S. 245; Gärtner, Was die Satire darf, 2009, S. 210.

$358 \mathrm{Zu}$ diesem Gedicht wird gesondert unter Kap. 6, A., II., 1. eingegangen.

359 Vgl. nur BVerfG, 21.6.1977, 1 BvL 14/76, NJW 1977, S. 1525, 1526.

360 BVerfG, 12.12.2000, 1 BvR 1762/95, 1 BvR 1787/95, GRUR 2001, S. 170, 174 Benetton-Werbung m.w.N.

361 BVerfG, 3.6.1987, 1 BvR 313/85, NJW 1987, S. 2661, 2662 - Strauß-Karikaturen. 
Schwein darstellt, das ein anderes Schwein in Richterrobe begattet, mit dem Tatbestand der Verletzung der Menschenwürde. ${ }^{362}$

III. Die (satirische) Äußerung in Abwägung mit dem Persönlichkeitsrecht

Letztlich müssen im Falle der Kollision die widerstreitenden Grundrechtspositionen des allgemeine Persönlichkeitsrechts Art. 2 Abs. 1, Art. 1 Abs. 1 GG und der Meinungsfreiheit aus Art. 5 Abs. 1 GG nach dem Prinzip der praktischen Konkordanz zu einem angemessenen Ausgleich gebracht werden. Auch eine Verhandlung der Satire unter der Kunstfreiheit muss dann zu einer Abwägung des Art. 5 Abs. 3 GG mit dem allgemeinen Persönlichkeitsrecht des Betroffenen führen.

Über die Zeit der äußerungsrechtlichen Rechtsprechung hat das BVerfG Leitlinien für die Abwägung im Falle des Konflikts zwischen Meinungsäußerung und Persönlichkeitsrecht herausgebildet. Auch im Rahmen dieser Entscheidungen überprüft das BVerfG die vorhergehenden Urteile der Gerichte nur auf die Verletzung spezifischen Verfassungsrechts, d.h. ob die Gestaltung des Verfahrens, die Feststellung und Würdigung des Tatbestandes, die Auslegung des einfachen Rechts und seine Anwendung auf den Einzelfall prinzipiell den dafür zuständigen Fachgerichten zustehen und einer etwaigen Nachprüfung durch das BVerfG entzogen sind. In den Fällen zur Meinungsfreiheit ist eine solche Verletzung spezifischen Verfassungsrechts aber bereits dann gegeben, wenn einer der drei folgenden Szenarien vorliegt: Erstens wenn die Gerichte ihrer Beurteilung eine Äußerung zugrunde legen, die nicht so gefallen ist, zweitens wenn die Gerichte der betreffenden Äußerung einen Sinn geben, den sie nach dem festgestellten Wortlaut objektiv nicht hat, oder drittens wenn sich unter mehreren objektiv möglichen Deutungen für eine entschieden wurde, ohne die anderen unter Angabe überzeugender Gründe auszuschließen. ${ }^{363}$ Daraus folgt, dass die Deutung der in Frage stehenden Äußerung maßgeblich ist, wofür das Verständnis eines unvoreingenommenen und verständigen Durchschnittspublikums zugrunde gelegt wird. ${ }^{364}$ Erst wenn der Sinn

362 BVerfG, ebd. Die Karikaturen wurden unter dem Grundrecht der Kunstfreiheit und nicht der Meinungsfreiheit verhandelt.

363 Ständige Rechtsprechung siehe unter vielen m.w.N. BVerfG, 8.7.1993, 2 BvR 1576/92, NJW 1994, S. 1149 f.; vgl. auch BVerfG, 12.12.2000, 1 BvR 1762/95, 1 BvR 1787/95, GRUR 2001, S. 170, 174 - Benetton-Werbung m.w.N.

364 Ständige Rechtsprechung siehe unter vielen m.w.N. BVerfG, 25.10.2005, 1 BvR 1696/98, NJW 2006, S. 207, 208 - Stolpe. 
der Äußerung gedeutet wurde, stellt sich die Frage nach der Abwägung und somit nach dem Ausgleich zwischen den beiden grundrechtlich verbürgten Rechtsgütern. Dies erfolgt nach den Grundsätzen der praktischen Konkordanz, „kollidierende Grundrechtspositionen [...] in ihrer Wechselwirkung zu erfassen und [... so in Ausgleich zu bringen [sind], dass sie für alle Beteiligten möglichst weitgehend wirksam werden". 365 Die vom BVerfG herausgearbeiteten Abwägungs- und Kollisionsregeln seien im Folgenden vorgestellt.

\section{Vermutungsregel bei Beiträgen zur öffentlichen Meinungsbildung}

Wie bereits herausgearbeitet kommt der Meinungsfreiheit wegen ihrer grundlegenden Bedeutung für die politische Meinungsbildung und somit für die demokratische Teilhabe und Ordnung ein ganz besonderer Schutz zu. Das BVerfG hat deutlich gemacht, dass der Persönlichkeitsrechtschutz in Bezug auf Meinungen in einer die Öffentlichkeit berührenden Frage zurückzutreten hat. ${ }^{366}$ Es wird insofern von einer Vermutung für die $\mathrm{Zu}$ lässigkeit der freien Rede, sofern es sich um einen Beitrag zur öffentlichen Meinungsbildung handelt, ausgegangen. ${ }^{367}$ Ein solcher Beitrag liegt vor allem dann vor, wenn es sich um Äußerungen im politischen Wahlkampf handelt, denn gerade in diesem ist „der politische Meinungskampf auf das Höchste intensiviert“. ${ }^{368}$ In Bezug auf politische Parteien gilt diese Vermutungsregel in besonderem Maße, so dass sogar scharfe, auch wenn für den politischen Meinungskampf nicht ungewöhnliche Polemik hinzunehmen ist, gerade weil eine politische Partei die Möglichkeit hat, „sich politisch

365 Zit. nach BVerfG, 23.10.2013, 1 BvR 1842/11, 1 BvR 1843/11, NJW 2014, S. 46, 47 m.w.N.; ständige Rechtsprechung seit BVerfG, 26.5.1970, 1 BvR 83, 244, 345/69, NJW 1970, S. 1729, 1730.

366 Ständige Rechtsprechung siehe BVerfG, 15.1.1958, 1 BvR 400/51, GRUR 1958, S. 254, 255 - Lüth; BVerfG, 15. 1. 1958, 1 BvR 400/57, NJW 1958, S. 257, 258; BVerfG, 22.6.1982, 1 BvR 1376/79, NJW 1983, S. 1415 - CSU NPD Europas; BVerfG, 10.10.1995, 1 BvR 1476/91, 1 BvR 1980/91, 1 BvR 102/92, 1 BvR 221/92, NJW 1995, S. 3303, 3305 - Soldaten sind Mörder; BVerfG, 4.11.2009, 1 BvR 2150/0, NJW 2010, S. 47, 55 - Wunsiedel.

367 Diejenigen die die Vermutungsregel ablehnen, können mit ihren Argumenten nicht überzeugen. Die Sorge aus den 1990er Jahren, dass der Ehrschutz zugunsten der Meinungsfreiheit "geopfert" werde (so Ossenbühl, ZUM 1999, S. 505, 508), hat sich nicht bewahrheitet. Siehe auch Gärtner, Was die Satire darf, 2009, S. $214 \mathrm{f}$.

368 BVerfG, 5.4.2001, 1 BvR 932/94, NJW, S. 2957, 2959 - Wilhelm Kaisen. 
zu wehren“. ${ }^{369}$ Der Öffentlichkeitsbezug als notwendiges Merkmal, damit die Vermutungsregel zugunsten der Meinungsfreiheit Wirkung entfaltet, ist gerade im Rahmen der Satire regelmäßig gegeben. Es ist der Satire wesenstypisch, solche Themen als Gegenstand ihres Angriffs zu behandeln. Folgerichtig muss diese Vermutungsregelung auch in Bezug auf satirische Äußerungen im Allgemeinen und im Konkreten für das künstlerische Politsatire-Plakat Anwendung finden. Auch die Plakate Klaus Staecks - dies sei schon vorweggenommen - behandeln gesamtgesellschaftlich relevante Themen wie die Umweltverschmutzung, Gleichberechtigung von Mann und Frau, Friedenspolitik oder Systemfragen bzgl. des sozialen Ungleichgewichts. ${ }^{370}$

\section{Rede und Gegenrede, das Recht auf Gegenschlag}

Das Recht auf Gegenschlag basiert auf dem Grundgedanken von Rede und Gegenrede. Demnach wird davon ausgegangen, dass derjenige, der selbst im Rahmen des öffentlichen Meinungskampfes ein abwertendes Urteil geäußert hat, auch eine mindestens ebenso abwertende bzw. scharfe Gegenreaktion ertragen muss, da er sie ja selbst veranlasst hat. ${ }^{371}$ Zugrunde gelegt wird die Überlegung, dass ein Vorverhalten des Betroffenen nicht außer Acht gelassen werden darf. Diese Verknüpfung von Anlass bzw. Aktion und Reaktion in einem schwebenden Meinungskampf ist aber nicht nur auf gegenseitige Beleidigungen beschränkt, sondern umfasst vielerlei einprägsame oder sonstige starke Formulierungen, die das Ansehen mindern können. ${ }^{372}$ Ferner kann auch die Form der Meinungsäußerung relevant sein. Die freie Rede, also das gesprochene Wort, zeichnet sich durch Schnelligkeit und Spontanität aus. Gerade in der Situation der freien Rede und Gegenrede müssen auch Schärfen, Herabsetzungen und Übersteigerungen hinzunehmen sein, auch wenn diese nicht zu einer sach-

369 BVerfG, 22.6.1982, 1 BvR 1376/79, NJW 1983, S. 1415, 1417 - CSU NPD Europas;

370 Vgl. Kap. 4 und 5.

371 Ständige Rechtsprechung und absolut hM siehe beispielsweise BVerfG, 25.1.1961, 1 BvR 9/57, NJW 1961, S. 819, 822 - Schmid-Spiegel; BVerfG, 6.11.1968, 1 BvR 501/62, NJW 1969, S. 227, 228 - GEMA; BVerfG, 13.5.1980, 1 BvR 103/77, NJW 1980, S. 2069, 270 - Kunstkritik; BVerfG, 25.1.1984, 1 BvR 272/81, NJW 1984, S. 1741, 1746 - Springer/Wallraff; Epping/Hillgruber/Schemmer, Art. 5, Rn. 120.

372 BVerfG, 6.11.1968, 1 BvR 501/62, NJW 1969, S. 227, 228 - GEMA. 
gemäßen Meinungsbildung beitragen können. ${ }^{373}$ Wäre dem nicht so, wäre die Gefahr eines sogenannten "chilling effects“ in der freien Rede wohl nicht mehr zu leugnen. Das Konzept des Rechts auf Gegenschlag ist weder auf den Fall einer hitzigen Diskussion zwischen zwei Parteien noch auf einen persönlichen Angriff begrenzt. Als Beispielsüberlegung sei der Fall zu nennen, in dem ein Politiker scharf kritisiert wird. Das Recht auf Gegenschlag bezieht sich eben dann nicht nur auf die Person des Politikers, oder Mitglieder seiner Partei, sondern auf alle Personen, die sich in den Grenzen dieses Kontexts zu einer Gegenreaktion veranlasst sehen. ${ }^{374}$

Ferner dürfen auch an die Gegenrede keine erhöhten Anforderungen gestellt werden, vor allem muss die Äußerung nicht zur Wiederherstellung der Ehre „unbedingt erforderlich“ sein. ${ }^{375}$

Das Konzept auf Rede und Gegenrede spielt - auch wenn nicht immer als solches bezeichnet - im Bereich der satirischen Äußerung eine nicht zu vernachlässigende Rolle, da satirische Äußerungen häufig eine Reaktion auf eine zuvor gefallene Äußerung sein können. Gärtner sieht z.B. bei Werbesatiren die satirisch aufgearbeitete Werbung als „die den Gegenschlag provozierende Aussage ". ${ }^{376}$ Aber auch andersherum muss sich der Satiriker die Gegenrede gefallen lassen, zumal Satiren besonders scharf in ihrer Aussage sein können. ${ }^{377}$ Das Rede und Gegenrede dabei nicht in der gleichen Form zu erfolgen haben, ist einleuchtend, sonst müsste der Musikkritiker selbst Musik machen, und der Plakat-Satiriker dürfte selbst nur auf satirische Plakate reagieren sowie der Kritiker eines Plakat-Satirikers nur mit satirischen Plakaten. ${ }^{378}$

373 Vgl. BVerfG, 13.5.1980, 1 BvR 103/77, NJW 1980, S. 2069, 2070 - Kunstkritik.

374 Vgl. dazu hier auch Kap. 5, C., I.

375 BVerfG, 25.1.1961, 1 BvR 9/57, NJW 1961, S. 819, 821 - Schmid-Spiegel.

376 Gärtner, Was die Satire darf, 2009, S. 219.

377 Vgl. dazu hier auch Kap. 5, C., I.

378 Wie schon mehrfach deutlich gemacht wurde, steht dem auch nicht die Hachfeld-Entscheidung entgegen, auch wenn es dort heißt: „Soweit sich der Bf. auf das für die Presse- und Meinungsäußerungsfreiheit entwickelte "Recht zum Gegenschlag” beruft [...] verkennt er bereits, dass sich der Bayerische Ministerpräsident ihm gegenüber nicht einer den Karikaturen vergleichbaren Sprache bedient hat." Hier ist nicht kontextlos auf die „vergleichbare Sprache“ abzuzielen, sondern wie das Gericht anschließend verdeutlicht, dass „der Umstand, dass dieser ein im Kreuzfeuer des öffentlichen Meinungskampfes stehender Politiker ist, $[\ldots]$ ihn nicht seiner personalen Würde [entkleidet] und [...] derartige Ehrverletzungen auch nicht unter Berufung auf die Freiheit der Kunst [rechtfertigt].“ BVerfG, 3.6.1987, 1 BvR 313/85, NJW 1987, S.2661, 2662 Strauß-Karikaturen. 


\section{Erhöhte Schwelle durch die Idee der Reizüberflutung}

$\mathrm{Da}$ jede Meinungsäußerung darauf ausgerichtet ist, Aufmerksamkeit zu erregen, wird gerade wegen der Reizüberflutung der heutigen Medienzeit davon ausgegangen, dass starke Formulierungen hinzunehmen sind. ${ }^{379}$ Diese Ausführung des BVerfG wird unter dem Stichwort der Reizüberflutung kontrovers rezipiert und diskutiert. ${ }^{380}$ So wurde das Argument stark gemacht, dass es mit diesem Konzept „zu einer ins Grenzenlose gesteigerten Verrohung der Sprache“"381 käme und lediglich zu einer Eskalation führe. ${ }^{382}$ Es sollte beachtet werden, dass der Beschluss, der die Überlegung der Reizüberflutung ins Spiel brachte, aus dem Jahr 1968 stammt. In Zeiten einer quantitativ betrachtet durch das Internet viel größeren Verbreitung der Massenmedien muss diese Idee der Reizüberflutung doch erst recht Anwendung finden.

\section{Die Sphärentheorie}

Das BVerfG hat auch die sogenannte Sphärentheorie entwickelt. Diese baut auf dem Gedanken auf, dass das allgemeine Persönlichkeitsrecht mit seiner Verankerung in Art. 2 Abs. 1 i.V.m. Art. 1 Abs. 1 GG durch seine Nähe zur unantastbaren Menschenwürde einer besonderen Rechtfertigung bedarf, wobei der Kernbereich privater Lebensführung sogar als unantastbar angesehen wird. ${ }^{383}$ Dieser wird im Rahmen der Theorie als die Intimsphäre bezeichnet, in die ein Eingriff niemals zu rechtfertigen ist. Doch wird auch diese Sphäre nur in äußersten Fällen angenommen. Mit sicherlich denkbaren Ausnahmen gehört die Sexualität grundsätzlich zu dem Kernbereich privater Lebensführung. Der rigide Umgang mit den Anwendungsfällen der Intimsphäre zeigt sich besonders an dem - wenn auch nicht unumstrittenen - Beispiel der persönlichen Tagebucheinträge. ${ }^{384}$ Denn letztlich schließt die Intimsphäre jeglichen Bezug zur Sozial- oder Privatsphäre aus.

379 BVerfG, 6.11.1968, 1 BvR 501/62, NJW 1969, S. 227, 228 - GEMA.

380 So beispielsweise Klass, Rechtliche Grenzen des Realitätsfernsehens, 2004, S. 299; Gärtner, Was die Satire darf, 2009, S. $221 \mathrm{f}$.

381 Kriele, NJW 1994, S. 1897, 1901.

382 Dazu kritisch Gärtner, Was die Satire darf, 2009, S. 222.

383 Maunz/Düring/Di Fabio, GG, Art. 2 I, Rn. 157. Siehe dazu schon in Bezug auf die Strauß-Karikaturen unter Kap. 3, E., II., 2.

384 Vgl. dazu BVerfG, 14.9.1090, 2 BvR 1062/87, NJW 1990, S. 563 f. - Tagebuch. 
Der Intimsphäre nachgelagert ist die Privatsphäre. Eingriffe in diese sind nicht ausgeschlossen, doch müssen für eine Rechtmäßigkeit des Eingriffs besondere Umstände vorliegen. Auf die Privatsphäre folgt die Sozialsphäre, an die bzgl. eines Eingriffs wiederum weniger strenge Voraussetzungen geknüpft werden. ${ }^{385}$ Diese Sphären besitzen aber keine starren Grenzen: Mag ein Sachverhalt erstmal eine Einordnung in die verschiedenen Sphären nahelegen, kann immer noch durch Kontext oder ggfs. den Inhalt ein anderes Ergebnis angebracht sein. Ferner sind die Grenzen fließend, weswegen eine Einordnung in die Sphären nicht von einer Einzelfallentscheidung befreit.

Letztlich folgt aus diesen Sphären, dass je näher in den Kernbereich privater Lebensführung eingegriffen wird, desto gewichtiger die Rechtfertigung ausfallen muss, bis zu dem Bereich, in dem eine Rechtfertigung wegen Art. 1 Abs. 1 GG nicht mehr möglich ist. Spiegelbildlich ergibt sich daraus, dass je weiter der Eingriff von dem Kernbereich der privaten Lebensführung entfernt ist, desto leichter dieser Eingriff gerechtfertigt werden kann.

\section{Schritt in die Öffentlichkeit}

Genauso wie im Rahmen des Rechts auf Gegenschlag auf das Vorverhalten abgestellt wird, ist es auch relevant, ob sich die betroffene Person bereits an die Öffentlichkeit gewandt hat. ${ }^{386}$ In der Kombination mit der Sphärentheorie ergibt sich daraus, dass auch Äußerungen oder satirische Darstellungen in Bezug auf das Privatleben zu rechtfertigen sind, wenn der Betroffene mit dieser Thematik zuvor selbst an die Öffentlichkeit getreten ist.

Aber auch Persönlichkeiten, die besonders in der Öffentlichkeit stehen und diese sich zu Nutze machen können, müssen herabsetzende Kritik aushalten, da sie mit einer größeren Reichweite auf solche Angriffe reagieren können. ${ }^{387}$ Daraus folgt die Überlegung, dass die Personen, die sich der Öffentlichkeit bedienen und von ihr profitieren, das Narrativ nicht mehr allein kontrollieren, sondern eben dann auch der, zum Teil sogar scharfen Kritik ausgesetzt sind. Selbstredend müssen die Grenzen der Privat-, jedoch spätestens der Intimsphäre geachtet werden.

385 Vgl. Maunz/Düring/Di Fabio, GG, Art. 2 I, Rn. 158-161.

386 Vgl. Götting/Schertz/Seitz/Hösch, Handbuch Persönlichkeitsrecht, $\$ 21$, Rn. 4.

387 Vgl. dazu Gärtner, Was die Satire darf, 2009, S. 217. 


\section{Rahmen der Äußerung}

Maßgeblich ist ferner in welchem Kontext die Äußerung getätigt wurde. Gerade bei künstlerischen Äußerungen kann wegen des Schutzes der Kunstfreiheit eine höhere Schwelle zu Gunsten der künstlerischen Aussage geboten sein. Diese Überlegung folgt aus Art. 5 Abs. 3 GG, wonach die Kunstfreiheit ohne ausdrückliche Schranke gewährleistet wird. ${ }^{388}$ Davon unberührt bleibt der Kernbereich des Persönlichkeitsrechts. Auch eine Aneinanderreihung von Schmähungen wird der Betroffene - mag die ÄuBerung auch unter die Kunstfreiheit fallen - nicht hinnehmen müssen. ${ }^{389}$

Es wird für den Betroffenen maßgeblich sein, in welcher Form und über welches Medium die satirische Äußerung verbreitet wird. Ob die satirische Äußerung im Rahmen beispielsweise einer Zeitschrift oder eines Fernsehformats mit einer entsprechend breiten Publikumswirkung verbreitet worden ist, oder ob es sich nur um eine private Äußerung handelt, macht demnach ebenso einen erheblichen Unterschied.

\section{Besonders schützenswerte Personen}

Unabhängig von den bisher genannten Punkten sind auch besonders schützenswerte Betroffenengruppen oder Situationen denkbar. Unabhängig vom Vorverhalten sind Minderjährige oder sonstige in der Geschäftsfähigkeit Beschränkte oder Unfähige zu schützen. Ausflüsse des Minderjährigenschutzes lassen sich in unterschiedlicher Weise im einfachen Recht wie im BGB wiederfinden. Auch im Rahmen der Abwägung im Äußerungsrecht ist auf besonders schützenswerte Personen zu achten.

388 Vgl. Götting/Schertz/Seitz/Hösch, Handbuch Persönlichkeitsrecht, $\mathbb{2} 21$, Rn. 8 m.w.N.; zur Kunstfreiheit hier unter Kap. 3, C., III.

389 LG Hamburg, 17.5.2016, 324 O 255/16, NJW-RR 2017, S. 36 - Böhmermann; LG Hamburg, 10.2.2017, 324 O 402/16, ZUM-RD 2017, S. 417 - Böhmermann; OLG Hamburg, 15.5.2018, 7 U 34/17, ZUM-RD, 2018, S. 484, 488 - Böhmermann; im Ergebnis zustimmend: Götting/Schertz/Seitz/Hösch, Handbuch Persönlichkeitsrecht, $\mathbb{2} 21$, Rn. 10; Fabl, NStZ 2016, S.313, 318; ablehnend u.a. Faßbender, NJW 2019, S. 705, 709; Rusch/Becker, AfP 2016, S. 201, 204. 


\section{Ergebnis}

Das heißt im Ergebnis, dass Äußerungen, die den Betroffenen in seiner Ehre herabsetzen, jedenfalls dann noch rechtmäßig sind, wenn sie gemessen an den von der Gegenseite erhobenen Ansprüchen oder aufgestellten Behauptungen nicht unverhältnismäßig erscheinen. Einen Einfluss darauf haben insofern Aspekte, wer betroffen ist (Person des öffentlichen Lebens oder nicht), in welcher Form (z.B. freie Rede, hitzige Diskussion) und vor allem in welchem Kontext und auf welchen Anlass hin (dies stets unter Berücksichtigung der Idee der Reizüberflutung) die Äußerung getätigt wurde.

Den Abwägungskriterien, die sich über die Zeit entwickelt haben, wird zugesprochen, dass sie eine klare Rechtsprechungslinie und so Rechtssicherheit ermöglichen und damit jedenfalls eine "Schwankungsbreite“ der Einzelfallabwägung vermindern. ${ }^{390}$

IV. Die Kriterien für die Auslegung der Satire im Besonderen

Welche Auslegungskriterien für die satirische Äußerung im Einzelnen herauszuarbeiten sind, soll im Folgenden gezeigt werden. Dabei wird zunächst auf das Verständnis der Rechtsprechung und vor allem des BVerfG eingegangen. Im Anschluss werden solche Stimmen in der Literatur aufgeführt, die sich mehrheitlich in Abgrenzung zum BVerfG positioniert haben.

1. Auslegungsmethodik der Rechtsprechung: Die Entkleidung der Aussage

Grundlegend für die Auslegung der Satire - unabhängig ob diese unter der Kunst- oder Meinungsfreiheit verhandelt wird - sind zunächst sogenannte werkgerechte Maßstäbe. ${ }^{391}$ Mit dem Ziel des werkgerechten Umgangs differenziert die Rechtsprechung zwischen dem Aussagekern und der satirischen Einkleidung. „Eine Satire oder ähnliche Übersteigerung darf als Stilmittel der Kommunikation grundsätzlich nicht schon selbst als Kund-

390 Gosche, Spannungsverhältnis, 2008, S. 63 m.w.N.

391 BVerfG, 3.6.1987, 1 BvR 313/85, NJW 1987, S. 2661 - Strauß-Karikaturen; BVerfG, 10.7.2002, 1 BvR 354/98, NJW 2002, S. 3767 - Bonnbons. 
gabe der Missachtung gewürdigt werden. “392 Die Entkleidung der Satire, das Verdeutlichen des Aussagekerns, ist der Hauptpunkt für die ständige Rechtsprechung und stellt die große und komplexe Herausforderung für die Rechtsprechung dar.

Es geht darum, dass zur rechtlichen Bewertung die Satire des „in Wort und Bild gewählten satirischen Gewandes" entkleidet wird, damit dann der eigentliche Inhalt ermittelt werden kann, denn entscheidend ist eben nicht der Wortlaut der Satire, sondern der dahinterstehende Aussagegehalt - ihre Botschaft. ${ }^{393}$ Für die Entkleidung muss die Satire in den richtigen Kontext gebracht werden. Eine Entkleidung kann nur gelingen, wenn der zeithistorische Bezug beachtet wird. Es folgt erst dann eine gesonderte Überprüfung des Aussagekerns und der Einkleidung mit der Frage, ob sie eine Kundgabe der Missachtung gegenüber der betroffenen Person enthalten. Dabei muss beachtet werden, dass die Maßstäbe im Hinblick auf das Wesensmerkmal der Verfremdung für die Beurteilung der Einkleidung, anders als im Regelfall, weniger streng sind als die für die Bewertung des Aussagekerns. ${ }^{394}$ Nach der erfolgreichen Entkleidung ist der Aussagekern zu überprüfen. Grundsätzlich gilt, sofern das Grundrecht der Meinungsfreiheit verhandelt und die Aussage mehrere Interpretationen zulässt, dass dann immer die für den Äußernden günstige Auslegung zu wählen ist. ${ }^{395}$ Für die Auslegung - gerade auch mehrdeutiger Aussagen - ist abermals der Gesamtkontext relevant. Es kommt hierbei auch auf sog. Sprachbenutzergruppen an: So kann ein Ausdruck für den einen Benutzerkreis eine andere Bedeutung haben als für einen anderen Benutzerkreis. ${ }^{396}$ Stellt sich der Aussagekern jedoch als unwahr bzw. gefälscht heraus, kann die

392 BVerfG, 10.7.2002, 1 BvR 354/98, NJW 2002, S. 3767 - Bonnbons m.w.N.

393 BVerfG, 3.6.1987, 1 BvR 313/85, NJW 1987, S. 2661 - Strauß-Karikaturen unter Rekurs auf RG, 5.6.1928, I 288/28, RGSt 62, S. 183; BVerfG 12.11.1997, 1 BvR 2000/96, NJW 1998, S.1386, 1387 - Münzen-Erna; BVerfG, 10.7.2002, 1 BvR 354/98, NJW 2002, S. 3767 - Bonnbons; BGH, 10.1.2017, VI ZR 562/15, NJW 2017, S. 1617 - Die Anstalt.

394 BVerfG, 3.6.1987, 1 BvR 313/85, NJW 1987, S. 2661 - Strauß-Karikaturen unter Rekurs RG, 5.6.1928, I 288/28, RGSt 62, 183; BVerfG, 25.3.1992, 1 BvR 514/90, GRUR 1992, S. 471, 473 - geb. Mörder; BVerfG 12.11.1997, 1 BvR 2000/96, NJW 1998, S.1386, 1387 - Münzen-Erna; BVerfG, 10.7.2002, 1 BvR 354/98, NJW 2002, S. 3767 - Bonnbons.

395 Mangoldt/Klein/Starck/Starck/Paulus, GG, Art. 5, Rn. 288.

396 Beater, JZ 2006, S. 432, 435; Gärtner, Was die Satire darf, 2009, S. 94. 
satirische Einkleidung nichts daran ändern, dass die satirische Äußerung im Gesamten als unzulässig eingeordnet wird. ${ }^{397}$

Ziel dieses zweistufigen Verfahrens ist, den Besonderheiten der Satire gerecht zu werden. Dies äußert sich schon darin, dass die Begriffe der satirischen Einkleidung und des Aussagekerns eine Besonderheit der Satire-Rechtsprechung darstellen, wobei eine Verschlüsselung von Aussagen generell auch in anderen Kunst- oder Äußerungsformen denkbar wäre.

2. Kritik und Auslegungsvorschläge der Literatur

Die Leitlinie der Rechtsprechung insbesondere zur Auslegung der Satire vor allem jene des BVerfG - wird aus unterschiedlichen Gesichtspunkten heraus beanstandet. Auf die Kritikpunkte sei im Folgenden eingegangen.

\section{a) Kritik an der Ausführung des Gesamtkontextkonzepts}

Die Rechtsprechung macht deutlich, dass sich eine reine Wortlautauslegung verbietet, da die Aussage immer im Gesamtkontext verstanden werden muss, aus diesem darf sie nicht herausgelöst oder in sonstiger Form isoliert werden. ${ }^{398}$ Von diesem generellen Grundsatz lassen sich Ausnahmen in der Rechtsprechung ausmachen. In dem sogenannten Schmähgedicht des Fernsehsatirikers Jan Böhmermann, das aus einer Aneinanderreihung von diffamierenden Ausdrücken besteht, gingen die Gerichte von einer Teilbarkeit des Gedichts aus, so dass einzelne Verse des Gedichts isoliert geprüft wurden. ${ }^{399}$ Dagegen wurde eingewandt, dass der Gesamt-

397 Vgl. dazu BVerfG, 14.2.2005, 1 BvR 240/04, GRUR 2005, S. 500, 501 - satirische Fotomontage; BGH, 8.11.2005, VI ZR 64/05, GRUR 2006, S. 255, 256 f. - satirische Fotomontage; BeckOGK/Specht-Riemenschneider, $\mathbb{8} 823$, Rn. 1297; Gersdorf/ Paal/Söder, \$823, R. 49; MüKoBGB/Rixecker, Anh. \12, R. 241.

398 Ständige Rechtsprechung vgl. nur BVerfG, 13.2.1996, 1 BvR 262/91, NJW 1996, S. 1529, 1530 - DGHS; BVerfG, 12.5.2009, 1 BvR 2272/04, NJW 2009, S. 3016, 3018 - durchgeknallter StA; BVerfG, 25.10.2012, 1 BvR 901/11, NJW 2013, S. 217, 218 - Focus-Ärzteliste; BGH, 30.1.1996, VI ZR 386/94, NJW 1996, S. 1131, 1133; BGH, 27.5.2014, VI ZR 153/13, GRUR 2014, S. 1021, 1022 - Die vierte Gewalt (jeweils m.w.N.).

399 LG Hamburg, 17.5.2016, 324 O 255/16, NJW-RR 2017, S. 36 - Böhmermann; LG Hamburg, 10.2.2017, 324 O 402/16, ZUM-RD 2017, S. 417 - Böhmermann; OLG Hamburg, 15.5.2018, 7 U 34/17, ZUM-RD, 2018, S. 484, 488 - Böhmermann. 
zusammenhang nicht ausreichend beachtet worden wäre und gerade eine Analyse der Aneinanderreihung (von zum Teil üblen Ausdrücken) für die Bewertung der Aussage notwendig gewesen wäre. ${ }^{400}$

Einen ähnlichen Vorwurf könnte man dem BVerfG machen, da das Gericht in seiner Entscheidung zur satirischen Fotomontage einzelne Bildbestandteile isoliert prüfte. ${ }^{401}$ Zuvor hatte sich der BGH zur gleichen Sache noch gegen eine getrennte Beurteilung ausgesprochen, da sonst die Gefahr bestünde, den satirischen Gehalt zu verfehlen. 402

Eine Aufspaltung könnte jedoch erst unter viel engeren Maßstäben angebracht sein. So wird im schweizerischen Rechtsraum eine isolierte Betrachtung nur dann vorgeschlagen, wenn eine einzelne Aussage von der satirischen Aussage so getrennt ist, dass sie ein, vom Zweck der Satire abgesehenes Ziel, verfolgt. ${ }^{403}$ Dies vermag im Einzelfall zu überzeugen, denn warum sollte eine Äußerung den besonderen Schutz der Satire erhalten, wenn sie gar nicht als solche einzustufen ist?

\section{b) Die „erträgliche“ Form}

Eine Strömung in der Literatur, hauptsächlich der 1990er Jahre schlug vor, sich anstatt auf den Inhalt nur auf die Form - genauer die Artikulationsform - zu stützen. ${ }^{404}$ Diesem Ansatz liegt die Überlegung zu Grunde, dass jede Meinung auch ohne inhaltlichen Verlust in einer angemessenen entschärften Art und Weise bzw. in einer „erträglichen Form“405, geäuBert werden könnte. ${ }^{406}$ Das BVerfG hatte 1976 in seinem Beschluss zum Deutschland-Magazin bereits ausgeführt, dass es nicht mit der Meinungsfreiheit in Einklang zu bringen sei, wenn man dem Äußernden vorschrei-

400 Faßbender, NJW 2019, S.705, 709; Rusch/Becker, AfP 2016, S. 201, 204; Cueni, Schutz von Satire im Rahmen der Meinungsfreiheit, 2019, S. 294, Fn. 1323.

401 BVerfG, 14.2.2005, 1 BvR 240/04, GRUR 2005, S. 500, 501 - satirische Fotomontage.

402 BGH, 30.9.2003, VI ZR 89/02, GRUR 2004, S. 590, 591 - satirische Fotomontage.

403 So auf Entscheide der Unabhängigen Beschwerdeinstanz für Radio und Fernsehen der Schweiz rekurrierend Cueni, Schutz von Satire im Rahmen der Meinungsfreiheit, 2019, S. 294.

404 Stark, Ehrenschutz in Deutschland, 1996, S. 72-74.

405 Ossenbühl, ZUM 1999, S. 505, 509.

406 Stark, Ehrenschutz in Deutschland, 1996, S.74; Ossenbübl, ZUM 1999, S. 505, 509; vgl. auch Zusammenstellung bei Gärtner, Was die Satire darf, 2009, S. 95, m.w.N. 
ben würde, wie er seine Gedanken „angemessen“ auszudrücken hätte. Auch hatte das Gericht anerkannt, dass sich Formulierungen eben gerade nicht immer auswechseln lassen, ohne dass der Inhalt der Aussage zu sehr verändert wird..$^{407}$

Sicherlich kann eine Kritik ohne Satire, d.h. dann auch ohne Überzeichnung oder ähnlichem auskommen, ohne dass die Kritik zu kurz kommt. Doch ist es maßgeblich, wie das zu Kritisierende geäußert bzw. beschrieben wird, denn jeder Begriff hat seine ganz eigene Wertung. Und erst die Bewertung durch den Begriff verleiht dem dahinterstehenden Faktum - hier der Kritik - seine Bedeutung. Besonders in der Satire, die nicht zuletzt von Witz, Nuancierung und Pointierung ihrer Aussage lebt, ${ }^{408}$ können einzelne Wörter nicht einfach ausgetauscht werden. Unabhängig davon, dass ein solcher Ansatz Gefahr läuft, die Kunstform der Satire zu negieren, ist dem Ansatz grundsätzlich entgegenzuhalten, dass er letztlich die Problematik nur verlagert. Denn wo ist die Grenze für diese erträgliche Form? ${ }^{409}$ Solche Überlegungen zur Artikulationsform führen letztendlich zu der wenig juristischen Frage „Muss das sein?“, statt der Frage „Darf das sein?"“.

c) Die alleinige Fokussierung auf den Aussagekern

Ebenso wie sich manche nur auf die Form stützen wollen, gibt es eine Meinung, die sich nur auf den Aussagekern beziehen will. Danach ist auch eine getrennte Bewertung von Aussagekern und satirischer Einkleidung abzulehnen, da es nur gilt den Aussagekern rechtlich zu bewerten. ${ }^{410}$ In diesem Ansatz wird der Vorteil gesehen, dass es so nicht zu einer Prüfung nach den „Regeln des guten Geschmacks“ kommen kann, wie es sonst den Gerichten zum Teil angelastet wird. ${ }^{411}$ Auch wirft diese Meinung den Gerichten vor, die intellektuelle Leistung des Rezipienten zu unterschätzen, mag er doch die Satire durchschauen und sie deshalb nicht als anstößig empfinden. ${ }^{412}$ Diese Meinung ist ausgesprochen satirefreundlich. In anderen Fällen, wie bei einer reinen Aneinanderreihung von Diffamierungen

407 BVerfG, 11.5.1976, 1 BvR 671/70, NJW 1976, S. 1677 f. - Deutschland-Magazin.

408 Siehe dazu hier Kap. 2.

409 Auch kritisierend Gärtner, Was die Satire darf, 2009, S. 97.

410 So Gärtner, ebd., S. 138.

411 Gärtner, ebd.

412 Gärtner, ebd. 
mag diese Forderung - die satirische Einkleidung völlig außer Acht zu lassen - aber schwerfallen. Ferner wird hier davon ausgegangen, dass so nur die sonst auf zwei Ebenen aufgeteilte Prüfung in einen Prüfungsschritt zusammengefasst wird, was letztlich für das Ergebnis, solange bei der Satire werkgerechte Maßstäbe herangezogen werden, auch irrelevant sein wird.

\section{d) Kritik an dem Maßstab des Durchschnittsbetrachters}

Für die Auslegung einer Äußerung ist nicht auf das subjektive Verständnis des Äußernden oder des Rezipienten abzustellen, sondern nach dem Sinn, den sie nach dem Verständnis eines unvoreingenommenen und verständigen Durchschnittspublikums hat, zu fragen. ${ }^{413}$ Es wird kritisiert, dass die Satire meist einen elitären Anspruch erhebt, der sich der Rezeption des Durchschnittsbürgers entzieht, ${ }^{414}$ weswegen der Durchschnittsleser bzw. -konsument nicht der Maßstab für die Bewertung der Satire sein soll. Dies wird damit begründet, dass „der nicht besonders gebildete und nicht besonders aufmerksame Durchschnittsbürger mit der Auseinandersetzung im Bereich der Satire schlichtweg überfordert ist“415 und „ihm [...] das geforderte Vor-Verständnis und häufig auch die notwendige Auf-

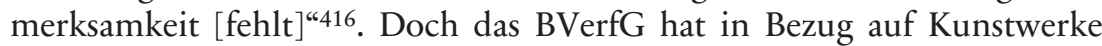
bereits verdeutlicht, dass der Maßstab nicht bei einem in künstlerischen Erscheinungsformen völlig Unbewanderten liegen kann, wobei auch nicht

413 BVerfG, 10.10.1995, 1 BvR 1476/91, 1 BvR 1980/91, 1 BvR 102/92, 1 BvR 221/92, NJW 1995, S. 3303, 3310 - Soldaten sind Mörder; BVerfG, 25.10.2005, 1 BvR 1696/98, NJW 2006, S. 207, 208 - Stolpe m.w.N.

Das schweizerische Bundesgericht hat im Falle eines Erotikfilms, der als unzüchtig in Rede stand, bezüglich des Durchschnittsbürgers ausgeführt, dass „[...] eine laxere Einstellung ist ebenso wenig Maßstab für den Bevölkerungsdurchschnitt wie die Überempfindlichkeit puritanischer Bevölkerungskreise. Im Übrigen wäre eine zuverlässige Meinungsforschung selbst dann kaum durchzuführen, wenn der inkriminierte Film einem repräsentativen Querschnitt der Bevölkerung vorgeführt würde, da die Antworten wohl häufig nicht ganz ehrlich lauten, sondern auf Konventionen, etc. Rücksicht nehmen würden.“, BGE 103 IV 96, S. 98.

414 Senn, Satire und Persönlichkeitsschutz, 1998, S. 73, bzw. Senn nennt es auch esoterischen (im Sinne der Eingeweihten) Anspruch.

415 Senn, ebd., S. $74 \mathrm{f}$.

416 Senn, ebd., S. 75 im Rückgriff auf BVerfG, 07.12.76, 1 BvR 460/72, NJW 1977, S. 799. 
auf den umfassend künstlerisch Gebildeten abgehoben werden kann. ${ }^{417}$ Typisch für die Satire ist der starke Aktualitätsbezug und die Kontextbezogenheit. Allein dadurch wird schon ein jedenfalls informierter Durchschnittsbetrachter im Gegensatz zu einem „flüchtigen Leser“ notwendig sein. Dies gilt umso mehr noch im Rahmen der Politsatire. Es sei angemerkt, dass eine gerichtliche Bewertung zum Teil auch stark zeitverzögert erfolgen kann, was das Nachvollziehen der satirischen Äußerung zuweilen erschweren kann, bzw. ist es dann besonders wichtig sie in ihren ursprünglichen Kontext zu setzen. So kann beispielsweise auch ein kritikwürdiger Satire-Gegenstand zum Zeitpunkt der Gerichtsverhandlung gar nicht mehr zu kritisieren sein. Es sind aber auch Fälle der Satire und auch des künstlerischen Politsatire-Plakats denkbar, in denen jedoch lediglich der Anlass für die satirische Äußerung aktualitäts- und kontextabhängig, die dahinterstehende Kritik aber davon unabhängig und insofern allgemeiner und genereller ist. Insofern soll die Voraussetzung an den Rezipienten auch nicht zu hoch angesetzt werden.

Wie in Bezug zu der Satire im Allgemeinen bereits thematisiert wurde und im Besonderen an den Plakaten Klaus Staecks noch zu zeigen ist, funktionieren alle Satiren ähnlich. Damit lässt sich bezogen auf den Maßstab von einem informierten Durchschnittsbürger sprechen, der der Satire und ihr verwandten Mitteln offen gegenübersteht. Wird die satirische Äußerung in einem offensichtlichen Satiremedium, wie beispielsweise der Zeitschrift Titanic, verbreitet, ließe sich auch vertreten, dass dieses eine spezifische Zielgruppe anzieht: Damit kommt für die Klientel-Satire als Maßstab ein der Satire vertrauter Durchschnittsrezipient in Frage. Im Fall des künstlerischen Politsatire-Plakats kann ein solches Argument aber nicht überzeugen, da die Plakate gerade im öffentlichen Raum angebracht werden; insofern überzeugt am ehesten ein Rezipient in Gestalt eines der unvoreingenommenen und verständigen Durchschnittsbetrachters. Im Ergebnis ist festzuhalten, dass eine generelle Kritik an dem Maßstab der verfassungsrechtlichen Judikatur in Bezug auf die Satire nicht überzeugen kann. Da das Gericht selbst schon - gerade vor dem Hintergrund von Kunstwerken - deutlich macht, dass auch von diesem Maßstab in verschiedenen Abstufungen abgewichen werden kann, wenn es der konkrete Fall bedarf, ist vom Grundsatz her ein Festhalten an dem unvoreingenommenen und verständigen Durchschnittsbetrachter sinnvoll.

417 BVerfG, 17.7.1984, 1 BvR 816/82, NJW 1985, S. 261, 263 - Anachronistischer Zug. 
3. Der Auslegungsmaßstab im Fall des künstlerischen Politsatire-Plakats

Der rechtlichen Bewertung im Wege der Trennung von Einkleidung und Aussagekern zur Ermittlung und zum Umgang mit der Satire als Meinungsäußerung wird vorgeworfen zu verkennen, dass es sich um Kunst im Sinne des Art. 5 Abs. 3 GG handelt. So wird ganz plakativ diesem Verfahren Gewalt gegen das Kunstwerk zugesprochen, „da Stoff, Gehalt und Form im Kunstwerk einer Forderung Goethes zufolge ,einander durchdringen'." 418 Verzichtet man auf diese Trennung, befreit es aber nicht von der Auseinandersetzung mit der satirischen Darstellung, d.h. zusammen mit dem „explizit Gesagtem“, auch das „Mit-Gemeinte“ zu ermitteln. Im Rahmen des künstlerischen Politsatire-Plakats muss der Kontext und die äußeren Umstände erst recht Einfluss auf die Abwägung ausüben. So ist - wie es das BVerfG deutlich gemacht hat - die Polemik ein typisches Mittel im Wahlkampf, ${ }^{419}$ weswegen für das satirische Wahlplakat eine Vermutung für die Zulässigkeit der freien Rede spricht, gerade „wenn es sich um Auseinandersetzungen in einem Wahlkampf handelt, also einer Situation, in welcher der politische Meinungskampf auf das höchste intensiviert ist." 420 Inwiefern dieser Leitgedanke sich in den Verfahren um die Plakate Klaus Staecks wiederfinden lässt, wird auch Gegenstand des fünften Kapitels sein.

\section{Die satirische Äußerung in Kollision}

Die Satire kann neben dem Persönlichkeitsrecht auch mit anderen Schutzgütern kollidieren. Bei religiöser Satire kann eine Abwägung von Meinungs- bzw. Kunstfreiheit und der Religionsfreiheit aus Art. 4 Abs. 1 GG maßgeblich sein. Da hier der Schwerpunkt auf der Politsatire liegt und religiöse Satire oder Karikaturen eine nur äußerst untergeordnete Rolle im Schaffen Klaus Staecks spielen, wird hier auf eine nähere Untersuchung verzichtet. Wegen einer thematischen Nähe zu den Fällen Staecks sei jedoch ein kurzer Blick auf Kollisionen der satirischen Äußerungen auf Ebe-

418 Solms, Warum stehen Satiriker in den 90er Jahren so oft vor Gericht?, in: Folckers/Solms (Hrsg.), Was kostet der Spaß? Wie Staat und Bürger die Satire bekämpfen, 1997, S. 11.

419 BVerfG, 22.6.1982, 1 BvR 1376/79, NJW 1983, S. 1415, 1416 - CSU NPD Europas.

420 BVerfG, ebd. 
ne des einfachen Rechts im Bereich des Markenrechts und des Namensrecht, das selbst wiederum eine besondere Ausprägung des allgemeinen Persönlichkeitsrechts ist, ${ }^{421}$ geworfen.

\section{Die Satire in Kollision mit dem Namensrecht}

Das Namensrecht des $₫ 12$ BGB schützt als absolutes Recht den Namensträger gegenüber jedermann und so vor Namensbestreitung und Namensanmaßung. Der Name ist das äußere Kennzeichen einer Person und dient nicht nur zur Unterscheidung, sondern ist auch Ausdruck ihrer Identität und Individualität. ${ }^{422}$ Darunter wird aber längst nicht nur der bürgerliche Name einer natürlichen Person erfasst, vielmehr auch der Name juristischer Personen, womit gerade keine persönlichkeitsrechtlichen, sondern wirtschaftliche Interessen geschützt werden. ${ }^{423}$ Mit der Marlene DietrichEntscheidung hatte der BGH jedoch verdeutlicht, dass ein Persönlichkeitsrecht wie das Namensrecht auch kommerzielle Interessen des Namensträgers schützt. ${ }^{424}$

Eine Form der Namensanmaßung ist die des Namensgebrauchs. Ein solcher kann vorliegen, wenn der Eindruck wirtschaftlicher oder organisatorischer Verbindungen zwischen Namensinhaber und dem Zweitnutzer hervorgerufen wird ${ }^{425}$ und so über die Identität getäuscht wird. Eine solche Identitätstäuschung ist auch im Rahmen der Satire denkbar, ${ }^{426}$ doch weitaus mehr Fälle sind höchstrichterlich in dem Bereich des Markenrechts entschieden worden. Deswegen sei im Folgenden ein kursorischer Blick auf die Parodie und Satire im Markenrecht geworfen.

2. Die Satire in Kollision mit dem Markenrecht

Im Markenrecht handelt es sich seltener um genuin satirische Beiträge, sondern eher um Fälle der Markenparodie. Wenn über den Schriftzug PU-

421 BGH, 1.12.1999, I ZR 49/97, GRUR 2000, S. 709, 712 - Marlene Dietrich.

422 BVerfG, 21.8.2006, 1 BvR 2047/03, GRUR 2007, S. 79 - maxem.de m.w.N; BVerfG, 8.3.1988, 1 BvL 9/85, 1 BvL 43/86, NJW 1988, S. 1577 - gemeinsamer Familienname.

423 MüKo/Säcker, $\mathbb{S} 12$, Rn. 2.

424 BGH, 1.12.1999, I ZR 49/97, GRUR 2000, S. 709, 712 - Marlene Dietrich.

425 BeckOK/Bamberger, BGB, $\mathbb{1 2}$, Rn. 75.

426 Vgl. im Besonderen bei Klaus Staeck Kap. 5, B., I. 
MA des gleichnamigen Sportartikelherstellers statt des athletischen Silberlöwens ein frisierter Pudel über den Schriftzug PUDEL springt, dann ist das in den Bereich der Parodie zu verorten, statt in die satirische Auseinandersetzung. ${ }^{427}$ In diesen Fällen wird die Abwägung zugunsten des Beklagten „nur“ über die Kunstfreiheit gelöst, wenn über die Parodie hinaus keine Kritik an der Marke oder dem dahinstehenden Unternehmen geübt werden soll. ${ }^{428}$ Aber gerade bei der Satire wird dies regelmäßig nicht vorliegen. Im Folgenden ist daher der rechtliche Konflikt der Satire im Warenwerbepalakt genauer zu untersuchen. Satirische Werbeplakate versprechen nach der AIDA-Formel sowohl ein erhöhte Aufmerksamkeit als auch ein verstärktes Interesse, da durch das Erkennen der Satire und des dahinterstehenden Witzes das Werbeplakat mit seiner an sich abgedroschenen Werbewirkung einen neuen intellektuellen Reiz erhält, der sich meist in einem wissenden Schmunzeln beim Betrachter äußert. ${ }^{429}$ Die Pullacher Autovermietung Sixt hat sich mit der von der Agentur Jung von Matt erschaffenen Werbekampagne, die Porträts berühmter Politiker verwendet, nicht nur als Beklagter vor Gericht, sondern auch in der rechtswissenschaftlichen Literatur einen Namen gemacht. „Sixt verleast auch Autos für die Mitarbeiter in der Probezeit" war der in fetten Buchstaben gedruckte Slogan unter den Porträtaufnahmen von 16 Mitgliedern der damaligen Bundesregierung, einschließlich der Fotografie von Oskar Lafontaine, dessen Bild mit einem orangenen Kreuz durchgestrichen wurde. ${ }^{430}$ Vorangegangen war der überraschende Rücktritt Lafontaines im März 1999 von all seinen politischen Ämtern inklusive seines Postens als Finanzminister nach einer knapp fünfmonatigen Amtszeit. Es sei daran erinnert, dass die Abgebildeten nicht eingewilligt hatten, für die Autovermietung im Allgemeinen, noch im Besonderen für diese Kampagne zu werben. Dementsprechend klagte Lafontaine auf Zahlung einer fiktiven Lizenzgebühr. Der BGH machte jedoch deutlich, dass im Zuge der Abwägung von Meinungsfreiheit des Beklagten und Persönlichkeitsrecht des Abgebildeten berücksichtigt werden muss, dass diese Sixt-Werbekampagne sichtlich nicht darauf abzielte, einen Image- oder Werbewert des Klägers auf die beworbene unternehmerische Leistung zu übertragen, sondern vielmehr ein tagespoli-

427 Referiert wurde dabei auf die Entscheidung BGH, 02.4.2015, I ZR 59/13, GRUR 2015, S. 1114 - Springender Pudel.

428 BGH, ebd., S. 1119, Rn. 51.

429 Vgl. dazu Kap. 1.

430 BGH, 26.10.2006 - I ZR 182/04, GRUR 2007, S. 139, 140 - Rücktritt des Finanzministers. 
tisches Ereignis in satirischer Form und offensichtlich mit Spott versehen zu thematisieren. ${ }^{431}$ Das Gericht stellt auch klar, dass die Tatsache, dass diese Aussage sich in einem Werbeplakat manifestiert, nichts an einer Einordnung als Meinung ändert. ${ }^{432} \mathrm{Da}$ die Satire auch immer verstanden werden muss, und damit rezeptionsabhängig ist, stellt ihre Verwendung im Rahmen der Produktwerbung - insbesondere im Kontext tagespolitischer Ereignisse - ein riskantes Unterfangen dar. Das hier behandelte Werbebild der Firma Sixt wurde aber gerade nicht als Plakat bundesweit im öffentlichen Raum aufgehängt, sondern als Werbeanzeige in der Frankfurter Allgemeinen Zeitung und der Welt am Sonntag geschaltet. Damit war sie an ein kleines, politisch interessiertes Publikum gerichtet, weswegen mehrheitlich von einem Verständnis der Rezipienten ausgegangen werden kann.

Für eine vertiefende Auseinandersetzung mit den Fällen der Markensatire und Markenparodie sei hier auf einschlägige Arbeiten wie die von Andrej Levin verwiesen. ${ }^{433}$

\section{F. Satire im Lichte der EMRK und des EU-Rechts}

Es sei ein kurzer Blick auf die Rechtsprechung des EGMR und damit auch auf den Schutz der satirischen Äußerung durch die EMRK (I.) sowie die Rechtsprechung des EuGH (II.) geworfen.

\section{Die Rechtsprechung des EGMR}

\section{Der Schutz der Satire unter den Kommunikationsfreiheiten}

Die Satire, geschützt über die Kommunikationsfreiheiten, allen voran die Meinungsfreiheit, findet ihre Verankerung nicht nur im nationalen - hier deutschen - Verfassungsrecht, sondern auch auf der völkerrechtlichen Ebene und dabei maßgeblich in der Europäischen Menschenrechtskonvention. Die Kommunikationsfreiheiten werden in Art. 10 EMRK geschützt und als grundlegend für eine demokratische Gesellschaft und als eine we-

431 BGH, ebd., S. 141, Rn. 20.

432 BGH, ebd., Rn. 21.

433 Siehe dazu Levin, Die lauterkeitsrechtlichen Möglichkeiten und Grenzen der humorvollen und satirischen vergleichenden Werbung, 2013. 
sentliche Bedingung für den Fortschritt einer Gesellschaft sowie der Entwicklung eines jeden Einzelnen erachtet. ${ }^{434}$ Das EGMR macht deutlich, dass es keine demokratische Gesellschaft ohne Pluralismus, Toleranz und den Geist der Offenheit geben kann. ${ }^{435}$ Für diesen Pluralismus ist die Meinungsfreiheit des Art. 10 Abs. 1 S. 1 EMRK elementar, in der erst einmal jede Kommunikation im zwischenmenschlichen Bereich geschützt ist. ${ }^{436}$ Ausdrücklich werden im zweiten Satz das Empfangen und Weitergeben von Informationen und Ideen geschützt. Im Gegensatz zum deutschen Verfassungsrecht fallen unwahre Tatsachenbehauptungen explizit unter den Schutzbereich der Meinungsfreiheit. Die Unterscheidung zwischen Werturteil und einer solchen Tatsachenbehauptung erlangt jedoch auf der Ebene der Rechtfertigung Relevanz. Die Grenzen der Meinungsfreiheit nach Art. 10 Abs. 1 EMRK formuliert schon der zweite Absatz, wonach die Freiheit mit Pflichten und Verantwortung verbunden ist. Die Freiheit kann gesetzlich beschränkt werden, wie es auch in einer demokratischen Gesellschaft notwendig sein kann: Dies lässt sich mit der nationalen Sicherheit, der territorialen Unversehrtheit oder der öffentlichen Sicherheit begründen. Außerdem kann es zur Aufrechterhaltung der Ordnung oder zur Verhütung von Straftaten, zum Schutz der Gesundheit oder der Moral, zum Schutz des guten Rufes oder der Rechte anderer, zur Verhinderung der Verbreitung vertraulicher Informationen oder zur Wahrung der Autorität und der Unparteilichkeit der Rechtsprechung eingesetzt werden. Für das die Satire häufig berührende Spannungsverhältnis zwischen der Meinungsfreiheit und dem Persönlichkeitsschutz, der völkerrechtlich in Art. 8 EMRK gewährleistet wird, bedarf es mangels abschließender Regelung für einen angemessenen Ausgleich zwischen den beiden Rechten einer Interessenabwägung im konkreten Einzelfall.

Eine weitere Grenze des Art. 10 EMRK findet sich in Art. 17 EMRK mit dem Missbrauchsverbot der konventionsrechtlich geschützten Rechte aus totalitären Zwecken oder einfacher aus konventionsfeindlichen Gründen. Diese Generalklausel, die die deutsche Verfassung in dieser Ausformung nicht kennt, findet in Bezug auf die Meinungsfreiheit gerade im Bereich extremistischer Hassreden Anwendung. Der Schutzzweck der Norm lässt sich besser einfassen, wenn man bedenkt, dass die Verfasser der EMRK im Jahre 1950 - vor dem Hintergrund der zeitgeschichtlichen Ereignisse

434 EGMR, 19.1.2006, 59491/00, Rn. 60 - United Macedonian Organisation Ilinden/Bulgarien.

435 EGMR, 8.7.2014, 53413/11, Rn. 101 - Sik/Türkei m.w.N.

436 Grabenwarter/Pabel, EMRK, $\$ 23$, Rn. 4. 
- einen durch liberal-demokratische Werte geprägten Rahmen schaffen wollten, der Nationalsozialismus und Faschismus überwindet und ein Gegengewicht gegen die damalige Bedrohung durch den stalinistischen Kommunismus bietet. ${ }^{437}$ Neben den historisch angelegten Fällen wie der Leugnung des Holocausts ${ }^{438}$ oder der antisemitischen Äußerungen ${ }^{439}$ sind Entscheidungen zu extremistischen, islamistischen ${ }^{440}$ sowie anti-muslimische Äußerungen hinzugekommen, ${ }^{441}$ in denen der Gerichtshof die Äußerungen aus dem Schutzbereich der Meinungsfreiheit wegen Art. 17 EMRK herausgenommen hat.

In Bezug auf die Satire erkennt der EGMR in ihr eine Form des künstlerischen Ausdrucks und sozialen Kommentars an. ${ }^{442}$ Die Satire will mit der ihr eigenen Übertreibung und Verzerrung der Realität naturgemäß provozieren und aufregen. ${ }^{443} \mathrm{Als}$ Maßstab gilt das Kriterium des vernünftigen Lesers. ${ }^{444}$ Die vom EGMR entschiedenen Fälle zur Satire erstrecken sich von satirischen Äußerungen im Rahmen von politischer Kritik und politischer Diskussion, ${ }^{445}$ in denen zum Teil lokale bzw. kulturelle Besonderheiten wie der portugiesische Karneval, in dem Politiker durch Satire kritisiert werden, oder zeitliche Umstände, die einen besonders sensiblen

437 Harris/O'Boyle/Warbick, Law of the ECHR, ${ }^{3} 2014$, S. $621 \mathrm{f}$.

438 EGMR, 24.6.2003, 65831/01 - Garaudy/Frankreich, NJW 2004, S. 3691, 3692 f., Die ebenfalls in diesem Fall zu entscheidenden antisemitisch und rassistischen Äußerungen zum Vorgehen des Staates Israels fallen hingegen schon unter Art. 10 Abs. 2 EMRK, siehe EGMR, 24.6.2003, 65831/01, NJW 2004, S.3691, 3693 - Garaudy/Frankreich. Vgl. zu dieser Entscheidung auch Hong, ZaöRV 2010, 89-96. Siehe auch EGMR 20.4.1999, 41448/98 - Witzsch/Deutschland und EGMR, 13.12.2005, 7485/03 - Witzsch/Deutschland.

439 EGMR, 20.10.2015, 25239/13, NJW-RR 2016, S. 1514 - Dieudonné M'bala M'bala/Frankreich.

440 EGMR, 1.7.1997, 20704/92 - Kalaç/Türkei; EGMR, 23.2.2003, 41340/98, 41342/98, 41343/98, 41344/98 - Refah Partisi/Türkei.

441 EGMR, 16.11.2004, 23131/03 - Norwood/Vereinigtes Königreich.

442 EGMR, 22.3.2016, 70434/12, NJW-RR 2017, S. 1194, 1195, Rn. 50 - Sousa Goucha/Portugal; EGMR, 27.11.2018, 28482/13, AfP 2019, S.142, 145, Rn. 39 Herman-Bischoff/Deutschland; EGMR, 19.2.2015, 53495/09, AfP 2015, S.323, 324, Rn. 50 m.w.N. - Bohlen/Deutschland.

443 Siehe beispielsweise EGMR, 22.3.2016, 70434/12, NJW-RR 2017, S.1194, 1195, Rn. 50 - Sousa Goucha/Portugal; EGMR, 27.11.2018, 28482/13, AfP 2019, S. 142, 145, Rn. 39 - Herman-Bischoff/Deutschland; EGMR, 19.2.2015, 53495/09, AfP 2015, S. 323, 324, Rn. 50 m.w.N. - Bohlen/Deutschland.

444 EGMR, 22.3.2016, 70434/12 NJW-RR 2017, S. 1194, 1195, Rn. 50 - Sousa Goucha/Portugal.

445 EGMR, 17.9.2013, 16812/11 - Welsh und Silva Canha/Portugal. 
Umgang mit gewissen Themen einfordern, ${ }^{446}$ berücksichtigt wurden, ${ }^{447}$ bis hin zu satirischer Wirtschaftswerbung, die lediglich ein unpolitisches Thema behandelt. ${ }^{448}$ Ein entscheidendes Kriterium kann für den EGMR auch der Träger und die Funktion der Satire sein. So lassen sich gerade bei satirischen Darstellungen, die für Handelsprodukte werben, weitergehende Ausführungen finden, insbesondere wenn das Produkt nicht sozial akzeptiert ist, oder wenn es ethische oder ernsthafte moralische Fragen aufwirft. ${ }^{449}$ Auch für den EGMR ist eine begriffliche Differenzierung nicht von Relevanz, so unterscheidet er beispielsweise nicht genau zwischen Karikatur und Satire. ${ }^{450}$

\section{Der Schutz der Satire unter der Kunstfreiheit}

Die Kunstfreiheit ist in der EMRK nicht ausdrücklich erwähnt, doch es wird davon ausgegangen, dass die Kunst- wie auch die Wissenschaftsfreiheit unter Art. 10 EMRK zu fassen sind. ${ }^{451}$ Denn nach dem Leitgedanken der pluralistischen Gesellschaft ist der Austausch von Ideen und Meinungen wesentlich, wozu auch derjenige beiträgt, der Kunstwerke schafft, interpretiert, verbreitet oder ausstellt. ${ }^{452}$ Eine Auseinandersetzung mit der Satire in Bezug auf die Kunstfreiheit erfolgte in Form von zahlreichen einzelnen Entscheidungen, von denen hier zwei Beispiele herausgegriffen werden. Die eine Entscheidung betrifft einen französischen Cartoonis-

446 So z.B. EGMR, 2.10.2008, 36109/03, NJOZ 2010, S. 512, 515, Rn. 45 - Leroy/Frankreich, vgl. dazu hier unter Kap. 3, F., I., 2., b).

447 So bei EGMR, 20.10.2009, 41665/07 - Alves da Silva/Portugal.

448 EGMR, 19.2.2015, 53495/09, AfP 2015, S. 323 - Bohlen/Deutschland; EGMR, 19.2.2015, 53649/09, AfP 2015, S. 327 -Ernst August von Hannover/Deutschland.

449 Hier in Bezug auf Zigarettenwerbung EGMR, 19.2.2015, 53495/09, AfP 2015, S. 323, 325, Rn. 55 - Bohlen/Deutschland; EGMR, 19.2.2015, 53649/09, AfP 2015, S. 327, 328, Rn. 49 - Ernst August von Hannover/Deutschland.

450 So z.B. bei EGMR, 2.10.2008, 36109/03, NJOZ 2010, S. 512, 513, Rn. 27, 515, Rn. 44 - Leroy/Frankreich.

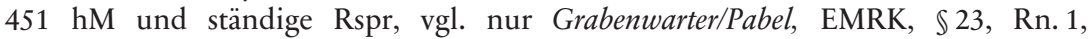
11; Götting/Schertz/Seitz/Lauber-Rönsberg, Handbuch Persönlichkeitsrecht, \57, Rn.32; EGMR, 24.5.1988, 25/1986/123/174, NJW 1989, 379, 380, Rn.33 Müller; EGMR, 25.1.2007, 68354/01, Rn. 25 f. -Vereinigung Bildender Künstler/Österreich.

452 EGMR, 24.5.1988, 25/1986/123/174, NJW 1989, 379, 380, Rn. 33 - Müller. 
ten ${ }^{453}$ und die andere erfolgte zu einem Werk des umstrittenen Wiener Aktionskünstlers Otto Muehl. ${ }^{454}$

\section{a) Satire und Sexualmoral}

Auf dem Gemälde „Apokalypse/Keinen Keks heute“ von Otto Muehl sind in neun gleichgroßen Quadraten auf comicartig gezeichneten nackten Körpern Gesichter realer Personen zu sehen, wobei die Körper in expliziter sexueller Handlung, d.h. beispielsweise mit erigierten Penissen, dargestellt sind. Die Gesichter hingegen sind Fotografien, meist aus Zeitungen entnommen, die vergrößert im Wege der Fotomontage an den Körpern angebracht wurden. ${ }^{455}$ Ein Quadrat zeigt eine Gruppen-Sex-Szene mit Mutter Teresa und Personen des öffentlichen Lebens aus Politik, Kirche und Kultur Österreichs mit unter anderem dem damaligen FPÖ-Generalsekretär Walter Maischberger. Das EGMR entschied zugunsten der Kunstfreiheit und sah keine Verletzung des Persönlichkeitsrechts des abgebildeten Politikers gegeben. ${ }^{456}$ Das Gericht betonte, dass die Darstellungsform zwar unverschämt („outrageous“), trotzdem jedoch als eine „Karikatur mit satirischen Elementen“ einzuordnen sei. ${ }^{457}$ Für die Satire-Definition bezog sich das Gericht auf die ständige Rechtsprechung und ordnete die Satire wiederum als eine Form des künstlerischen Ausdrucks und des gesellschaftlichen Kommentars ein, die durch ihre inhärenten Merkmale der Übertreibung und der Verzerrung der Wirklichkeit naturgemäß darauf abzielt, zu provozieren und zu erregen. ${ }^{458}$ Es werden darüber hinaus zwei weitere Argumente geltend gemacht: Zum einen machte das Gericht eine Form des Rechts des Gegenschlags geltend, da das Kunstwerk als ein „counter-attack“ gegen die politische Partei und ihre Vertreter, die wiederum den Künstler und sein Euvre schwer kritisiert hatten, angesehen wird. ${ }^{459}$ Und zum anderen die erschwerte Erkennbarkeit, da der Politiker als einer von 33 abgebildeten Personen erstens sowieso schon „untergeht“, zweitens als lediglich ehemaliges gewöhnliches Mitglied des Parlaments kaum erkannt wird (,is hardly remembered by the public at all“) und

453 EGMR, 2.10.2008, 36109/03, NJOZ 2010, S. 512 - Leroy/Frankreich.

454 EGMR, 25.1.2007, 68354/01 - Vereinigung Bildender Künstler/Österreich.

455 https://www.estateottomuehl.com/news/.

456 EGMR, 25.1.2007, 68354/01 - Vereinigung Bildender Künstler/Österreich.

457 EGMR, ebd., Rn. 32 f.

458 EGMR, ebd., Rn. 33.

459 EGMR, ebd., Rn. 34. 
drittens durch einen Farbanschlag auf das Gemälde durch einen Museumsbesucher bereits vor dem rechtlichen Vorgehen kaum noch auszumachen war. 460

Diese Entscheidung wurde mit dem knappen Stimmenverhältnis von 4:3 gefällt. Anhand zweier Sondervoten lässt sich hierbei ablesen, wie eindeutig sich drei der insgesamt sieben Richter gegen die Entscheidung gestellt haben. Einer der Richter sah in dem Gemälde kein Kunstwerk, was er mittelbar dadurch äußerte, dass er das Wort Gemälde grundsätzlich in Anführungszeichen gesetzt hat. ${ }^{461}$ In dem anderen Sondervotum wurde argumentativ ein starker Bezug zu der deutschen verfassungsrechtlichen Rechtsprechung, namentlich zu der Entscheidung zu den Strauß-Karikaturen, gezogen und so die Würde des Betroffenen in den Mittelpunkt gestellt. ${ }^{462}$ Diesem Vergleich liegt die Überlegung zu Grunde, dass gerade sexualisierte Darstellungen geeignet seien, den engsten und unantastbaren Kernbereich des privaten Lebens zu verletzen.

Die Moral und vor allem die Sexualmoral unterliegen jedoch einem zuweilen starken Wandel. So hat sich die Auffassung der Sexualmoral in den letzten Jahrzehnten erheblich geändert. Auch wenn es auf reiner Spekulation fußt, sei die Vermutung geäußert, dass die Karikatur Hachfelds mit dem kopulierenden Schwein bei einer aktuellen Bewertung weitaus weniger Aufsehen erregen und somit eine Entscheidung eher zu Gunsten der Kunstfreiheit ausfallen würde.

b) Der zeitliche und örtliche Bezug

Denis Leroy, französischer Cartoonist, zeichnete für eine baskische Lokalzeitung den Anschlag auf die Zwillingstürme des World Trade Centers am 9.11.2001 und versah diese mit den Worten „Nous en avions tous rêve

460 Das Kunstwerk wurde bei der Ausstellung in einem Museum von dem selbst als „Pornojäger" proklamierten Martin Humer mit roter Farbe überschüttet, weswegen der Politiker nahezu gar nicht mehr zu erkennen war, vgl. zum Bild mit dem Farbanschlag https://www.estateottomuehl.com/news/; EGMR, 25.1.2007, 68354/01, Rn. 36 - Vereinigung Bildender Künstler/Österreich.

461 EGMR, Dissenting Opinion of Judge Loucaides, 25.1.2007, 68354/01 - Vereinigung Bildender Künstler/Österreich. Ferner führt er aus, dass „the ,painting' is just a senseless, disgusting combination of lewd images whose only effect is to debase, insult and ridicule each and every person portrayed.“.

462 EGMR, Joint Dissenting Opinion of Judges Spielmann and Jebens, 25.1.2007, 68354/01, Rn. 10 f. - Vereinigung Bildender Künstler/Österreich. 
... Le Hamas l'a fait“463 - zu Deutsch: wir haben alle davon geträumt... Hamas hat es getan“. Der Cartoonist, der wegen Befürwortung des Terrorismus von einem französischen Gericht zu einer geringen Geldstrafe verurteilt wurde, wandte sich daraufhin an den europäischen Gerichtshof und berief sich - mit der Begründung, seine Zeichnung beinhalte lediglich antiamerikanische Kritik - u.a. auf eine Verletzung von Art. 10 Abs. 1 EMRK. ${ }^{464}$ Der Gerichtshof verneinte eine solche Verletzung und machte deutlich, dass satirische Werke im Bereich politischer Äußerungen unter Art. 10 Abs. 2 EMRK fallen: Denn wer von seiner Meinungsfreiheit Gebrauch mache, übernehme, mit den Worten des zweiten Absatzes, „Pflichten und Verantwortlichkeiten ". ${ }^{465}$ Solche treffen einen Cartoonisten noch stärker, sobald seine Karikatur in dem unmittelbaren Kontext eines terroristischen Anschlags steht. Das Gericht legte seinen Schwerpunkt der Bewertung gezielt auf den zeitlichen und örtlichen Kontext, denn der Karikaturist hatte die Zeichnung noch am Tag des Anschlags angefertigt, wobei die Veröffentlichung des Cartoons bereits zwei Tage später erfolgte und damit zu einer Zeit, in der die Welt noch unter Schock stand und der weitere Verlauf der Ereignisse nicht im Geringsten abzuschätzen war. In Bezug auf den örtlichen Kontext floss ebenfalls die Tatsache in die Bewertung ein, dass der Cartoon in einem baskischen Organ erschien und somit im Umfeld einer politisch sensiblen Gegend, in der eine solche Karikatur starke Reaktionen bis hin zu Gewalt auszulösen vermag.

Die Rechtsprechung des EGMR zur Satire wird - besonders in Bezug auf die Art. 10 und Art. 17 EMRK - in der Literatur zum Teil sehr kritisch bewertet. Diese Kritik liegt jedoch weniger in den der Satire eigenen Problemen, sondern in der Anwendung des Art. 17 auf Art. 10 EMRK, mit der ein Risiko einer missbräuchlichen Anwendung der Artikels der jeweiligen Staaten und so eine Gefahr für die erwünschte Meinungsvielfalt gesehen

463 EGMR, 2.10.2008, 36109/03, Rn. 6 - Leroy/Frankreich.

464 Die Botschaft liege in der „Vernichtung des amerikanischen Imperialismus“, EGMR, 2.10.2008, 36109/03, NJOZ 2010, S. 512, 513, Rn. 27 - Leroy/Frankreich.

465 Der Wortlaut der Entscheidung „Toutefois, il n'en reste pas moins que le créateur, dont l'œuvre relève de l'expression politique ou militante, n'échappe pas à toute possibilité de restriction au sens du paragraphe 2 de l'article 10 : quiconque se prévaut de sa liberté d'expression assume, selon les termes de ce paragraphe, des ,devoirs et responsabilités'“" EGMR, 2.10.2008, 36109/03 Leroy/Frankreich, Rn. 44. 
wird. ${ }^{466}$ Auch wenn der spezielle Fall des Cartoons von Denis Leroy - wegen der Einzigartigkeit des zu Grunde liegenden Ereignisses - eher nicht als zu verallgemeinerndes Beispiel dienen kann, zeigt diese Entscheidung jedoch einmal mehr, wie wichtig die Beachtung des zeitlichen und örtlichen Kontextes von Karikaturen oder satirischen Arbeiten ist.

\section{Die Rechtsprechung des EuGH}

\section{Deckmyn gegen Vandersteen}

Die thematisch hier eher einschlägige Rechtsprechung des EuGH wird unter dem Parodie-Begriff verhandelt. ${ }^{467}$ Den bereits in Bezug auf die Begrifflichkeiten angesprochene Fall Deckmyn gegen die Erben Vandersteen gilt es im Folgenden näher zu beleuchten.

\section{a) Der Sachverhalt}

Als Vorlage für seine Parodie verwendete der flämisch-nationalistische Politiker Johan Deckmyn 2011 eine Zeichnung, die der erfolgreiche belgische Comiczeichner Willy Vandersteens 1961 für das Deckblatt der Folge „De Wilde Weldoener, („Der wilde Wohltäter“) aus seiner erfolgreichen belgischen Comicreihe „Suske en Wiske“ („Suske und Wiske“) angefertigt hatte. In dieser sieht man einen Mann in weißer Tunika und Melone über eine Stadt fliegen, während er Personen gönnerhaft Münzen zuwirft. Eine Menschenmasse versucht diese aufzufangen. Die Protagonisten der Reihe "Suske und Wiske“ schauen diesem erschrocken am Bildrand zu. In dem streitgegenständlichen Bild wurde der Bürgermeister der Stadt Gent zum „wilden Wohltäter" gemacht, der in gleicher Pose - jetzt mit der belgischen Flagge um den Bauch - diesmal Verschleierten und Personen mit einer dunkleren Hautfarbe Münzen zuwirft. ${ }^{468}$ Johan Deckmyn, Politiker der rechtsnationalen Partei „Vlaams Belang“, wollte auf diese Weise den

466 Vgl. beispielsweise Harris/O'Boyle/Warbick, Law of the ECHR, New York ${ }^{3} 2014$, S. 623; Cueni, Schutz von Satire im Rahmen der Meinungsfreiheit, 2019, S.91, Fn. 436. m.w.N.

467 Siehe dazu bereits hier Kap. 2, C., II.

468 Vgl. zum Sachverhalt EuGH, 3.9.2014, C-201/13, GRUR Int. 2014, S. 969, 970, Rn. 9 - Deckmyn, ferner auch die Abbildung im Urteil des belgischen Gerichts, Hof van Beroep te Brussel, 8.4.2013, 2011/AR 914, 2011/AR 915, S. 4 f. 
Umgang mit den Steuergeldern der Stadt Gent durch ihren damaligen Bürgermeister angreifen. Die verfremdete Zeichnung wurde für das Deckblatt von Kalendern eingesetzt, die 2011 bei einer Neujahrsveranstaltung der „Vlaams Belang“, d.h. in einem politischen Kontext, verteilt wurden.

b) Rechtliche Bewertung: Zwischen Parodie und Satire

Im Rechtsstreit Deckmyn vs. Vandersteen ging es im Kern jedoch nicht, wie in den vielen davor besprochenen Fällen, um eine Kollision von Äußerungsfreiheit und dem Persönlichkeitsrecht des Bürgermeisters, sondern um eine Abwägung zwischen der Meinungsfreiheit und dem Urheberrecht des Vorlagenschöpfers. Ohne hier auf die urheberrechtlichen Details einzugehen, die in der fachspezifischen Literatur umfassend besprochen wurden, seien jedoch einige Punkte angemerkt.

Zunächst fällt ins Auge, dass der EuGH die Zeichnung unter dem Begriff der Parodie verhandelt hat. Das mag zunächst, angesichts der Ausführungen des zweiten Kapitels der vorliegenden Arbeit überraschen, vor allem wenn man bedenkt, dass die parodistische Verfremdung des „Suske en Wiske“-Covers eher der Satire zuzuordnen ist. Schließlich wird durch die Verfremdung in nicht unwitziger Weise Kritik an der Politik des Genter Bürgermeisters, dem auf diese Weise eine unausgewogene Verteilung der Finanzmittel der Stadt vorgehalten wird, geübt. Da in diesem Rechtsstreit aber nicht das Angriffsobjekt - der Bürgermeister - sich gegen die Darstellung gewehrt hatte, sondern die Erben des Urhebers des Comics, verschiebt sich die Perspektive von der gegenständlichen Kritik auf die Ebene des Umgangs mit der Vorlage. Diese Beziehung zwischen Werk und Vorlagewerk mag dann nur der Begriff der Parodie auffangen, denn es ist der Parodie wesenseigen, dass sie sich einer Vorlage bedient. Dies spiegelt sich auch in dem Wortlaut der einschlägigen europarechtlichen Richtlinie in Art. 5 Abs. 3 lit. k RL 2001/29/EG wider, in der explizit nur von Karikaturen, Parodien und Pastiches gesprochen wird.

Als zweiten Punkt bezüglich der Urteilsfindung in Sachen Deckmyn gegen Vandersteen fällt auf, dass für die Einordnung als Parodie die entscheidenden Merkmale darin gesehen werden, dass zum einen an ein bestehendes Werk erinnert wird, wobei aber trotzdem wahrnehmbare Unterschiede erkennbar sind, und zum anderen ein Element von Humor oder 
eine Verspottung vorliegt. ${ }^{469}$ Entscheidend in diesem Fall war aber auch, dass der unionsrechtliche Parodiebegriff nicht von den Voraussetzungen abhängt, „dass die Parodie einen eigenen ursprünglichen Charakter hat, der nicht nur darin besteht, gegenüber dem parodierten ursprünglichen Werk wahrnehmbare Unterschiede aufzuweisen, dass sie vernünftigerweise einer anderen Person als dem Urheber des ursprünglichen Werkes zugeschrieben werden kann, dass sie das ursprüngliche Werk selbst betrifft oder dass sie das parodierte Werk angibt." ${ }^{\text {"470 }}$

Es wird weder das Comic „Suske und Wiske“, noch der Zeichner Vandersteen angegriffen oder humoristisch verspottet, vielmehr wird die Originalzeichnung lediglich als Mittel verwendet, um den Bürgermeister anzugreifen. Das hat zur Folge, dass die Perspektive relevant ist. Zwischen Deckmyn und dem Zeichner Vandersteen ist die Parodie relevant, die mit der Drittwirkung gegenüber dem Bürgermeister satirisch aufgeladen ist, wohingegen in der Beziehung zwischen Deckmyn und dem Bürgermeister das Bild als eine Satire einzustufen ist, die in Bezug auf den Comiczeichner in diesem Fall eben nicht parodierend ist und nach der EuGH-Entscheidung auch nicht in diesem Verhältnis parodierend sein muss. Das Gericht merkte in diesem Zusammenhang an, dass es grundsätzlich ein berechtigtes Interesse des Urhebers sei, dass ein geschütztes Werk nicht mit einer diskriminierenden Aussage in Verbindung gebracht wird. ${ }^{471}$ Eine solche Diskriminierung könnte laut dem Gerichtshof darin gesehen werden, dass die Figuren, die im Vorlagewerk die Münzen einsammeln, in der Deckmyn-Version durch verschleierte Personen und Menschen mit dunklerer Hautfarbe, die stellvertretend jeweils für Menschen muslimischen Glaubens und afrikanischer Herkunft stehen, ausgetauscht wurden. ${ }^{472}$

c) Zwischen Parodie und Satire im Lichte des Europarechts

Im Ergebnis ist damit festzuhalten, dass abhängig von der Perspektive und dem damit zusammenhängenden rechtlichen Schutzgut der parodistische oder der satirische Aspekt stärker in den Vordergrund rückt.

469 EuGH, 3.9.2014, C-201/13, GRUR Int. 2014, S. 969, 970, Rn. 33 - Deckmyn; vgl. dazu auch Kap. 2, C., II.

470 EuGH, ebd.

471 EuGH, 3.9.2014, C-201/13, GRUR Int. 2014, S. 969, 970, Rn. 31 - Deckmyn.

472 EuGH, ebd., Rn. 29. 
2. Das Spannungsverhältnis Persönlichkeitsrecht und Kommunikationsfreiheiten im Europarecht

In den Unionsgrundrechen wird die Meinungsfreiheit über Art. 11 und die Kunstfreiheit über Art. 13 der EU-Grundrechtecharta (GRCh) geschützt. Der Persönlichkeitsschutz ergibt sich erst einmal aus Art. 7 GRCh in Form der Achtung des Privat- und Familienlebens. Der Datenschutz, der auf der nationalen Ebene mit dem Grundrecht auf informationelle Selbstbestimmung, grundrechtlich verankert ist, findet seine Entsprechung in den Unionsgrundrechten in dem Art. 8 GRCh - dem Schutz personenbezogener Daten.

Aufsehen erregten bzgl. des Anwendungsbereichs der GrundrechteCharta die beiden Beschlüsse des BVerfG zu Recht auf Vergessen I und II. Dem Beschluss Recht auf Vergessen I liegt ein Rechtsstreit zu Grunde, der lediglich im Anwendungsbereich des Unionsrecht liegt, für das die Mitgliedstaaten aber einen Gestaltungsspielraum haben, wohingegen der Rechtsstreit der Entscheidung Recht auf Vergessen II auf einer unionsrechtlich vollständig determinierten Materie basiert. ${ }^{473}$ In dieser Entscheidung statuiert das BVerfG, dass „soweit die Grundrechte des Grundgesetzes durch den Anwendungsvorrang des Unionsrechts verdrängt werden, das BVerfG dessen Anwendung durch deutsche Stellen am Maßstab der Unionsgrundrechte kontrolliert." 474 Dies stützt das BVerfG auf seine Integrationsverantwortung aus Art. 23 Abs. 1 GG. ${ }^{475}$ Es setzt dabei aber auf eine enge Kooperation mit dem EuGH und weist darauf hin, dass im Zweifelsfalle das BVerfG den EuGH mittels des Vorabentscheidungsverfahrens auch im Grundrechtsbereich anrufen werde. ${ }^{476}$ Beim Beschluss Recht auf Vergessen I, prüfte das BVerfG nach der Feststellung, dass in diesem Fall keine vollständige unionsrechtliche Vereinheitlichung des Fachrechts vorliegt, die Auslegung am Maßstab der nationalen Grundrechte, auch wenn daneben gleichzeitig die Unionsgrundrechte gelten. Die nationalen Grundrechte sind dann mit der Vermutung, dass das Schutzniveau der Unionsgrundrechte durch die Anwendung der nationalen Grundrechte mitgewährleistet wird, primär anzuwenden. ${ }^{477}$ Dies wird da-

473 BVerfG, 6.11.2019, 1 BvR 16/13, GRUR 2020, S. 74-88 - Recht auf Vergessen I.

474 BVerfG, 6.11.2019, 1 BvR 276/17, GRUR 2020, S. 91, Rn. 50 - Recht auf Vergessen II.

475 BVerfG, ebd., S. 92, Rn. 52 - Recht auf Vergessen II.

476 BVerfG, 6.11.2019, 1 BvR 276/17, GRUR 2020, S.93, Rn. 68-71 - Recht auf Vergessen II.

477 BVerfG, 6.11.2019, 1 BvR 16/13, GRUR 2020, S. 74-88 - Recht auf Vergessen I. 
rauf gestützt, dass das Unionsrecht in den Bereichen mit Gestaltungsspielraum nicht eine Einheitlichkeit des Grundrechtschutzes verlangt, sondern Grundrechtsvielfalt zulässt. ${ }^{478}$

Die Unionsgrundrechte werden sicherlich an Bedeutung gewinnen, wenn sie im Falle einer völlig unionsrechtlich determinierten Rechtsmaterie zumindest im Rahmen einer Urteilsverfassungsbeschwerde vor dem BVerfG geprüft werden können. Es bleibt aber abzuwarten, ob und gegebenenfalls inwiefern die Unionsgrundrechte nun im Gefüge von BVerfG und EuGH den Bereich des äußerungsrechtlichen Bereichs des Persönlichkeitsrechts prägen werden.

Dem Völkerrecht hingegen kam für das Äußerungs- und Persönlichkeitsrecht ${ }^{479}$ mit einer Vielzahl von Entscheidungen des EGMR zu diesem Spannungsverhältnis von Persönlichkeitsschutz und Kommunikationsfreiheiten, wie es die Beispiele der Caroline von Monaco-Entscheidungen ${ }^{480}$ zeigen, bis hin zu der Rechtsprechung zu satirischen Äußerungen, von denen hier zwei Fälle beispielhaft besprochen wurden, durchaus bereits eine Leitfunktion zu.

Für die Politsatire-Plakate Klaus Staecks ist die Frage nach den Unionsgrundrechten aus zeitlicher Sicht nicht von Relevanz.

\section{G. Zwischenfazit}

Der rechtliche Satirebegriff ist im Gegensatz zu den feinen Nuancen, die in der Literatur- und Kulturwissenschaft herausgearbeitet wurden, weniger ausdifferenziert. Die Gerichte legen einen Schwerpunkt auf ein häufiges, aber nicht notwendiges Mittel der Satire, welches mit Verfremdung, Verzerrung oder Übertreibung beschrieben wird. Der Kritikpunkt in der Literatur, dass die Gerichte fälschlicherweise von dem Merkmal des Witzigen ausgehen, wird hier nicht geteilt.

Es wurde gezeigt, dass die Satire rechtlich entscheidend unter dem Grundrecht der Meinungsfreiheit beurteilt wird. Es ist zu beobachten, dass die Kunstfreiheit sowohl in der deutschen als auch in der völkerrecht-

478 BVerfG, ebd., S. 76 ff., Rn. 50-52, 66-68 - Recht auf Vergessen I.

479 Vgl. zur Leitfunktion in Fragen des unionalen Grundrechtsschutzes Grabitz/ Hilf/Nettesheim/Schorkopf, EUV, Art. 6, Rn. 57.

480 EGMR, 24.6.2004, 59320/00, GRUR 2004, S. 1051 - von Hannover/Deutschland I; EGMR, 7.2.2012, 40660/08, 60641/08 - von Hannover/Deutschland II; EGMR, 19.9.2013, 8772/10, NJW 2014, S. 1645 - von Hannover/Deutschland III. 
lichen Rechtsprechung nur bei der Karikatur oder aber im Falle der unter den formalen Kunstbegriff zu subsumierenden Arbeiten als einschlägiges Recht aufgefasst wird. Letztlich ist aber eine solche Differenzierung zwischen Kunst- und Meinungsfreiheit im Ergebnis irrelevant, da im Rahmen der Satire nicht die Äußerung oder die Kunst, sondern das Satirespezifische im Vordergrund steht.

Die nicht unumstrittene, aber dennoch grundlegende Auslegungsmethodik basiert auf der Entkleidung der Satire bis der Aussagekern deutlich wird, die selbstredend nicht von einer ausgiebigen Abwägung im Einzelfall befreit. Ausschlaggebend für die Abwägung zwischen Meinungsfreiheit und Persönlichkeitsrecht sind im Rahmen von satirischen Äußerungen neben der allgemeinen Vermutungsregel und der Idee der Reizüberflutung, die Äußerung selbst, der Kontext dieser, das Vorverhalten des Äußernden und Betroffenen sowie sonstige besonders schützenswerte Umstände. 
- Zweiter Teil - 


\section{Viertes Kapitel: Die Plakate Klaus Staecks}

\section{A. Ausgangslage: Der Stand der Plakatkunst in der BRD}

Im frühen 20. Jahrhundert besaß das künstlerisch gestaltete Plakat mit seinem politischen, Missstände entlarvenden und satirischen Charakter eine große Verbreitung und Wirkung. Abrupt endete diese Blüte mit dem Beginn der nationalsozialistischen Diktatur und der damit einhergehenden massiven staatlichen Kontrolle. Das einstige Medium der freien Meinungsäußerung, politischen Aufklärung oder auch nur der wirtschaftlichen Sachwerbung wurde zu einem einflussreichen Werkzeug nationalsozialistischer Propaganda: Adolf Hitler, das Militär und das sogenannte "Arische“ wurden in pseudopathetischer Weise heroisiert, während gegen die jüdischen Mitbürger und die marxistisch-leninistische Ideologie („Bolschewismus") in übel diffamierender und verleumderischer Form gehetzt wurde.

Nach dem Ende des Weltkrieges und der Befreiung durch die Alliierten stagnierte die deutsche Plakatkunst; zu deutlich war die manipulative Kraft des politischen Plakats aufgrund des Missbrauchs durch die nationalsozialistische Ideologie erkennbar geworden. Es musste nach neuen Wegen gesucht werden. Die US-amerikanischen Werbeplakate wurden richtungsweisend, da gerade dort an die Stelle der ideologischen Inhalte die kommerzielle Produktbewerbung trat. Die Macht der Werbung und des Konsums wurde von der US-amerikanischen Pop-Art-Bewegung und ihrem berühmtesten Vertreter Andy Warhol in einer neuen Form aufgenommen und interpretiert. Diese Plakatkunst hatte sich vom Einfluss des europäischen Jugendstils nun gänzlich gelöst. Im geteilten Deutschland entwickelte sich der künstlerische Stil der Plakatgestaltung unterschiedlich, der wirtschaftliche Aufschwung in der BRD förderte die kommerzielle Plakatwerbung. 


\section{B. Klaus Staeck}

\section{Kurzbiographie}

Klaus Staeck wurde am 28. Februar 1938 in Pulsnitz in der ehemaligen DDR geboren und wuchs in der Industriestadt Bitterfeld bei Halle an der Saale auf. Nach dem Abitur siedelte er in die BRD über, machte das westdeutsche Abitur nach und studierte in Heidelberg Rechtswissenschaften. Kurz nach seinem Studium gründete er zusammen mit Joseph Beuys 1968 den Produzentenverlag „Edition Tangente“, der seit 1972 losgelöst von den einstigen Gründungspartnern „Edition Staeck“ genannt wurde. Staeck arbeitet als Grafiker, Verleger Jurist und engagiert sich in der Politik. 1960 trat er der SPD bei, bis heute setzt er sich als Mitglied kommunal wie bundesweit für die SPD ein. Seit 1968 ist er zugelassener Rechtsanwalt. ${ }^{481}$ In den 1960er Jahren, noch während seines juristischen Studiums, begann er als politischer Künstler zu arbeiten. Seine ersten Werke sind Holzschnitte und Objekte, seit 1969 gestaltet er vor allem Plakate. Sein Werk umfasst mittlerweile über sechshundert Plakate, Postkarten und Fotografien, die zusammen mit dem Göttinger Verleger, Drucker und Grafiker Gerhard Steidl realisiert wurden. Steidl, der für qualitativ sehr anspruchsvolle Drucke bekannt ist, setzte die Skizzen und Ideen Staecks in seiner Druckerei um. ${ }^{482}$

Staeck nahm auch an etablierten Großausstellungen zeitgenössischer Kunst wie der Documenta in Kassel teil. ${ }^{483}$ Die „Edition Staeck“ verfolgt seit ihrer Gründung das Ziel, für vergleichsweise wenig Geld Grafiken und Objekte vieler berühmter Künstler zu verkaufen und auf diesem Weg auch zu popularisieren. ${ }^{484}$ Von 2006 bis Mai 2015 war Staeck in drei Amts-

481 Als Rechtsanwalt seit 5.12.1968 zugelassen.

482 Gerhard Steidl fertigte Drucke unter anderem für Joseph Beuys oder Karl Lagerfeld, vgl. ferner die umfangreiche Künstlerliste Steidls auf https://steidl.de/Kue nstler-0104172350.html. Vgl. zur Zusammenarbeit zwischen Staeck und Steidl ferner Steidl, Plakate drucken für Staeck, in: Museum Folkwang (Hrsg.), Klaus Staeck. Sand fürs Getriebe, Ausst. Kat. Museum Folkwang, 2018, S. 233-241; Steidl, Before Photoshop, in: Merkert (Hrsg.), Klaus Staeck. Schöne Aussichten. Eine Retrospektive, Ausst. Kat. Berlinische Galerie, 2009, S. 180-187.

483 Beiträge im Rahmen der Documenta 6 (1977), 7 (1982), 8 (1987), 9 (1992).

$484 \mathrm{Zu}$ den Künstlern gehören beispielsweise Bernd und Hilla Becher, Joseph Beuys, Max Bill, KP Brehmer, Marcel Broodthaers, Christo, Hans Haacke, Jannis Kounellis, Harald Naegeli, Nam June Paik, Blinky Palermo, Sigmar Polke, Gerhard Richter, Timm Ulrichs, Tomi Ungerer, Wolf Vostell und weitere. Vgl. http://www.edition-staeck.de/kuenstler.html. 
zeiten Präsident der Akademie der Künste in Berlin. Klaus Staeck wurde mit unterschiedlichen Preisen wie dem Kulturgroschen des Deutschen Kulturrats, dem August-Bebel Preis und Ehrenpreisen diverser Städte ausgezeichnet. ${ }^{485}$ Anlässlich seines 80 . Geburtstag 2018 erschienen zahlreiche Interviews im Hörfunk, Fernsehen und den Printmedien. Unter dem Titel „Klaus Staeck. Sand fürs Getriebe“ zeigte das Museum Folkwang in Essen vom 9. Februar bis zum 8. April 2018 eine umfassende Retrospektive seines Schaffens.

Die zahlreichen Auszeichnungen und nicht zuletzt das Präsidentenamt an der Berliner Akademie können vielleicht belegen, dass der Plakat-Agitator, dessen Arbeiten - wie später gezeigt wird - heftige Reaktionen auslösten, mittlerweile zum künstlerischen „Establishment“ gehört.

\section{Wichtige künstlerische Stationen}

\section{Intermedia 69}

Aufsehenerregend war das frühe Ausstellungsprojekt mit dem Namen „Intermedia 69“ im Mai 1969. Auslöser war eine geplante Ausstellung des Heidelberger Kunstvereins mit dem Titel „Plastik der Gegenwart“. Thema sowie die Auswahl der künstlerischen Beiträge empfanden die Beiratsmitglieder Klaus Staeck und Jochen Goetze als zu konservativ und begannen eine Gegenveranstaltung zu organisieren, die zu einem dreitätigen FluxusFestival mit Aktionen, Happenings, Filmen und Konzerten wurde. 486

Den Veranstaltern Staeck und Goetze gelang es, den damals noch wenig bekannten und jungen Verpackungskünstler Christo (1935-2020) zu gewinnen. So wurde das Amerika-Haus in Heidelberg (heute DeutschAmerikanisches Institut) mit einer Handvoll freiwilliger Helfer in einer 24-Stunden-Aktion für das Festival in große weiße Planen gehüllt. Dieses anspruchsvolle Projekt konnte nicht in perfekter Form umgesetzt werden und blieb daher bis zum Abbau unvollständig. Auch wenn Christo selbst über den Verlauf offensichtlich unzufrieden - diese Aktion nicht als Arbeit in seiner Werkliste führt, ${ }^{487}$ bestimmte sie doch als wichtigste Aktion das

485 August-Bebel-Stiftung (Hrsg.), Demokratie stärken, 2017.

486 Vgl. dazu https://hdkv.de/leseraum/1969-intermedia-69-das-gegenprogramm-zu m-kunstverein-2/; Staeck, Ohne Auftrag, ${ }^{2} 2001$, S. 106.

487 So wird das Projekt z.B. in der Christo eigenen Timeline seiner Projekte nicht erwähnt. Vgl. https://christojeanneclaude.net/timeline. 
Heidelberger Festival. Man muss sich darüber hinaus vergegenwärtigen, dass das Jahr 1969, also die Phase unmittelbar nach den massiven Studentenprotesten des Sommers 1968, politisch weiterhin hoch explosiv war. Zwar attackierten Staeck und Goetze mit der Intermedia die antiquierte Haltung des Heidelberger Kunstvereins, für viele Studenten war aber auch dieser Ansatz noch viel zu bürgerlich und nicht politisch genug. Im Zentrum der Kritik stand dabei die Verhüllung des Amerika-Hauses durch den amerikanisch-bulgarischen Künstler Christo: Parolen wie „Kunst als Weißmacher“, „Diese Scheiß-Verpackungsaktion ist natürlich ein prima Publicity-Gag für die Amis“ und „Kultur+Napalm! Amis raus aus Vietnam!“, „Außen Scheiß-Kunst, innen Scheiß-Dunst“ wurden auf die weißen Planen gesprüht. 488

$\mathrm{Zu}$ den 80 Teilnehmern des Heidelberger Fluxus-Festivals gehörten Künstler, die heute zu den bekanntesten ihrer Generation zählen, wie der Kanadier Dick Higgins, Günther Uecker, Michelangelo Pistoletto, Dieter Roth, Blinky Palermo und andere. ${ }^{489}$ Die Intermedia war mit ihren Aktionen, Performances, Filmen, Happenings, experimenteller Musik, Land-, Eat-, Sound- und Street-Art trotz gewisser Exzesse letztlich ein nie da gewesenes Kunst-Spektakel und das in einer pittoresken-Stadt an den Ufern des Neckars. Mit immerhin 5.000 Besuchern fand das Ereignis in den wichtigen nationalen Medien Beachtung. ${ }^{490}$

\section{Die Verbindung zu Joseph Beuys}

„Staeck ist mein politischer Gegner“ soll Joseph Beuys (1921-1986) auf einer Ausstellungseröffnung schimpfend geäußert haben. Staeck als SPDMitglied und Beuys, der der alternativen Bewegung der jungen Partei

488 Vgl. die Auswertung des städtischen Archivmaterials und der beiden Veranstalter anlässlich der Ausstellung des Kunstvereins „Intermedia 69|2009. Rückblick auf eine öffentliche Geste“, abrufbar unter http://old.hdkv.de/media/mgz/20 09/HDKV_intermedia.pdf; N.N., Richtig kühn, Der Spiegel, 1969/22, S. 185, https://magazin.spiegel.de/EpubDelivery/spiegel/pdf/45741284; Staeck, Ohne Auftrag, ${ }^{2}$ 2001, S. 107.

489 Wolf Vostell sagte ab, nachdem er erfahren hatte, dass Joseph Beuys kommen würde. Letztlich sagte dieser jedoch auch kurzfristig ab. Für eine vollständige Liste der teilnehmenden Künstler, siehe den Ausstellungskatalog. Goetze/Staeck/Gerling (Hrsg.), Intermedia '69, Ausst. Kat. Heidelberg, ${ }^{2} 1969$, o. Seitenabgaben.

490 So z.B. N.N., Richtig kühn, Der Spiegel, 1969/22, S. 185 f. (https://magazin.spieg el.de/EpubDelivery/spiegel/pdf/45741284). 
„Die Grünen“ angehörte, trennte mehr als nur die Parteimitgliedschaft. ${ }^{491}$ Gerade ihre parteipolitische Aktivität zeigt, dass Staeck sich eher in einer gemäßigten, pragmatischen Haltung für politische Entscheidungen in der SPD einsetzte, während Beuys - im Streben nach Legendenbildung und Mystifizierung - für radikale gesellschaftliche und politische Veränderungen eintrat. ${ }^{492}$ Und doch verband die beiden - trotz der offensichtlichen Unterschiede - eine Freundschaft, die in einer langjährigen und engen Zusammenarbeit mündete. So war es z.B. Staeck selbst, der veranlasste, dass das eingangs genannte Zitat von Beuys „Staeck ist mein politischer Gegner“ auf einer Postkarte, die übrigens weiterhin über die „Edition Staeck" vertrieben wird, aufgedruckt und somit festgehalten wurde.

„Wir betreten den Kunstmarkt“ war eine kollektive Protestaktion von Staeck, Beuys, Wolf Vostell und dem Galeristen Helmut Rywelski, die am 12.10.1970 stattfand und sich gegen die Zulassungsbestimmungen des „Kölner Kunstmarkts“ richtete. ${ }^{493}$ Die Protestierenden fühlten sich vom Kunstmarkt ausgeschlossen, da dieser Editoren, als welcher sich beispielsweise Klaus Staeck verstand, keinen Zugang gewährte. Der Kunstmarkt musste folglich erst „betreten“ werden. Die Parole „Wir betreten den Kunstmarkt" sollte nicht nur deutlich machen, dass es eine Schwelle gab, die es zu übertreten galt, sondern auch dass diese - ohne Einladung - nicht hätte betreten werden können. Nicht nur im Sinne einer symbolhaften Handlung, sondern sicherlich auch als Störung klopften die Beteiligten daher mit Schlüsseln an die Glastüren und Fenster der Kölner Kunsthalle.

Die „Freie Hochschule für Kreativität und interdisziplinäre Forschung“ bzw. „Free International University (F.I.U.) “ war ein von Joseph Beuys und Klaus Staeck 1973 gegründeter Verein, der bis zu seiner Auflösung 1988,

491 Beuys kandidierte 1980 im Rahmen des Bundestagswahlkampfs für die Partei Die Grünen. Diese verfehlten mit 1,5\% der Stimmen die Fünf-Prozent-Hürde deutlich. Klaus Staeck glaubt, dass der darauffolgende Kontaktverlust mit Beuys und auch den Mitgliedern der Free International University darauf zurückzuführen ist, dass diese glaubten, Staecks Einsatz für die SPD hätte das Ergebnis für die Grünen negativ beeinflusst. Letztlich war aber Beuys, als die Grünen zum ersten Mal 1983 in den Bundestag einzogen, nicht mehr dabei. Staeck, Ohne Auftrag, ${ }^{2} 2001$, S. 118.

492 Vgl. zur Gegenüberstellung zwischen Beuys und Staeck Ullrich, Art 2014/12, S. 52-56.

493 Vgl. ferner zur Dokumentation das Sediment Magazin, was eine ganze Ausgabe Joseph Beuys und der "Wir betreten den Kunstmarkt"-Aktion widmete: Zentralarchiv des internationalen Kunsthandels e.V. ZADIK (Hrsg.), Joseph Beuys. Wir betreten den Kunstmarkt, sediment. Mitteilungen zur Geschichte des Kunsthandels, 2009. 
also zwei Jahre nach Beuys Tod, bestand und keinen geringeren Anspruch formulierte, als das Hochschul- und Bildungsangebot der Bundesrepublik Deutschland durch eine alternative Kunstakademie zu ergänzen. Vielleicht scheiterte das Projekt letztendlich an den zu hoch gesetzten Zielen und sicherlich auch den fehlenden finanziellen Mitteln. Im Rahmen der Documenta 6 von 1977 sowie der Documenta 7 von 1982 erhielt das Projekt jedoch für die jeweils hundert Ausstellungstage hohe Aufmerksamkeit. So begleitete z.B. die Installation „Honigpumpe am Arbeitsplatz“ von Joseph Beuys während der Documenta 6 ein dauerhaftes Diskussionsforum, in welchem Themen aus dem Lehrplan der „Freien Hochschule für Kreativität und interdisziplinäre Forschung" vorgestellt und diskutiert wurden. ${ }^{494}$ An diesem Ort wurden vor allem die zentralen Begriffe der Beuysschen Kunsttheorie wie beispielsweise der „erweiterte Kunstbegriff“ oder aber die „soziale Plastik“verhandelt.

Georg Steidl und Klaus Staeck waren übrigens auch stete Begleiter der Reisen von Joseph Beuys. Sie nutzten diese Gelegenheiten, zahlreiche Performances wie auch die berühmten Aktionen von Beuys, die er 1974 in den USA durchgeführt hat, zu dokumentieren. ${ }^{495}$

\section{Die Plakate Klaus Staecks}

\section{Ein Einblick in die frühen Plakataktionen Klaus Staecks}

Eine der ersten Plakataktionen schuf Klaus Staeck in zeitlichem Bezug zu dem feierlich in Nürnberg begangenen 500. Geburtstag von Dürer 1971. Die Reihe, die damals entstand und später erweitert wurde, besteht aus sechs Grafiken Dürers. Staeck gab ihr den vielleicht respektlosen, jedoch humoristischen und leicht dadaistischen Titel „Fromage à Dürer“. $\mathrm{Zu}$ dieser Reihe gehören die Studie Dürers zu den betenden Händen eines Apostels, die Staeck mit Flügelschrauben versieht und den Titel „Zur Konfirmation“ gibt ${ }^{496}$, sowie Dürers Porträtzeichnung von dessen 63-jähriger Mutter Barbara Dürer von 1514. ${ }^{497}$ Diese Kohlezeichnung seiner von Alter,

494 Die Documenta 7 begleitete auch ein durch die Free International University organisiertes Veranstaltungsprogramm, in dem der erweiterte Kunstbegriff als wesensgemäßer Kapitalbegriff diskutiert wurde.

495 Vgl. Staeck/Steidl, Beuys in Amerika, 1987.

496 http://www.edition-staeck.de/index.php?url=pl002-pl-zur-konfirmation.html.

497 Mit Dürer setzte sich Staeck über die Zeit hinweg häufiger auseinander. So schuf er 1987 zum Welttierschutztag 1987 eine Version des berühmten Feldha- 
Krankheit und Arbeit gezeichneten Mutter, die kurz vor ihrem Tod entstanden ist, gehört zu den bedeutendsten Arbeiten Dürers, denn sie zeigt in bemerkenswerter Weise ein lebensnahes Porträt - ohne Stilisierung oder Typisierung. In der Zeit des Nationalsozialismus wurde diese Zeichnung zum Inbegriff einer „Deutschen Mutter“, auch die Person Barbara Dürer wurde wegen ihrer Frömmigkeit und ihres Aufopferungswillens als hart arbeitende, viel gebärende Mutter von 18 Kindern (von denen nur drei das Erwachsenenalter erreichten) als Vorbild stilisiert. ${ }^{498}$

Staeck versah dieses Bild 1971 mit der einfachen und provokativen Frage „Würden Sie dieser Frau ein Zimmer vermieten?“ (Abb. 1). Die Wirkung des Plakats in der Öffentlichkeit wurde durch einen Zufall verstärkt: Gleichzeitig mit der Plakatierung an 330 Litfaßsäulen, einer Aktion, die Staeck selbst als „Plakatanschlag“ bezeichnet, fand eine Tagung des Haus- und Grundbesitzervereins in Nürnberg statt, ohne dass Staeck davon Kenntnis hatte. Der örtlich aktive Jung-Verein der SPD (die Jungsozialisten) benutzte das Plakat jedoch für eine Flugblattkampagne gegen die Wohnungsvermittlung durch Makler. ${ }^{499}$ So wurden die Plakate inhaltlich - seien sie von Staeck schon noch so politisch gemeint gewesen - mit einer genuin politischen Kampagne, die Staeck nicht antizipiert hatte, zusätzlich aufgeladen.

Dieser Vorgang sollte keine Seltenheit bleiben, vielmehr wurde eine Vielzahl der Plakate Staecks von den Jungsozialisten verwendet, auch wenn sie nie gezielte Auftragsarbeiten der SPD waren.

Die Plakate mit dem höchsten Bekanntheitsgrad hat Staeck im Wahlkampfjahr 1972 geschaffen. ${ }^{500}$ Sie nutzen allesamt eine ähnliche Dialektik. Ein Plakat aus dieser Phase ziert beispielsweise der Spruch: „Deutsche Arbeiter! Die SPD will euch eure Villen im Tessin wegnehmen.“ (Abb. 2). Ein anderes: „Die Reichen müssen reicher werden. Deshalb CDU.“ Beide Plakate wurden auch während der heißen Phase des Bundestagswahlkampfes 1972 geklebt und verbreitet, wobei sie vor dem Hintergrund des harten Ringens der beiden Volksparteien, also der SPD und der Union aus CDU und CSU, um die Wählergunst falsch verstanden werden konnten und auch wurden.

sen Dürers. Den Hasen sperrte er jedoch in einen Holzkasten, der Assoziationen zu einem Sarg weckt. http://www.edition-staeck.de/index.php?url=pl196-pl-duer er-hase.html.

498 Vgl. auch: Fleischhack, Deutsche Mütter, 1942, S. 103-125.

499 Staeck, Ohne Auftrag, ${ }^{2} 2001$, S. 41.

500 Vgl. ferner Staeck, Plakate abreißen verboten! Politische Plakate im Bundestagswahlkampf $72,{ }^{2} 1975$. 


\section{Die Methodik}

Staeck arbeitet in seinen Plakaten meist mit Collagen und bzw. oder Text-Bild-Montagen, in deren Kombination es zu einem hier genannten satirischen Bruch kommt, d.h. sie sind antithetisch aufgebaut. Abgesehen vom Aufgreifen einzelner tagespolitischer Ereignisse, beschäftigt sich Staeck meist mit großen Themen wie Fragen des sozialen Ungleichgewichts, der Gleichberechtigung zwischen Mann und Frau, Umweltpolitik und Friedenspolitik. Die Satire lebt gerade von dem inhaltlichen Verständnis der Situation, der Geschehnisse, der Personen und der Handlung, die satirisch aufgegriffen werden. Damit ist es für das Verständnis - vor allem auch in Hinblick auf die Gerichtsverfahren, die in dem nachfolgenden Kapitel besprochen werden - relevant, einen Einblick in die Geschehnisse und deren Protagonisten hauptsächlich der 1970er bis 1980er Jahre zu geben, auf die Staeck anspielt.

Mit dem Ausruf „Die Kunst findet nicht im Saale statt“501 macht Staeck seine Überzeugung erneut sichtbar, dass das Werbemedium des Plakats als Ausdrucksform und Vehikel nutzbar gemacht werden kann. Plakate wirken im öffentlichen Raum und eben nicht in den abgegrenzten Bereichen der Kontemplation, also den Museen und Galerien. Werbeplakate bzw. politische Wahlplakate folgen den schnellen Mechanismen von visueller Kommunikation, sollen innerhalb einer kurzen Zeitspanne informieren, überzeugen und appellieren. Gemäß einem inzwischen überholten Verständnis gehört Kunst in die ihr „adäquaten“ Räumlichkeiten, seien dies Museen, Ausstellungsräume oder Galerien, in denen sich der Betrachter an dem Genuss der zweckfreien Kunst erfreuen soll. Nach einem solchen, antiquierten Verständnis würden sich Kunst und politisches Plakat gegenseitig ausschließen, zumal das Plakat weder zweckfrei, noch für die Wahrnehmungsprozesse (eines obsoleten Konzepts) in den geschlossenen Räumen eines Museums konzipiert ist. Insofern wird das Spannungsverhältnis von Kunst und Politik gerade im Medium des Plakats eindringlich erfahrbar. Der öffentliche Raum ist naturgemäß jedem zugänglich. Für

501 Der Ausruf war auch der Titel von Ausstellungen, Büchern und einem Fernsehbeitrag. Vgl. beispielsweise Staeck/Adelmann, Die Kunst findet nicht im Saale statt. Politische Plakate, 1976; Die Kunst findet nicht im Saale statt - Der Plakatkünstler Klaus Staeck, 2020, Fernsehreportage, SWR, 16.4.2020, 22:45 Uhr, 60 $\min$. 
Staeck ist deshalb das Plakat ein demokratisches Medium. ${ }^{502}$ Es ist jedoch aus den gleichen Gründen ebenso aufdringlich. Es lebt nicht in einer Aura, der sich der Interessierte willentlich hingibt, sondern es „attackiert“ den Passanten, den Wartenden, den Bürger, der sich dem öffentlichen Raum nicht entziehen kann. Diese Form von Aufdringlichkeit relativiert sich jedoch von selbst, da das Plakat - ob kommerzielles Werbe-, Kunst- oder Wahlplakat - mit all seinen aggressiven Strategien der Kommunikation sui generis ein akzeptiertes Element im öffentlichen Leben darstellt. ${ }^{503}$ Der flüchtige Blick des Rezipienten muss von dem Plakat eingefangen werden, denn der Passant ist - wenn überhaupt - nur für einen kurzen Moment bereit, das Plakat aufmerksam wahrzunehmen. Deswegen fließt bei der Konzeption eines Plakats viel Einfallsreichtum in die Verknüpfung von Text und Bild. Vordergründige Wirkprinzipien von Text-Bild-Kombinationen sind Überraschung, Spannung, Schock, Übertreibung und Paradoxon, mit denen etablierte Normen bewusst gebrochen werden. ${ }^{504}$ Und doch kann auch das politische Plakat das Ergebnis eines kreativen Prozesses und demnach künstlerisch sein.

Die Plakate Staecks wurden in hohen, sechsstelligen Auflagen gedruckt und sind daher auch einfach und preiswert zu erwerben. Sie widersetzen sich auf diese Weise dem - in der Kunstwelt noch immer verbreiteten Unikatsverständnis, also der Forderung nach der Einzigartigkeit des einzelnen Kunstwerks. Dabei ist das Phänomen, „Kunst als Ware“ auf einem hierfür spezialisierten Markt zu kommerzialisieren, in gewissem Sinne erst Produkt einer Entwicklung, die die bürgerlichen Gesellschaften der westlichen Welt angestoßen haben. War das Kunstwerk doch über lange Zeiträume zumeist im Auftrag der Monarchen, Herrscher, der geistlichen oder weltlichen Würdenträger entstanden, ohne dass sich die Öffentlichkeit in irgendeiner Form einschalten konnte.

Im Vergleich zum künstlerischen Anspruch des Jungendstilplakats ${ }^{505}$, fällt andererseits ins Auge, dass die „künstlerische Durchdringung“ für Staeck nicht so sehr im Vordergrund steht. Staeck überhöht das Medium

502 Vgl. Staeck, Ohne Auftrag, ${ }^{2} 2001$, S. 101 („Als Angebote in Sachen Demokratiebedarf und Arbeitsmaterial für künstlerisch-politisch Engagierte habe ich meine Produkte oft beschrieben.").

503 Vgl. dazu die Ausführungen zum Plakat im ersten Kapitel, S. 8 ff.

504 Vgl. dazu ausführlich: Gaede, Abweichen von der Norm. Enzyklopädie kreativer Werbung, 2002.

505 Vgl. dazu Kap. 1. 
Plakat nicht aus einer rein künstlerischen Perspektive, ${ }^{506}$ da sein Schwerpunkt auf der zu vermittelnden Botschaft liegt.

Klaus Staecks Arbeiten manifestieren sich aber nicht nur in Plakaten, sondern auch in Bildpostkarten. Ansichtskarten sind wahrscheinlich das wichtigste Massenmedium in der Zeitspanne vom späten 19. Jahrhundert bis in die 1920er Jahre, ${ }^{507}$ erfreuen sich aber auch heute noch Beliebtheit. Staeck bedruckt Postkarten mit den Motiven seiner Plakate und fördert auf diesem Wege noch einmal die Verbreitung und damit die Bekanntheit der Plakatmotive. Sie erreichten aber zu keiner Zeit eine vergleichbare polarisierende Wirkung, da sie nicht im öffentlichen Raum anzutreffen waren, sondern nur von einzelnen Personen gezielt ausgewählt wurden, um wiederum an einzelne Personen verschickt zu werden. ${ }^{508}$

Wie hier im ersten Kapitel gezeigt, bedürfen Staecks Plakate einer inhaltlichen und wirkungsbezogenen Analyse, darüber hinaus sind sie kunsthistorisch und zeithistorisch einzuordnen. Ein wichtiges Kriterium stellt auch die sehr spezifische Vorgehensweise in der Kombination von Text- und Bildelementen dar. Daher soll im Folgenden die Methodik der Text-Bild-Montagen untersucht werden. Dafür gilt es zunächst die Formen der Fotomontage zu bestimmen und anschließend auf das Verhältnis von Text und Bild einzugehen. Gegenstand dieser Untersuchung sind 628 Plakate, die zwischen 1969 bis 2018 entstanden sind. Der hier gesetzte Schwerpunkt auf die Text-Bild-Montage lässt sich damit rechtfertigen, dass nur 21 Plakate reine Bildmontagen sind und nur 24 Plakate aus reinem Text bestehen, womit über 92\% der Plakate in Hinsicht auf ihr Text-BildVerhältnis untersucht werden können.

506 Vgl. dazu Fetscher, Kritik, Aufklärung und Sichtbarmachen des Verdrängten, in: Staeck/Bussmann/et al., Klaus Staeck - Rückblick in Sachen Kunst und Politik, Ausst. Kat. Frankfurter Kunstverein, Heidelberger Kunstverein, Kunstamt Tiergarten Berlin u.a., ${ }^{2} 1980$, S. 62.

507 Mit der Qualität und Aktualität vieler Postkarten konnten kaum andere Medien, wie z.B. Pressefotografien, mithalten. Ein Beispiel für massenhaft verbreitete Postkarten waren vor allem antisemitische Postkarten aus dem deutschen Kaiserreich. Vgl. dazu ausführlich Gold/Heuberger, Abgestempelt. Judenfeindliche Postkarten. Auf der Grundlage der Sammlung Wolfgang Haney, Ausst. Kat. Jüdisches Museum Frankfurt am Main, 1999.

508 Vgl. zu einer Staeck-Postkarte v.a. Kap. 5, A. 


\section{Die Montage}

Als Begründer der Montagetechnik in Form der politischen Fotomontage wird Helmut Franz Joseph Herzfeld (1891-1968), besser bekannt unter seinem anglisierten Namen John Heartfield, angesehen. ${ }^{509}$ Geprägt wurde Heartfield durch sein Mitwirken in der künstlerischen Bewegung des Dada, die die Fotomontage als künstlerische Ausdrucksform entwickelt hatte. Dabei muss man jedoch in diesem Zusammenhang beachten, dass die dadaistische Fotomontage zunächst gar nicht politisch ausgerichtet war. So verweigerte sich beispielsweise Kurt Schwitters (1887-1948), ein wichtiger Protagonist des Dada, jeder Form einer politischen Auslegung seiner Arbeiten. Heartfield wählte die Technik der Fotomontage offensichtlich aus einem ganz bestimmten Beweggrund. Er versprach sich von ihr die Überwindung der eingefahrenen Ausdrucksformen der europäischen Kunst. ${ }^{510}$ Mit seiner berühmten Arbeit „Väter und Söhne 1924“ (1924), in der er die zerstörerische Gewalt des Krieges anprangert, legt er schließlich den Grundstein für die Fotomontage im politischen Plakat als Produkt eines künstlerischen Schaffensprozesses. Die Fotomontage war nach dem Zweiten Weltkrieg eine nicht besonders beliebte künstlerische Technik. Dies sollte sich Ende der 1960er Jahre mit der Studentenbewegung wieder ändern. So wird gerade die Montage - „das Medium der Agitation, Aufklärung und Utopie“511 - als eine Möglichkeit zur politischen Aufklärung und als Überzeugungsmittel verstanden.

\section{Text-Bild-Verhältnisse}

Bilder können unter anderem informieren, emotionalisieren, manipulieren, traumatisieren, auffordern, Klischees und Stereotypen bedienen, Handlungen rechtfertigen, Diskussionen auslösen, veranschaulichen oder unterdrücken. Dass Bilder eine große Kraft und Macht im politischen Entscheidungsprozess und in der allgemeinen gesellschaftlichen Diskussion

509 Vgl. Wüst-Kralowetz, John Heartfield und die politische Fotomontage: drei Werke aus dem Jahr 1932 für die Arbeiter Illustrierte Zeitung (AIZ), in: Hemingway/Schneider (Hrsg.), Schwerpunkt: Hauptwerke politischer Kunst im 20. Jahrhundert, 2016, S. 45-56.

510 Hiepe, Die Fotomontage, Geschichte und Wesen einer Kunstform, in: Feuchtinger, Heinz-Werner, Plakatkunst des 19. und 20. Jahrhunderts, 1977, S. 21.

511 Hiepe, ebd., S. 25. 
haben, ist nicht zu leugnen. Die Satire, nahezu egal in welchem Format sie sich manifestiert, wird, selbst wenn sie nur aus Bildelementen besteht, vornehmlich nicht als Bild mit bildwissenschaftlichen Kriterien, sondern aus einem sprachwissenschaftlichen bzw. literaturwissenschaftlichen Verständnis heraus diskutiert. Die Plakate Klaus Staecks sind unter diesem Gesichtspunkt, da sie Bild und Text verwenden, grundsätzlich multimedial angelegt. Doch nur selten werden in den wissenschaftlichen Analysen beide Aspekte in ausreichendem Maß berücksichtigt. ${ }^{512}$

Die Auseinandersetzung mit dem konventionellen Bild, das aus einer höfischen und später bürgerlichen Tradition stammt, wird, bezüglich seiner künstlerischen Ausdrucksformen, genuin von den Kunstwissenschaften der alten Prägung geleistet. Es sind die formal-typischen und konventionellen Bilder, die übrigens noch weit bis in die zweite Hälfte des 20. Jahrhunderts dem ästhetischen Erleben des Kunstconnaisseurs vorbehalten waren und als solche die Forschungsobjekte der klassischen, tradierten Kunstgeschichte darstellen. Um jedoch den Kriterien einer Medienanalyse gerecht zu werden, muss der wissenschaftliche Umgang mit dem Bild um zahlreiche Einzelwissenschaften, die (inter-, trans-) disziplinär ausgerichtet sind, erweitert werden. ${ }^{513}$ Die Plakate Staecks sollen insofern hier gerade nicht nur als ein Exemplum der Satire aus einer literaturwissenschaftlichen Sicht, oder nur als Bilder im Sinne einer bildwissenschaftlichen Perspektive, sondern vielmehr in Bezug auf Text-Bild-Verhältnisse analysiert werden. Die Bild-Linguistik ist im Rahmen der sprachwissenschaftlichen Forschung ein relativ neuer Anknüpfungspunkt, nach welchem die Wirkung von Text und Bild im Kommunikationsprozess untersucht wird. Maßgeblich in diesem Bereich sind ein Sammelband zur Bild-Linguistik, herausgegeben von Hajo Dieckmannshenke, Michael Klemm und Hart-

512 Vgl. dazu stellvertretend, Rosenberger, JbGSG 2014, S. 267: „[...] die Satire bei aller Multimedialität - [wird] wesentlich durch Sprache konstituiert [...]. Bei der Satire handelt es sich um eine bestimmte Art, Sprache zu gebrauchen und sie als Kampfmittel einzusetzen. Die Analyse der Satire und der sie konstituierenden sprachlichen Merkmale ist damit ein wesentlicher Teil der linguistischen Diskursanalyse und verdient folglich verstärkte Aufmerksamkeit.“.

513 Darunter werden Medien-, Kommunikations- und allgemein Kulturwissenschaften verstanden. 
mut Stöckl ${ }^{514}$ sowie die Dissertation von Franziska Große zu Grundbegriffen und Methoden der linguistischen Bildanalyse ${ }^{515}$.

a) Die bild-linguistische Untersuchung der Plakate im Allgemeinen

Plakate sind in ihrer Wahrnehmung non-lineare Kommunikationsformen. Dem Rezipienten wird also freigestellt, die Reihenfolge, in der die Angebote rezipiert werden, selbst zu bestimmen. Dennoch lassen sich bei der - ja zumeist intuitiv ablaufenden - Wahrnehmung von Plakaten einzelne Gesetzmäßigkeiten bezüglich der Abfolge des Blickes ausmachen. In der für das Plakat typischen Beziehung zwischen Text und Bild kann das Verhältnis dieser zueinander unterschiedlich ausfallen. So kann das Bild den vorbeistreifenden Blick des Betrachters fangen, aber eben auch der Text. Schriftzeichen sind - in der Perspektive der Kulturgeschichte - zumeist aus Bildelementen, bzw. Glyphen - vielleicht in einem ähnlichen Prozess, wie in der Entwicklung des einzelnen Menschen das Sehen dem Lesen und Sprechen vorausgeht - entstanden. Liegt der Vorteil der Schrift und des Textes darin, in konkreter und präziser Form bestimmte Aspekte zu benennen, Handlungen zu beschreiben oder aufzurufen, so muss doch zunächst die Schwelle der Schrift, nämlich die Dekodierung der Schriftzeichen, überwunden werden. Das Bild ist insofern verständlicher, als dass es ohne diese Hürde ganzheitlich wahrgenommen wird, auch wenn die Bedeutung meist unbestimmter bleibt. Betrachtet man den Wahrnehmungsund Vermittlungsprozess von Bildern in zeitlicher Hinsicht, dann können diese als „schnelle Schüsse ins Gehirn“ bezeichnet werden. ${ }^{516}$ Das Verhältnis von Text und Bildern kann aber typologisch aufgeteilt werden, wofür sich an die bildlinguistischen Gruppen der Dominanz, Redundanz, Komplementarität und Kontradiktion angelehnt wird.517 Diese sollen anhand von Beispielen aus den 628 Plakaten Klaus Staecks gezeigt werden.

514 Dieckmannshenke/Klemm/Stöckl (Hrsg.), Bildlinguistik. Theorien - Methoden Fallbeispiele, Berlin 2011.

515 Große, Bild-Linguistik. Grundbegriffe und Methoden der linguistischen Bildanalyse in Text- und Diskursumgebungen, 2011.

516 So in Kroeber-Riel, Bildkommunikation. Immagery-Strategien für die Werbung, 1993, S. 53; Stöckl, Sprache-Bild-Texte lesen. Bausteine zur Methodik einer Grundkompetenz, in: Dieckmannshenke/Klemm/Stöckl (Hrsg.), Bildlinguistik. Theorien - Methoden - Fallbeispiele, 2011, S. 49.

517 Vgl. zur Terminologie mit weiteren Nachweisen Nöth, Der Zusammenhang von Text und Bild, in: Antos/Brinker/Heinemann/Sager (Hrsg.), Text- und Ge- 
b) Plakatbeispiele

aa) Dominanz und Redundanz

Das Plakat „Achtung Arbeiter! Die SPD will euch eure Villen im Tessin wegnehmen" (Abb. 2) von 1972 zeigt in einer Untersicht das gelb hinterlegte Schwarzweißfoto einer Villa im modernen Stil aus Sicht-Beton auf einem steilen Berg vor blauem Grund. Die gelbe Villa und der blaue Himmel teilen die untere und obere Fläche des Plakats unter sich auf. In großen schwarzen Lettern altdeutscher Schrift werden die deutschen Arbeiter angesprochen - mit Ausrufezeichen. In dicken, schwarzen, serifenlosen Druckbuchstaben folgen als Unterüberschrift die Worte „Die SPD will euch eure Villen im Tessin wegnehmen“. Betrachtet man zur Auslegung des Plakats das Bild genauer, dann fällt auf, dass die Villa kein historisches oder älteres Gebäude ist. Die Architektur der Villa erschien, als Staeck das Plakat Anfang der 1970er Jahre entworfen hatte, ultramodern und verkörperte den damals aktuellen Traum von einem luxuriösen Wohnhaus in Hanglage, wobei die Untersicht den repräsentativen Charakter betont. Es geht hier nicht darum, assoziativ auf das „alte“ Geld, die Vermögen des europäischen Adels oder sonstige, traditionell elitäre, Bevölkerungsgruppen anzuspielen, sondern auf das „neue Geld“: Vor der steuerlichen Belastung in Deutschland häufig durch Steuervermeidung oder Steuerflucht geschützt, manifestiert sich privater Reichtum als Eigentum in der italienischen Schweiz. Das Bild der Villa ist grafisch leicht umsetzbar und mit ihren klaren, nicht verschnörkelten Linien in ihrer Wirkung eindeutig. Auf dem Plakat konkurrieren jedoch Schrift und Bild. Die Unteransicht auf die Villa stört eine Leserichtung von oben nach unten, die durch das große Schriftbild in der oberen Hälfte eigentlich eingefordert wird. Das Text-Bild-Verhältnis behindert den Wahrnehmungsprozess, obwohl das Bild keine weitere Zusatzinformation liefert, sondern nur die Aussage „Villen im Tessin“ exemplarisch verbildlicht, bzw. präzisiert, welche Art von Villen gemeint ist. Da der deutsche Arbeiter keine Villen im Tessin besitzt, und da die Aussage, die SPD wolle diese Villen wegnehmen, einen Bruch zur Realität darstellt, schafft das Plakat eine scharfe Antithese, die aber nicht zwischen Text und Bild liegt, sondern in den Textelementen verortet ist. Somit kommt dem Text gegenüber dem Bild eine dominante Rolle zu.

sprächslinguistik. Ein internationales Handbuch zeitgenössischer Forschung, 1. Halbband, 2001, S. 492 ff. 


\section{bb) Komplementarität}

Das bereits zu Beginn des Kapitels behandelte Plakat von 1971 mit dem Titel „Sozialfall“, das eine Reproduktion der Kohlezeichnung Albrecht Dürers von seiner alten Mutter und der in Kontrastfarbe abgedruckten Frage „Würden Sie dieser Frau ein Zimmer vermieten?" (Abb. 1) zeigt, ist ein Beispiel für eine Arbeit von Klaus Staeck, in der Text und Bild ergänzend, ohne Bruch und gleichwertig nebeneinanderstehen. Der Text bezieht sich unmittelbar auf das Bild, indem es mit dem Demonstrativpronomen „dieser" die Verbindung zu der abgebildeten Frau aufbaut. Das Bild ist dementsprechend nicht beispielhaft veranschaulichend, da es nicht so einfach auszutauschen wäre. Text oder Bild würden für die Plakataussage nicht unabhängig voneinander funktionieren.

Wie das Plakat verstanden und wahrgenommen wird, hängt vom Betrachter ab. Der Wahrnehmungsprozess reicht vom gebildeten Bestimmen, dass es sich um eine Zeichnung von Dürer handelt, über das Erkennen, dass es sich um eine historische Zeichnung oder die Reproduktion eines Kunstwerks handelt, bis hin zum Nicht-Erkennen von alledem. Wird der Kunstwerksbezug nicht gesehen, so bleibt die Frage, ob man diese offensichtlich alte und vor allem wahrscheinlich arme Frau als Mieterin nehmen würde, als eine Frage an das soziale Gewissen des Betrachters bestehen. Wird der Bezug zu Dürer erkannt, eröffnet sich eine neue Bedeutungsebene. Die Zeichnung Albrecht Dürers von 1514 lässt sich als ein Meisterwerk und Meilenstein der Renaissance nicht nur im nordalpinen Raum bewerten: Sicherlich würde das Bildungsbürgertum ausnahmslos diese Arbeit in die eigene Kunstsammlung - wenn es auch nur des Künstlernamens wegen sein mag - aufnehmen. Das von Staeck hinzugefügte Textelement blockiert jedoch die Betrachtung der Zeichnung unter ästhetischen Gesichtspunkten, sondern verweist auf eine sozialethische Ebene. Die unterschiedlichen Auslegungsebenen des Bildes zeigen auch das Verständnis des Demonstrativpronomens in „dieser Frau“. Mit „dieser Frau“ kann erstmal nur Barbara Dürer gemeint sein, oder es verweist unbestimmter eher auf „eine solche Frau“ oder in Kombination beider Möglichkeiten „eine solche Frau wie die Mutter Dürers“.518 Wie auch immer das Plakat rezipiert wird, es zeichnet sich durch die Komplementarität von Text und Bild aus, die durch das Demonstrativpronomen noch einmal verstärkt wird.

518 Dazu ausführlicher Muckenhaupt, Text und Bild, 1986, S. 59-61, v.a. S. 61. 
cc) Kontradiktion

"Jeder zweite Abgeordnete ist eine Frau"steht in großen, gelben, serifenlosen Lettern im oberen rechten schwarzen Feld eines Staeck-Plakats von 1976. ${ }^{519}$ Die restliche Fläche füllt die Schwarzweißfotografie einer Parlamentssitzung. In den Reihen sitzen nur Männer. Hier kommt es zum „Bruch“ zwischen der auf dem Bild dargestellten Realität und dem Text, der letztlich nur wie ein unerfülltes Versprechen verhallt. Für den Realitätsbezug bedarf es - anders als in dem Plakat zu den deutschen Arbeitern - kein weiterführendes Verständnis. Der „Bruch“ wird mit dem Bildteil des Plakats selbst erreicht. Erst durch das ausgewogene Zusammenspiel von Bild und Text kommt die volle Wirkung des Plakats zum Tragen, womit in diesem Fall Text und Bild für das Verständnis des Satirischen gleichermaßen wichtig sind.

Die Kontradiktion ist für Staeck ein beliebter Umgang mit Text-BildKombinationen, z.B. auch im Falle eines Plakats von 1977, das die Überschrift "Jeder 2. Deutsche hat Übergewicht" trägt und eine Schwarzweißfotografie zweier Kinder mit ausgezehrten, stark unterernährten Körpern zeigt, die leere Teller in den Händen halten und um Essen bitten. ${ }^{520}$ In den beiden letztgenannten Fällen wird die Fotografie als Beweis der Realität verwendet.

In dem Plakat „Im Mittelpunkt steht immer der Mensch“ (1980)521 kommt es auch zu einem Bruch zwischen Text und Bild, jedoch nicht durch eine Fotografie, sondern eine Fotomontage, die eine für den Satiriker bestehende Wahrheit wiedergibt. Diese besteht aus der Fotografie eines Mannes in Anzug und Krawatte, von dem jedoch nur der obere Brustbereich sichtbar ist, und einem Strichcode, der das Gesicht und damit den unverwechselbaren Teil der Physiognomie eines Menschen überdeckt. Der Barcode und somit das Bild stehen im scharfen Gegensatz zur Aussage des Textes.

519 https://www.edition-staeck.de/produkt/pl-gleichberechtigung/.

$520 \mathrm{https} / /$ www.edition-staeck.de/produkt/pl-uebergewicht/.

521 https://www.edition-staeck.de/produkt/pl-im-mittelpunkt-steht-immer-der-mens $\mathrm{ch} /$. 
dd) Kontextualität

Wie schon bei der Analyse des Dürer-Plakats gezeigt wurde, ist der Wahrnehmungs- bzw. Verständnisprozess maßgeblich vom Kenntnis- und Erfahrungsschatz des Betrachters abhängig. Das Plakat, das Klaus Staeck 1972 entworfen hat und das Franz Josef Strauß mit der Überschrift „Entmannt alle Wüstlinge" (Abb. 3) in Metzgerkleidung und den Worten "Wählt christlich“ auf der Schürze zeigt, entfaltet seine Wirkung in ganz besonderem Maße durch den Kontext. Denn erst ein differenziertes kulturhistorisches Wissen ermöglicht das vertiefte Verständnis des Plakats. Mit John Heartfields Fotomontage „Nur keine Angst, er ist Vegetarier“ (1936), auf der Adolf Hitler als Metzger abgebildet ist, die Messer wetzend, um den vor sich auf einem Tisch stehenden gallischen Hahn zu schlachten, vor dem geistigen Auge erkennt man, welche zusätzliche, weitreichende Dimension die Strauß-Kritik erhält. Mit der ähnlichen Pose und der Darstellung als Metzger werden Strauß und Hitler auf eine auch inhaltlich verwandte Ebene gestellt. Dieses Plakat ist aber auch ein gutes Beispiel für das Phänomen, dass ein Künstler, sobald er sein Werk veröffentlicht hat, kaum noch Einfluss auf den Wahrnehmungsprozess nehmen kann. Nach Angaben Staecks war das Plakat längst nicht so „böse gemeint“522 und ein Bezug zu Heartfield und dessen Hitlerkarikatur gar nicht beabsichtigt. Staeck konnte nicht verhindern, dass dieses Plakat einerseits häufig in den kunsthistorischen Kontext eingeordnet wurde, sprich mit Heartfield verbunden wurde, und andererseits, dass das Plakat vornehmlich von Mitgliedern der CDU/CSU-Fraktion als besonders verletzend eingestuft wurde.

\section{c) Das Satirische in den Plakaten Staecks}

Die Aufwertung des eigenen Produkts bzw. die dadurch indirekte Abwertung des fremden Produkts sind nicht nur Mittel der Werbesprache, sondern auch des politischen Plakats. Im Politischen steht die Abwertung der anderen Parteien, oder der inhaltlich nahen Parteien und damit in Bezug auf den anvisierten Wählerkreis größten Konkurrenten, oder der von diesen Parteien verkörperten Werte im Vordergrund. Auch wenn nur wenige Plakate von Klaus Staeck genuine politische Wahlplakate sind, haben doch alle Plakate Staecks die Gemeinsamkeit, dass sie politisch

522 Staeck, Ohne Auftrag, ${ }^{2} 2001$, S. 95. 
sind. $\mathrm{Zu}$ beachten ist dabei jedoch, dass nicht zwingend alle Plakate des Künstlers als satirische Arbeiten verstanden werden müssen.

Wie bereits ausgeführt, wird der „Bruch“ in Form eines überraschenden Gegensatzes als das zentrale Stilmittel der Staeckschen Plakatentwürfe angeführt. Diese „Brüche“ können jedoch in ganz unterschiedlicher Art und Weise hervorgerufen werden. Die Staeck-Plakate können so mit den Kriterien, die sich zum einen in Bezug auf Werbeplakate für Text-Bild-Verhältnisse und zum anderen bzgl. Wahlplakaten entwickeln ließen, untersucht und eingeordnet werden: So kann die Frage, ob und wann welche Mittel für die Satire verwendet wurden, herausgearbeitet werden. Der „Bruch“ in den Plakaten Staecks kann zum einen satirisch, und zwar im engeren Sinne des Begriffs sein. Die Auseinandersetzung mit der Funktionsweise des Plakats und so dem sogenannten Bruch oder dargestellten Gegensatz befreit aber nicht von der Untersuchung, ob eine Satire definitionsgemäß - wie es im zweiten Kapitel herausgearbeitet wurde - vorliegt. Das Plakat mit der Zeichnung Dürers Mutter und der Aufschrift „Würden Sie dieser Frau ein Zimmer vermieten?" stellt beispielsweise eine direkte Frage, die sozialethisches Verhalten hinterfragt. Die Kritik liegt in dem Ungleichgewicht, dass Vermieter nur einkommensstarke Mieter bevorzugen und es daher besonders für Arme und Alte schwer ist, an Mietwohnungen zu gelangen. Dieser Kritik wird mit der Referenz auf Dürers Mutter eine zweite Ebene gegeben. Nun trifft das Plakat eine Hypokrisie der Deutschen, zum einen die Mutter des größten deutschen Künstlers zu stilisieren, wenn sie doch aus anderer Perspektive ein Sozialfall wäre. Die Kritik richtet sich insofern auf ein Ungleichgewicht, welches mit Hilfe der Text-Bild-Kombination in humoristischer Form beim Betrachter durch die direkte Frage einen Denkanstoß auslösen soll. Staeck baut insofern, nahezu idealtypisch für den Witz, eine Erwartung auf, die anschließend überraschend - oder eben pointiert - aufgelöst wird. Das Witzige in den Plakaten liegt also in der Inszenierung des Unerwarteten.

\section{Konflikte und Aktionen nicht juristischer Art}

\section{Der Fall Staeck}

Anlass für den sogenannten „Fall Staeck“ (manchmal auch „Affäre Staeck“ oder „Londoner Zwischenfall“) war eine Ausstellung deutscher Gegenwartskünstler mit dem Titel „Art into Society - Society into Art: Seven German Artists“, die vom 30. Oktober bis zum 24. November 1974 im 
Londoner „Institute of Contemporary Arts“ gezeigt wurde. Die beteiligten Künstler waren neben Staeck unter anderem Joseph Beuys, KP Brehmer, Hans Haacke, Dieter Hacker, Albrecht/d. und Gustav Metzger. Von Staeck waren unter anderem die Plakate „Konturen eines Amtsarsches“ (1974) und der messerwetzende Strauß mit dem Text „Entmannt alle Wüstlinge“ (1972) vertreten. Der CSU-Bundestagsabgeordnete Max Schulze-Vorberg erkundigte sich bei dem damaligen Außenminister Hans-Dietrich Genscher einerseits nach Möglichkeiten, sich gegen die in seinen Augen verletzenden Plakate zur Wehr zu setzen und andererseits wollte er wissen, wie viel Geld diese Kunstausstellung den deutschen Steuerzahler gekostet habe. ${ }^{523}$ Die Kosten wie auch die Resonanz der Ausstellung hielten sich in Grenzen, auch wenn ihr rückblickend eine ermutigende Wirkung auf die politische Kunst Großbritanniens zugesprochen wurde. ${ }^{524}$ Insgesamt besuchten 9.000 Menschen die Ausstellung, die wohl umgerechnet ca. 100.000 DM kostete. Der größte Teil der Kosten wurde von der britischen Regierung, einer britischen Privatfirma und dem Institute of Contemporary Art getragen. Der Londoner Standort des deutschen Goethe-Instituts hatte den Katalogdruck mit ca. 10.000 DM unterstützt. Der damalige Außenminister kommentierte in einem Brief an Schulze-Vorberg, der in den Medien zitiert wurde, dass er „den Präsidenten und das Präsidium des Goethe-Instituts [hat] wissen lassen, dass [er] die Zahlung eines Zuschusses $[\ldots]$ ohne ausreichende Prüfung des Verwendungszweckes, d.h. der Förderungswürdigkeit der Ausstellung missbilligt. Die von [dem Bundestagsabgeordneten] zu Recht monierte Mitfinanzierung des Katalogs ist zu bedauern. " 525 Die Ausstellung wurde auch in Großbritannien nicht nur positiv aufgenommen. So wurde beispielsweise einer ganzen Künstlergeneration die Pervertierung von Kunst vorgeworfen. ${ }^{526}$

523 Zit. nach Zimmer, Wie liberal wollen wir sein, Die Zeit,1975/5; N.N., Affären. Verdikt gegen Entmannung, Der Spiegel, 1975/4, S. 91.

524 „This show demonstrated that the politicization of art was not confined to Britain and therefore it encouraged British, left-wing artists." Walker, Left Shift. Radical Art in 1970s Britain, 2002, S. 125.

525 Zit. nach Zimmer, Wie liberal wollen wir sein, Die Zeit, 1975/5.

526 „This generation of political artists has contrived to give us the worst of all possible worlds - they have subverted (or perverted) art while failing to alter the art establishment by one iota and they have rendered suspect any genuine attempt to introduce political and social content back into art." Daley, Art into Society - Society into Art, U Magazine, Vol. 1, No. 2 (Dezember 1974), o. Seitenangeben, zit. nach: Walker, Left Shift. Radical Art in 1970s Britain, 2002, S. 125 . 
Diese „Affäre Staeck“ wurde einem größeren Publikum bekannt, als Heinrich Böll im Januar 1975 in der Kultursendung „ttt - titel, thesen, temperamente“ der ARD von "ganz massiven Zensurmaßnahmen“ sprach und so die deutsche Kulturpolitik kritisierte. ${ }^{527}$

Es war das Anliegen Staecks, durch eine aufwendige Dokumentation zu verdeutlichen, dass es sich bei dieser "Affäre“ nicht um einen Einzelfall, sondern um ein gängiges und häufiges Phänomen in dem System Kulturpolitik handele. .28

\section{Der sogenannte Bonner Bildersturm}

Im März 1976 folgte Klaus Staeck der Einladung zu einer Ausstellung einer Auswahl seiner Plakate bei der Deutschen Parlamentarischen Gesellschaft - einer überparteilichen Vereinigung von Bundestagsabgeordneten. Während der Eröffnung bestand eine Reihe von Mitgliedern der CDU/ CSU-Fraktion erfolglos darauf, dass die Plakate entfernt werden sollten. Einige der Unionsabgeordneten - unter anderem der damalige CDU-Fraktionsgeschäftsführer Philipp Jenninger - rissen daraufhin die Plakate eigenhändig von den Wänden. Letztlich schloss der Vorstand der Deutschen Parlamentarischen Gesellschaft nur drei Stunden nach Eröffnung die Ausstellung. Dieser Eklat, der unter dem Begriff „Bonner Bildersturm“ und so in begrifflicher Nähe zu dem reformatorischen Bildersturm des 16. Jahrhunderts rezipiert wird, wurde in der Presse ausführlich besprochen. „Schweinestall“, „Der Mist muss rausgetragen werden“, „Nächstens lässt der seine Hose runter und zeigt seinen nackten Hintern und sagt, das wäre Kunst“529 sollen neben den Ausdrücken "politischer Pornographie“530 und „entarteter Kunst“ ${ }^{\star 531}$ die Ausrufe gewesen sein, mit denen die Ausstellungsräume „gestürmt“ wurden. Mag das nach einer Affekttat einzelner

527 Böll, Wie man eine Sache hochspielen kann, in: Karst (Hrsg.), Der Fall Staeck oder: wie politisch darf die Kunst sein?, 1975, S. 9-11.

528 Vgl. zu der Dokumentation: Karst (Hrsg.), Der Fall Staeck oder: wie politisch darf die Kunst sein?, 1975.

529 Vgl. Berichterstattung Foerster, „Der Mist muss unbedingt rausgetragen werden“, Nürnberger Nachrichten, 1.4.1976.

530 Richard Stücklen (CSU), zit. nach: N.N., Rheinische Post, 1.4.1976, abgedruckt in: Staeck/Adelmann, Der Bonner Bildersturm oder: was die CDU von Demokratie hält, ${ }^{2} 1976$, S. 17.

531 Vgl. Berichterstattung, N.N., FAZ, 1.4.1976, abgedruckt in: Staeck/Adelmann, Der Bonner Bildersturm oder: was die CDU von Demokratie hält, ${ }^{2} 1976$, S. 12. 
Abgeordneter auf die provozierenden Plakate klingen, berichteten jedoch Augenzeugen, dass die Politiker erst die Räume stürmten, als Journalisten anwesend, Kameras eingestellt und Fernsehkameras angeschaltet worden waren. ${ }^{532}$ Es sei außerdem hinzugefügt, dass die Ausstellung angekündigt war und zunächst keinen Widerspruch hervorgerufen hatte. Die Plakate, die der Auslöser der Kritik waren und heruntergerissen wurden, standen allesamt in Bezug zu dem Militärputsch und dem Sturz des zuvor demokratisch gewählten sozialistischen Präsidenten Salvador Allende in Chile am 11. September 1973. So zeigt ein Plakat eine Fotografie des chilenischen Junta-Generals Pinochet verbunden mit dessen Worten: „Die Demokratie muss gelegentlich in Blut gebadet werden“. Ein weiteres Plakat dieser Ausstellung trägt den Text „25 Jahre Menschenrechte - 25 Jahre Menschenfolter", während ein drittes Plakat eine Fotografie der verhafteten Allende-Anhänger im Fußballstadion von Santiago de Chile mit der Überschrift „Seit Chile wissen wir genauer, was die CDU von Demokratie hält" zeigt. Dieses Plakat zitierte darüber hinaus die umstrittenen Ausführungen „Das Leben im Stadion ist bei sonnigem Wetter recht angenehm.“, die der frühere CDU-Generalsekretärs Bruno Heck nach dem Besuch des besagten Stadions, in dem mehr als 5.000 Menschen unter unwürdigen Umständen festgehalten wurden, getätigt hatte. ${ }^{533}$

Es stellt sich die Frage, warum diese Ausstellung, bei der auf Grund des Ausstellungsortes und einer Dauer von nur zwei Wochen keine besonders große Außenwirkung zu erwarten war, solch heftige Reaktionen auslösen konnte. Sicherlich machen die Plakate, die Folter und politische Unterdrückung zeigen, betroffen und „das Sichtbarmachen des Verdrängten ist gewiss eine - wenn nicht die wichtigste Ursache für die Wirkung Staeckscher Plakate. " 534 Der von den USA unterstützte Putsch war als zentrales Ereignis im Kalten Krieg ein außenpolitisch brisantes Thema, das in der westdeutschen Presse und von vielen Politikern - trotz men-

532 Romain, Die alltägliche Kunstfeindlichkeit, in: Staatliche Museen Preußischer Kulturbesitz (Hrsg.), 1945-1985. Kunst in der Bundesrepublik, Ausst. Kat. Nationalgalerie Berlin, Berlin 1985, S. 635.

533 Das Zitat stammt aus der Süddeutschen Zeitung, 18.10.1973; wieder aufgegriffen aber auch in: N.N., Bruno Heck, Der Spiegel, 25.9.1989, https://www.spieg el.de/spiegel/print/d-13498978.html; N.N., Pinochet und das Chaos, 26.9.1986, https://www.zeit.de/1986/40/pinochet-und-das-chaos/seite-1.

534 Fetscher, Kritik, Aufklärung und Sichtbarmachen des Verdrängten, in: Staeck/Bussmann/Frankfurter Kunstverein, Klaus Staeck - Rückblick in Sachen Kunst und Politik, Ausst. Kat. Frankfurter Kunstverein, Heidelberger Kunstverein, Kunstamt Tiergarten Berlin u.a., ${ }^{2}$ 1980, S. 61. 
schenverachtender Gewalt und Folter - als ein notwendiger Schritt für die Stärkung der westlichen Welt in der Auseinandersetzung mit dem „Ostblock" positiv aufgenommen wurde. So schrieb Franz-Josef Strauß im CSU-Parteiorgan Bayernkurier, dass „angesichts des Chaos, das in Chile geherrscht hat, das Wort Ordnung für die Chilenen plötzlich wieder einen süßen Klang [erhält]. “535 Eine Tageszeitung feierte einen zu erwartenden vorteilhaften wirtschaftlichen Effekt mit den Worten „Putsch in Chile für Banken positiv - in Südamerika kann wieder investiert werden “536.

Staeck hat in einer Publikation, die im Juni 1976 erschienen ist, die These vertreten, dass sich die CDU/CSU-Abgeordneten nicht so sehr gegen ihn selbst als vielmehr gegen die in den Plakaten geäußerte Kritik an dem Putsch in Chile aufbegehrten. Hierin zeige sich, so Staeck damals, letztlich die Umwandlung der CDU/CSU in eine „deutsch-nationale Kampfpartei“. 537

Jedoch darf man nicht übersehen, dass der chilenische Putsch zum Zeitpunkt der Bonner Ausstellung schon fast drei Jahre zurücklag. Die getätigten Ausrufe der Unionsabgeordneten im Bundestag, die versuchten, Staeck als Künstler zu diskreditieren, aber auch die Tatsache, dass Staeck als SPD-Mitglied als politischer Gegner wahrgenommen wurde, sprechen dafür, dass es nicht so sehr um eine Verteidigung der Politik Pinochets, sondern vielmehr um ein medienwirksam eingesetztes Statement gegen den linken Künstler ging, dessen „Londoner Zwischenfall“ von 1974 vielleicht auch noch nicht vergessen war.

\section{E. Kritische Rezeption Staecks}

Es überrascht nicht, dass die Einordnung Staecks in die politische Kunst Deutschlands sich in zwei Lager spaltet. Wurde er von den einen als derjenige gefeiert, der Verdrängtes sichtbar macht, war er für die anderen ein „Polit-Pornograph“"538. Es wird rasch klar, dass eine künstlerische Be-

535 N.N., Bayernkurier, 22.9.1973.

536 N.N., Neue Westfälische Zeitung, 29.9.1973; auch Carl Karstens (der damalige Fraktionsvorsitzender der CDU/CSU im Bundestag) erklärte im Bundestag am 12.9.1973: „Die Ereignisse in Chile haben bewiesen, dass Marxismus und freiheitlich-demokratische Grundsätze unvereinbar sind.“ Zit. nach: Eckel, Die Ambivalenz des Guten, Göttingen, ${ }^{2} 2015$, S. 614.

537 Staeck/Adelmann, Der Bonner Bildersturm oder: was die CDU von Demokratie hält, ${ }^{2} 1976$, S. 6; 37-126.

538 Vgl. Fn. 523; Staeck, Staecks Umwelt. Texte und politische Plakate, 1990, S. 12. 
wertung in diesen Fällen hauptsächlich auf die politische Einstellung des Kritikers zurückzuführen ist, was wiederum im Rahmen der politischen Kunst häufig in der Natur der Sache liegen wird. Ein sich wiederholender Topos in der kunsthistorischen Bewertung und der allgemeinen Kunstkritik zu dem Künstler Klaus Staeck liegt aber - sicherlich nicht zu Unrecht - in der Bewertung des Mediums Plakat, denn die Massenauflage macht - wie bereits ausgeführt wurde - eine Verbreitung der Aussage ohne besonderen finanziellen Aufwand möglich. Auch hier wurde ein besonderer Stellenwert auf die Charakteristika des Mediums Plakat gelegt. ${ }^{539}$ Kunsthistorisch wurde damit eine Untergruppe der politischen Kunst der BRD eröffnet. So argumentiert beispielsweise der Publizist und Sammler Jürgen Schweinebraden, dass sich politische Kunst in Westdeutschland in der Nachkriegszeit nur schwer etablieren konnte: Eine Veränderung scheiterte seines Erachtens „an der Lethargie der dem Konsumrausch verfallenen [...] Massen" ${ }^{540}$ Politische Kunst sei daher im Westen Deutschlands bis in die 1960er Jahre nicht oder kaum vorhanden gewesen, die sich jedoch in den folgenden Jahren z.B. in der Gestalt vom Performances und Aktionen der Fluxus-Bewegung sowie dem Massenmedium des Plakats - immer außerhalb des etablierten Kunstbetriebs - in zunehmendem Maße äußerte. ${ }^{541}$

Es wurde hier jedoch versucht zu zeigen, dass Klaus Staeck sich auch in seinem frühen Schaffen nicht nur außerhalb des Kunstbetriebs bewegte. Zum einem darf nicht übersehen werden, dass die Plakate nicht sein ganzes Werkschaffen ausmachen. Gerade die Anfänge der künstlerischen Tätigkeiten von Klaus Staeck lagen nämlich in ein paar wenigen kleinund mittelformatigen Gemälden und Zeichnungen, in der Anfertigung von Holzschnitten, besonders von Objekten, aber auch von Fotografien. ${ }^{542}$ Auch stellte er (und stellt weiterhin) seine Plakate in für den gängigen Kunstbetrieb typischen Räumlichkeiten, seien es Museen, Ausstellungshallen, Kunstvereinen, Kunstmessen wie die documenta, die Art Karlsruhe

539 Siehe dazu Kap. 1, A.

540 Schweinebraden, Kunst und Politik, in: Staatliche Museen Preußischer Kulturbesitz (Hrsg.), 1945-1985. Kunst in der Bundesrepublik, Ausst. Kat. Nationalgalerie Berlin, 1985, S. 300.

541 Schweinebraden, ebd., S. 302.

542 Vgl. Staeck/Bussmann/et al., Klaus Staeck - Rückblick in Sachen Kunst und Politik, Ausst. Kat. Frankfurter Kunstverein, Heidelberger Kunstverein, Kunstamt Tiergarten Berlin u.a., ${ }^{2} 1980$, S. 12 f.; Vgl. zu den Fotografien beispielsweise Staeck, Frohe Zukunft, 2004; Vgl. insbesondere zu den Holzschnitten: Burg, Offene Formen und prägnante Zeichen, in: Museum Folkwang (Hrsg.), Klaus Staeck. Sand fürs Getriebe, Ausst. Kat. Museum Folkwang, 2018, S. 23-26. 
oder die Art Cologne aus. Staeck ist also tatsächlich nicht nur ein Künstler, der sich außerhalb des Kunstbetriebs oder des Kunstmarkts bewegt, auch wenn diese nicht seine einzigen Verbreitungswege darstellen. Da Staeck mittlerweile als ehemaliger Präsident der Akademie der Künste ${ }^{543}$, als Thema von Fernseh-Dokumentationen ${ }^{544}$ und großen Einzelausstellungen ${ }^{545}$ zu einem allgemein angesehenen Künstler geworden ist, fällt auch die Kritik an seiner Person und seinen Plakaten bei weitem nicht mehr so scharf und politisch aufgeladen aus wie vielleicht in den Zeiten der Rechtsstreitigkeiten. Wolfgang Ullrich nennt ihn 2014 sogar den nützlichsten Künstler der Bundesrepublik. ${ }^{546}$

\section{F. Zwischenfazit}

In diesem Kapitel wurde ein Überblick auf Klaus Staeck als Person und sein Schaffen gegeben. Das Hauptaugenmerk lag hierbei auf den Plakaten von Klaus Staeck, die einen großen Teil seines Werks ausmachen. Die Plakate wurden hinsichtlich ihres Aufbaus untersucht, und unter Betrachtung des zentralen Gestaltungselements, nämlich des Verhältnisses von Text zu Bild, in die vier Kategorien "Dominanz“, „Komplementarität“, "Kontradiktion" und „Kontextualität" unterteilt.

Die rechtlichen Streitigkeiten sind der Gegenstand des folgenden Kapitels.

543 Vgl. Kap. 4, B., I.

544 Die Kunst findet nicht im Saale statt - Der Plakatkünstler Klaus Staeck, 2020, Fernsehreportage, SWR, 16.4.2020, 22:45 Uhr, $60 \mathrm{~min}$.

545 Museum Folkwang (Hrsg.), Klaus Staeck. Sand fürs Getriebe, Ausst. Kat. Museum Folkwang, 2018.

546 Ullich, Art 2014/12, S. 52-56. 


\section{Fünftes Kapitel: Die Prozesse}

Es seien hier aus einer Reihe von juristischen Auseinandersetzungen, die ein Plakat Klaus Staecks zum Gegenstand haben, einzelne Prozesse exemplarisch herausgegriffen. Die Auswahl erklärt sich durch ihre Beispielhaftigkeit, Länge oder den Umfang des Rechtsstreits. Die hier zu besprechenden Prozesse, die gegen Staeck geführt wurden, verlaufen auf dem Zivilrechtsweg. Dies entspricht einer allgemeinen Verlagerung der Satire-Rechtsprechung vom Strafrecht hin zum privaten Rechtsweg. Eine Besprechung von etwaigen verwaltungsrechtlichen Auseinandersetzungen wegen Veranstaltungs- oder Ausstellungsverboten wurde in dieser Arbeit bewusst ausgeklammert.

Als Prälimenaria zu den Prozessen, die gegen Klaus Staeck geführt wurden, wird hier zunächst ein Fall besprochen, der sich nicht unmittelbar gegen die Person Klaus Staeck richtet. Vielmehr ist eine seiner Arbeiten Gegenstand in einem Strafprozess (A.). Es folgt die Besprechung der zivilrechtlichen Prozesse gegen Staeck, die den Schwerpunkt bilden. Im Rahmen eines jeden Verfahrens wird hierbei ein besonderer Blick auf den Umgang mit dem künstlerischen Politsatire-Plakat in den entsprechenden Urteilen und Schriftsätzen gelegt (B.). Anschließend gilt es Klaus Staeck als Kläger zweier Rechtsstreitigkeiten zu beleuchten (C.). Die aus den Rechtsverfahren und aus den ersten vier Kapiteln gewonnen Erkenntnisse werden schließlich für eine Einordnung Klaus Staecks angewendet (D. und E.), bevor das Zwischenfazit abschließend eine knappe Zusammenfassung liefert (F.).

\section{A. Ein Staeckmotiv im Strafprozess}

\section{Sachverhalt}

Dem Strafverfahren lag ein Aufeinandertreffen des Angeklagten mit einem Polizisten zu Grunde. Der diensttuende Polizist hatte den Angeklagten wegen des Verdachts eines „Rotlicht-Verstoßes“ ${ }^{547}$ angehalten und überprüft. Die Situation war für den Angeklagten Anlass, dem Polizisten eine Post-

547 AG Hamburg, 9.11.1988, 201, 518/88 Cs/1100 Js 430/88, NJW 1989, S. 410. 
karte Klaus Staecks zu schicken. Auf der besagten Postkarte ist die Rückansicht eines dicken, nackten Gesäßes auf einem für dessen Größe viel zu kleinen Bürostuhl dargestellt (Abb. 7). Dem Bild folgt der Text „Konturen eines Amtsarsches (Prototyp) Gewidmet Herrn/Frau/Frl. ". In dem freien Textfeld hatte der Angeklagte den Namen des Polizisten eingefügt, das „Frau/Frl.“ gestrichen und die Postkarte an die Polizeidienststelle des Polizisten geschickt. ${ }^{548}$

\section{Entscheidung}

Der Angeklagte hatte den objektiven Tatbestand eingeräumt. Doch erklärte er, dass er den Polizisten nicht beleidigen wollte. „Er habe geglaubt, an der Karte würde sich der Zeuge erfreuen, wenn er nur Humor und künstlerisches Verständnis habe. Aus diesem Grunde habe er sie ihm ja auch ,gewidmet'. Mit einer Widmung versehe man ja schließlich zum Beispiel auch Bücher, die man jemandem schenke. Schließlich stelle die Karte ja ein Kunstwerk dar, er versende sehr viele Karten des Künstlers Staeck, er sei eben bemüht, Kunst zu verbreiten. ${ }^{\text {" }} 49$ Diese Erklärung wird vom Gericht als Schutzbehauptung eingeordnet und als widerlegt angesehen. Die Ehrverletzung sieht das Gericht darin begründet, dass der Angeklagte den Polizisten mit dem auf der Karte abgebildeten Menschen „in all seiner Unästhetik und Häßlichkeit“ gleichgestellt hätte und so verdeutlicht, „was er von diesem ,hält ““. ${ }^{550}$ Der Angeklagte wurde zu einer Geldstrafe verurteilt. 551

\section{Bewertung}

Der derbe Ausdruck „Arsch“ wird häufig nicht als Synonym für den Hintern, sondern als Schimpfwort für eine Person verwendet. Der Ausdruck

548 AG Hamburg, 9.11.1988, 201, 518/88 Cs/1100 Js 430/88, NJW 1989, S. 410.

549 AG Hamburg, ebd.

550 AG Hamburg, ebd.

551 Das Gericht hatte noch deutlich gemacht, dass es das Verfahren gegen eine geringe Geldbuße für einstellungswürdig erachte, sofern sich der Angeklagte entschuldige. Dies Entschuldigung erfolgte nicht, vielmehr bot er dem Polizisten an, er könne doch auf Kosten des Angeklagten einen Volkshochschulkursus über Kunst besuchen. AG Hamburg, 9.11.1988, 201, 518/88 Cs/1100 Js 430/88, NJW 1989, S. 410, 411. 
Amtsarsch beschreibt daher abwertend einen Beamten, der besonders träge, starr den Richtlinien folgend oder einfach ungenügend seinen Amtsaufgaben nachkommt. ${ }^{552}$ Diese negative Charakterisierung wird mit der Darstellung eines besonders fetten und konturlosen Gesäßes auf der Postkarte Staecks unterstrichen. Die Diffamierung liegt daher nicht nur, bzw. nicht vordergründig, in der „Unästhetik und Häßlichkeit“ des Gesäßes wie es das Gericht begründet, sondern in der diffamierenden Bedeutung des Wortes.

Das Gericht geht davon aus, dass es sich bei der Karte um ein Kunstwerk handele und ordnet dieses als eine künstlerische Karikatur ein. Es erkennt, dass es sich bei dem „Amtsarsch“ nicht um eine Karikatur des Betroffenen handele, sondern dass der Kläger als einer bezeichnet und mit einem solchen gleichgesetzt wird. Es führt aus, dass die Karte nur dann nicht beleidigend wäre, „wenn der Täter nach den gesamten Umständen des konkreten Einzelfalles davon ausgehen durfte, der Karikierte oder mit der Karikatur Gleichgesetzte werde dies nicht als Angriff auf seine Ehre, sondern als Scherz oder Satire auffassen. " 553 Betrachtet man die Karte ohne die Widmung, dann zeigt diese Text-Bild-Montage erstmal nur ein besonders formloses, aufgeschwemmtes, nacktes Gesäß als eine überzogene Illustration des Worts „Amtsarsch“ und damit die bildliche Zuspitzung eines abwertenden und auf Stereotypen basierenden Ausdrucks. Das Gericht wiederum eröffnet in seiner Argumentation einen Aspekt, der sich im Rahmen der Satiredefinition in dem sogenannten Wahrnehmungsprozess durch den Rezipienten wiederfinden lässt: Der Polizist hat die Karte nicht als Satire aufgefasst.

Staeck kann naturgemäß nicht kontrollieren, in welcher Form seine Postkarten verwendet und ob diese beispielsweise beleidigend eingesetzt werden, auch wenn er mit dem freien Textfeld auf der Karte absichtsvoll den Platz für solche Widmungen schafft. Das Motiv dieser Karte gehört sicherlich zu den derberen unter den Plakaten und Postkarten Staecks.

Der Fall ist ein Beispiel dafür, dass ein allgemeines, nicht gegen eine Einzelperson gerichtetes Motiv - durch eine nachträgliche persönliche Adressierung - als Beleidigung empfunden werden und damit zu einer Verletzung des Persönlichkeitsrechts führen kann.

552 Ähnlich ist der Begriff des Amtsesels, der weniger derb die vorgeworfene Dämlichkeit und Langsamkeit unterstreicht. Vgl. dazu Eintrag im DRW https://drw -www.adw.uni-heidelberg.de/drw-cgi/zeige?term=amtsesel\&index=lemmata.

553 AG Hamburg, 9.11.1988, 201, 518/88 Cs/1100 Js 430/88, NJW 1989, S. 410. 


\section{B. Die zivilrechtlichen Prozesse gegen Arbeiten Klaus Staecks}

In den folgenden zivilrechtlichen Gerichtsverfahren war nicht die Art der Verwendung entscheidend, sondern das Plakat selbst. Von einer Ausnahme abgesehen war Staeck in allen folgenden Gerichtsverfahren als Beklagter selbst Prozesspartei. Die hier gewählte Unterteilung der Verfahren erfolgt nach chronologischen und thematischen Gesichtspunkten. Den Anfang bilden Verfahren zu Plakaten mit satirischer Wahlaufforderung zu Lasten der CDU (I.), gefolgt von einem Rechtsstreit zwischen dem Springer-Verlag und Staeck zu "Juso beißt wehrloses Kind“ (II). In der Folge bilden die zwei größten Verfahren zu den Plakaten „Alle reden vom Frieden“ (III.) und „Alle reden vom Klima“ (IV) den Schwerpunkt des gesamten Abschnitts. Anschließend wird ein Blick auf eine Rechtsstreitigkeit geworfen, in der es zu keiner Gerichtsentscheidung kam (V.). Schließlich folgt eine bewertende Zusammenfassung der besprochenen Fälle (VI.).

\section{Plakate mit satirischer Wahlaufforderung zu Lasten der CDU}

Die ersten Prozesse, die hier untersucht werden, haben jeweils Plakate mit satirischen Wahlaufforderungen zum Gegenstand. Diese Plakate bestehen hauptsächlich und schwerpunktmäßig aus einem Textteil und gehen zulasten der CDU-Partei.

1. „Die Reichen müssen reicher werden. Deshalb CDU“

a) Sachverhalt

In klaren, serifenlosen, schwarzen Buchstaben auf weißem Grund stehen auf einem Plakat Staecks, das die Anmutung eines Wahlplakats besitzt, die Worte: „Die Reichen müssen noch reicher werden“. Am unteren rechten Ende des Plakats folgen die Worte „Deshalb CDU“, wobei der Parteiname im originalen, also charakteristischen Erscheinungsbild - kursiv und in rot - abgedruckt wurde.

Das Plakat wurde anlässlich der Landtagswahl in Baden-Württemberg im April 1972 von Staeck konzipiert, gedruckt und vertrieben. Bundesweite Aufmerksamkeit erhielt es, als es von länderübergreifenden Landes- und Ortsverbänden der SPD im Wahlkampf zu der vorgezogenen Bundestagswahl vom November 1972 verwendet wurde. Schon zur Landtagswahl in 
Baden-Württemberg im April 1972 und dann im anschließenden Herbst folgten Anträge einstweiliger Verfügungen auf Unterlassung von Seiten der CDU, die eine Verletzung ihres Namensrechts nach $\$ 12$ BGB geltend machten.

Bemerkenswert ist darüber hinaus die Tatsache, dass das genannte Plakat bereits zur Landtagswahl im Stadtgebiet Heidelberg auf Plakatflächen der CDU und FDP über deren Wahlplakate geklebt worden war.

\section{b) Entscheidung}

Das Gericht macht deutlich, dass eine Verletzung des Namensrechts vorliegen kann, wenn ein fremder Name in der Weise gebraucht wird, dass dadurch ein Identitätsirrtum hervorgerufen wird. ${ }^{554}$ Das Zeichen CDU ist so angebracht, dass der Anschein erweckt wird, es handle sich um ein Wahlplakat der CDU. Das Gericht führt ferner aus, dass gerade das dem Senat vorliegende Plakat, mit dem ein Originalplakat der CDU überklebt wurde, den Identitätsirrtum besonders veranschaulicht. ${ }^{55}$ Dass aber gerade der Sinn und Zweck des Plakats darin besteht, zunächst einen Identitätsirrtum hervorzurufen, der dann vom Betrachter aus Gründen der Erfahrung aufgelöst wird, erkennt das Gericht auch an und führt aus: ${ }^{556}$

„Durch diesen Identitätsirrtum will der Beklagte den von ihm erstrebten Effekt erreichen. Er beruft sich als Beispiel auf das Stilmittel der Verfremdung. Die Leser sollen das Plakat zunächst für eines der CDU halten und als solches lesen. Erst nach dem Lesen kommt der Gedanke: Da kann doch etwas nicht stimmen. Das muss doch von einem Gegner der CDU sein. Der Identitätsirrtum wird also beim politisch kundigen Leser zwar rasch beseitigt, zunächst einmal aber bewusst als Mittel des politischen Kampfes verwendet. “557

Das Gericht schmettert mit wenigen Worten die Einordnung des Plakats als Satire oder Parodie ab, wenn es davon ausgeht, dass die CDU „es

554 vgl. nur OLG Karlsruhe, 1.9.1972, 10 U 137/72, NJW 1972, S. 1810, 1811; in der Literatur rekurriert auf die Entscheidung BeckOK BGB/Bamberger, $\mathbb{1} 12, \mathrm{Rn}$, $75-77$.

555 Inwiefern genau dieses Plakat den Identitätsirrtum weitergehend - abgesehen von der Tatsache das ein Plakat der CDU überklebt wurde - veranschaulichen soll, kann nicht nachvollzogen werden.

556 OLG Karlsruhe, 1.9.1972, 10 U 137/72, NJW 1972, S. 1810, 1811.

557 OLG Karlsruhe, ebd. 
sich nicht gefallen lassen muss, dass eine gegen [sie] gerichtete Parole in einer Weise verwendet wird, die durch den Gebrauch [ihres] Namens zunächst den Irrtum hervorruft, dass sie von [ihr] stamme. Das hat mit dem Stilmittel der Parodie nichts zu tun. Denn die Parodie ruft keinen Identitätsirrtum über den Urheber hervor, wenn sie die Eigentümlichkeit einer Person oder eines Werks durch Übersteigerung ins Lächerliche zieht. Dasselbe gilt für die Satire als literarische Form. “558

\section{c) Bewertung}

Dass der Name einer politischen Partei - auch in ihrer Kurzform oder in ihrer Form als Zeichen - von $\$ 12$ BGB geschützt wird, wird nicht bezweifelt. ${ }^{559}$ Das Gericht übersieht aber die Funktionsweise dieses Plakats. Das Plakat funktioniert nämlich nur, wenn der Irrtum gerade nicht anhält, sondern von dem Betrachter erkannt wird. In der provokanten Aussage steckt die Kritik, dass nach Staeck die CDU nur für die Interessen einer reichen Oberschicht einträte und so nicht als eine Volkspartei verstanden werden könne. Das gewählte Mittel liegt hier weniger in einer Übertreibung oder Überzeichnung, sondern vielmehr in dem Auseinanderfallen der Aussage und dem vorgegebenen Kontext des Werbeplakats. Dies führt dazu, dass selbst der flüchtige Blick eines vorbeieilenden Passanten von dem Plakat eingefangen wird und dass der irritierte Betrachter versucht, den vorgestellten Widerspruch aufzulösen - frei nach dem Motto, selbst wenn es stimmt, kann man das doch auf einem "Wahlplakat" nicht so offen sagen. Dabei lässt sich die Urheberschaft bei genauerem Hinsehen eindeutig feststellen, da im linken unteren Bildviertel der Urheber Klaus Staeck namentlich genannt wird. Die Kontradiktion zwischen Aussage und vermeintlichem Erscheinungsbild ist das hier gewählte Mittel, um das für Staeck bestehende sozialpolitische Ungleichgewicht zu thematisieren. Hinzukommt, dass sich in der Zeitspanne zwischen dem ersten flüchtigen Lesen bis zum Erkennen der wahren Urheberschaft, d.h. im Prozess des Aufdeckens der Irreführung, die satirische Wirkung manifestiert.

558 OLG Karlsruhe, ebd. Der Argumentation folgt das Landgericht Ravensburg anlässlich der Ausstellung des Plakats in der „Oberschwabenschau“, siehe LG Ravensburg, 14.10.1972, III O 974/72.

559 hM vgl nur MüKo BGB/Säcker, $\mathbb{S} 12$, Rn. 24, ferner zum Namensbegriff vgl. Lange, Marken- und Kennzeichenrecht, 2012, \$1 Rn. 160. 
Auch wenn das Gericht Staeck zumindest einen gewissen originellen Einfall zuspricht, ${ }^{560}$ verkennt es den grundsätzlich satirischen Charakter des Entwurfs. Diese Entscheidung ist somit als ein klassisches Beispiel für die mangelnde Auseinandersetzung mit dem Begriff der Satire einzuordnen.

\section{2. „Die Reichen müssen reicher werden, wählt christdemokratisch“}

Auch die Entfernung des CDU-Zeichens in der zweiten Version des Plakats „Die Reichen müssen reicher werden, wählt christdemokratisch“ (Abb. 4) und das Plakat „Die Mieten müssen steigen, wählt christdemokratisch“, in einer der ersten Version entsprechenden Formatierung führten zu rechtlichen Auseinandersetzungen. Der CDU-Ortsverein Niedermarsberg stellte einen Antrag auf Erlass einer einstweiligen Verfügung gegen Staeck, die das örtliche AG auch erließ, da es in dem Inhalt der angeführten Plakate unter Berücksichtigung der Bedeutung der politischen Parteien eine Verunglimpfung der Unterorganisation der CDU sah. ${ }^{561}$ Die Aussage des Plakats liegt nach Ansicht des Gerichts für den unbefangenen Betrachter darin, dass die CDU „nur eine bestimmte Bevölkerungsgruppe fördere“, dass für „sowieso schon benachteiligte Kreise der Bevölkerung nichts getan wird“ und somit im Falle eines Wahlsieges „einseitig und ungerecht" regiert werden würde. ${ }^{562}$ Dass das Aufzeigen der Nachteile und Mängel des politischen Gegners ein gängiges Mittel im Wahlkampf ist, wird vom Amtsgericht gesehen, doch gerade dieses wird als eines „die Grenzen einer zulässigen Wahlreklame“ überschreitendes Plakat gewertet, was ein Vergleich mit den gleichzeitig angeschlagenen Plakaten der anderen Partei in dem kleinen Ort in Nordrhein-Westfalen zeigen soll. ${ }^{563}$

Das LG Lüneburg setzt sich mit dem Urteil des OLG Karlsruhe zum Namensrecht über $\$ 12$ BGB hinausgehend auseinander und moniert, dass das OLG die Wahlparole getrennt von dem angeblichen Urheber (der CDU) würdigt. Für das LG ist es klar, dass „eine Partei, die mit der Parole ,Die Reichen müssen reicher werden' zu ihrer eigenen Wahl aufrufen würde, zum Wahlkampf überhaupt nicht erst anzutreten [braucht]. Schon aus diesem Grunde lässt die Verbindung des erwähnten Wahlslogans mit

560 OLG Karlsruhe, 1.9.1972, 10 U 137/72, NJW 1972, S. 1810, 1812.

561 AG Niedermarsberg, 14.11.1972, 1 C 168/72, S. 3.

562 AG Niedermarsberg, ebd., S. 3 f.

563 Vgl. AG Niedermarsberg, 14.11.1972, 1 C 168/72, S. 4. 
dem Aufruf ,wählt christdemokratisch' bei jedem nur halbwegs vernunftbegabten Wähler sofort die Erkenntnis entstehen, dass mit dieser Parole nicht etwa die CDU zu ihrer eigenen Wahl aufrufen will, sondern dass diese Parole von einem Gegner der CDU - gleich welcher Art - der CDU untergeschoben werden soll. " 564

Im Gegensatz zu der Aussage des Gerichts zeigt eine Fotografie des Plakats „Die Mieten müssen steigen, wählt christdemokratisch“, welches an einem Baumstamm befestigt worden war und zwischen den Teilsätzen mit dem Aufkleber "JUSO-Plakat, Kein CDU-Plakat" erklärt wurde, dass diese Plakate wohl doch missverstanden wurden. ${ }^{565}$

\section{BVG Berlin und das Niedersachsenroß}

„Berlin! Wir haben die Korruption wieder wählbar gemacht. CDU - die Partei der schlagenden Argumente. Jede Menge Vergangenheit." So lautet ein weiteres umstrittenes Plakat, das im Januar 1989 - in den Wochen vor der Wahl zum Abgeordnetenhaus von West-Berlin am 29.1.1989 in Berlin und vor allem auf Werbeflächen der Berliner Verkehrs-Betriebe (BVG) angebracht worden war. Der CDU-Landesverband stellte zur Verhinderung der Verbreitung des Plakats einen Strafantrag, doch wurde dieser von der Staatsanwaltschaft nicht weiter verfolgt. ${ }^{566}$ Trotz des Einstellungsbescheids war die Situation um das Plakat politisch so aufgeladen,

564 LG Lüneburg, 16.11.1972, 5 O 404/72, S. 5.

Ursprünglich waren in Baden-Württemberg zunächst vier Verfahren gegen Staeck eingeleitet worden. Die vier Verfahren bestehen aus zwei einstweiligen Verfügungen von jeweils der CDU Heidelberg und der CDU Baden-Württemberg und zwei Bestrafungsverfahren wegen Verstößen gegen die Verfügungen. Die Bestrafungsanträge wurden vor der Hauptverhandlung zurückgenommen. Die veränderte Version führte zu zwei Verfahren gegen die SPD bzw. ein das Plakat aufhängendes Mitglied und ein Verfahren gegen Staeck. Das Motiv dieses Plakats führte in Einzelfällen zu großer Aufregung. So kam es beispielsweise bei einer Postkarte desselben Motivs, die an der Heckscheibe eines PKWs befestigt war, zu einer polizeilichen Anzeige (aus einem privaten Brief vom 27.9.1972 an Klaus Staeck entnommen).

565 Fotografie beigelegt in einer Briefkorrespondenz zwischen dem damaligen Kassierer der Ortsgruppe Niedermarsberg und Staeck vom 7.1.1973.

566 Vorausgegangen war eine Beschlagnahme von ca. 150 Plakaten bei Mitgliedern der Jugendorganisation der SPD sowie einer Festnahme dreier Jungsozialisten wegen Sachbeschädigung, Vgl. SPD, Pressemitteilung, Staeck-Plakate staatsanwaltlich geprüft und freigegeben, 19.1.1989. 
dass die BVG äußerte, sich nicht in Wahlkampfauseinandersetzungen verwickeln lassen zu wollen und deswegen die Plakate nicht anbringen zu wollen. Klaus Staeck ging davon aus, dass, da „es sich bei der Verkehrs-Reklame um einen ,Eigenbetrieb von Berlin' handelt, die Berliner CDU die Plakatierung eines ihr unliebsamen Plakats unter Missbrauch staatlicher Einrichtungen verhindern [wollte]." 567 Der von Klaus Staeck mit dem Druck und der Anbringung des Plakats beauftragte Steidl-Verlag erwirkte erfolgreich am Landgericht Berlin eine einstweilige Verfügung, wonach die Plakate noch vor der Wahl an den Reklame-Flächen der BVG zu kleben waren. ${ }^{568}$ Nach eingelegtem Widerspruch wurde die einstweilige Verfügung jedoch nur fünf Tage später wieder aufgehoben, wobei es in der Sache allein um die Frage ging, ob ein wirksamer Vertrag zwischen den Parteien zustande gekommen war. ${ }^{569}$ Die von Steidl eingelegte Berufung vor dem Kammergericht wurde zwei Tage vor der Wahl zurückgewiesen. ${ }^{570}$ Klaus Staeck war letztlich zufrieden mit dem Streit um das Verfahren, denn nun sei „das Thema Korruption in Berlin doch noch zum Wahlkampfthema gemacht [worden]. ${ }^{\text {"571 }}$

$\mathrm{Zu}$ einem ähnlichen Verfahren kam es 18 Jahre nach dem ersten Verfahren zu „Die Reichen müssen reicher werden“ in Bezug auf ein Plakat anlässlich der niedersächsischen Landtagswahl. Das Plakat zeigt das sogenannte Niedersachsenroß mit einem Tausendmark-Schein im Rücken und der Überschrift „In Niedersachen läuft es wie geschmiert“ und links unten am Bildrand die Worte „Ihre CDU“ (Abb. 5). Dem vorausgegangen war zum einen die Ablehnung der Plakatierung durch das Unternehmen Deutsche-Städte-Reklame (DSR) wegen „erheblich rechtlicher Bedenken gegen

567 Aktion für mehr Demokratie, Klaus Staeck, Presse-Information ,Berlin ist Feigheit', 13.1.1989.

568 LG Berlin, 13 O 36/89, 21.1.1989.

569 LG Berlin, ebd. Der entsprechende Vertreter der Abteilung Vereinigte Verkehrsreklame VVR-BEREK der BVG hatte erklärt, „dass die Plakatierung so erfolgen könne, vorbehaltlich der inhaltlichen Prüfung durch die Rechtsabteilung." Mit dieser Äußerung versteht das Gericht, dass eine Annahme des nunmehr konkretisierten Vertragsangebots durch Steidl erst zu einem späteren Zeitpunkt erklärt werden sollte und es damit noch an einem Rechtsbindungswillen fehle. Die Ablehnung des Angebots vom 6.1.1989 ist weder rechtsmissbräuchlich noch sittenwidrig, sondern bewegt sich im Rahmen des Grundsatzes der Vertragsfreiheit. Auch hat die BVG, zumindest in Bezug auf Werbeflächen, keine Monopolstellung inne. LG Berlin, 13 O 36/89, 26.1.1989, S. 3 f.

570 KG Berlin, 20 U 646/89, 27.1.1989.

571 Aktion für mehr Demokratie, Klaus Staeck, Presse-Information ,Berlin ist Freiheit?', 28.1.1989. 
dessen Zulässigkeit“572 und zum anderen ein Abmahnungsschreiben gegen Staeck durch die anwaltliche Vertretung der CDU in Niedersachsen und den CDU Landesverband Hannover. ${ }^{573}$ Der Steidl Verlag erwirkte vor dem LG Frankfurt eine einstweilige Verfügung gegen die DSR, wonach diese das Plakat auf ihren Flächen in Hannover zu kleben hatte. ${ }^{574}$ Gegen den Beschluss des LG Frankfurt legte die DSR noch Widerspruch ein. ${ }^{575}$ Als die DSR die Plakate dann doch klebte, sich aber der Erledigungserklärung nicht anschloss, erging nach Antrag des Klägers ein Feststellungsurteil zu Lasten der DSR. ${ }^{576}$

\section{Zwischenfazit}

Bei diesen Verfahren ist grundlegend, dass die Plakate Staecks den Wahlplakaten der CDU zum Verwechseln ähnlich scheinen, aber mit provokanten, die CDU kritisierenden Wahlslogans versehen sind. Die besondere satirische Raffinesse dieser Staeck-Plakate liegt darin, dass man, will man juristisch einen Identitätsirrtum annehmen, davon ausgehen müsste, dass der Rezipient das Plakat tatsächlich für eins der CDU halte. Insofern ließe sich zugespitzt formulieren, dass die Rechtsstreitigkeiten die kritisierte gesellschaftspolitische Situation und damit das der Kritik zu Grunde liegende Ungleichgewicht bestätigen könnten; letztlich also die Satire selbst.

Es verwundert dann auch nicht, dass Staeck selbst diese Auseinandersetzungen zuweilen mit ironischem Unterton kommentierte: „[...] der Rechtsanwalt und Grafiker Klaus Staeck [wollte] der stark gebeutelten [...] CDU selbstlos und auf eigene Kosten unter die Ellenbogen greifen und die Bevölkerung auf die wahren Leistungen [...] hinweisen. ${ }^{~} 577$

572 DSR, Auftrag vom 11.4.1990, 19.4.1990.

573 CDU Niedersachsen gegen Staeck, Abmahnung, 19.4.1990.

Das Plakat wird von Staeck auch als Reaktion auf ein Wahlkampfplakat der CDU gesehen. So wurden in Niedersachsen Plakate mit dem Satz „Die Wiedervereinigung ist eine Lebenslüge. Gerhard Schröder“ geklebt. Vgl. dazu CDU Niedersachsen gegen Staeck, Schutzschrift, LG Hannover, 23.4.1990, S. 3 f.

574 LG Frankfurt, 3.5.1990, 2/6 O 259/90.

575 Steidl./. DSR, Widerspruch, LG Frankfurt, 8.5.1990, 2/6 O 259/90.

576 LG Frankfurt, 23.5.1990, 2/6 O 259/90.

577 Staeck, Pressemitteilung, Niedersachsen wie geschmiert, 19.4.1990. 


\section{II. „Juso beißt wehrloses Kind“}

War die Medienberichterstattung bzgl. der Verfahren zu den satirischen Wahlslogans zu Lasten der CDU noch vergleichsweise gering, ${ }^{578}$ so erwies sich das Verfahren um ein anderes, ebenfalls für den Bundestagswahlkampf 1972 hergestelltes Plakat Staecks als weitaus medienwirksamer. Letztlich wird sich aber zeigen, dass die jeweils resultierenden Rechtsstreitigkeiten in ihrem Verlauf nicht unähnlich sind.

Das Plakat zeigt den damaligen CSU-Politiker Franz Josef Strauß, der eine vom Layout und Design entsprechende Nachbildung einer Bild-Titelseite mit dem bekannten roten Rechteck, in dem mit weißen Buchstaben „Bild“ steht, mit beiden Händen vor sich hält. Auf der Titelseite ist die Schlagzeile "Juso beißt wehrloses Kind" zu lesen (Abb. 6). Doch nicht der CSU-Politiker, sondern der Axel-Springer-Verlag stellte 1976, vier Jahre nach Erscheinen des Plakats, Antrag auf Erlass einer einstweiligen Verfügung. Die Ansprüche wurden auf Verstöße des Kennzeichnungsrechts und des unlauteren Wettbewerbs gestützt. Laut dem Antrag handele sich in diesem Fall um eine offensichtliche Schädigung des Verlags, da ihm unwahre, boshafte Artikel der Zeitung untergeschoben würden. ${ }^{579}$

Auffällig ist der zeitliche Abstand zwischen dem Entstehen des Plakats, damit der erstmaligen Verwendung des Plakats im Jahre 1972 und dem Jahr der einstweiligen Verfügung, die im Bundestagswahlkampfjahr 1976 beantragt wurde. Doch behauptet der Verlag, dass seine Mitarbeiter in den verantwortlichen Positionen erst zu dem besagten Zeitpunkt Kenntnis von der Existenz dieses Posters erlangt hätten. Die Glaubhaftmachung Klaus Staecks, dass er das gegenständliche Plakat in nicht unerheblichem Ausmaße (Erstauflage von 200.000 Stück) in Verkehr brachte, und die Darlegung der umfangreichen Berichterstattung 1972 - von der ZEIT, über die Frankfurter Allgemeine Zeitung bis hin zu Organen der Springer-Presse selbst - durch den Anwalt Staecks in der mündlichen Verhandlung, reichten aus, um das Gericht davon zu überzeugen, dass eine einstweilige Verfügung abzulehnen sei: Denn es wäre in den zurückliegenden vier Jahren - die Rechtsauffassung des Verlages zugrunde gelegt - bereits in nicht unerheblichem Umfang zu Rechtsverletzungen gekommen. Darüber hinaus

578 Aber z.B. in einem Artikel im Spiegel erwähnt, vgl. N.N., Alles ordentlich, Der Spiegel, 1972/44, S. 197-199, https://www.spiegel.de/spiegel/print/d-42787592.h tml.

579 Springer./. Staeck, Antrag auf Erlass einer einstweiligen Verfügung, 18.2.1976, S. 7. 
wurde festgestellt, dass die Beeinträchtigungen bis zu einer Entscheidung im Hauptsacheverfahren nicht so gewichtig wären. ${ }^{580}$ Folglich bedürfe es keiner einstweiligen Verfügung mehr.

Das mediale Interesse und die Berichterstattung waren, obwohl es nie zu einer Hauptverhandlung kam, groß. Verstärkt wurde diese Aufmerksamkeit der Presse nicht zuletzt auch durch die Aussage des Antragstellers, dass keiner der min. 40 Springer-Prokuristen vier Jahre lang von der Existenz des Plakats gewusst habe, obwohl selbiges im Oktober 1975 in dem Archiv des Springer-Verlages registriert worden war. Der Anwalt Staecks kommentierte diesen Vorgang mit den Worten „Nimmt Springer noch am öffentlichen Leben teil?“ und „Die Leute lesen ja nicht einmal ihre eigenen Zeitungen!“, Äußerungen, die von der Presse vielfach aufgegriffen wurden. ${ }^{581}$

Klaus Staeck vermutete, dass der Verlag nur auf Anraten der CDU gegen ihn zu diesem späten Zeitpunkt vorgegangen sei. Er unterstellte die Absicht, „vor den Bundestagswahlen einen lästigen ,Störer' aus dem Verkehr zu ziehen. " 582 Der Axel-Springer-Verlag erklärte in diesem Sinne, dass „es nicht gut [sei], wenn solche Plakate in Wahlzeiten auf den Markt kommen." $" 583$

Obwohl es in der Verhandlung und in den Entscheidungsbegründungen der Kammer nie um den inhaltlichen Aspekt des Plakats ging, wurde dieses Verfahren als ein Sieg der Satire gewertet. ${ }^{54}$ Dies geht mittelbar aus der Begründung hervor, die ausführt, dass - entsprechend den zuvor besprochenen Fällen der satirischen Wahlwerbung - ein Irrtum nur dann vorliegen könne, wenn der Kläger davon ausginge, dass der Rezipient das auf dem Plakat Abgebildete tatsächlich für eine originale Schlagzeile der Bildzeitung hielte.

580 LG Hamburg, 27.2.1976, 74 O 64/76, S. 4.

581 Vgl. Presseberichterstattung der mündlichen Verhandlung: Castorp, „Nimmt Springer noch am öffentlichen Leben teil?“‘, Deutsches Allgemeines Sonntagsblatt, 7.3.1976; Stäcker, „Juso beißt wehrloses Kind“-Plakat darf verbreitet werden, Frankfurter Rundschau, 28.2.1976, S. 1; Stäcker, Juso darf wehrloses Kind weiterbeißen, Badische Zeitung, 28.2.1976, S. 12; N.N., Klaus Staeck gegen Axel C. Springer 1:0, Deutsche Volkszeitung Nr.11, 11.3.1976; N.N. Erste Runde ging an Staeck: „Bild“-Plakat darf verkauft werden, pro, Nr. 24, 05.1976, S. 1, 3.

582 Staeck in Korrespondenz mit seinem Anwalt, 8.2.1976.

583 Zit. nach Berichterstattung der mündlichen Verhandlung Vinsor, In Hamburg lächelte das Gericht, Neue Rhein-Zeitung, 28.2.1976, o. Seitenangaben.

584 Vgl. Presseberichterstattung Fn. 574. 
Ein weiteres Mal wurde der inhaltliche Aspekt der von Staeck durch das Plakat ausgedrückten Kritik an Phänomenen der deutschen Gesellschaft im Verlauf des Rechtsstreits nicht in Frage gestellt und erfuhr auf diese Weise eine Bestätigung. Die Aussage „[...] hier konnte man doch nur fragen, für wie dumm die BILD-Zeitung die Durchschnittsbetrachter solcher Plakate halten mochte, Durchschnittsbetrachter, wie sie doch zu Millionen auch zu ihren eigenen Lesern zählen dürften.“, die sich in der Schutzschrift zum Verfahren bzgl. des Niedersachsenroß findet, ließe sich für diesen Fall gleichermaßen anwenden. ${ }^{585}$

III. „Alle reden vom Frieden. Wir nicht“

\section{Einstimmung}

Fünf männliche Vertreter des Managements von Rheinmetall waren am 25.10.1978 nach Unterlüß in die Lüneburger Heide gereist, um auf dem firmeneigenen Übungsfeld die neue Feldhaubitze FH 70 feierlich an den Bundesminister der Verteidigung und damit an die Truppen der Bundeswehr zu übergeben. Anwesend waren Journalisten und Fotografen als Vertreter der Presse. Wie die Süddeutsche Zeitung beschrieb, ließen sich die Vorstandsvorsitzenden „nicht lange zum Gruppenfoto bitten. Damit das Bild aber nicht norddeutsch-steif würde, plauderten sie miteinander und nahmen, weil sie halt ein unbefangenes Verhältnis zu Waffen haben, die verschiedenen Geschosse für den Leopard in die Hand.“586

\section{Das Plakat}

Diese Fotografie entnahm Klaus Staeck einem Beitrag des Magazins „Der Spiegel“ vom 17. August 1981, der über das Rüstungsunternehmen Rheinmetall berichtete. ${ }^{57}$ Er ergänzte die Fotografie mit dem Ausspruch „Alle reden vom Frieden! Wir nicht.“ (Abb. 8). Das Design des Plakats sowie die Formulierungen waren der damalig weit verbreiteten Bundesbahn-Werbekampagne aus dem Jahr 1966 entlehnt. Auf dieser war in weißer serifenlo-

585 CDU Niedersachsen./. Staeck, Schutzschrift, LG Hannover, 23.4.1990, S. 6.

586 Kröncke, Gruppenbild mit Zündstoff, SZ, 23.11.1981, S. 3.

587 N.N., Auf Umwegen, Der Spiegel, 34/1981, S. 76, https://magazin.spiegel.de/Ep ubDelivery/spiegel/pdf/14337614. 
ser Fettschrift auf schwarzem Grund über drei Zeilen der Satz „Alle reden vom Wetter!“ gesetzt, darunter die Farbfotografie einer Lokomotive, die unbeeindruckt von harten Witterungsbedingungen durch eine verschneite Landschaft zu fahren scheint und darunter folgend, wieder auf schwarzem Grund, zwei deutlich kleiner gedruckte Worte: „Wir nicht.“ (Abb. 9).

Vor Staeck hatte sich bereits der Sozialistische Deutsche Studentenbund (SDS) von dieser Bundesbahnwerbung anregen lassen. Der SDS verwendete nämlich 1968 den Spruch wörtlich, setzte die ikonenhaften Profilbilder von Karl Marx, Friedrich Engels sowie von Wladimir Iljitsch Lenin statt der Lokomotive in die Mitte und benutzte einen leuchtend roten Grund. ${ }^{588}$

\section{Der Hintergrund}

Das Rüstungsunternehmen Rheinmetall geriet in den Fokus der Öffentlichkeit, als bekannt wurde, dass das BKA gegen das Unternehmen wegen Verstößen gegen das Kriegswaffenkontrollgesetz ermittelt. ${ }^{589}$ Für Staeck ausschlaggebend war der bereits genannte Artikel im Magazin „Der Spiegel“ in der Ausgabe vom 17. August 1981. Unter dem Titel „Auf Umwegen" beschrieb der Autor, wie es im Rahmen der Ermittlungen zu Hausdurchsuchungen kam und welche Verdachtsmomente gegenüber dem Unternehmen vorlägen: „Nach der Blitzaktion bei Rheinmetall in Düsseldorf hofft das Bundeskriminalamt, Waffenschiebungen großen Stils nachweisen zu können". ${ }^{590}$ So wurde von dem Verdacht berichtet, Rheinmetall liefere an Argentinien, ein Land, das zu diesem Zeitpunkt von einer Militärjunta diktatorisch regiert wurde (1976-1983), sowie an Saudi Arabien und auch an Südafrika zu Zeiten des Apartheidsregimes Waffen und Munition ohne die notwendige Genehmigung der Bundesregierung und zwar verschleiert durch Zwischenstationen in Drittländern. ${ }^{591}$

588 Jürgen Holtfreter, Alle reden vom Wetter. Wir nicht. Plakat für den SDS, 1968.

589 Vgl. auch schon Brzoska/Wulf, In aller Stille ist die Bundesrepublik Deutschland zu einem Hauptexporteur für Rüstung geworden, Deutsches Allgemeines Sonntagsblatt, 30.11.1980, S. 10.

590 N.N., Auf Umwegen, Der Spiegel, 1981/34, S. 76, https://magazin.spiegel.de/Ep ubDelivery/spiegel/pdf/14337614.

591 N.N., Auf Umwegen, Der Spiegel, 1981/34, S. 76. 


\section{Verfahrensverlauf - ein Überblick}

Im Oktober 1981 erhielt Klaus Staeck die anwaltliche Aufforderung, dieses Poster weder öffentlich noch privat zu verbreiten. ${ }^{592}$ Maßgeblich wurde geltend gemacht, dass es sich bei diesem Plakat um eine erhebliche Diskriminierung handele, da zumindest einem nicht unerheblichen Teil der Betrachter des Posters suggeriert werde, dass das Unternehmen und die abgebildeten Geschäftsführer gegen den Frieden seien. ${ }^{993}$ Nachdem Staeck dieser Aufforderung nicht nachkam, folgten Anträge auf den Erlass einer einstweiligen Verfügung beim LG Heidelberg sowie dem LG Frankfurt am Main. Antragsteller vor dem LG Heidelberg war einer der abgebildeten Vorstandsvorsitzenden der Firma Rheinmetall Berlin AG. ${ }^{594}$ Vor dem LG Frankfurt am Main hingegen war das Unternehmen Rheinmetall $\mathrm{GmbH}$, Tochterfirma der Rheinmetall Berlin AG mit Sitz in Düsseldorf, Antragstellerin. ${ }^{595}$ Die einstweiligen Verfügungen wurden durch Beschluss sowohl vom LG Heidelberg als auch vom LG Frankfurt am Main zurückgewiesen. ${ }^{596}$ Auch die eingelegten Beschwerden wurden von der jeweils nächsten Instanz, namentlich dem OLG Karlsruhe und dem OLG Frankfurt am Main, zurückgewiesen. ${ }^{597}$

Da die beiden Verfahren nicht nur zeitgleich stattfanden, sich mit dem gleichen Plakat beschäftigten und vor allem auch zu einem ähnlichen Ergebnis kamen, werden die Verfahren hier zusammen besprochen.

592 Rheinmetall./. Staeck, Abmahnung, 27.10.1981, S. 1.

593 Rheinmetall./. Staeck, ebd.

594 Rheinmetall./. Staeck, Antrag auf Erlass einer einstweiligen Verfügung, LG Heidelberg, 5.11.1981.

595 Rheinmetall./. Staeck, Antrag auf Erlass einer einstweiligen Verfügung, LG Frankfurt, 5.11.1981.

596 LG Heidelberg, 7.11.1981, 3 O 503/81, S. 1; LG Frankfurt, 5.11.1981, 2/3 O 482/81, S. 1.

597 OLG Karlsruhe, 27.11.1981, 10 W 72/81, S. 1; OLG Frankfurt, 10.12.1981, 16 W 47/81, S. 1 . 


\section{Die Verfahren im Einzelnen}

a) Die Verfahren in der ersten Instanz

\section{aa) Die Anträge}

Die Antragsteller, das Unternehmen und der Vorstandsvorsitzende, gehen davon aus, dass sie mit dem Plakat „erheblich diskriminiert“ werden ${ }^{598}$ und der Vorstandsvorsitzende in seinem Recht am eigenen Bild verletzt werde ${ }^{599}$. Es handele sich bei Rheinmetall um ein Rüstungsunternehmen, das zum einen für die Bundeswehr zu Verteidigungszwecken Waffen und Munition und zum anderen für den Export bestimmte Produkte herstelle, diese würden laut der Ausführung in der Begründung der Anträge „überwiegend in NATO-Länder" 600 exportiert werden.

Die „erhebliche Diskriminierung“ wird darin gesehen, dass das Plakat suggeriere, dass "die abgebildeten Herren und die Firma [...] gegen den Frieden [seien]“ und darüber hinaus auch noch „dem imaginären Zweckverband der Rüstungsindustrie [angehören würden], dessen Ziele gegen den Frieden gerichtet [seien]"601. In den Anträgen wird zwar darauf Bezug genommen, dass sich das Staeck-Plakat an die Bundesbahnkampagne anlehnt, wenn es dort heißt: „In der vom Antragsgegner offensichtlich beabsichtigten direkten Assoziation enthält das beanstandete Poster die Behauptung: Frieden - von dem alle reden - interessiert die abgebildete Person nicht; ohne Rücksicht auf Frieden ,fahren' sie, d.h. produzieren sie Rüstungsgüter." ${ }^{602}$ Dagegen führen die beiden Antragsteller jedoch an, dass gerade sie - das Unternehmen und der Vorstandsvorsitzende - in besonderem Maße der Erhaltung des Friedens dienten.

Unter Bezugnahme auf das Autoritätsargument der Mehrheit wird davon ausgegangen, dass nach „Ansicht der ganz überwiegenden Mehrheit aller Bundesbürger und sämtlicher Bundesregierungen seit dem Krieg die

598 Rheinmetall./. Staeck, Antrag auf Erlass einer einstweiligen Verfügung, LG Heidelberg, 5.11.1981, S. 3.

599 Rheinmetall./. Staeck, ebd., S. 6 f.

600 Rheinmetall./. Staeck, Abmahnung, 27.10.1981, S. 3.

601 Rheinmetall./. Staeck, Antrag auf Erlass einer einstweiligen Verfügung, LG Heidelberg, 5.11.1981, S. 3; Rheinmetall./. Staeck, Antrag auf Erlass einer einstweiligen Verfügung, LG Frankfurt, 5.11.1981, S.3.

602 Rheinmetall./. Staeck, Antrag auf Erlass einer einstweiligen Verfügung, LG Heidelberg, 5.11.1981, S. 4; Rheinmetall./.Staeck, Antrag auf Erlass einer einstweiligen Verfügung, LG Frankfurt, 5.11.1981, S. 4. 
Aufstellung und entsprechende Ausrüstung einer Bundeswehr zum Zweck der Verteidigung und Abschreckung erforderlich [sei], ebenso wie die Zusammenarbeit wehrtechnischer Unternehmen innerhalb der nordatlantischen Verteidigungsgemeinschaft.“" ${ }^{603}$ Die Antragsteller gehen davon aus, dass der Vorwurf, gegen den Frieden zu sein, ein besonders schwerer sei und daher eine Schmähkritik vorliege. Denn mit dem Plakat würde suggeriert werden, dass die Antragsteller „sich erst im Krieg so recht wohlfühlen, woraus ja auch die lachenden Gesichter aller abgebildeten Herren mit schwerer Munition in der Hand hindeuten". ${ }^{604}$ Auch sind sie der Ansicht, dass jeglicher Sachbezug fehle, wenn man davon ausginge, dass es sich um ein kritisches Werturteil handele, da das Foto aus einem ganz anderen Zusammenhang herausgerissen und in einem Plakat verarbeitet worden sei, das wiederum eine offizielle Haltung eines nicht existierenden Zweckverbandes der Rüstungsindustrie zeige. ${ }^{605}$

Zwar werden weder das Unternehmen noch die abgebildeten Personen namentlich genannt, doch gehen die Antragsteller davon aus, dass eine Verbindung zwischen der im Plakat verwendeten Fotografie und dem Artikel im Nachrichtenmagazin „Der Spiegel“, in dem sowohl das Unternehmen als auch die Personen benannt werden, gezogen werden könne. Der Leserkreis des Magazins, die mehreren Tausend Mitarbeiter Rheinmetalls, sowie „Freunde und Bekannte des Antragstellers“ und alle diejenigen, mit denen er in beruflichem Kontakt stünde, könnten diesen Rückschluss ziehen. ${ }^{606}$

Die Antragsteller beantragen Unterlassung der Verbreitung, Ausstellung oder Zugänglichmachung der Plakate. Als Anspruchsgrundlagen kommen

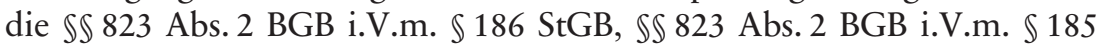
StGB sowie $\mathbb{8} 824 \mathrm{BGB}, \mathbb{} 823$ Abs. $1 \mathrm{BGB}$ und insbesondere für den Vor-

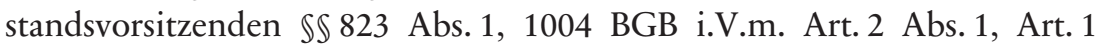
Abs. 1 GG in Betracht.

603 Rheinmetall./. Staeck, Antrag auf Erlass einer einstweiligen Verfügung, LG Heidelberg, 5.11.1981, S. 4.

604 Rheinmetall./. Staeck, Antrag auf Erlass einer einstweiligen Verfügung, LG Heidelberg, 5.11.1981, S. 6; Rheinmetall./. Staeck, Antrag auf Erlass einer einstweiligen Verfügung, LG Frankfurt, 5.11.1981, S. 5.

605 Rheinmetall./. Staeck, Antrag auf Erlass einer einstweiligen Verfügung, LG Heidelberg, 5.11.1981, S. 6; Rheinmetall./. Staeck, Antrag auf Erlass einer einstweiligen Verfügung, LG Frankfurt, 5.11.1981, S. 5 f.

606 Rheinmetall./. Staeck, Antrag auf Erlass einer einstweiligen Verfügung, LG Heidelberg, 5.11.1981, S. 5; Vgl. auch Rheinmetall./. Staeck, Antrag auf Erlass einer einstweiligen Verfügung, LG Frankfurt, 5.11.1981, S. 6. 
Die wesentlichen Punkte der Anträge vor dem LG Heidelberg und LG Frankfurt am Main lagen also insofern darin, dass in dem Plakat die unwahre Behauptung stecke, die Abgebildeten und das hinter diesen stehende Unternehmen sei gegen den Frieden und gehöre einem Zweckverband der Rüstungsindustrie an. Besonders schwer wiege, dass die Personen und das Unternehmen auch ohne Namensnennung erkannt werden würden.

Im Wesentlichen wurde diesen beiden Anträgen entgegnet, dass das Plakat eine politische Meinungsäußerung darstelle und darüber hinaus keinerlei unrichtige Behauptung in Bezug auf die Antragsteller beinhalte. Dies sieht der Antragsgegner auch in den Anträgen bestätigt, da „im Wesentlichen politische Meinungen" wiedergegeben würden. ${ }^{607}$ Ferner würde ja auch auf die Berichterstattung über den vermeintlichen Verstoß gegen das Kriegswaffenkontrollgesetz verwiesen, um so einen Sachbezug aufzuzeigen. ${ }^{608}$

\section{bb) Die Beschlüsse}

Sowohl in dem Beschluss des LG Frankfurt am Main als auch in dem des LG Heidelberg machen die Richter deutlich, dass es sich bei dem Plakat um eine reine Meinungsäußerung handele. „Der Antragsgegner bringt nicht mehr zum Ausdruck als seine allgemein gehaltene Meinung, Frieden sei nicht mit Rüstung zu erreichen." ${ }^{609}$ Eine etwaige Schmähkritik wird vom LG Frankfurt am Main ohne Begründung abgelehnt. Weitaus ausführlicher ist der Beschluss des LG Heidelberg. ${ }^{610} \mathrm{Zu}$ den Grenzen einer nicht sachbezogenen Schmähkritik geht das LG hier davon aus, dass die satirische Kritik die berufliche Tätigkeit des Vorstandsvorsitzenden betrifft und die Äußerung, der Vorstandsvorsitzende berücksichtige bei der Waffenproduktion nicht ausreichend die Erhaltung des Friedens, sei eine politische Meinung, die eben noch keine Schmähung der Person darstelle. Das Gericht bewertet auch den Vergleich mit der Bundesbahnwerbung, die für Staeck auch als Vorlage gedient hatte. Das Gericht sieht es als nicht gegeben, dass das Plakat die Aussage transportiere, Rheinmetall sei gegen

607 Rheinmetall./. Staeck, Schutzschrift, LG Düsseldorf, 17.11.1981, S. 3.

608 Vgl. schon bei Rheinmetall./. Staeck, ebd.

609 LG Frankfurt, 5.11.1981, 2/3 O 482/81.

610 LG Heidelberg, 7.11.1981, 3 O 503/81. 
den Frieden. Der Vorlage könne ja auch nicht entnommen werden, dass „die Bundesbahn [...] für schlechtes Wetter [sei]“. 611

Außerdem geht die Kammer davon aus, dass der Vorstandsvorsitzende und die anderen abgebildeten Personen zu einer Grundfrage des Gemeinschaftslebens mit dieser Fotografie - vor allem durch die abgelichtete Pose - Stellung bezogen haben. Zumal man auch bedenken muss, dass diese Pose bei der öffentlichen Übergabe der Waffen an den Bundesminister der Verteidigung in Anwesenheit der Pressefotografen gewählt wurde. ${ }^{612}$ Auch für die Abgebildeten müsse insofern klar gewesen sein, dass eine Verbreitung der Bilder naheliege. Im Ergebnis überwiege nach Ansicht des Gerichts die Meinungsfreiheit gegenüber dem allgemeinen Persönlichkeitsrecht des Vorstandsvorsitzenden. ${ }^{613}$

b) Die Verfahren in der zweiten Instanz

aa) Die Anträge

Nachdem gegen die Entscheidung des LG Heidelberg Beschwerde eingelegt wurde und das LG Heidelberg im Rahmen des Abhilfeverfahrens an seiner Entscheidung festgehalten hatte, wurde die Sache dem OLG Karlsruhe zur Entscheidung vorgelegt. ${ }^{614}$

In der Beschwerde wurden die schon in der ersten Instanz genannten Ausführungen im Wesentlichen wiederholt. So geht es maßgeblich darum, das Plakat suggeriere, die Antragsteller seien aus egoistischen geschäftlichen Gründen gegen den Frieden. ${ }^{615}$ Es sei nämlich „unverantwortlich, jemandem, der etwas mit Wehrtechnik zu tun hat, ohne den geringsten Anhaltspunkt seine persönliche Friedensliebe abzusprechen." 616 Und es sei „entstellend und rufgefährdend“ als jemand dargestellt zu werden, der sich nicht um den Frieden als Elementaranliegen einer humanen Welt kümmere. ${ }^{617}$

Besonders angegriffen wird die Entscheidung des LG Heidelberg in Bezug auf die Ausführungen, die Antragsteller hätten mit der Fotografie

611 LG Heidelberg, ebd., S. 2.

612 LG Heidelberg, ebd., S. 2.

613 LG Heidelberg, ebd., S. 3 f.

614 LG Heidelberg, ebd., S. 1.

615 Rheinmetall./. Staeck, Beschwerde, LG Heidelberg, 11.11.1981, S. 4.

616 Rheinmetall./. Staeck, ebd., S. 6.

617 Rheinmetall./. Staeck, ebd., S. 8. 
zu einer Grundfrage des Gemeinschaftslebens Stellung bezogen, da es sich bei der Fotografie nur um ein „Erinnerungsfoto“ handele. ${ }^{618}$

Ob es sich bei dem Plakat um Kunst handeln könnte wird klar verneint: „Von Kunst kann bei dem Poster des Antragsgegners keine Rede sein. Es ist kein ,Kunststück ${ }^{6}$, sich ein Pressefoto zu beschaffen und zu veröffentlichen und mit einem Text zu versehen, den der Antragssteller sich bei der Werbung der Bundesbahn abgeguckt hat.“619

Dem erwidert Klaus Staeck als Antragsgegner, dass das Plakat keineswegs den abgebildeten Personen die "persönliche Friedensliebe“ abspräche, da es sich um eine sachbezogene Meinungsäußerung handele. ${ }^{620} \mathrm{Im}$ Rahmen des Beschwerdeverfahrens vor dem OLG Frankfurt am Main wird in dem Schriftsatz darüber hinaus sehr deutlich ausgeführt: „Die Geschäftsführer der Antragstellerin hielten die Granaten, mit denen bekanntlich Menschen getötet werden, derart fröhlich, fast zärtlich, den Kameras entgegen, dass die Bewertung bzw. Interpretation dieser Geschmacklosigkeit durch den Antragsgegner noch als zurückhaltend bezeichnet werden muss." 621

\section{bb) Entscheidungen}

Das OLG Karlsruhe bestätigt die Entscheidung des LG Heidelbergs und erachtet die Beschwerde als unbegründet. Das LG Heidelberg hatte in seiner Entscheidung im Rahmen des Abhilfeverfahrens verdeutlicht, dass es sich bei „diesem graphischen Produkt erkennbar um eine politisch satirische Darstellung handelt“, das OLG Karlsruhe bestätigt diese Deutung. ${ }^{622}$ Unter Berücksichtigung des Satireaspektes zeige das Plakat, auch für den Durchschnittsbetrachter ausreichend deutlich, dass es nicht die Behauptung beinhalte, der Vorstandsvorsitzende rede im Gegensatz zu allen anderen nicht vom Frieden, was ihm eine persönliche Friedensliebe

618 Rheinmetall./. Staeck, ebd., S. 6.

619 Rheinmetall./. Staeck, Beschwerde, LG Heidelberg, 11.11.1981, S. 9.

620 Rheinmetall./. Staeck, Beschwerdeerwiderung, OLG Frankfurt, 30.11.1981, 16 W 47/ 81, S. 2; Rheinmetall./. Staeck, Beschwerdeerwiderung, OLG Karlsruhe, 20.11.1981, S. 2.

621 Rheinmetall./. Staeck, Beschwerdeerwiderung, OLG Frankfurt, 30.11.1981, 16 W 47/ 81, S. 3.

622 OLG Karlsruhe, 27.11.1981, 10 W 72/81, NJW 1982, S. 647; LG Heidelberg, 13.11.1981, 3 O 503/81. 
abspräche. ${ }^{623}$ Vielmehr enthalte das Plakat die Äußerung, dass die von dem Unternehmen betriebene Waffenproduktion die Erhaltung des Friedens gefährde. Diese politische Meinung sei folglich als ein Beitrag zum geistigen Meinungskampf in einer die Öffentlichkeit wesentlich berührenden, politischen und weltanschaulichen Frage zu klassifizieren. ${ }^{624}$ Das OLG Karlsruhe geht ferner davon aus, dass von der Fotografie nicht auf die Rheinmetall GmbH oder Rheinmetall AG geschlossen werden könne. Im Gegenteil weise der Bildtext durch den Zusatz „Zweckverband der Rüstungsindustrie“ in eine „fiktive Richtung“. ${ }^{625}$ Die Kenntnis einer lediglich kleineren Gruppe reiche nicht aus, um von einer unmittelbaren Betroffenheit der Antragstellerin durch die bildliche Darstellung auszugehen. ${ }^{626}$

In dem hier zu Grunde liegenden Verfahren zu dem Plakat Staecks „Alle reden vom Frieden" war noch die Unterscheidung zwischen relativen und absoluten Personen der Zeitgeschichte herrschend. So geht das Gericht davon aus, dass zwar keine Einwilligung für die Nutzung der Fotografie nach $₫ 22$ S. 1 KUG vorliege, aber die Ausnahme des $\$ 23$ Abs. 1 Nr. 1 KUG greife. Da das Bild anlässlich der feierlichen Übergabe der Feldhaubitze FH 70 an den Bundesminister der Verteidigung aufgenommen wurde, stehe es in sachlicher Verbindung zum Zeitgeschehen.627 Ferner geht das Gericht davon aus, dass Staeck „mit der Veröffentlichung des Bildes ein noch bestehendes legitimes Informationsinteresse der Allgemeinheit befriedigt “628 habe, wie der Artikel im Magazin „Der Spiegel“ zu dem Rüstungsunternehmen mit dem gleichen Bild zeige. ${ }^{629}$ Dass persönliche Belange des Vorstandsvorsitzenden überwiegen und so berechtigte Interessen des $\$ 23$ Abs. 2 KUG bestehen würden, wurde laut Begründung vom Antragsteller nicht ausreichend dargelegt.

Exkurs: Der Bildnisschutz nach dem KUG

Maßgeblich im Rahmen des Rechtsstreits zwischen dem Vorstandsvorsitzenden und Staeck ist die Fotografie, die als eine erkennbare Wiedergabe des äußeren Erscheinungsbildes einer Person ein Bildnis im Sinne des KUG ist. ${ }^{630}$ Der Bildnisschutz des KUG ist eine einfachrechtliche Ausprä-

623 OLG Karlsruhe, ebd.

624 OLG Karlsruhe, ebd.

625 OLG Frankfurt, 30.11.1981, 16 W 47/ 81, S. 5.

626 OLG Frankfurt, ebd., S. 5 f.

627 OLG Karlsruhe, 27.11.1981, 10 W 72/81, NJW 1982, S. 647.

628 OLG Karlsruhe, ebd.

629 OLG Karlsruhe, ebd.

630 Zur Definition des Bildnis Wandtke/Bullinger/Fricke, UrhR, $\$ 22$ KUG, Rn. 5 m.w.N. 
gung des Rechts am eigenen Bild im Rahmen des allgemeinen Persönlichkeitsrechts aus Art. 2 Abs.1, Art. 1 Abs.1 GG. Auf das Grundrecht des allgemeinen Persönlichkeitsrechts und die Abwägung zu Herstellung einer praktischen Konkordanz im Falle der Kollision mit der Meinungsfreiheit wurde im Rahmen des dritten Kapitels bereits eingegangen, soweit kann verwiesen werden. ${ }^{631} \mathrm{Im}$ Wege dieses Exkurses soll der Blick im Speziellen auf die Regelung der $\$ \$ 22,23 \mathrm{KUG}$ geworfen werden.

$\$ 22$ S. 1 KUG regelt, dass Bildnisse nur mit Einwilligung des Abgebildeten verbreitet oder öffentlich zur Schau gestellt werden dürfen. Der S. 2 der Norm enthält eine Vermutung für die Erteilung der Einwilligung des Abgebildeten, wenn er für die Abbildung eine Entlohnung erhielt. Der Zweck der Norm liegt in der Abwehr ideeller Persönlichkeitsrechtsverletzungen auf der einen Seite und dem Schutz kommerzieller Interessen am eigenen Bild auf der anderen Seite.

$\$ 23$ Abs. 1 KUG enthält dagegen zum Schutz der Informations-, Presse-, Kunst- und Meinungsfreiheit der Allgemeinheit vier Ausnahmen von dem Erfordernis der Einwilligung ${ }^{632}$ des $\$ 22$ S. 1 KUG, sofern dem nicht nach $\$ 23$ Abs. 2 KUG ein berechtigtes Interesse des Abgebildeten entgegensteht. $\$ 23$ Abs. 1 Nr. 1 KUG ist die in der Praxis relevanteste der vier Ausnahmen jene, die Bildnisse aus dem Bereich der Zeitgeschichte von der Einwilligungserfordernis befreit. In Anlehnung an die Definition des Reichsgerichts gehören zur Zeitgeschichte alle „Erscheinungen im Leben der Gegenwart, die von der Öffentlichkeit ,beachtet werden, bei ihr Aufmerksamkeit finden und Gegenstand der Teilnahme oder Wissbegier weiter Kreise sind““. ${ }^{633}$ Der Begriff ist insofern zugunsten der Presse- und Informationsfreiheit weit auszulegen, als dass alle Fragen von allgemeinen gesellschaftlichen Interesse unabhängig ihrer Qualität umfasst werden und so auch solche von lediglich regionaler oder gar nur lokaler Bedeutung zu berücksichtigen sind. ${ }^{634}$ Für eine Konkretisierung der Ausnahmeregelung und des Begriffes der Zeitgeschichte unterschieden die frühere Rechtsprechung und herrschende Lehre jahrzehntelang zwischen relativen und absoluten Personen der Zeitgeschichte. ${ }^{635}$ Absolute Personen

631 Vgl. dazu besonders Kap. 3, E., II.

632 Zur umstrittenen Frage nach der Rechtsnatur der Einwilligung vgl. Dreier/Schulze/Specht, UrhR, $\mathbb{} 22$ KUG, Rn. 16 m.w.N.

633 RGZ 125, S. 80, 82 - Tull Harder; Wandtke/Bullinger/Fricke, UrhR, $\$ 23$ KUG, Rn. 3.

634 Wandtke/Bullinger/Fricke, UrhR, $\$ 23$ KUG, Rn. 4, m.w.N.

635 Diese Unterscheidung geht grundlegend auf Neumann-Duesberg zurück, vgl. Neumann-Duesberg, JZ 1960, S. 114-118. 
der Zeitgeschichte, beispielsweise Staatsoberhäupter oder führende Politiker, bekannte Sportler, Musiker, Schauspieler oder sonstige prominente Personen des gesellschaftlichen Lebens, mussten stets Abbildungen ohne ihre Einwilligung hinnehmen, da Bilder dieser Personen als Bildnisse der Zeitgeschichte eingeordnet wurden, sofern nicht nach $\$ 23$ Abs. 2 KUG berechtigte Interessen entgegenstanden. Anerkannt waren solche berechtigten Interessen, wenn sich die betroffene Person in den eigenen vier Wänden oder in anderer Weise örtlich zurückgezogen hatte. ${ }^{636}$ Relative Personen der Zeitgeschichte waren hingegen solche Personen, an denen ein allgemeines Interesse nur aufgrund eines Ereignisses bestand, d.h. dass diese vorübergehend zu Personen der Zeitgeschichte wurden. ${ }^{637}$ Dementsprechend konnten Abbildungen von relativen Personen der Zeitgeschichte auch nur ohne Einwilligung verwendet werden, sofern die Bilder in Bezug zu dem Ereignis, das sie zu relativen Personen der Zeitgeschichte machte, standen. Auch relative Personen konnten sich auf die berechtigten Interessen des $\mathbb{} 23$ Abs. 1 KUG berufen. Die Caroline-von-Monaco-Entscheidung des EGMR von 2004, in der das Straßburger Gericht - entgegen der Annahme des BGH und des BVerfG - von einer Verletzung der Privatsphäre ausging, ${ }^{638}$ führte in der Rechtsprechung zu einer Abkehr von dem Konzept der absoluten und relativen Personen der Zeitgeschichte hin zu dem sogenannten abgestuften Schutzkonzept. ${ }^{639}$ Nach diesem muss im Einzelfall zwischen den Grundrechten der abgebildeten Person und der Pressefreiheit abgewogen werden. Erst wenn die Pressefreiheit überwiegt, liegt dann ein Ereignis der Zeitgeschichte im Sinne des $\$ 23$ Abs. 1 KUG vor. ${ }^{640}$

636 Vgl. dazu BGH, 19.12.1995, VI ZR 15/95, NJW 1996, S. 1128 - Caroline von Monaco.

637 Neumann-Duesberg, JZ 1960, S. 115; Dreier/Schulze/Specht, UrhR, $\$ 23$ KUG, Rn. 6 m.w.N. Ein Beispiel aus den Caroline-von-Monaco-Fällen ist für relative Personen der Zeitgeschichte auch die Begleitpersonen von absoluten Personen der Zeitgeschichte. Vgl. BVerfG, 15.12.1999, 1 BvR 653/96, NJW 2000, S. 1021, 1023 - Caroline von Monaco II.

638 EGMR, 24.6.2004, 59320/00, GRUR 2004, S. 1051 - von Hannover/Deutschland I.

639 Vgl. dazu Teichmann, NJW 2007, S. 1917, 1918 f. m.w.N.

640 Vgl. BGH, 6.3.2007, VI ZR 13/06, GRUR 2007, S. 523, 525 - Abgestuftes Schutzkonzept; BGH, 3.7.2007, VI ZR 164/06, NJW 2008, S. 749, 751 - Abgestuftes Schutzkonzept II; Dreier/Schulze/Specht, UrhR, $\$ 23$ KUG, Rn. 10 m.w.N. 


\section{Bewertung}

a) Die Auseinandersetzung der Gerichte mit der Satire

Vor allem die Beschlüsse des LG Heidelberg im Rahmen des Abhilfeverfahrens und des OLG Karlsruhe thematisieren die Satire. ${ }^{641}$ Das LG Heidelberg beschreibt bemerkenswert deutlich: „Es ist geradezu das Wesen der Satire und der Karikatur, Tatsachen zu verfremden und zu überspitzen, um damit ein Werturteil abzugeben. Dabei kann es nicht darauf ankommen, dass jeder Betrachter das Werk als Satire erkennt, denn jede Satire läuft Gefahr von jenen verkannt zu werden, die keinen Sinn dafür haben." ${ }^{642}$ Damit spricht das Gericht die für die Satire typische Vereinigungsund Ausgrenzungsfunktion an, denn diejenigen, die sich in der durch die Satire geäußerten Meinung wiederfinden, nehmen diese ganz anders wahr als diejenigen, die sich durch diese angegriffen fühlen.

Nach dem OLG will die Satire „durch Ironie und Übertreibung bestimmte Personen, Ereignisse und Zustände kritisieren." ${ }^{463}$ Das Gericht führt ferner aus: „Bei einer Interpretation des Posters muss daher die textliche Aussage ihrer spezifisch satirischen Form entkleidet und in erster Linie die vom Antragsgegner mit der Gesamtdarstellung verfolgte Absicht berücksichtigt werden."644 In Bezug auf den vom BVerfG herausgearbeiteten Maßstab der getrennten Prüfung der satirischen Entkleidung und des Aussagekerns greift das OLG Karlsruhe nur einen Teil dieses Maßstabs auf. Es geht nämlich davon aus, dass der primäre Anknüpfungspunkt der Aussagekern sei. Man könnte die Definition der Satire des OLG oder gar des LG für zu knapp oder unzureichend halten. Doch setzt sich das Gericht ausführlich mit der Interpretation des Plakats „Alle reden vom Frieden“ und der Frage auseinander, ob das Plakat so gelesen werden könnte, dass die abgebildeten Personen gegen den Frieden seien.

Ein weiterer Anknüpfungspunkt für die Herausarbeitung des Satirischen hätte darüber hinaus aus dem Verhältnis zur Bundesbahn-Werbekampagne gezogen werden können. Werbesprüche oder Werbeslogans, wie eben damals die Werbekampagne „Alle reden vom Wetter. Wir nicht“ der Deutschen Bundesbahn, können sich - gerade wenn die Werbekampa-

641 LG Heidelberg, 13.11.1981, 3 O 503/81; OLG Karlsruhe, 27.11.1981, 10 W 72/81, NJW 1982, S. 647.

642 LG Heidelberg, 13.11.1981, 3 O 503/81, S. 1.

643 OLG Karlsruhe, 27.11.1981, 10 W 72/81, NJW 1982, S. 647.

644 OLG Karlsruhe, ebd. 
gne über einen längeren Zeitraum flächendeckend wiederholt wird - fest im Gedächtnis der Rezipienten verankern. In der Öffentlichkeit ist der Bürger einer Flut von Werbung ausgesetzt. In dieser Situation bleibt der ja meistens nur flüchtige Blick des Rezipienten am ehesten bei einem Plakat hängen, welches scheinbar die Erwartung an einen allseits bekannten Werbeslogan erfüllt, tatsächlich diese Erwartung jedoch durch einen klaren Bruch konterkariert. ${ }^{645}$ Auch in diesem Verhältnis liegt das Satirische in Form einer Pointierung oder eben eines solchen „Bruches“ vor, d.h. das Satirische äußert sich quasi im Spiel mit der Erwartung.

\section{b) $\$ 23$ Abs. 1 Nr. KUG}

Das OLG Karlsruhe geht von einer Ausnahme des Einwilligungsvorbehalts nach $₫ 23$ Abs. 1 Nr. 1 KUG aus. Diese Einordnung ließe sich - unabhängig von der mittlerweile herrschenden einzelfallbezogenen Abwägung des sogenannten abgestuften Schutzkonzeptes - anzweifeln. Die Nr. 1 befreit von der Einwilligung in den Fällen eines Informationsinteresses der Allgemeinheit in den typischen Fällen der redaktionellen Berichterstattung. Es lässt sich daher vertreten, dass in dem Falle des künstlerischen PolitsatirePlakat nicht die Nr. 1, sondern die Nr. 4 des $\$ 23$ Abs. 1 KUG einschlägig sei. Die Nr. 4 befreit Bildnisse vom Einwilligungserfordernis des $₫ 22$ S. 1 KUG, die nicht auf Bestellung angefertigt sind, sofern die Verbreitung oder Schaustellung einem höheren Interesse der Kunst dient. Die $\$ 23$ Abs. 1 Nr. 4 i.V.m. $\$ 23$ Abs. 2 KUG lassen sich insofern als eine einfachgesetzliche Regelung zur Kollision von Kunstfreiheit und Persönlichkeitsrecht ansehen. ${ }^{646}$ Eine Einordnung des künstlerischen Politsatire-Plakats überzeugt, wenn man ein solches vorrangig der Kunst und nicht der Information zuordnen möchte. Christian Schertz präferiert eine solche Einordnung, da es „bei satirischen Darstellungen [...] weniger um die Information der Allgemeinheit als vielmehr um die künstlerische Auseinandersetzung mit gesellschaftlichen oder politischen Begebenheiten" gehe. ${ }^{647}$ Gegen diesen Ansatz spricht zum einen, dass die Satire durchweg - wie im dritten Kapitel aufgezeigt wurde - über das Grundrecht der Meinungsfreiheit verhandelt wird und zum anderen hauptsächlich, dass die für die

645 Vgl. zum Werbeplakat Kap. 1, A., III., zum Bruch im Staeck-Plakat Kap. 4, C., II., 2., b.

646 Schertz, GRUR 2007, S. 558, 559.

647 Schertz, ebd. 
Satire typischen Funktionen dem entgegenstehen. Grundlegend für die Satire sind - auf das zweite Kapitel rekurrierend - gerade die Informations-, Aufdeckungs- und die Änderungsfunktion. Das künstlerische PolitsatirePlakat auf eine „künstlerische Auseinandersetzung mit gesellschaftlichen oder politischen Begebenheiten" 648 zu reduzieren, wird den komplexen Mechanismen des Mediums ebenso wenig gerecht, wie das Plakat allein als eine informatorische Äußerung zu verstehen. Gegen ein etwaiges Vorrangverhältnis wird sich in dieser Arbeit seit dem ersten Kapitel ausgesprochen. Und so lange nämlich die künstlerische Ausdrucksform in der Abwägung ausreichend berücksichtigt wird, steht einer Einordnung unter die Nr. 1 nichts entgegen.

\section{Nachtrag}

Auf ihre gerichtlichen Niederlagen hin erklärten das Unternehmen Rheinmetall und der Manager in einer Pressemitteilung schließlich, dass ,in verschiedenen juristischen Instanzen [...] dem sogenannten künstlerischen Interesse des Herrn Staeck eine übergeordnete Bedeutung gegenüber den im Grundgesetz gesicherten Persönlichkeitsrechten " beigemessen wurde. ${ }^{649}$ Einmal ganz abgesehen von der Tatsache, dass auch die Kunstfreiheit ein im GG verankertes Grundrecht ist und diese im Rahmen der Abwägung nicht im Vordergrund stand, soll die Formulierung „sogenanntes künstlerisches Interesse“ die Berechtigung dieses Interesses infrage stellen.

Die Mitteilung endet mit der Aussage: „Eine weitere Auseinandersetzung mit Herrn Staeck - in jüngster Zeit durch mehrere großen Ausstellungen in der DDR und Ost-Berlin ausgezeichnet - führt ausschließlich zu einer unnötigen Aufwertung dieser nunmehr unzweideutig politisch qualifizierten ,Kunst'“. .650

Ein weiteres gerichtliches Verfolgen dieser Sache wäre wohl nicht ratsam gewesen. Denn nachdem führende Manager des Unternehmens am 1. August 1983 angeklagt wurden, vorsätzlich Kriegswaffen ausgeführt oder aus dem Bundesgebiet verbracht zu haben, ohne dass die hierzu er-

648 Schertz, ebd.

649 Vgl. Anhang A.

650 Vgl. Anhang A. 
forderliche Beförderung genehmigt war, ${ }^{651}$ und 1986 verurteilt wurden, ${ }^{652}$ wäre der Sachbezug des Plakats wohl noch schwieriger zu entkräften gewesen.

IV. „Alle reden vom Klima. Wir ruinieren es“

Die Arbeit „Alle reden vom Klima. Wir ruinieren es" reiht sich in die Gruppe von Plakaten ein, die Klaus Staeck den Fragen der Umwelt widmet. Die Umweltschutzorganisation Greenpeace hatte Staeck beauftragt, dieses Plakat im querrechteckigen Format eines Großflächenplakates zu entwerfen, um es für eine bundesweite Plakataktion zu verwenden. Die Anträge bzw. Klagen richteten sich insofern nicht gegen Klaus Staeck selbst, sondern gegen Greenpeace.

\section{Das Plakat}

Das Plakat zeigt auf weißem Grund - in ästhetischer Anlehnung an die damals aktuelle staatliche Informationskampagne „Die Bundesregierung informiert" - jeweils eine schwarzweiße Porträtabbildung der Vorstandsvorsitzenden der Hoechst AG und der Kali Chemie AG (Abb. 10). Über den Fotografien steht in großen roten Lettern „Alle reden vom Klima“ und unmittelbar darunter in gleich großer, jedoch schwarzer Druckschrift „Wir ruinieren es:“ Dieser Textteil variierte, wie auch „Alle reden vom Frieden. Wir nicht“, die Werbekampagne der Bundesbahn aus den 1960er Jahren. Die Abgebildeten werden mit Titel, Vor- und Zuname und der entsprechenden Unternehmenszugehörigkeit genannt. Unter den Fotografien und den Namen folgt klein und mittig gesetzt der Text: „Absolute Spitze bei Ozonzerstörung und Treibhauseffekt: Verantwortlich für die deutsche Produktion des Ozon- und Klimakillers FCKW. Rufen Sie an: Hoechst AG 069/3050, Kali Chemie 0511/8570.“ Die abgedruckten Telefonnummern führten zu den Presseabteilungen der jeweils genannten Unternehmen. In

651 StA Düsseldorf, Anklageschrift, 1.8.1983, 810/8 Js 489/80 - VS 1I 1/80 Geheim. Zum Teil abgedruckt in: Hauschild/Lorscheid, Ermittlungen gegen Rheinmetall, 1987, S. 54-56, Vgl. auch den Beschluss zur Beschwerde gegen den erhobenen Haftbefehl OLG Düsseldorf, 15.12.1983, 1 WS 1053, 1055/833, NStZ 1987, S. $565 \mathrm{f}$.

652 LG Düsseldorf, 27.5.1986, X 64/83, NStZ 1988, S. 231-233; Vgl. Hauschild/Lorscheid, Ermittlungen gegen Rheinmetall, 1987, S. 84-89. 
einem gewissen Abstand folgt, ebenfalls mittig gesetzt: „Eine Information von Greenpeace“.

Ein roter Balken schließt das Plakat an der unteren Kante ab, in ihm steht in schwarzen Buchstaben der Satz „Bundesumweltminister Klaus Töpfer weigert sich immer noch, die Produktion von FCKW zu verbieten.“. Nach rechts erscheint im roten Balken eine kleine Wiedergabe des Bundesadlers in schwarzer Farbe.

\section{Der Hintergrund}

Die Umweltschutzorganisation Greenpeace veranlasste im Sommer 1990, dass das Plakat bundesweit auf Werbeflächen angebracht wurde. Wie das Plakat in seinem Textteil schon verdeutlicht, richtet es sich gegen die Produktion von Fluorchlorkohlenwasserstoffen (FCKW). Die Hoechst AG und die Kali Chemie AG waren damals die einzigen deutschen Unternehmen, die diese Stoffe noch produzierten. Gleichzeitig ist, wie bereits in den 1970er/1980er Jahren herausgearbeitet worden war, FCKW ein Auslöser gravierender Umweltschäden, da die Freisetzung dieser Verbindung zum Abbau der Ozonschicht in der Stratosphäre und zur Erwärmung der Erdatmosphäre durch den sogenannten Treibhauseffekt führt. ${ }^{653}$ Auf der UNUmweltkonferenz 1987 unterzeichnete u.a. Deutschland das sogenannte Montrealer Protokoll.654 In diesem Vertrag legten die Länder fest, die Ozonschicht durch die Reduzierung der Produktion entsprechender Stoffe zu schützen. Mit den Londoner Änderungen von 1990 wurden auch vollhalogenierte FCKW in das Montrealer Protokoll aufgenommen. Anlass für die Plakataktion 1990 war insofern - neben der Tatsache, dass weiterhin FCKW-Verbindungen produziert wurden, obwohl der Ausstieg aus der Produktion bereits durch einen völkerrechtlich verbindlichen Vertrag beschlossen war - auch eine Reihe von Presseerklärungen der Chemie-Unternehmen. In einer solchen Presseerklärung vom Oktober 1989 meldete die Hoechst AG, dass sie als erstes und bisher einziges Unternehmen weltweit einen Ausstieg aus der Produktion vollhalogenierter FCKW entschieden habe. In einer weiteren Erklärung verpflichteten sich dann beide Unternehmen gegenüber dem Bundesminister für Umwelt, Naturschutz und Reaktorsicherheit, die Produktion dieser FCKW zu reduzieren und 1995

653 Vgl. Weart, The Discovery of Global Warming, 2004, S. $126 \mathrm{f}$.

654 https://www.bundesregierung.de/breg-de/aktuelles/schutz-der-ozonschicht-1671 328. 
ganz einzustellen. ${ }^{65}$ Greenpeace bezeichnete das angekündigte Vorgehen der Unternehmen als „Etikettenschwindel“, da von den als Ersatzstoffe geplanten teilhalogenierten FCKW und FKW langfristig dieselbe zerstörerische Wirkung ausgehen würde wie von den vollhalogenierten FCKW. ${ }^{656}$

Am 1. August 1991 trat die FCKW-Halon-Verbots-Verordnung (FCKWHalonVerbV) in Kraft, die den stufenweisen Ausstieg aus der Herstellung nicht nur von FCKW sondern ebenso von den anderen Halogenkohlenwasserstoffen, ${ }^{657}$ die eine vergleichbare umweltzerstörerische Wirkung haben, regelte. 1994 wurden vollhalogenierte FCKW verboten, wohingegen erste Verbote teilhalogenierter FCKW (HFCKW) erst im Jahr 2000 in Kraft traten. ${ }^{658}$

\section{Die Verfahren}

a) Verfahrensverlauf - ein Überblick

Beide auf dem Plakat abgebildeten Vorstandsvorsitzende der jeweiligen Chemie-Unternehmen gingen gerichtlich gegen die Umweltorganisation Greenpeace vor. Bevor auf die - vor allem gerichtliche - Argumentation im Einzelnen eingegangen werden soll, wird zunächst der Verlauf, der von den beiden Vorstandsvorsitzenden angestrengten Verfahren skizziert.

\section{aa) Kali Chemie AG}

Der damalige Vorstandsvorsitzende der Kali Chemie AG stellte 1990 einen Antrag auf Erlass einer einstweiligen Verfügung gegen Greenpeace beim LG Hannover auf Unterlassung wegen Persönlichkeitsrechtsverletzungen

655 OLG Frankfurt, 19.6.1990, 6 W 101/90, NJW 1991, S. 361.

656 BGH, 12.10.1993, VI ZR 23/93, NJW 1994, S. 124.

657 Vgl. $\$ 1$ Abs. 1 FCKWHalonVerbV.

$658 \mathrm{Vgl}$. zur Chronologie ferner https:/www.bmu.de/themen/luft-laerm-verkehr/luf treinhaltung/ozonschicht-ozonloch/chronologie-der-massnahmen/.

Es sei angemerkt, dass der für die teil- und vollhalogenierten FCKW entwickelte Ersatzstoff HFKW, da es sich um eine chlorfreie Verbindung handelt, nicht die Ozonschicht, tragen aber dennoch erheblich zur Klimaerwärmung bei. In der Kigali Änderung des Montrealer Protokolls von 2016 wurde auch eine schrittweise Reduzierung und ein Ausstieg von der Produktion und Verbreitung von FKWs beschlossen. 
und Verletzung am eigenen Bild nach $\$ \$ 823$ Abs. 1, 1004 Abs. 1 BGB i.V.m. $\$ \$ 22,23$ I KUG. ${ }^{659}$ Der Antrag wurde vom LG zurückgewiesen, die daraufhin ebenfalls 1990 eingelegte Berufung beim OLG Celle wurde zugunsten des Vorstandsvorsitzenden entschieden, weswegen Greenpeace den Antragsteller aufforderte, im Hauptsacheverfahren Klage einzureichen. ${ }^{660}$ Das LG Hannover wies die Klage im Hauptsacheverfahren ab, in der Berufung am OLG Celle 1991 hatte der Vorstandsvorsitzende schließlich auch im Hauptsacheverfahren Erfolg. ${ }^{661}$ Die Revision zum BGH wurde nicht zugelassen. Greenpeace erhob daraufhin 1992 wegen des Berufungsurteils Verfassungsbeschwerde beim BVerfG. ${ }^{662}$

\section{bb) Hoechst AG}

Auch der damalige Vorstandsvorsitzende der Höchst AG beantragte 1990 im Rahmen des einstweiligen Rechtsschutzes die Unterlassung der genannten Plakatkampagne nach $\$ \$ 823$ Abs. 1, 1004 Abs. 1 BGB i.V.m. $\$ \mathbb{S} 22,23$ I KUG. Wurde dieser Antrag noch in der ersten Instanz zurückgewiesen, entschied das OLG Frankfurt am Main in der Berufung bzgl. des Abdrucks des Bildes und des Namens schließlich zu Gunsten des Vorstandsvorsitzenden. ${ }^{663}$ Da Greenpeace auch in diesem Verfahren die einstweilige Verfügung nicht annahm, reichte der Vorstandsvorsitzende die Klage im Hauptsacheverfahren ein, welche vom LG Frankfurt am Main - an seiner Auffassung festhaltend - abgewiesen wurde. ${ }^{664}$ In der Berufungsinstanz (OLG Frankfurt am Main) hatte die Berufung im Hauptsacheverfahren Erfolg. Als Folge wurde das Urteil des LG Frankfurt am Main zugunsten des Vorstandsvorsitzenden der Höchst AG abgeändert. Greenpeace wurde darüber hinaus zur Unterlassung der Veröffentlichung des Plakats verurteilt, sofern das Plakat das Porträt und den Namen des antragstellenden Vorstandsvorsitzenden wiedergibt. ${ }^{665} \mathrm{Im}$ Rahmen der Revision vor dem BGH im Jahre 1993 hatte wiederum die Umweltorganisati-

659 Vgl. Kali Chemie./. Greenpeace, Antrag auf Erlass einer einstweiligen Verfügung, 12.6.1990, S. 1 .

660 Vgl. OLG Celle, 27.9.1990, 13 U 148/90.

661 Vgl. OLG Celle, 2.7.1992, 13 U 117/91.

662 Greenpeace, Verfassungsbeschwerde, 21.8.1992.

663 OLG Frankfurt, 19.6.1990, 6 W 101/90, NJW 1991, S. 361.

664 LG Frankfurt, 7.3.1991, 2/3 O 415/90.

665 So schon bei OLG Frankfurt, 19.6.1990, 6 W 101/90, Vgl. zum Prozessverlauf auch BGH, 12.10.1993, VI ZR 23/93, S. 2. 
on mit ihrem Antrag auf Wiederherstellung des landgerichtlichen Urteils Erfolg. ${ }^{666}$ Mit der Verfassungsbeschwerde rügte der Vorstandsvorsitzende der Höchst AG eine Verletzung seines allgemeinen Persönlichkeitsrechts aus Art. 2 Abs. 1 i.V.m. Art. 1 Abs. 1 GG. ${ }^{667}$

\section{cc) Zwischenergebnis}

Die schwerpunktmäßig mit der Höchst AG verbundenen Inhalte des Plakats „Alle reden vom Klima. Wir ruinieren es“, das Klaus Staeck für Greenpeace entworfen hat, wurden an fünf Gerichtsständen verhandelt. Erst der Beschluss des BVerfG, der annähernd zehn Jahre nach der Plakataktion erfolgte, beendete die Rechtsstreitigkeiten. ${ }^{668} \mathrm{Im}$ Folgenden wird gesondert auf die Gerichtsverfahren, die durch der Kali Chemie AG und deren Vorstandsvorsitzenden vor dem OLG Celle, dem OLG Frankfurt am Main, dem BGH sowie dem BVerfG angestrengt wurden, eingegangen.

\section{b) OLG Celle}

Im Hauptsacheverfahren wurde vom klagenden Vorstandsvorsitzenden der Kali Chemie AG beantragt, festzustellen, dass der Rechtsstreit in der Hauptsache erledigt sei, da Greenpeace mittlerweile die Plakataktion eingestellt hatte, und die Kosten des Verfahrens vom Beklagten (Greenpeace) $\mathrm{zu}$ tragen seien. Diesen Anträgen gab das OLG Celle in seinem Urteil statt. ${ }^{69}$ Die Kostenentscheidung begründet das Gericht damit, dass der Kläger bis zum Eintritt des erledigenden Ereignisses vom Beklagten verlangen konnte, dass die Umweltorganisation es unterließ, das Plakat von Klaus Staeck zu veröffentlichen. Dieses Veröffentlichungsverbot bezog sich dabei auf das Plakat, auf welchem das Bild des Vorstandsvorsitzenden der Kali Chemie AG zusammen mit seinem Namen wiedergegeben wurde, da der Kläger einen Anspruch aus $\$ 1004$ BGB i.V.m. $\$ \$ 22,23$ Abs. 2 KUG und aus $\$ \mathbb{S} 823$ Abs. 1, 1004 BGB habe. ${ }^{670}$

666 BGH, 12.10.1993, VI ZR 23/93, NJW 1994, S. 124, 125.

667 BVerfG, 8.4.1999, 1 BvR 2126/93, NJW 1999, S. 2358.

668 BVerfG, ebd.

669 OLG Celle, 2.7.1992, 13 U 117/91, S. 2.

670 OLG Celle, ebd., S. 2 f. 
Auch das OLG Celle wog letztlich zwischen der Meinungsfreiheit und dem allgemeinen Persönlichkeitsrecht aus Art. 2 Abs. 1, Art. 1 Abs. 1 GG ab. In der Abwägung des Gerichts überwiegt eine schwere Verletzung des Persönlichkeitsrechts. Es geht davon aus, dass die durchgeführte Plakataktion wegen des Bildes zu einer schweren sozialen Anprangerung und Ächtung des Klägers geführt hätten. Der Kläger würde „unter Abbildung seines überlebensgroßen Portraits auf einem Plakat erheblichen Ausmaßes einseitig für ein globales Umweltproblem verantwortlich gemacht" und so „der öffentlichen Schande preisgegeben“. ${ }^{671}$ Besonders schwer wiege darüber hinaus, dass sich der Vorstandsvorsitzende der Kali Chemie AG bisher nicht öffentlich als Verfechter oder Befürworter einer Fortführung der FCKW-Produktion hervorgetan habe. ${ }^{672}$ Das OLG Celle überzeugt auch der Vergleich mit einem Straftäter, wenn es in seinem Urteil ausführt, dass es sich bei dem Vorstandsvorsitzenden auch nicht um einen Straftäter, der den Rechtsfrieden gebrochen hatte, handele. Und selbst ein Straftäter müsse nur eine sachbezogene Berichterstattung und eine seriöse Tatinterpretation hinnehmen, die in diesem Fall nicht vorliege. Schließlich sei die bildliche Darstellung unter der Überschrift „Wir ruinieren es“ auch kränkend, weil sie dem darunter abgebildeten Vorstandsvorsitzenden diese Worte als eigene in den Mund lege, womit der Anschein erweckt werde, er selbst hätte sich in diesem Sinne geäußert und handele skrupellos gegen die Belange des Umweltschutzes. ${ }^{673}$

Außerdem führt das Gericht aus, dass durch die Möglichkeit der Identifizierung und wegen „der Emotionsgeladenheit des Themas und einer zunehmenden Radikalisierung der Bevölkerung in dieser Frage [...] es zu Tätlichkeiten kommen [könnte]. Angesichts der pointierten Darstellung des Beklagten [könnte] für den einzelnen Bürger auch der Eindruck entstehen, dass mit der Beseitigung der abgebildeten Person auch die vom Beklagten mit ihr im Zusammenhang gestellten Umweltprobleme zu lösen wären. “674 Letztlich könne die einzelne Person für sich in Anspruch nehmen, vor Verletzungen geschützt zu werden, ohne dass die Verwirklichung der Meinungsfreiheit es erforderlich mache, der Öffentlichkeit den vermeintlichen Gegner bildlich zu präsentieren. ${ }^{675}$

671 OLG Celle, 2.7.1992, 13 U 117/91, S. 6.

672 OLG Celle, ebd., S. 7.

673 OLG Celle, ebd.

674 OLG Celle, ebd., S. 8.

675 OLG Celle, ebd. 
c) OLG Frankfurt am Main

Das OLG Frankfurt am Main unterscheidet in seiner Urteilsbegründung maßgeblich zwischen dem Textteil und dem Bildteil sowie zwischen den unternehmensbezogenen und den auf die Person der Vorstandsvorsitzenden bezogenen Aspekten. In Bezug auf den Text überwiegt zwar in der Meinung des Gerichts die Meinungsfreiheit nach Art. 5 Abs. 1 GG, doch betont es auch eine Prangerwirkung zu Lasten des Vorstandsvorsitzenden. ${ }^{676}$ Für die Aussage, dass die Chemieunternehmen "absolute Spitze bei Ozonzerstörung und Treibhauseffekt" seien, wird im Zusammenhang mit der Aussage „Verantwortlich für die deutsche Produktion des Ozonund Klimakillers FCKW.“ gelesen. Die Aussage „absolute Spitze“ wird als Meinung gewertet. Wegen des tatsächlich maßgeblichen Anteiles an der FCKW-Herstellung, wenn auch unter Umständen die genannten Unternehmen nicht weltweit die „absolute Spitze“ bilden, sei die Aussage hinzunehmen. ${ }^{677}$

Anders entscheidet sich das Gericht in Bezug auf die Abbildung des Vorstandsvorsitzenden der Höchst AG und die Nennung seines vollen Namens. Das Gericht erkennt entgegen des Vortrags des Managers, dass das Plakat nicht dahingehend zu verstehen ist, dass der Unternehmer sich bedenkenlos für die Ruinierung des Klimas einsetze. Doch sieht es eine Prangerwirkung in der Art, dass das Plakat die Unternehmer zu den „eigentlichen Verantwortlichen für die Ruinierung des Klimas"678 macht. Das Gericht geht davon aus, dass das Bild und der Name „in der Art eines Steckbriefs zur Schau gestellt" ${ }^{\text {"679 }}$ werden. Ein entscheidendes Argument für die genannte Prangerwirkung wird in dem Medium des Plakats gesehen. Denn für das Gericht macht es einen Unterschied, ob die Abbildung des Unternehmers im Rahmen eines kritischen Zeitungsartikels oder für ein Plakat mit einer bundesweiten Verbreitung verwendet wird. Bei einem journalistischen Artikel hätte nämlich das Interesse der Öffentlichkeit am Bildnis des Unternehmers durchaus bejaht werden können. ${ }^{600}$ Das Gericht ist insofern von dem Vortrag des Managers überzeugt, dass „eine bundesweite Verbreitung seines Bildnisses und Namens auf dem beanstandeten Plakat in Verbindung mit dem Vorwurf, für die Zer-

676 OLG Frankfurt, 19.6.1990, 6 W 101/90, NJW 1991, S. 361.

677 OLG Frankfurt, ebd., S. $361 \mathrm{f}$.

678 OLG Frankfurt, ebd, S. 362.

679 OLG Frankfurt, ebd.

680 OLG Frankfurt, ebd. 
störung des Klimas persönlich verantwortlich zu sein, geeignet ist, ihn jedenfalls zeitweise aus der Gruppe der Personen herauszuheben, die als Repräsentanten großer Wirtschaftsunternehmen durch personenbezogene terroristische Anschläge gefährdet sind." 681 Letztlich überwiege insofern das Persönlichkeitsrecht des Unternehmers, weswegen er „diese negative Anprangerung und Zurschaustellung seines Bildnisses" auch im Rahmen der Informationskampagne der Umweltschutzorganisation nicht hinnehmen muss. ${ }^{682}$

\section{d) $\mathrm{BGH}$}

Den BGH überzeugte die Argumentation des OLG Frankfurt am Main wie auch die Revisionserwiderung hingegen nicht.

Zunächst ist das Urteil in Bezug auf den Schutzbereich der Meinungsfreiheit Art. 5 Abs. 1 GG zu besprechen.

In der erfolglosen Erwiderung bezog sich der Vorstandsvorsitzende der Höchst AG verstärkt auf die Argumentation, dass das Plakat in seiner vollständigen Text-Bild-Aussage eine unwahre Tatsachenbehauptung darstelle, die nicht von Art. 5 Abs. 1 GG geschützt sei. ${ }^{683}$ Der BGH erkennt an, dass der Text durchaus Tatsachenbehauptungen enthalte. Er stellt sogar klar, dass es sich bei den Aussagen, dass die beiden Chemieunternehmen für die deutsche Produktion von FCKW verantwortlich seien und die FCKW-Produktion zur Zerstörung der Ozonschicht und zum Treibhauseffekt beitrage, um wahre Tatsachen handele. ${ }^{64}$ Dem widerspreche auch nicht der von den Unternehmen geplante Ausstieg aus der Produktion vollhalogenierter FCKW bis zum Jahr 1995. Die wahren Tatsachen zur FCKW-Produktion seien die Grundlage für die Wertungen. So erkennt der BGH in dem Satz „Wir ruinieren es“ „die Anklage einer als für das Klima verhängnisvoll bewerteten unternehmerischen Entscheidung" und in der Aussage „Verantwortlich für die deutsche Produktion“ den Vorwurf, dass „die die FCKWProduktion der Hoechst-AG normativ dem [Vorstandsvorsitzenden] als dem Repräsentanten der Hoechst-AG und einem Entscheidungsträger für ihre Produktion zuzurechnen" sei. ${ }^{685}$ Das Gericht arbeitet insofern

681 OLG Frankfurt, ebd.

682 OLG Frankfurt, ebd.

683 Vgl. BGH, 12.10.1993, VI ZR 23/93, NJW 1994, S. 124, 125.

684 BGH, ebd.

685 BGH, ebd. 
heraus, dass es sich bei dem Textteil um eine Verbindung von Meinungsäußerungen und (wahren) Tatsachenbehauptungen handele. Diese fallen im Gesamten unter den Schutzbereich der Meinungsfreiheit nach Art. 5 Abs. 1 GG, da eine Trennung zwischen den Tatsachen und den wertenden Aussagen nicht ohne Verlust der offensichtlichen Zweckbestimmung der Aussage, in Form der umweltpolitischen Kritik von Greenpeace an der FCKW-Produktion, möglich wäre. ${ }^{686}$

Auch die Nennung des vollen Namens und der Abbildung der Vorstandsvorsitzenden sind Teil der Gesamtaussage und fallen in den Schutzbereich des Art. 5 Abs. 1 GG, da die Personalisierung des Angriffs eine Wirkungssteigerung der Meinungsäußerung bezwecke. ${ }^{67}$

Auf Betroffenenseite steht auch hier der Meinungsfreiheit das allgemeine Persönlichkeitsrecht des Vorstandsvorsitzenden entgegen. ${ }^{688}$ In der Abwägung dieser beiden Rechtspositionen berücksichtigt der BGH neben einer generellen Betrachtung des Stellenwerts der betroffenen Grundrechtspositionen auch die Intensität der Grundrechtsbeeinträchtigung im konkreten Fall und kommt zu dem Ergebnis, dass das allgemeine Persönlichkeitsrecht zurücktreten müsse. ${ }^{689}$

Für die Abwägung bezieht sich das Gericht zum einen auf die Idee der Reizüberflutung und zum anderen auf die Vermutung zu Gunsten der Meinungsfreiheit. Sie gilt im Rahmen von Beiträgen des geistigen Meinungskampfs in Fragen, die die Öffentlichkeit wesentlich berühren, unter Beachtung der Grenze zur Schmähung. Darüber hinaus statuiert es, dass der Kritiker seine Meinung grundsätzlich auch dann äußern darf, wenn sie andere für "falsch" oder für "ungerecht" halten. ${ }^{690}$

In Bezug auf die Plakataktion erkennt das Gericht keine eigennützigen Ziele, sondern eine engagierte Meinungsäußerung zu einer Thematik mit elementarer Bedeutung für die Öffentlichkeit. Zu Lasten des Betroffenen wirke, dass er von sich aus bzgl. der Thematik im Wege einer umfangreichen Pressemitteilung bereits an die Öffentlichkeit getreten war und so sogar selbst Anlass für die Inhalte des Plakats gegeben hätte. ${ }^{691}$ Hingegen kann der BGH die vom OLG stark gemachte Prangerwirkung nicht erkennen, denn nach seiner Ansicht richtet sich das Plakat nicht gegen

686 Vgl. BGH, ebd., S. 126.

687 BGH, ebd.

688 Vgl. dazu Kap. 3, E.

689 BGH, 12.10.1993, VI ZR 23/93, NJW 1994, S. 124, 126.

690 BGH, ebd., m.w.N.

$691 \mathrm{BGH}$, ebd. 
den Vorstandsvorsitzenden als Privatperson, sondern als einen der beiden für die FCKW-Produktion verantwortlichen Entscheidungsträger. ${ }^{692}$ Für diese Bewertung spricht auch, dass erstens den Namen der Vorstandsvorsitzenden mit vollständiger Titelbezeichnung die jeweiligen Firmennamen in Großbuchstaben folgen und zweitens die angegebenen Rufnummern nicht etwa zu privaten Anschlüssen, sondern zu den Presseabteilungen des jeweiligen Unternehmens führen.

Darüber hinaus wurde auf Seiten des Vorstandsvorsitzenden von Aggressionen gegen seine Person berichtet, so sah er die Gefahr „terroristischer Anschläge“. Der BGH spricht diesen Befürchtungen ihre belastende Wirkung nicht $a b$, doch rechtfertigen diese nicht ein etwaiges Verbot der Plakataktion. ${ }^{693}$

Letztlich resümiert der Gerichtshof, dass es mit der Stellung und Wichtigkeit der Meinungsfreiheit nicht vereinbar sei, dass eine Person, die sich kraft ihrer Stellung Entscheidungen von einer solchen Tragweite zurechnen lassen müsse, eine Kritik an diesen unterbinden könne, indem sie sich auf ihre Privatsphäre berufe. ${ }^{694}$

Auf eine Auseinandersetzung mit dem Plakat unter der Kunstfreiheitsgarantie verzichtet der $\mathrm{BGH}$, da das allgemeine Persönlichkeitsrecht bereits gegenüber der Meinungsfreiheit zurücktreten müsse. ${ }^{695}$

\section{e) BVerfG}

Nach dem erfolglosen BGH-Urteil erhob der Vorstandsvorsitzende der Höchst AG Verfassungsbeschwerde und rügte eine Verletzung seines Persönlichkeitsrechts. Auch Greenpeace wollte im Verfahren mit dem Vorstandsvorsitzenden der Kali Chemie eine verfassungsrechtliche Klärung und rügte in ihrer Verfassungsbeschwerde eine Verletzung von Art. 2 Abs. 1, Art. 3, Art. 5 Abs. 1 und Abs. 3 sowie Art. 103 GG. 696

Zunächst sei vorweggenommen, dass die beiden Verfassungsbeschwerden nicht zur Entscheidung angenommen wurden, da beiden keine grundsätzliche verfassungsrechtliche Bedeutung zukomme (vgl. $\$ 93$ a Abs. 2 lit. a BVerfGG), denn für das Verhältnis von Meinungsfreiheit und Persönlich-

692 BGH, ebd.

693 BGH, 12.10.1993, VI ZR 23/93, NJW 1994, S. 124, $126 \mathrm{f}$.

694 BGH, ebd., S. 127.

695 BGH, 12.10.1993, VI ZR 23/93, S. 18.

696 Vgl. Greenpeace, Verfassungsbeschwerde, 21.8.1992. 
keitsschutz sind die verfassungsrechtlichen Maßstäbe geklärt. ${ }^{697}$ Zur weiteren Begründung wird auf die beiden Beschwerden im Folgenden getrennt eingegangen.

aa) Die Verfassungsbeschwerde von Greenpeace

Die Verfassungsbeschwerde der Umweltorganisation richtet sich gegen die Urteile des OLG Celle sowohl aus dem einstweiligen Rechtsschutz als auch aus dem Hauptsacheverfahren. ${ }^{698}$ Außerdem rügt sie eine Verletzung der Grundrechte aus Art. 2 Abs. 1, Art.3, Art. 5 Abs. 1 und Abs. 3 sowie 103 Abs. 1 GG, ${ }^{699}$ wobei auch in dieser Beschwerde Art. 5 Abs. 1 GG die maßgebliche Bedeutung zu kommt, sodass auf die anderen gerügten Grundrechtspositionen hier nicht eingegangen wird. Es wird in der Verfassungsbeschwerde die Ansicht vertreten, dass das OLG verkenne, „dass die Meinung in Schrift und Bild frei geäußert werden darf." Dazu wird in der Beschwerde ausgeführt, dass „bei der Vielzahl der optischen Reize [...] Plakate überhaupt nur wahrgenommen [werden], wenn von ihnen eine hinreichende Bildwirkung ausgeht. Reine Texte werden eher übersehen als Texte mit Illustrationen und Bildern [und] Namen [sind] einprägsamer, wenn ihnen ein Bild zugeordnet werden kann..${ }^{" 700}$ Dieses Argument wird durch einen Vergleich mit anderen Medienformaten, in denen Texte mit Bildern und Abbildungen von Personen regelmäßig kombiniert sind, untermauert. ${ }^{701}$ Darüber hinaus meint der Beschwerdeführer, dass das Plakat vom OLG „überinterpretiert" ${ }^{\text {"702 }}$ worden sei. Beweise für die besonders anprangernde Wirkung und der Preisgabe der öffentlichen Schande, wie es das OLG formuliert, ${ }^{703}$ seien nicht erbracht bzw. nicht erhoben wurden. ${ }^{704}$ Eine ganz besondere „Überinterpretation“ liege nach der Ansicht des Beschwerdeführers in dem Satz des OLG, dass das Plakat beim Bürger

697 BVerfG, 8.4.1999, 1 BvR 1498/92, Rn. 11; BVerfG, 8.4.1999, 1 BvR 2126/93, NJW 1999, S. 2358.

698 OLG Celle, 27.9.1990, 13 U 148/90; OLG Celle, 2.7.1992, 13 U 117/91.

699 Greenpeace, Verfassungsbeschwerde, 21.8.1992, S. 2.

700 Greenpeace, ebd., S. 10.

701 Vgl. Greenpeace, ebd.

702 Greenpeace, ebd.

703 Vgl. Kap. 5, B., IV, 3., b).

704 Greenpeace, Verfassungsbeschwerde, 21.8.1992, S. 10. 
den Anschein erwecke, dass „mit der Beseitigung der abgebildeten Person auch $[\ldots]$ die Umweltprobleme zu lösen wären. “705

In dem Nichtannahmebeschluss stellt das BVerfG fest, dass die geltend gemachten Grundrechtsverletzungen kein besonderes Gewicht haben. Zum einen hat sich das OLG Celle mit den Grundrechtspositionen auseinandergesetzt und zum anderen geht von dessen Entscheidung auch keine abschreckende Wirkung aus. ${ }^{706}$ Dies wird damit begründet, dass in dem parallellaufenden Verfahren des Vorstandsvorsitzenden der Hoechst AG bereits der BGH festgestellt habe, dass das umstrittene Plakat von der Meinungsfreiheit gedeckt gewesen sei. ${ }^{707}$ Diese Entscheidung hält das BVerfG auch für unbedenklich.

bb) Die Verfassungsbeschwerde des Vorstandsvorsitzenden

Die Verfassungsbeschwerde des Vorstandsvorsitzenden der Hoechst AG wurde parallel mit der Verfassungsbeschwerde von Greenpeace beschlossen. Im Rahmen des Hoechst-Verfahrens kommt das BVerfG zu dem Ergebnis, dass das Urteil des BGH den Vorstandsvorsitzenden weder in seinem allgemeinen Persönlichkeitsrecht noch in seiner Menschenwürde verletze. ${ }^{708}$

Dazu führt es die Entscheidung des BGH bekräftigend aus, dass der Unternehmer zwar „persönlich angegriffen, nicht aber in seiner personalen Würde entkleidet" werde. ${ }^{709}$ Vielmehr stehe gerade der Sachbezug - die Produktion von FCKW - auch in Bezug auf den Vorstandsvorsitzenden

705 OLG Celle, 2.7.1992, 13 U 117/91, S. 8; Greenpeace, Verfassungsbeschwerde, 21.8.1992, S. $11 \mathrm{f}$.

706 BVerfG, 8.4.1999, 1 BvR 1498/92, S. 5 f. Darüber hinaus geht das BVerfG bereits von einer Unzulässigkeit aus, soweit die Berufungsentscheidung aus dem einstweiligen Rechtsschutzverfahren (OLG Celle, 27.9.1990, 13 U 148/90) angegriffen werden. Da das einstweilige Rechtsschutzverfahren ein rechtlich selbstständiges Verfahren ist, „kann eine Entscheidung aus dem einstweiligen Rechtsschutzverfahren auch Gegenstand einer Verfassungsbeschwerde sein [...]. Behauptet jemand durch eine Entscheidung im einstweiligen Rechtsschutzverfahren in Grundrechten betroffen zu sein, muss er diese Entscheidung dann aber auch entsprechend den gesetzlichen Voraussetzungen [...] angreifen." In diesem Fall war insofern selbstredend die Monatsfrist nach $₫ 93$ Abs. 1 S. 1 BVerfGG bereits verstrichen. BVerfG, 8.4.1999, 1 BvR 1498/92, S. 5.

707 BVerfG, 8.4.1999, 1 BvR 1498/92, S. 6.

708 BVerfG, 8.4.1999, 1 BvR 2126/93, NJW 1999, S. 2358.

709 BVerfG, ebd., S. 2359. 
als Entscheidungsträger im Vordergrund, so dass es sich eben nicht um eine Schmähkritik handeln könne. Das BVerfG bekräftigt aber, dass ein Angriff gegen den Entscheidungsträger, auch wenn nicht an seiner Person, sondern in seiner Funktion, massiv und durchaus konkret gewesen sei. ${ }^{710}$ An der Abwägung des BGH zwischen den beiden Grundrechtspositionen hat das BVerfG jedoch trotzdem nichts zu beanstanden und hält diese für vertretbar. ${ }^{711}$

\section{Bewertung}

a) Methodik des satirischen Plakats

Das BVerfG erwähnt das Satirische des Plakats lediglich knapp in einem Satz, wenn es davon ausgeht, dass der „Angriff [...] durch das Zusammenspiel von Bild und Wort sowie die satirischen Elemente verstärkt [wurde]."712 Worin die satirischen Elemente jedoch liegen, macht das Gericht nicht deutlich. Im Rahmen der Bewertung der Gerichtsentscheidungen wird hier zunächst auf die Methodik des Plakats, d.h. dieses Zusammenspiel von Bild und Wort und auf das Satirische eingegangen.

Grundlegend für die Entscheidungen war eine differenzierte Untersuchung von Text und Bild. Der BGH analysiert detailliert die einzelnen Aussagen ohne die Gesamtaussage - die umweltpolitische Kritik - zu vernachlässigen.

Der Bildteil des Plakats unterstreiche die dominante Textaussage, ${ }^{713}$ da sie die Verantwortlichkeit personalisiere. Der BGH geht davon aus, dass das Bild mit der Namensnennung deutlich machen wolle, „dass für die Unternehmenspolitik auch so großer Wirtschaftsunternehmen wie der Hoechst AG Personen verantwortlich" seien. ${ }^{714}$

Das Plakat bestehe in seiner Text-Bild-Kommunikation aus einem informierenden, wertenden und zur Partizipation aufrufenden Teil. Letzterer liegt in der direkten Aufforderung, die Chemieunternehmen anzurufen, wobei die Telefonnummern der entsprechenden Unternehmen sogar angegeben seien.

710 BVerfG, ebd.

711 BVerfG, ebd.

712 BVerfG, 8.4.1999, 1 BvR 2126/93, NJW 1999, S. 2358, 2359.

713 Vgl. dazu Kap. 4, C., II., 2., b), aa).

714 BGH, 12.10.1993, VI ZR 23/93, NJW 1994, S. 124, 126. 
Aus der Sicht der vorliegenden Arbeit vereint dieses Plakat geradezu mustergültig eine Reihe für die Satire typischen Funktionen und Zielen, ${ }^{715}$ wie die Informations- bzw. Aufdeckungsfunktion und das beabsichtigte Bewirken einer Reaktion mit der dadurch verbundenen Hoffnung auf Änderung. Die Informationsfunktion wird mit den Textteilen „Absolute Spitze bei Ozonzerstörung und Treibhauseffekt: Verantwortlich für die deutsche Produktion des Ozon- und Klimakillers FCKW“ und „Bundesumweltminister Klaus Töpfer weigert sich immer noch, die Produktion von FCKW zu verbieten" erfüllt. Das an die damaligen Informationskampagnen des Bundes angelehnte Design unterstreicht den Informationscharakter noch einmal mehr. Die wertenden Ausdrücke der Aussage wie „absolute Spitze“ und „weigert sich immer noch“ sollen helfen, eine Reaktion bei dem Rezipienten zu bewirken, die bestenfalls zu der Partizipation in Form eines Telefonanrufs führt. Damit verbunden ist die Hoffnung auf eine Änderung der politischen (Verbotsgesetz) und unternehmerischen Entscheidung (Einstellung der Produktion).

Der BGH geht in seiner Bewertung sogar noch einen Schritt weiter und sieht in der Aufforderung zum Anruf den Gedanken formuliert, „dass eine Einwirkung der Öffentlichkeit auf die beiden FCKW produzierenden Unternehmen geboten sei, um der Klimazerstörung Einhalt zu gebieten. “716

Anzumerken ist, dass die Gerichte sich nicht ausreichend mit dem Satirischen in dem Plakat auseinandergesetzt haben. Der BGH geht beispielsweise davon aus, dass die satirische Ausdrucksform in der Überschrift („Alle reden vom Klima. Wir ruinieren es”) und dem Sarkasmus in der Einleitung des ersten Satzes („Absolute Spitze...“) vorliegen würden. ${ }^{717}$

Es sei aber andererseits darauf verwiesen, dass sogar in der Verfassungsbeschwerde der Umweltorganisation gegen die Urteile des OLG Celle kaum auf das Satirische eingegangen wird. So heißt es lediglich „die ironische bzw. satirische Zeile, Wir ruinieren es' ist auch nicht kränkend. "718

Werden in den diesen Rechtsstreitigkeiten die für die Satire typischen Funktionen allenfalls in einem allgemeinen Sinne beleuchtet, gilt es im Folgenden den satirischen Gehalt des Plakats im Speziellen herauszuarbeiten.

In der Literatur wird der satirische Effekt des hier behandelten Plakats in der „Personalisierung der zur damaligen Zeit akuten Sachproblematik

715 Vgl. dazu Kap. 2, D., V., 1.

716 BGH, 12.10.1993, VI ZR 23/93, NJW 1994, S. 124, 125.

717 BGH, 12.10.1993, VI ZR 23/93, NJW 1994, S. 124, 126.

718 Greenpeace, Verfassungsbeschwerde, 21.8.1992, S. 10. 
und $[\ldots]$ die prägnante Überschrift" ${ }^{" 719}$ gesehen. Dem wäre hinzuzufügen, dass dieses Umwelt-Plakat von Klaus Staeck - wie ja auch das Staeck-Plakat "Alle reden vom Frieden. Wir nicht" - gut erkennbar an die ehemalige Bundesbahn-Werbekampagne angelehnt sind. Auf diese Weise hat Klaus Staeck, indem er einen offensichtlichen Bezug zwischen seinen beiden Plakatentwürfen und einem weit verbreiteten Bundesbahn-Plakat hergestellt hat, das Mittel der Parodie genutzt. Eine auf den ersten Blick zu erwartende, positive Werbebotschaft (wie im Falle der deutschen Bundesbahn) wird für das Umwelt-Plakat mit den Worten „Wir ruinieren es“ unerwartet "gebrochen" ${ }^{720}$ Dieser Überraschungseffekt wird - als eine Erweiterung im Vergleich mit dem Friedensplakat - zusätzlich durch die namentliche Nennung der Unternehmen und deren führenden Manager, aber auch durch die optische Anlehnung an die Informationskampagnen der deutschen Bundesregierung verstärkt.

\section{b) Verpflichtungen der Satire}

Mit der Satire - wie im zweiten Kapitel dieser Arbeit herausgearbeitet äußert der Satiriker seine Meinung in bewusst einseitiger Form. So ist es der Satire eigen, eine gerade nicht austarierte Stellungnahme abzugeben. In dem hier behandelten Fall ließe sich überlegen, ob bei einer Informationskampagne nicht doch die Verpflichtung bestünde, die Sachverhalte sorgfältig, vollständig und ausgewogen zu beschreiben oder über sie zu berichten. Dieses Argument nimmt der Vorstandsvorsitzende der Hoechst AG mit dem Verweis auf die Tatsache, dass seine Firma zum Zeitpunkt der Plakataktion bereits einen Ausstieg aus der FCKW-Produktion geplant habe, in Anspruch. Dies überzeugt den BGH jedoch nicht. Denn auch wenn die Hoechst AG nach ihren eigenen Angaben die Produktion vollhalogenierter FCKW stufenweise zu reduzieren beabsichtigte, wäre sie doch bis zum Augenblick des geplanten Produktionsstopps weiterhin ein weltweit maßgeblicher Hersteller dieses Stoffes gewesen. Deswegen sah das Gericht keinen Anlass die Verpflichtung auszusprechen, das Plakat, das ja die Behauptung trug, die Hoechst AG produziere in erster Linie weiterhin FCKW, müsse zusätzlich mit einem Hinweis auf die geplanten

719 Oppermann, Ehrensache Satire, 2015, S. 61.

720 Vgl. zum „Bruch“ im satirischen Plakat, Kap. 4, C., II., 2., b); siehe ferner auch Gärtner, Was die Satire darf, 2009, S. 82 m.w.N. 
Reduzierungen versehen werden. ${ }^{721}$ Erst recht könne, so das Gericht, eine solche Hinweispflicht nicht überzeugen, wenn man bedenke, dass die von der Hoechst AG ins Auge gefassten teilhalogenierten Ersatzstoffe nicht weniger umweltschädlich als ihr vollhalogeniertes Pendant seien. Diesem Vorwurf wurde im gerichtlichen Verfahren von Seiten der Hoechst AG nicht widersprochen. ${ }^{722}$

c) „Alle reden vom Klima. Wir ruinieren es“ und „Alle reden vom Frieden. Wir nicht“ - Ein Vergleich

Aufgrund der formalen Verwandtschaft bietet sich eine Gegenüberstellung der beiden Staeck-Plakate „Alle reden vom Frieden. Wir nicht“ und „Alle reden vom Klima. Wir ruinieren es", die auf ein und dasselbe Bundesbahn-Werbeplakat „Alle reden vom Wetter. Wir nicht“ zurückgreifen, und damit ein Vergleich der juristischen Verfahren an. Die Plakate sind mit ihrer Anlehnung an die Bundesbahnkampagne ähnlich konzipiert. Mögen sie sich thematisch mit ihrem Bezug einerseits auf die Friedenspolitik und andererseits auf die Umweltpolitik unterscheiden, ähneln sich doch die Angriffsobjekte - zwei große deutsche Wirtschaftsunternehmen mit ihren jeweils leitenden Führungspersonen. Beide Plakate sind mit Hilfe abgedruckter Fotografien personalisiert: Das Klimaplakat stellt allerdings mit der Nennung des vollen Namens und der Verwendung eines Profilbilds einen weitaus konkreteren Bezug zur Person her, als das Friedensplakat. So wurde im Rheinmetall-Verfahren noch als ein besonderes Argument angeführt, dass das Plakat nicht erkennen ließe, dass die abgebildeten Personen zum Management von Rheinmetall gehören oder sonst mit genau diesem Unternehmen in Verbindung stehen würden. ${ }^{723}$ In den Verfahren zu dem Umweltplakat sah das OLG Frankfurt am Main einen erheblichen Unterschied zu dem parallel laufenden Verfahren vor dem OLG Karlsruhe darin, dass die auf dem Friedensplakat verwendete Fotografie als eine „zeitgeschichtliche Dokumentation"724 zu werten sei, wohingegen die Fotografien der Vorstandsvorsitzenden der Chemieunternehmen jeweils Profilbilder und damit den maßgeblich individualisierenden Teil des menschlichen Körpers, das Gesicht, zeigen würden.

721 BGH, 12.10.1993, VI ZR 23/93, NJW 1994, S. 124, 125.

722 BGH, 12.10.1993, VI ZR 23/93, NJW 1994, S. 124, 125.

723 Vgl. OLG Frankfurt, 10.12.1981, 16 W 47/81, S. 5.

724 OLG Frankfurt, 19.6.1990, 6 W 101/90, NJW 1991, S. 361, 362. 
Im letzteren Fall sind die Fotografien m.E. jedoch notwendig, um die beiden verantwortlichen Entscheidungsträger abzubilden. Darauf kommt es bei der Fotografie des Plakats „Alle reden vom Frieden“ jedoch nicht an. Bei der Abbildung mit den Vorständen der Firma Rheinmetall ist es irrelevant, dass es sich um genau diese Personen handelt. Es könnten auch andere Manager in Führungspositionen der Rheinmetall abgebildet sein. Das Bild unterstreicht die Aussage des Plakats, da es fünf Personen mit verantwortungsvollen Leitungsfunktionen zeigt, die alle ein auffällig entspanntes Verhältnis zur Munition von Kriegswaffen haben. Die Schwere des Eingriffs in das Persönlichkeitsrecht liegt in dem Klimaplakat andererseits maßgeblich darin, dass die Kombination von Namen und Profilbild eine leichte Identifizierung ermöglicht.

\section{V. „Der größte Schwindel seit der Farbe Grün“}

Abschließend wird auf eine Streitigkeit eingegangen, in der eine einstweilige Verfügung zurückgezogen wurde, so dass es zu keiner gerichtlichen Entscheidung kam.

\section{Plakat und Hintergrund}

Ausgangspunkt war Staecks Plakat und Postkarte zum Grünen Punkt. Über einem Müllberg war unter der Überschrift „Der größte Schwindel seit der Farbe Grün“ mittig das Logo der Marke „Der Grüne Punkt“ abgedruckt (Abb. 11). Gegen dieses Motiv wendete sich das Unternehmen Duales System Deutschland GmbH (DSD), das Betreiber eines Mülltrennungssystems ist. Die Aufgaben und die Zielsetzung des Mülltrennungssystems sind in $\mathbb{1}$ Abs. 1 VerpackV festgelegt. Mit dem Ziel die Auswirkungen von Abfällen aus Verpackungen auf die Umwelt zu vermeiden oder zu verringern, sind hiernach Verpackungsabfälle wiederzuverwenden oder zu verwerten. Ein Betreiber wie Duales System Deutschland hat nach $\$ 6$ Abs. 3 VerpackV regelmäßig die Abholung gebrauchter, restentleerter Verkaufsverpackungen beim privaten Endverbraucher oder in dessen Nähe in ausreichender Weise zu gewährleisten. Der Grüne Punkt wiederum dient als Erkennungszeichen, für die bei der DSD GmbH lizensierten Produkte, die dann auch dem Verwertungssystem zugeführt werden können. Die Kennzeichnung mit dem Grünen Punkt ist keine Voraussetzung, um an dem dualen System teilzunehmen, doch wenn man Produkte, die mit 
dem Grünen Punkt gekennzeichnet sind, vertreiben möchte, sind dafür Lizenzgebühren an die DSD GmbH zu zahlen

\section{Verfahren}

In der Abmahnung mit der Aufforderung zur strafbewehrten Unterlassungserklärung macht die DSD GmbH geltend, dass Staeck erstens das Recht an ihrer Marke „Der Grüne Punkt“ nach $\mathbb{} 14$ Abs. 2 Nr. 3 MarkenG verletzt habe und zweitens eine Verletzung des allgemeinen Persönlichkeitsrechts als sonstiges Recht im Sinne von $₫ 823$ Abs. 1 BGB vorliege. ${ }^{725}$ Die ehrverletzende, herabwürdigende Kritik wird in dem Bezug zwischen Überschrift, dem Grünen Punkt und dem Müllberg gesehen. Denn damit würde eine betrügerische Absicht unterstellt und der DSD vorgeworfen, ihren gesetzlichen Aufgaben und Pflichten nicht nachzukommen und für „das Entstehen von Müllbergen verantwortlich"726 zu sein.

In der Schutzschrift hingegen wird das Argument stark gemacht, dass es sich bei der Abbildung um ein satirisches Kunstwerk handele und damit das Kennzeichen gerade nicht „im geschäftlichen Verkehr“, sondern zu künstlerische Zwecke benutzt werde. ${ }^{727}$ Denn „in satirischer Weise wird dargestellt, dass nach Meinung des Künstlers die Einführung des ,Grünen

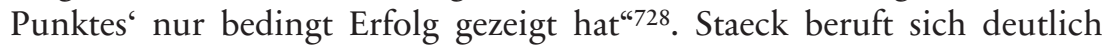
in Bezug auf eine vermeintliche Verletzung des allgemeinen Persönlichkeitsrechts auch auf die Meinungs- und Kunstfreiheit aus Art. 5 Abs. 1 respektive Abs. 3 GG. Zur Glaubhaftmachung einer Begründetheit der Kritik wurden zahlreiche Presseberichte zur Entsorgungspraxis des DSD beigelegt. ${ }^{729}$

Ferner wird gegen den Verfügungsgrund vorgebracht, dass das Plakat und die Postkarte mit dem Motiv des Grünen Punkt bereits seit vier Jahren im Umlauf seien, weswegen eine besondere Dringlichkeit nicht nachvollzogen werden könne. ${ }^{730}$

Ausschlaggebend war wohl für die Entwicklung dieses Rechtsstreits auch das Verhalten des baden-württembergischen Umweltministeriums.

725 DSD./. Staeck, Abmahnung, 9.2.1996, S. 3 f.

726 DSD./. Staeck, ebd., S. 4.

727 Vgl. DSD./. Staeck, Schutzschrift, 16.2.1996, S. 3.

728 DSD./. Staeck, ebd.

729 DSD./. Staeck, ebd.

730 DSD./. Staeck, ebd., S. 4. 
In einer Pressemitteilung des Ministeriums wird die These vertreten, dass „allein die Ankündigung einer Pressekonferenz [mit Staeck und dem Umweltminister, Anm. d. Verf.] offenbar bereits das angestrebte Ziel erreicht [habe]", ${ }^{731}$ denn der DSD zog seine Anträge auf einstweilige Verfügung beim LG Köln zurück..$^{732}$

Der Antragsteller hingegen verzichtete auf die weitere Verfolgung dieser Angelegenheit, mit dem Argument, dass man mittlerweile festgestellt habe, „dass diese Postkarte offensichtlich nur marginal vertrieben“werde. ${ }^{733}$

\section{Bewertung}

Auch wenn es zu keiner Entscheidung kam, ist dieser Fall hier von Interesse. Es handelt sich nämlich um das bislang letzte Verfahren, das gegen Staeck angestrengt wurde. Dass in diesem auf eine Rechtsdurchsetzung verzichtet wurde, vielleicht weil die Erfolgsaussichten als gering erachtet wurden, lässt Rückschlüsse zu. So könnte den Verlauf dieses Rechtsstreits beeinflusst haben, dass Staeck zwischenzeitlich eine umfassende und für die Allgemeinheit gültige Anerkennung als Künstler erfahren hatte. Dieser Eindruck wird durch die Schutzschrift, in der sich explizit auf die Kunstfreiheit berufen wurde, verstärkt. Vielleicht drohte aber auch bei einer weiteren Verfolgung der Ansprüche für den Antragsteller - nicht nur wegen des politischen Rückhalts Staecks durch das, von einem Mitglied der SPDFraktion geführte Umweltministerium des Landes Baden-Württemberg ein darüber hinaus gehender Imageschaden.

\section{Zwischenfazit zu den zivilrechtlichen Prozessen}

Auf den ersten Blick scheint es, dass die Plakate wegen der Annahme eines mangelnden Kunstverständnisses der Gesellschaft und vor allem der Richter selbst nicht unter dem Grundrecht der Kunstfreiheit diskutiert wurden: So wurde doch das Plakat beispielsweise die ,illegitime Tochter der Kunst" ${ }^{\text {"734 }}$ genannt. Der verallgemeinernde Vorwurf eines mangelnden Kunstverständnisses der Richter mag in Bezug auf das Medium Plakat

731 Umweltministerium BW, Pressemitteilung, DSD, 13.3.1996, S. 1.

732 Umweltministerium BW, ebd.

733 DSD./. Staeck, Anwaltliches Schreiben, 8.3.1996, S. 2.

734 Schindler, Monografie des Plakats. Entwicklung, Stil, Design, 1972, S. 254. 
jedoch nicht zu überzeugen. Die Ausführungen im dritten Kapitel dieser Arbeit, aber auch alle hier besprochenen Entscheidungen haben vielmehr gezeigt, dass sich das künstlerische Politsatire-Plakat abschließend und verfassungsrechtlich sachgerecht unter Bezugnahme des Grundrechts der Meinungsfreiheit verhandeln lässt, sofern die für die Satire typischen Besonderheiten einbezogen und so werkgerechte Maßstäbe angelegt werden. Das belegen nicht zuletzt die beiden Nichtannahmebeschlüsse des BVerfG zu dem Plakat „Alle reden vom Frieden. Wir nicht“.

\section{Klaus Staeck als Kläger}

Es werden im Folgenden zwei Prozesse, in denen Klaus Staeck als Kläger auftrat, beispielhaft herausgegriffen, detailliert beschrieben und auch bewertet.

I. „typisch faschistisch“

Klaus Staeck war tatsächlich nicht nur auf der Beklagten-Seite tätig: Dem hier zu erörternden Prozess war der als „Bonner Bildersturm“ bezeichnete Eklat von 1976 vorausgegangen. Anlässlich einer Ausstellung von StaeckPlakaten im damaligen Bonner Sitz der Deutschen Parlamentarischen Gesellschaft hatten CDU/CSU-Fraktionsmitglieder die Ausstellungsobjekte von den Wänden gerissen. ${ }^{735}$ In einem im Mai 1976 erschienenen Leserbeitrag des damaligen Bundestagsabgeordneten und Mitglied der CDU/ CSU-Fraktion Wilfried Böhm wurden darüber hinaus folgende Ausführungen und zwar unter der Überschrift „Staecks ,Kunst" politische Hetze“ veröffentlicht: „Die neuste Masche der Sozialisten im Kampf gegen die CDU/CSU ist es, dass sie ihre politischen Kampfplakate zu ,Kunstwerken hochstilisieren und dafür allgemein gültigen Aussagewert beanspruchen. Der politische Agitator Staeck ist ein Musterbeispiel für diese zu ,Kunst ${ }^{6}$ verklärte Hetze gegen politisch Andersdenkende.“ Nach einer Beschreibung dreier Plakate Klaus Staecks - unter anderem das Plakat „Entmannt alle Wüstlinge“, in welchem Franz Josef Strauß als Schlachter dargestellt wird - führt der Autor aus: „Diese Agitation Staecks ist typisch faschistisch. Wenn sie ,Kunst ${ }^{\star}$ ist, dann sind auch die Hetzkarikaturen der Nazis, mit

735 Vgl. dazu Kap. 4, D., II. 
denen sie im ,Stürmer ${ }^{6}$ unsere jüdischen Mitbürger verächtlich machten, nachträglich als ,Kunstwerke“ anzusehen." ${ }^{736}$

Klaus Staeck sah sich wegen der Charakterisierung als „typisch faschistisch" und der Gleichsetzung mit den antisemitischen Karikaturen des "Stürmer" beleidigt.

Im einstweiligen Rechtsschutzverfahren hatte das LG Fulda durch einstweilige Verfügung ohne mündliche Verhandlung dem Unterlassungsbegehren Staecks stattgegeben. Diese Entscheidung bestätigte das LG in seinem Urteil vom August 1976 und sah in der Aussage ein in der Ehre herabsetzendes Werturteil. ${ }^{737}$ Dabei erkennt das Gericht an, dass sowohl bei einer zur Meinungsbildung beitragenden öffentlichen Äußerung einprägsame und starke Formulierungen hingenommen werden müssten, als auch - im Sinne eines Rechts auf Gegenschlag - scharfe Angriffe mit ebenso scharfen Entgegnungen beantwortet werden dürften. ${ }^{738}$ In dem Vergleich mit den Stürmer-Hetz-Karikaturen sieht das Gericht eine Schmähkritik, da der Vergleich den Vorwurf beinhalte, die Plakate Staecks seien aus demselben Geiste wie die Karikaturen der nationalsozialistischen Propaganda entstanden. Angesichts der menschenverachtenden Judenhetze des Stürmers und der Nationalsozialisten liege darin der Vorwurf einer ,in hohem Maße verbrecherischen Motivation“. ${ }^{739}$

Diese Ansicht teilt das OLG Frankfurt am Main hingegen nicht und wirft dem LG vor, für ihre Bewertung lediglich eine isolierte Betrachtungsweise vorgenommen zu haben. Für das OLG ergibt sich aus dem Gesamtzusammenhang des Leserbriefs eindeutig, dass der Abgeordnete eine - sicherlich abwertende - Kritik abgeben wollte, da - wie es in dem Leserbrief heißt ${ }^{740}$ - „hässliche Agitation die Atmosphäre vergifte“ ${ }^{741}$ Die Aussage, dass Staeck dabei „typisch faschistisch“ handele, trete aber zurück. In Bezug auf den Vergleich mit den nationalsozialistischen Stürmer-Karikaturen geht das Gericht davon aus, dass der Autor das Argument eröffne, dass die Plakate Staecks von ihrer Machart her „typisch faschistisch“ seien, und wenn diese als Kunst bezeichnet werden, dann seien die Hetzkarikaturen auch als Kunst anzusehen. Diese Ausführung diene nur dazu, die Meinung des Autors zu veranschaulichen, dass Staeck ein Musterbeispiel für eine als

736 Vgl. Anhang B.

737 LG Fulda, 12.8.1976, 4 O 190/76.

738 Vgl. LG Fulda, 12.8.1976, 4 O 190/76, S. 6 f.

739 LG Fulda, 12.8.1976, 4 O 190/76, S. 7.

740 Vgl. Anhang B.

741 Vgl. Frankfurt/Main, 7.6.1977, 14 U 216/76, S. 9. 
„Kunst“ verklärte Hetze gegen politische Andersdenkende sei. Dabei seien keine Ausführungen zur Gesinnung Staecks gemacht worden, womit auch Staeck nicht mit der verbrecherischen Gesinnung der Nationalsozialisten gleichgesetzt worden wäre. ${ }^{742}$ Der Vorwurf, die gleichen Mitteln wie die nationalsozialistischen Stürmer-Karikaturisten zu verwenden, hat sicherlich eine mittelbare herabsetzende Wirkung, die jedoch nach Ansicht des Gerichts von Staeck hingenommen werden müsse, da er selbst in seinen Plakaten der CDU/CSU Handlungen vorwerfe, die nicht mit den Grundsätzen einer freiheitlich Demokratie vereinbar seien und so als faschistisch bezeichnet werden könnten. ${ }^{73}$

Dieser Fall eröffnet die Frage nach dem Umgang mit der Kritik an der Kritik. Ist es der Satire gerade wesenseigen zu übertreiben und zu verzerren, stellt sich die Frage wo die angemessene Grenze für eine Satire-Kritik einzuordnen ist. Auch der Kritiker einer Kritik - hier der Satire - ist zu einer Rücksichtnahme auf die Ehre des Satirikers verpflichtet. Auch darf von ihm - genauso wie vom Satiriker - nicht erwartet werden, das mildeste Mittel zur Demonstration seiner Kritik einzusetzen. Setzt man die Grenze zu niedrig an, wäre der Kritiker gezwungen, seinerseits in der Form der Satire zu antworten, denn dann könnte er sich selbst auf den wesenseigenen Kern der Satire in Form von Übertreibung berufen. Nach Ansicht des OLG Frankfurt ließe sich jedoch dies als ein untragbares Ergebnis einstufen, da so „der Angreifer dem Gegner gewissermaßen Waffen vorschreiben könnte, die dieser nicht in gleichem Maße beherrschte. "744 Die Maßgabe des Gegenschlags richte sich insofern nur nach dem Inhalt und nicht nach den verwendeten Mitteln. Es ist selbstverständlich, dass das kritisierte Werk weder das Medium, die Gattung noch den Stil der Kritik vorgibt.

Die von Klaus Staeck erhobene Verfassungsbeschwerde wurde vom BVerfG mangels hinreichender Aussicht auf Erfolg nicht zur Entscheidung angenommen. Es lagen demnach keine Auslegungsfehler vor, die auf grundsätzlich unrichtiger Auffassung von Inhalt und Tragweite eines Grundrechts beruhen. Der Leserbrief sei in Ausübung des Grundrechts der freien Meinungsäußerung abgefasst und veröffentlicht und sei vom Beschwerdeführer, der seinerseits erheblichen Anlass zu öffentlicher Kritik

742 OLG Frankfurt/Main, 7.6.1977, 14 U 216/76, S. 14 f.

743 Vgl. OLG Frankfurt/Main, ebd., S. 16 f.

744 OLG Frankfurt/Main, ebd., S. 18. 
gegeben habe, auch insoweit hinzunehmen, als er geeignet sei, sein Ansehen zu mindern. ${ }^{745}$

Rein faktisch sei zu beachten, dass die Plakate Staecks in vergleichsweiser hoher Auflagenzahl erscheinen und vor allem durch das Anbringen im privaten wie auch vor allem öffentlichen Raum - sei es auf der Straße, in Universitäten oder ähnlichem - von einem weitaus größeren Publikum wahrgenommen werden würden, als es ein Leserbrief, der zwar von einem Bundespolitiker stamme, jedoch nur in einer lokalen Tageszeitung erschienen sei. An dieser Stelle sei der Blick auf die Tatsache gelenkt, dass der Leserbrief überhaupt nur über die lokalen Grenzen hinweg bekannt wurde, weil Klaus Staeck ein öffentlichkeitswirksames Verfahren angestrengt hatte. Dass Staeck seit dem verlorenen Berufungsverfahren in der Öffentlichkeit vermehrt als „Kunstfaschist“ bezeichnet wurde, ${ }^{746}$ führte er daher auf die Verfahren im Zusammenhang mit dem Leserbrief von Wilfried Böhm zurück. Der Pressedienst der CDU/CSU-Fraktion im Deutschen Bundestag kommentierte das verlorene Gerichtsverfahren mit den Worten: „Staeck müsse erkennen, dass es Freiheit nicht nur für ihn selbst gibt, sondern auch für diejenigen, die sich gegen seine grafischen Aggressionen zur Wehr setzten. Die SPD solle sich von Staeck distanzieren, da „dessen zu ,Kunst ${ }^{6}$ hochgejubelten Hetzplakate seit Jahren in Deutschland zur Vergiftung des politischen Klimas ${ }^{\text {“7 }}$ (47 beitrügen.

II. „Vetternwirtschaft ist für sowas ein noch zu freundlicher Ausdruck“

Am 1. Januar 1993 schloss die Stadt Heidelberg mit Klaus Staeck und dem Bildhauer Rolf Schneider einen Mietvertrag über die Anmietung von Lagerräumen, die die beiden Künstler als Atelier nutzten. Dieser Mietvertrag wurde zum 30. Juni 1994 wirksam gekündigt, da die Stadt das Gelände mit den Lagerräumen im Rahmen eines breit angelegten Wohnraumentwicklungsprogramms mit dem Ziel der Wohnraumbebauung nutzen wollte. Gegen diese Kündigung erhoben die Künstler „Widerspruch“. Dieser wurde zwar nicht berücksichtigt, aber das Gebäude mit den Lagerräumen

745 BVerfG, 22.6.1980, 1 BvR 556/77.

746 Ein Argument, das im Rahmen der Verfassungsbeschwerde geltend gemacht wurde. Staeck, Verfassungsbeschwerde, 1 BvR 556/77, S. 6 f.

747 Pressedienst CDU/CSU, Pressemitteilung, 31.7.1980, S. 2. 
wurde letztlich von einer solchen "Nachverdichtung" ausgenommen. ${ }^{748}$ Bezüglich dieser kommunalpolitischen Entscheidung, der eine intensive Diskussion um die Entwicklung des städtischen Wohnungsbaus vorausgegangen war, endet eine Erklärung des damaligen Fraktionsvorsitzenden der CDU im Gemeinderat der Stadt Heidelberg, die am 28. März 1994 in der Rhein-Neckar-Zeitung unter der Überschrift „CDU wirft OB Vetternwirtschaft vor“ abgedruckt wurde, mit den Worten: „Der Schuppen wurde kürzlich von Oberbürgermeisterin Beate Weber (SPD) an Herrn Klaus Staeck (SPD) vermietet. Dieser obskure Beschluss, der Herrn Staeck begünstigt, verhindert 35 Wohnungen. [...] Vetternwirtschaft ist für sowas ein noch zu freundlicher Ausdruck. "

Gegen diese Äußerung wandte sich Klaus Staeck. Das LG Heidelberg bezieht sich in seiner Entscheidung auf die ständige Rechtsprechung und herrschende Lehre, dass regelmäßig eine Persönlichkeitsrechtsverletzung vorliege, wenn die Meinungsäußerung erwiesen falsche oder bewusst unwahre Tatsachenbehauptungen enthalte. ${ }^{750}$ Dementsprechend sei für das Gericht entscheidend, ob zum einen der Mietvertrag einen Wohnungsbau zum entsprechenden Zeitpunkt und auch in der Zeitphase davor verhindert habe ${ }^{751}$ und zum anderen, ob bei dem Mietverhältnis von einer Begünstigung Staecks durch die Stadt Heidelberg gesprochen werden könne. ${ }^{752}$ Das Gericht stellt ferner fest, dass der Mietvertrag jedoch wirksam gekündigt worden wäre und auch der sogenannte Widerspruch der Künstler hätte hieran nichts geändert, da es sich um eine Gewerberaummiete und damit um eine Kündigung ohne Widerspruchsmöglichkeit handelte. Anhaltspunkte für eine Begünstigung konnte das Gericht nicht erkennen ${ }^{753}$

Anders beurteilte den Fall das OLG Karlsruhe. Als Argument, wieso der Vorwurf der Vetternwirtschaft Staeck in besonderem Maße treffe,

748 Der Bauausschuss sprach sich für eine Wohnungsverdichtung von 300 Wohnungen auf dem gesamten Gelände aus. Die Beschlussvorlage der Verwaltung stellte daneben aber - vor allem wegen „Einwendungen der Nutzer der vorhandenen von der Planung betroffenen Gebäude“ - zwei weitere Varianten zur Abstimmung vor. Die dritte Variante, die den Erhalt der als Atelier genutzten Lagerräume vorsah und nur 200 Wohnungseinheiten ermöglichte fand die Mehrheit im Bauausschuss. OLG Karlsruhe, 6 U 199/94, 23.11.1994, S. 4 f.

749 Rhein-Neckar-Zeitung, 28.3.1994, Siehe für den kompletten Bericht Anhang, C.

750 LG Heidelberg, 31.5.1994, 1 O 105/94, S. 7.

751 Vgl. LG Heidelberg, ebd., S. 9.

752 Vgl. LG Heidelberg, ebd., S. 9 f.

753 Vgl. LG Heidelberg, ebd., S. 10. 
wurde in der Berufungserwiderung noch ausgeführt, dass Klaus Staeck als „sozial außerordentlich engagiert und für sich auch ein moralisches Podest stets in Anspruch genommen [habe], eine ganz wesentliche Basis für sein künstlerisch politisches Engagement entzogen [werde]; ihm würde nämlich gerade dieses moralische Engagement abgesprochen, indem der Äußernde Staeck gleichsam die Maske vom Gesicht [reiße] und sich genauso wie andere aufgrund seiner Parteizugehörigkeit rechtswidrige Vorteile zu-

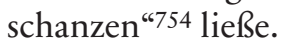

In der rechtlichen Abwägung setzt das Gericht aber seinen Schwerpunkt auf den Umstand, dass erstens die Tatsachenbasis für das mitgeteilte Werturteil keine erwiesen falsche oder bewusst unwahre Tatsachenbehauptung enthalte. ${ }^{755}$ Zweitens habe der Äußernde seine Kritik als politischer Mandatsträger im Rahmen einer kommunalpolitisch relevanten Diskussion eingebracht. ${ }^{756}$ Drittens richte sich dessen Kritik primär gegen die Personen des Bauausschusses, auch wenn diese Kritik im Hinblick auf die Motivationslage für die Entscheidung des Ausschusses sich auch auf Staeck mit auswirke - zumal dieser namentlich genannt werde. ${ }^{757}$ In der Gesamtabwägung des OLG wird daher dieser nur mittelbaren Ehrbeeinträchtigung, der insofern kein unmittelbarer persönlicher Angriff zugrunde liege, im öffentlichen Meinungskampf nur ein geringes Gewicht zugesprochen.

In Bezug auf die Frage nach dem Wahrheitsgehalt der Aussage gehe das LG Heidelberg nicht auf die Tatsache ein, dass es trotz der Kündigung zu einem faktischen Erhalt der als Atelier genutzten Räumlichkeiten gekommen war. Auch reiße das Landgericht die oben zitierte Aussage insofern aus dem Zusammenhang, da dieser letzte Absatz mit dem Verweis auf den Bauausschuss beginne. ${ }^{758}$

754 OLG Karlsruhe, Berufungserwiderung, 6.10.1994, 10 U 124/94, S. 3.

755 Vgl. OLG Karlsruhe, 23.11.1994, 6 U 199/94, S. 20 f.

756 Vgl. OLG Karlsruhe, ebd., S. 19.

757 Vgl. OLG Karlsruhe, ebd., S. 20.

758 „Die Krönung dieser Politik leistete sicher aber kürzlich die Mehrheit des Bauausschusses: Für eine unserer größten Reserveflächen, das Gelände der ehemaligen Glockengießerei Schilling in Bergheim, hat er beschlossen einen wesentlichen Teil von der Bebauung auszunehmen und einen dort vorhandenen Schuppen stehen zu lassen." Rhein-Neckar-Zeitung, 28.3.1994, Siehe für den kompletten Bericht Anhang C. 


\section{Reaktionen}

Die beiden zuletzt besprochenen Verfahren wurden von Medien und der Öffentlichkeit unterschiedlich aufgenommen. War die Berichterstattung zu den Urteilen beider Instanzen in Bezug auf den Vorwurf der Vetternwirtschaft hauptsächlich deskriptiv und wertneutral, ${ }^{759}$ fiel die mediale Resonanz zum Verfahren in Bezug auf die Aussage „typisch faschistisch“ weitaus wertender, wenn nicht spöttisch aus. ${ }^{760}$

\section{Klaus Staeck der rechtsstaatliche Künstler}

Klaus Staeck sieht seine Arbeiten als einen Beitrag im Kampf um die Meinungsfreiheit an. ${ }^{761}$ „Ich habe die Durchsetzung der in Artikel 5 des Grundgesetzes garantierten Meinungsfreiheit zum Beruf gemacht "762 schrieb Staeck 1988. Der Ansatz, dass sich die Meinungsfreiheit und die Demokratie in einem Kampf befinde, wonach sie konstant angegriffen würde und sie deswegen zu verteidigen sei, entspricht einem grundtiefen politischen Verständnis. Staeck sieht dabei jeden Einzelnen in der Pflicht sich zu involvieren: „Unruhe ist die erste Bürgerpflicht. Jede Form von Einmischung ist dringend erforderlich. "763 Er selbst wählt den Weg der Einmischung über seine künstlerischen Politsatire-Plakate. Es ließe sich jedoch der Vorwurf formulieren, dass Staeck mit seiner Parteizugehörigkeit bei der SPD keine Grenzen der Meinungsfreiheit auslote, sondern vielmehr - etwas polemisch formuliert - eine Klientelsatire für seine Parteifreunde schaffe. Legt man das Verständnis Staecks zu Grunde, widerspricht sich aber eine solche Herangehensweise nicht. Vielmehr könnte man Klaus Staeck Inkonsequenz vorwerfen, wenn er - im Widerspruch zu seinem Verständnis der Notwendigkeit der Teilnahme - gerade nicht Mitglied in einer politischen Partei wäre.

759 So beispielsweise unter vielen N.N., Klaus Staeck muss mit Vorwurf der Vetternwirtschaft leben, Süddeutsche Zeitung, 24.11.1994, S.6; N.N., Künstler muss Kritik hinnehmen, Stuttgarter Zeitung, 24.11.1994, Der Meinungsfreiheit den Vorrang gegeben, Rhein-Neckar-Zeitung, 24.11.1994, S. 3.

760 N.N., Wer anderen unter die Gürtellinie schlägt..., Bild, 28.7.1977, S. 2; A.W., Denkzettel für Staeck, Die Welt, 9.6.1977, S. 3.

761 So u.a. Staeck, Plakate, 1988, S. 44;

762 Staeck, ebd., S. 16.

763 Staeck, ebd., S. 21. 
Folgerichtig drängt sich die Frage auf, ob die Prozesse, in denen man Staeck begegnet, nicht vielmehr immer auch als ein - womöglich bewusst gesteuerter - Beitrag zur Schärfung der Meinungsfreiheit angesehen werden müssen.

Als erstes ließe sich überlegen, ob nicht auch das Namens- und/oder Kennzeichnungsrecht in den Verfahren Staecks im Vordergrund standen. ${ }^{764}$ Und doch auch wenn zum Teil verloren oder nicht entschieden, galt auch in diesen Fällen die Meinungsäußerung zu bedenken.

Gleichfalls fällt ins Auge, dass es in allen Gerichtsverfahren kaum um das Ausloten des Sagbaren und seiner Grenzen zur Schmähkritik oder Formalbeleidigung ging. So ist beispielsweise das Plakat „Konturen eines Amtsarsches" im Ansatz als rüde und vulgär zu werten. Die Aussage ist aber ohne Widmung nicht individualisierbar und richtet sich so auch als Kollektivbeleidigung nicht gegen eine einzelne Person oder Personengruppe. ${ }^{765}$ Das Plakat oder die Postkarte kann daher per se, d.h. ohne individualisierende Widmung als Formalbeleidigung oder Schmähkritik gewertet werden. Insofern mag es auch in diesem Fall nicht um das Ausloten der Grenzen der Satire gehen. ${ }^{766}$

Klaus Staeck wurde hier ebenso in seiner Rolle als Kläger besprochen. In den beiden erörterten Fällen wehrte er sich gegen Äußerungen zu seiner Person und seinen Aktionen.

$\mathrm{Zu}$ ergänzen wären unter dieser Rubrik „Staeck als Kläger“ drei Verfahren zu der Verbreitung des Staeck-Plakats „Entmannt alle Wüstlinge“ in der Wahlkampfbroschüre für Franz Josef Strauß anlässlich der Bundestagswahl 1980. In dieser Publikation war ein verkleinertes Bild des Plakats ohne Einwilligung Staecks und ohne Quellenangabe unter der Überschrift „Die Gegner.“ abgedruckt. ${ }^{767}$ Die Gerichte entschieden diesmal zu Gunsten des Staecks, da sie entweder den Zitatzweck aus $\$ 51$ S. 1 Nr. 2 UrhG nicht erfüllt sahen, ${ }^{768}$ eine Verletzung der Pflicht der Quellenangabe aus

764 So bei „Die Reichen müssen reicher werden. Deshalb CDU“ (Kap. 5, B. I., 1.), „Juso beißt wehrloses Kind“ (Kap. 5, B. II.) oder „Der größte Schwindel seit der Farbe Grün“ (Kap. 5, B. V.,1.).

765 Siehe dazu Kap. 5, A.

766 Ganz im Gegenteil zu dem sogenannten „Schmähgedicht“ von Jan Böhmermann. Vgl. dazu Kap. 6, A., II.

767 Referat Offentlichkeitsarbeit der CSU-Landesleitung (Hrsg.), Der Mann., 1979, o. Seitenangaben.

768 Der Abdruck des Plakats unterfiel nach Ansicht des LG Köln nicht unter das Zitatrecht aus $₫ 51$ S. 1 Nr. 2, da es gar keinerlei Beziehung zum Textinhalt gab. LG Köln, 12.3.1980, 78 O 51/80, S. 6. 
$\$ 63$ Abs. 1 UrhG erkannten ${ }^{769}$ oder einen Verstoß gegen die Unterlassungserklärung herausarbeiteten. ${ }^{770}$

Die biographische Besonderheit, dass Klaus Staeck Jurist und zugelassener Rechtsanwalt ist, mag für die Prozesse - ob Kläger/Antragsteller oder Beklagter/Antragsgegner - aber auch für ihn als Künstler eine maßgebliche Rolle gespielt haben. So sieht er seinen juristischen Hintergrund als sein „Arbeitsmittel“771 und als einen Grund sich von Abmahnungen, Anträgen auf einstweiligen Verfügungen, anwaltlichen Schreiben oder Schriftsätzen nicht einschüchtern zu lassen. ${ }^{772}$

In Bezug auf das allgemeine Persönlichkeitsrecht, den Ehrschutz oder sonstige Rechtsgüter, wegen deren Verletzung gegen ihn vorgegangen wurde, sieht sich Staeck andererseits jedoch nicht als Rebell. Weder setzt er sich für die Meinungs- oder gar Kunstfreiheit als ein allen anderen Grundrechten übergeordnetes Grundrecht ein, noch zweifelt er die Gesetze zum Schutze des Persönlichkeitsrechts oder die rechtsstaatlichen Institutionen an. Vielmehr hält er es für „lohnender, sich im Rahmen der Gesetze zu bewegen, die in den meisten Fällen gar nicht so schlecht" ${ }^{\text {"773 }}$ seien und hält es für notwendig, „den von der Verfassung garantierten Freiheitsraum immer wieder neu zu beanspruchen und zu erweitern. " 774 Denn nach seiner Ansicht würden „die meisten Freiheitsrechte verkümmern, wenn man keinen Gebrauch von ihnen macht. "“75 So wurde für Wolfgang Ullrich Klaus Staeck „zum Testimonial für die demokratische Grundordnung “776.

769 Den erforderlichen inneren Zusammenhang zwischen Zitat und dem zitierenden Werk in gleicher Sache annehmend LG München I, 17.7.1980, 7 O 7038/80, S. 5. Das Gericht sieht jedoch eine Verletzung der Verpflichtung der Quellenangabe aus $₫ 63$ Abs. 1 UrhG, siehe LG München I, 17.7.1980, 7 O 7038/80, S. 9 f. Im Rahmen eines gerichtlichen Vergleichs einigten sich die Parteien auf die Zahlung einer Entschädigung in Höhe von 1.000 DM, LG München I, Vergleichsprotokoll, 12.5.1981, 7 O 7038/80, S. 2.

770 OLG Köln, 10.10.1980, 6 U 72/80.

771 Staeck, Reichen müssen reicher werden, 1973, S. 7.

772 Staeck, Ohne Auftrag, ${ }^{2} 2001$, S. 84.

773 Staeck, Plakate, 1988, S. 45.

774 Staeck, ebd.

775 Staeck, ebd., S. 46.

776 Ullrich, Art 2014/12, S. 52 f. 


\section{E. Klaus Staeck als Gesamtkunstwerk}

Die Frage, inwiefern sich die Gerichtsverfahren in das künstlerische Schaffen Klaus Staecks einordnen lassen, soll mit der Besprechung unterschiedlicher Motive beantwortet werden.

\section{Die Motive}

\section{Der Topos des Prozessrisiko als finanzielles Existenzrisiko}

Mit Streitwerten im sechsstelligen Bereich kann das Prozessrisiko für eine Einzelperson ohne eine entsprechende Versicherung ein nicht zu unterschätzendes Risiko darstellen. Gerade wenn gleichzeitig mehrere Verfahren laufen, besteht die Gefahr, dass die Prozesskosten exorbitant in die Höhe schießen. ${ }^{777}$ Die Streitwerte der einzelnen Verfahren lagen meist im sechsstelligen Bereich, ${ }^{778}$ auf dieser Grundlage kann auch auf die Höhe der Gerichts- und Anwaltskosten geschlossen werden. Klaus Staeck macht in Gesprächen, Interviews und Publikationen immer wieder deutlich, dass ein verlorener Prozess auch zu einer finanziellen Not hätte führen können. ${ }^{779}$

\section{Die David-Goliath-Inszenierung}

Dem Topos des finanziellen Risikos verwandt ist die Inszenierung einer David-Goliath-Situation zwischen den Prozessparteien. Der Heidelberger Plakatkünstler Klaus Staeck, der seine Plakate anfänglich für $5 \mathrm{DM}$ verkauft, steht so Aktiengesellschaften mit Umsätzen in der Milliarden-Höhe, finanzstarken großen politischen Partei oder international operierenden Medienkonzernen gegenüber. ${ }^{780}$

777 Es sei auf die während der Gerichtsverfahren Staecks noch bestehende Singularzulassung hingewiesen, womit bei Prozessen an unterschiedlichen Gerichtsständen auch unterschiedliche Anwälte zu mandatieren waren.

778 Der Streitwert beim OLG Celle wurde für das Berufungsverfahren für die Zeit bis zur Erledigungserklärung auf 100.000 DM und im Übrigen auf 25.000 DM festgesetzt.

779 Vgl. Ullich, Art 2014/12, S. 52 f., Vgl. ausführlich Staeck, Ohne Auftrag, ${ }^{2} 2001$, S. 83 f.; - ders., Plakate, 1988, S. 44.

780 Staeck, Plakate, 1988, S. 44 f. 


\section{Die starke mediale Berichterstattung}

Über den Verlauf der Prozesse, die gegen und von Staeck geführt wurden, informierten Tageszeitungen, Nachrichtenmagazine und Zeitschriften auf internationaler, nationaler und regionaler Ebene. Die zum Teil auch meinungsstarken Prozessbesprechungen zeigen, wie sehr die Fälle der Politsatire im Zentrum der öffentlichen Wahrnehmung standen, zumal man bedenken muss, dass Rechtsstreitigkeiten, die in der ersten Instanz verhandelt werden, im Normalfall kaum mediale Beachtung finden.

\section{Der Künstler ist anwesend}

Staeck hat sich nie selbst verteidigt, war jedoch in den mündlichen Verhandlungen oder Urteilsverkündungen anwesend. Dies wurde auch der Öffentlichkeit durch Pressemitteilungen mitgeteilt. So endet eine dieser Pressemitteilungen typischerweise mit den Worten „Klaus Staeck ist bei der Verhandlung ebenfalls anwesend." ${ }^{\circ 81}$ Wobei die Nähe zu der standardisierten Formulierung „Der Künstler ist anwesend“ in Mitteilungen, die zu Ausstellungseröffnungen einladen, von Staeck sicherlich bewusst gesucht wurde. Schließlich wird durch diese Analogie eine formale und inhaltliche Verwandtschaft von Gerichtssaal und Ausstellungsfläche suggeriert.

Somit sei die Vermutung erlaubt, dass die Anwesenheit Staecks ganz gezielt auch zu einer Steigerung der medialen Aufmerksamkeit führen sollte. Offensichtlich hat sich dieses Kalkül als erfolgreich erwiesen.

\section{Der Künstler als eigener Archivar}

Klaus Staeck bewahrt neben den Schriftsätzen, Urteilen oder Korrespondenzen zu den juristischen Prozessen, auch Anfragen zu Ausstellungen, Medienberichterstattung zu seiner Person, Material zu den Plakaten und den in den Plakaten dargestellten Themen, den Prozessen oder sonstigen Konflikten auf. Wobei nicht nur die Prozesse, in denen er selbst Prozesspartei war, sondern auch die Prozesse, die gegen diejenigen geführt wurden, die das jeweilige Plakat verbreiteten, von Staeck gesammelt wur-

781 Beispielsweise Staeck, Pressemitteilung, „Zweiter Versuch Rheinmetall gegen Staeck“, 1.12.1981. 
den. ${ }^{782}$ Den Akten zu den juristischen Streitigkeiten sind auch journalistische Artikel beigelegt, die sich mit den Themen und Personen beschäftigen, die er in der Form der Satire angriff. Diese wurden zum Teil auch den anwaltlichen Schriftsätzen als Beleg für die Berechtigung der Kritik bzw. den Sachbezug hinzugefügt. So findet sich im Verfahren zu seinem Plakat „Alle reden vom Frieden. Wir nicht" neben der Presseberichterstattung über die Ermittlung gegen das Unternehmen Rheinmetall wegen Verstößen gegen das Kriegswaffenkontrollgesetz auch allgemeines Informationsmaterial zu dem Unternehmen selbst sowie auch dessen Geschäftsberichte. ${ }^{783} \mathrm{Ob}$ man darin erkennen kann, dass Staeck aus Selbstschutzgründen Material bereits im Vorfeld gesammelt hat, um für mögliche Rechtsstreitigkeiten vorbereitet zu sein oder - anders formuliert - den Prozess schon in der Phase der Konzipierung des Plakats antizipiert oder zumindest einkalkuliert hatte, lässt sich nicht belegen. Fest steht nur, dass im Rahmen der Gerichtsverfahren zur Darlegung der Berechtigung der Kritik - mag sie noch so scharf gewesen sein - Presseartikel zum kritisierten Verhalten der Betroffenen verwendet wurden.

Diese ausführliche Dokumentation ist nicht allein auf die mediale Berichterstattung zu den Prozessen selbst beschränkt, sondern umfasst ebenso die ältere, aber auch neuere mediale Berichterstattung zu Themen, die Staeck auf seinen Plakaten aufgreift. Als Beispiel sei hier der bereits besprochene Bonner Bildersturm herausgegriffen. ${ }^{784}$ Staeck verfolgte damals nicht nur die Rezeption des eigentlichen Skandals ausführlich, sondern sammelte darüber hinaus alles ihm zugängliche Material, das das Wort „Bildersturm“ verwendete, auch wenn kein Bezug zu Klaus Staeck und dem Bonner Skandal selbst aufgenommen wurde. ${ }^{785}$ Eine besondere Aufmerksamkeit schenkte Staeck im Rahmen dieses Falles der leitenden Figur Philipp Jenninger (CDU). Dies reichte über die ausführliche Berichterstattung in Bezug auf dessen kurze Karriere als Bundestagspräsidenten mit der im Debakel endenden Rede zum 50. Jahrestag der Reichspogromnacht 1988 vom 10. November 1988, die zu seinem Rücktritt am darauf folgen-

782 So das Verfahren Greenpeace und das Verfahren gegen die SPD Ortsverband Friedrichshafen bzgl. des Plakats „Die Reichen müssen reicher werden. Deshalb CDU“ LG Ravensburg, 14.10.1972, III O 974/72.

783 Vgl. Rheinmetall, Wehrtechnik, Materialsammlung zur wehrtechnischen Industrie im internationalen Vergleich, Stand 1980; Rheinmetall AG, Geschäftsbericht 1979.

784 Vgl. Kap. 4, D., II.

785 So beispielsweise Beaucamp, Der neue Bildersturm, FAZ, 7.9.2001; Hasselmann, Aufruf zum Bildersturm, Tagesspiegel, 15.4.2004, S. 11. 
den Tag führte, bis hin zu den Protesten, die 1997 zur Zurücknahme seiner Kandidatur für das Amt des Präsidenten des renommierten Stuttgarter Instituts für Auslandsbeziehungen (ifa) führte. War für den Rücktritt als Bundestagspräsident nur Jenningers eigene unglückliche Rede verantwortlich, waren es in Bezug auf das ifa-Präsidentenamt wohl auch die Proteste wegen des damals schon 21 Jahre zurückliegenden Bonner Bildersturms. ${ }^{786}$

\section{Der Künstler als Publizist}

Für Staeck ist aber nicht nur bezeichnend, dass er sammelt, sondern auch, dass er publiziert. Die umfängliche Dokumentation der Berichterstattung dient damit auch als Grundlage für seine publizistische Aufarbeitung. So hat Staeck z.B. die Geschehnisse um den sogenannten Bonner Bildersturm in Buchform dargelegt. ${ }^{787}$ Das Herabreißen der Plakate in der Ausstellung der Deutschen Parlamentarischen Gesellschaft löste eine Diskussion aus, die in dieser Ausführlichkeit nur in der Publikation des Künstlers selbst festgehalten wurde. So scheute Staeck nicht den Aufwand und druckte eine Auswahl der Presseberichterstattung, die Reden zur kurz danach wiedereröffneten Ausstellung in der Bremer Landesvertretung in Bonn ${ }^{788}$ und kleine Aufsätze unterschiedlicher Autoren, im originalen Wortlaut ab. Mit dieser Publikation hält Staeck die Reden oder die Tagesberichterstattung, die der Natur nach flüchtig sind, fest. Diesem vielleicht um Objektivität bemühten Unterfangen steht die einschränkende Tatsache gegenüber, dass

786 Vgl. unter vielen N.N.,„Bilderstürmer“ Jenninger Präsident?, Stuttgarter Zeitung, 7.11.1997, S. 21; N.N., Jenninger zieht es in die Kultur, Frankfurter Rundschau, 7.11.1997, S. 4; N.N.,Wessen Kultur?, FAZ, 8.11.1997, S. 37.

787 Staeck/Adelmann, Der Bonner Bildersturm oder: was die CDU von Demokratie hält, ${ }^{2}$ 1976. Ähnlich dokumentiert wurde auch der sogenannte Fall Staeck, in dem es um die finanzielle Beteiligung des Londoner Goethe Hauses bei einer Ausstellung von Staeck Plakaten in London ging. Ziel des Buches war nach dem Vorwort der Herausgeberin Ingeborg Karst, dass „die für die Kulturpolitik Verantwortlichen ihre [sic] Meinung noch einmal überdenken." Es wird aber zugestanden, dass es für Politiker lästig sei, „wenn ihre Verfügung über Massenloyalität durch Kritik und Satire eingeengt wird, und die intoleranten Reaktionen zeigen, wie ängstlich an dieser dünnen Loyalitätsdecke festgehalten wird." Karst, (Hrsg.), Der Fall Staeck oder: wie politisch darf die Kunst sein?, 1975, S. 7.

788 So z.B. die Reden zur Wiedereröffnung der Plakatausstellung am 9.4.1976, abgedruckt in: Staeck/Adelmann, Der Bonner Bildersturm oder: was die CDU von Demokratie hält, ${ }^{2} 1976$, S. $13-15 ; 129-131$. 
Staeck nur die von ihm selbst, also aus einer subjektiven Warte ausgewählten Quellen bewahrt und in seine Publikationen eingebaut hat.

Ferner ist festzuhalten, dass Staeck, indem er selbst die Archivierung und Veröffentlichung seiner Arbeiten und der mannigfaltigen Reaktionen übernimmt, letztlich jenen Künstlern zuzuordnen ist, die die Bewertung und Vermarktung ihres eigenen Werks selbst in die Hand nehmen, bzw. - aus anderer Perspektive betrachtet - sich zusätzlich zumuten. Man mag diese Aufgaben nun als Teil einer erweiterten Kompetenz oder als zusätzliche Last einordnen. Eigentlich handelt es sich hier um die klassischen Tätigkeiten von Galeristen, Kuratoren und Kunstwissenschaftlern, die normalerweise eine Mittlerrolle zwischen Künstler und Publikum bzw. Sammler einnehmen. Im Falle Staecks fließen diese Aufgaben in einer Person zusammen und bilden in diesem Verbund womöglich einen unverzichtbaren Bestandteil einer ganzheitlichen Kunstaktion, die Objekt und Rezeption als untrennbar versteht.

Die Bücher, die vorwiegend im Steidl Verlag 789 erschienen sind, sind aber nicht nur auf Erhalt und Verbreitung der künstlerischen Aktionen und der Plakate mit ihren Konflikten ausgerichtet. ${ }^{790}$ Vielmehr hat Klaus Staeck auch politische Bücher verfasst, durch die er von seiner politischen Ansicht überzeugen und so Veränderungen bewirken möchte. $\mathrm{Zu}$ den Themen seiner Umweltplakate veröffentlichte er 1989 ein Buch, in dem er diese zum einen essayistisch bespricht, zum anderen konkrete Veränderungen einfordert und von jedem Einzelnen eine Auseinandersetzung mit den Fragen zur Gefährdung der Umwelt abverlangt. So fordert er beispielsweise ein Umweltstrafrecht und einen internationalen Gerichtshof mit weitreichenden Kompetenzen, um den globalen Zerstörungen des Klimas und der Natur begegnen zu können. ${ }^{791}$ Er wünscht sich, dass ein „Konzernchef aus der Automobil- oder der chemischen Industrie neben einem Minister vor Gericht steht wegen Zerstörung unserer Lebensgrundlage“792.

Zum Bundeswahlkampf 1990 erschien von ihm ein Buch mit dem fragenden Titel „Brauchen wir eine neue Regierung?““ 793 Staeck kämpft darin gegen das „weiter so“ des damaligen Bundeskanzlers Helmut Kohl, dessen Politik von vielen Bürger als lähmend empfunden wurde. ${ }^{794}$ Es handelt

789 Vgl. zum Steidl Verlag Kap. 4, B., I.

790 Als Beispiele dafür seien aber genannt Staeck, Plakate, 1988; Staeck, Ohne Auftrag, ${ }^{2} 2001$.

791 Staeck, Unser täglich Gift. Anschläge auf die Gleichgültigkeit, 1989, S. 170.

792 Staeck, ebd.

793 Staeck, Brauchen wir eine neue Regierung?, 1990.

794 Staeck, ebd., S. 7 und Rückseitentext. 
sich also um eine Auseinandersetzung mit der Politik Deutschlands, nämlich der Politik der bereits seit zwei Amtszeiten regierenden CDU/CSU/ FDP-Koalition unter Helmut Kohl. Die Publikation handelt aber auch von den beiden Spitzenkandidaten im damals aktuellen Bundestagswahlkampf, also Helmut Kohl für die Unionsparteien (CDU/CSU) einerseits und Oskar Lafontaine für die SPD andererseits.

Der Veröffentlichung „Brauchen wir eine neue Regierung?“ lässt Staeck 1991 den „Bericht zur Schieflage der Nation“ folgen, in welchem er die Politik der Bundesregierung unter Helmut Kohl angreift und gesellschaftliche Probleme wie zum Beispiel das des ansteigenden Rassismus anprangert. ${ }^{795}$ Die beiden letztgenannten Bücher haben gemein, dass sie nicht die Plakate oder die diesbezüglichen gerichtlichen Verfahren zum Inhalt haben, sondern eigenständig politische Ideen entwickeln, indem sie den Zustand der Regierungspolitik analysieren.

Alle drei - hier beispielhaft ausgewählten - Schriften sind vom Steidl Verlag als kostengünstige Taschenbücher veröffentlicht worden. Somit stellen sie keine limitierten Editionen oder dekorative Wohnzimmeraccessoires im Stil eines Coffee Table Book oder Bildbandes dar, für die der Verlag durchaus bekannt und renommiert ist.

\section{Der Rechtskonflikt als Ausstellungsobjekt}

Die Gerichtsverfahren wie auch die nicht gerichtlichen Konflikte werden nicht nur archiviert und in den Publikationen besprochen, ${ }^{796}$ sondern auch zum Gegenstand von Ausstellungen gemacht. ${ }^{797}$ Dafür werden einzelne Urteile, mediale Berichterstattungen über diese, oder Auszüge der Abmahnungen herausgegriffen. Aus kuratorischer Perspektive kommt so den Gerichtsverfahren ein eigener Ausstellungswert zu. Sowohl in seinen eigenen Publikationen als auch in den Publikationen über Klaus Staeck ist die Einschätzung zu finden, dass er alle 41 Prozesse, die gegen seine

795 Staeck, Bericht zur Schieflage der Nation, 1991.

796 Unter vielen seien hier genannt Staeck, Ohne Auftrag 22001, S. 83-98; Staeck, Plakate, 1988, S. 43-49. Auflistung von Konflikten und Rechtsverfahren von 1975-1980 in Staeck/Bussmann/et al., Klaus Staeck - Rückblick in Sachen Kunst und Politik, Ausst. Kat. Frankfurter Kunstverein, Heidelberger Kunstverein, Kunstamt Tiergarten Berlin u.a., ${ }^{2} 1980$, S. 81-97.

797 Vgl. u.a. Museum Folkwang (Hrsg.), Klaus Staeck. Sand fürs Getriebe, Ausst. Kat. Museum Folkwang, 2018. 
Plakate und Postkarten geführt wurden, gewonnen habe. ${ }^{798}$ Am Beispiel des ersten hier besprochenen zivilrechtlichen Gerichtsverfahrens, das zu seinen Lasten ausgegangen ist, ist zu erkennen, dass diese Behauptung einer Überprüfung nicht in ihrer Absolutheit standzuhalten vermag. ${ }^{799}$ Doch unabhängig von diesem einen Verfahren, das auch dazu führte, dass das Plakat in „Die Reichen müssen reicher. Wählt christdemokratisch“ geändert wurde, hat Staeck sonst in keinem letztinstanzlichen Verfahren verloren. Die Anzahl von 41 Verfahren ist auch nicht mehr ganz nachvollziehbar, ${ }^{800}$ doch - und das hat schon dieses Kapitel gezeigt - ist die Anzahl sicherlich beachtlich. Als Ausstellungsobjekt eignet sich so neben den größeren Verfahren, die auch hier ausführlich besprochen wurden, auch einfach die Fülle der Prozesse.

8. Gerichtlicher Prozess und die Verfahren als verkaufsförderndes Moment

Aufgrund gestiegener Verkaufszahlen von Buchproduktionen lässt sich zuweilen ein wirtschaftlicher Vorteil nachweisen, der unmittelbar mit gerichtlichen Klagen und der damit verbundenen medialen Berichterstattung zusammenhängt. So wehrten sich beispielsweise zahlreiche in der betreffenden Publikation namentlich genannte Prominente wegen Persönlichkeitsrechtsverletzung gegen die - in Zusammenarbeit mit Ernst Herhaus entstandene - Autobiographie des Verlegers und Schriftstellers Jörg Schröders. Diese Schrift entwickelte sich aufgrund des öffentlichkeitswirksamen Streites zu einem gefeierten und viel gekauften Skandalbuch,

798 Staeck, Ohne Auftrag 22001, S. 87; Staeck, Demokratie kommt nicht aus der Steckdose, in: Museum Folkwang (Hrsg.), Klaus Staeck. Sand fürs Getriebe, Ausst. Kat. Museum Folkwang, 2018, S. 14; auf der eigenen Website „Insgesamt $41 \mathrm{mal}$ wurde erfolglos versucht, Plakate und Postkarten von Klaus Staeck juristisch verbieten zu lassen.“ http://klaus-staeck.de/?page_id=2.

799 Vgl. dazu Kap. 5, B., I., 1.

800 Staeck versteht wohl unter Prozess jegliche Form von rechtlichen Schritten, die wegen eines seiner Werke eingeleitet worden sind und so nicht zwingend gegen ihn persönlich gerichtet gewesen sein müssen. Insofern fallen darunter Abmahnungen mit strafbewehrten Unterlassungserklärungen, die im Sand verlaufen oder zurückgenommen worden sind. Verständlicherweise werden Verfahren zu ein und dem gleichen Plakat, die aber von unterschiedlichen Klage- bzw. Antragsberechtigten an unterschiedlichen Gerichtsorten angestrengt wurden, als getrennte Verfahren gerechnet. Aber auch dann ist eine vollständige Nachprüfung der genannten Zahl nicht mehr möglich. 
das seit seiner Erstveröffentlichung 1972 zahlreiche Neuauflagen erfahren hat. Auf gerichtliche Anordnung mussten seit 1975 einzelne Passagen geschwärzt werden. ${ }^{801}$ Vor diesem Hintergrund kann man womöglich auch im Falle der Plakateditionen von Klaus Staeck von einer verkaufsfördernden Wirkung, die in vergleichbarer Weise durch das breite mediale Interesse an den juristischen Verfahren ausgelöst wurde, ausgehen. Man könnte sogar noch einen Schritt weitergehen und den Erwerb von Exemplaren der Staeckschen Plakateditionen selbst als eine Form der Solidaritätsbekundung durch den Käufer deuten. Jedoch kann im Rahmen dieser Arbeit ein solches komplexes Kausalitätsverhältnis aufgrund fehlender einschlägiger Untersuchungen und des insoweit fehlenden Zahlenmaterials nicht beleuchtet werden.

\section{Klaus Staeck, Künstler oder Kämpfer für die Meinungsfreiheit?}

Ebenso führt Klaus Staeck selbst als Argument für sein politisches Engagement an, dass er sich im Rahmen der Gerichtsverfahren immer nur auf die Meinungsfreiheit und nicht auf das in der Kunstfreiheit verbürgte „Sonderrecht des Künstlers" berufen habe. ${ }^{802}$ Die Frage nach der Einordnung Klaus Staecks mag mittlerweile, also spätestens seit seiner Ernennung zum Präsidenten der Akademie der Künste in Berlin, die 2006 ausgesprochen wurde, überholt sein, doch zeichnet sich rückwirkend in den Rechtsstreitigkeiten und der medialen Presseberichterstattung ab, wie schwer die Einordnung als politischer Künstler im Zeitraum vor einer offiziellen Anerkennung, die sich wohl erst nach 2000 eingestellt hat, gefallen ist. Es soll aber nicht übersehen werden, dass die Einordnung der Plakate als Kunstwerke und damit die Einordnung Staecks als Künstler auch durchaus zum Nachteil von Klaus Staeck verwendet wurden. Wie im Rahmen des Rheinmetall-Verfahrens bereits dargelegt, ordnete man ihn beispielsweise in diesem Fall gezielt als „sogenannten“ Künstler ein. Damit konnte ihm gerade

801 Die letzte und erweiterte Ausgabe des Buches erschien 2018 bei Schöffling \& Co. Die Gesamtauflage wird auf über 100.000 Exemplare geschätzt. In den Rezensionen wird es als eine „geniale Selbstoffenbarung“, „Kultbuch“ und als ein „phänomenales Pandämonium der Literatur- und Sozialgeschichte" bezeichnet. Die literarische Qualität dieses Buches soll daher keineswegs abgesprochen werden. Vgl. die Zusammenstellung der Rezensionen bei https://www.schoeffli ng.de/buecher/jörg-schröder/siegfried.

802 Staeck, Ohne Auftrag, ${ }^{2} 2001$, S. 84. 
im Vergleich zu den Managern Rheinmetalls, die ihr Persönlichkeitsrecht verletzt sahen, jedes berechtigte Interesse abgesprochen werden. ${ }^{803}$

Es soll hier aber nicht der Anschein erweckt werden, als wären das Wirken und die Arbeiten von Klaus Staeck nie unter dem Aspekt der Kunstfreiheit diskutiert worden. Im Folgenden werden einzelne Beispiele genannt, eine Vollständigkeit ist nicht beabsichtigt. Das erste Beispiel zeigt, wie das BVerfG die Plakate als Kunst einordnete und das zweite, wie Staeck sich in den Schriftsätzen auf die Kunstfreiheit beruft.

In dem ersten Beispiel entschieden die Richter des BVerfG in einem Nichtannahmebeschluss 1979, dass ein Bundeswehrsoldat, der die StaeckPlakate "Juso beißt wehrloses Kind“804 (Abb. 6) und „Entmannt alle Wüstlinge "805 (Abb. 3) in seiner Unterkunft aufgehängt hatte, disziplinarisch belangt werden darf. Er kann sich dabei, so das Gericht, nicht auf die Kunstfreiheit berufen. ${ }^{806}$ Die disziplinarischen Maßnahmen gegenüber dem Bundeswehrsoldat seien gerechtfertigt, da die Anlagen der Bundeswehr als ein Raum, in dem keinerlei visuellen Äußerungen zur aktuellen Parteipolitik zugelassen sind, gelten und die - zwar künstlerisch gestaltete, jedoch eminent parteipolitische - Aussage der Plakate, die leicht ersichtlich zu einer kritischen Auseinandersetzung mit einem prominenten Vertreter einer bestimmten Partei und der von ihm vertretenen Politik anregen soll, dem Gebot zuwiderlaufe. Für die Perspektive der vorliegenden Arbeit ist jedoch ganz entscheidend, dass das BVerfG im Zuge dieses Verfahrens die beiden vom Soldaten verwendeten Plakate selbst als Kunstwerke einordnet und ihnen eine künstlerische Gestaltung attestiert. 807

In dem zweiten Beispiel wurde in der von Klaus Staeck angestrengten Verfassungsbeschwerde zum Urteil des OLG Frankfurt am Main bzgl. der Leserbrief-Äußerung „typisch faschistisch“ des Bundestagsabgeordneten Böhm für eine Einordnung von Klaus Staeck als Künstler argumentiert. ${ }^{808}$ Am Rande sei nur daran erinnert, dass sich Staeck ebenso in der

803 Vgl. Kap. 5, B. III., 7.; Anhang A.

804 Vgl. Kap. 4, C., II., 2., b), dd).

805 Vgl. Kap. 5, B., II.

806 BVerfG, 4.4.1979, 2 BrR 326/76, Krit. Justiz, S. 321 f.

807 „Die in ihnen in der Form künstlerischer Gestaltung enthaltene politische Aussage soll ersichtlich zu kritischer Auseinandersetzung mit einem prominenten Vertreter einer bestimmten Partei und der von ihm vertretenen Politik anregen." BVerfG, 4.4.1979, 2 BrR 326/76, Krit.Justiz, S. 321.

808 Vgl. dazu Kap. 5, C., I. Ebenso wurde in der Verfassungsbeschwerde von Greenpeace auch eine Verletzung des Grundrechts der Kunstfreiheit gerügt, da das 
Schutzschrift zum Rechtsstreit zum Grünen Punkt auf die Kunstfreiheit bezieht. ${ }^{809}$

Als eine Position der universitären Kunstwissenschaft sei hier eine Kunstkritik des Kunsthistorikers Lothar Romain dargelegt. Er äußerte anlässlich des sogenannten Bonner Bildersturms die Auffassung, dass Staecks Wahl des Plakats als Medium „ein qualitativer Schritt fort von traditionellen Kunstvorstellungen, nicht aber ein Schritt ins Außerkünstlerische“ sei. ${ }^{810}$ Romain folgert letztlich und durchaus politisch, dass die Verweigerung der Gesellschaft, Staeck in seiner Rolle als Gegner, Kläger oder Antragsteller als Künstler anzuerkennen, „Ausdruck eines lang und breit angelegten Versuchs, essentielle Grundrechte zu bloßen Formalien zurückzunovellieren" 811 sei.

Es fällt auf, dass kunstkritische Ausführungen zu Staeck sich auf seine Prozesse, auf die Skandale - seien es der sogenannte Bonner Bildersturm oder der Fall im Londoner Goethehaus - seine Wahl des Plakats als demokratisches Massenmedium oder seinen politischen Einsatz beziehen. ${ }^{812}$

Die Diskreditierung der Person Klaus Staeck ${ }^{813}$, die sich durch den Versuch äußert, den Plakaten die Kunsteigenschaft oder ihm die Künstler-

Plakat ein „Kunstwerk des Künstlers Klaus Staeck sei“. Greenpeace, Verfassungsbeschwerde, 21.8.1992, S. 12.

809 DSD./. Staeck, Schutzschrift, 16.2.1996, S. 3.

810 Romain, Kunst die auf die Straße geht. Anmerkungen zu den Plakaten von Klaus Staeck, in: Staeck/Adelmann, Der Bonner Bildersturm oder: was die CDU von Demokratie hält, ${ }^{2} 1976$, S. 25.

811 Romain, ebd., S. 33.

812 Als politischer Einsatz sei hier neben vielen unter anderem seine zahlreichen Interviews gegen die Wahl Philipp Jenningers zum Präsidenten für das Institut für Auslandsbeziehungen genannt. Staeck im Interview, „Ein Bilderstürmer taugt nicht als Kultur-Repräsentant“, Stuttgarter Nachrichten, 8.11.1997, S. 21.

Vgl. bspw. Teuber, Klaus Staeck, in: Holten (Hrsg.), Bilderbedarf, Ausst. Kat., Staatliche Kunsthalle Baden-Baden, 2012, S. 69.

Eine Kunstkritik aus dem rein ästhetischen Blickwinkel wäre aber auch zu kurz gegriffen.

813 Staeck wurde als „Polit-Pornograph“ bezeichnet. Viel rezipiert wurde dieser Ausdruck als Ausruf bei dem sogenannten Bonner Bildersturm. Spätestens im vierten Kapitel zu den Plakaten Staecks müsste jedoch deutlich geworden sein, dass seine Arbeiten nicht anzüglich und sicher nicht pornographisch sind. Damit soll keineswegs die Aussage einhergehen, dass die Verbindung von den Bereichen Politik und Pornographie bzw. Sexualität für Parodien oder Satiren unüblich seien, doch lässt sich eine solche Verbindung in den Arbeiten von Staeck nicht finden. Aus diesen Gründen muss in dieser Bezeichnung eine generelle Diskreditierung gesehen werden. Der Begriff der politischen Pornographie reiht sich dabei in die typische Sprache Rechtsradikaler und Antisemi- 
eigenschaft abzusprechen, oder aber Ausstellungsprojekte zu verhindern, wertet Staeck selbst nicht als Angriff auf seine Kunstfreiheit. Vielmehr sieht er sich hierdurch in der Position gestärkt, in der es gilt, darum zu kämpfen Demokrat zu sein. ${ }^{814}$ So kommentiert Staeck beispielsweise im Zusammenhang mit den Auseinandersetzungen um das Projekt „Niedersachsenroß“ 1990 auch das Unternehmen, welches wegen rechtlicher Bedenken das umstrittene Plakat nicht an ihren Werbeflächen anbringen wollte, mit den Worten: „Die Monopolfirma Deutsche Städte-Reklame, die sich zum wiederholten Male als Zensurbehörde einen traurigen Ruf erwerben wollte, wird nach der Frankfurter Entscheidung das Recht auf Meinungsfreiheit wieder ernst nehmen müssen" ${ }^{\text {"815. }}$.

\section{Gerichtsprozess als Katharsis}

Die Satire kann als eine Möglichkeit des Abbaus von einem Gefühl der Ohnmacht in (gesellschafts-)politischen Fragen angesehen werden. Dies entspricht zunächst auch insofern dem Verständnis Staecks, da er seine Plakataktionen als eine persönliche Form der politischen Einmischung ansieht.

Darüber hinaus kann von einer kathartischen Wirkung, die von den Rechtsstreitigkeiten ausgegangen sind, gesprochen werden, da mit der Verhandlung und dem darauffolgenden Urteil oder Beschluss das gegenständliche Plakat und dessen Inhalte jeweils einer richterlichen Prüfung unterzogen und schließlich für rechtens erachtet wurden. Durch das rechtskräftige Urteil führt diese kathartische Wirkung zur Stärkung der Position des Prozessgewinners, damit des Künstlers Klaus Staeck in der Gesellschaft.

ten zu Diffamierung von Künstlern, Schriftstellern und Musikern ein, die in der Nachkriegszeit z.B. seit den 1960er Jahren von der NPD verwendet wurde (Vgl. Stelmach/Wegner, Kunst in der politischen Diskussion. Der Vorwurf der „politischen Pornographie“, Hypotheses, 8.10.2017). Laut der NPD schwärmte z.B. Brian Epstein für Homosexualität und da „wo die SPD regiert, da haben Dirnen und Zuhälter gute Tage“" (Zit. nach Bott, Die Volksfeind-Ideologie: Zur Kritik rechtsradikaler Propaganda, 1969, S. 36).

814 Vgl. Kapitelüberschrift „Teil III: Es geht um das Recht, Demokrat zu sein“ in: Staeck/Adelmann, Der Bonner Bildersturm oder: was die CDU von Demokratie hält, Göttingen ${ }^{2} 1976$, S. 127-155.

815 Staeck, Pressemitteilung „Hannover muss kleben“, 4.5.1990. 
II. Das Gesamtkunstwerk und seine Auswirkungen

Auf der Grundlage der hier verhandelten Kriterien wird die These vertreten, dass die Prozesse in das künstlerische Schaffen von Klaus Staeck einzubeziehen sind und so zu einem Gesamtkunstwerk beitragen. Darüber hinaus ließe sich argumentieren, dass Staeck den Rechtsstreit von Anfang an als eine Form von Happening oder Performance angesehen habe. Dafür sei angeführt, dass Staeck die Mechanismen der Performance-Kunst schon in 1960er Jahren vertraut waren. An der der Intermedia $69^{816}$ nahm er unter anderem mit einer Aktion, die als Performance eingeordnet werden kann, teil: In Anlehnung an das ästhetische Konzept der damals sehr präsenten Bewerbung des Waschmittels „Omo“, steckte er ein Ölgemälde mit der Ansicht des Heidelberger Schlosses in eine Waschmaschine. ${ }^{817}$ Eine mögliche Auffassung, der Rechtsstreit für sich tauge als eigenständige Performance, erscheint jedoch spekulativ und vermag nicht vollständig zu überzeugen. Der publikumswirksame Teil eines gerichtlichen Verfahrens nimmt vielmehr nur einen untergeordneten Teil ein. Die anderen genannten Kriterien überwiegen so sehr, dass es näherliegend erscheint, den Rechtsstreit als Teil eines Gesamtkunstwerks, das aus dem Medium Plakat, dessen Aussage und aus allen Formen der Rezeption, zu der eben auch der Rechtsstreit gehört, anzusehen.

Wäre dann eine solche Bewertung - nämlich die Behauptung, der Prozess sei ein von vorne herein intendierter Bestandteil eines Gesamtkunstwerks - im hypothetischen Fall einer erneuten juristischen Auseinandersetzung wegen eines Plakats Staecks von juristischer Bedeutung?

Dies kann wohl aus rechtlicher Perspektive bezweifelt werden. Eine Verhandlung der Plakate über die Kunstfreiheit mag vielleicht indirekt eine Bewertung dahingehend abgeben, dass das künstlerische Politsatire-Plakat als Kunstwerk anerkannt wird, über die Einordnung als Gesamtkunstwerk wird damit aber keine Aussage getroffen. Zumal - wie in der Absteckung des rechtlichen Rahmens deutlich wurde - bei satirischen Äußerungen die Meinungsfreiheit das elementare Grundrecht darstellt und das Spezifische der Satire im Vordergrund steht. Wegen des Satirespezifischen kommt der Frage nach der Einordnung unter der Meinungs- oder Kunstfreiheit dann auch nur eine untergeordnete Stellung zu.

816 Vgl. dazu Kap. 4, C., II., 1.

817 Vgl. die Dokumentation in: Goetze/Staeck/Gerling, (Hrsg.), Intermedia '69, Ausst. Kat. Heidelberg, Heidelberg ${ }^{2} 1969$, o. Seitenabgaben. 
Aus der Perspektive des Betroffenen auf der anderen Seite kann jedoch die Tatsache, dass Staecks Wirken als Gesamtkunstwerk zu verstehen ist, in dem die juristischen Verfahren durchaus Teil des Kunstwerks werden, eine Auswirkung haben. Wenn der Betroffene sich beispielsweise in seinem allgemeinen Persönlichkeitsrecht verletzt sieht und dagegen juristisch vorgehen möchte, kann er im Falle einer Gerichtsentscheidung maximal von einem Urteil oder Beschluss zu seinen Gunsten ausgehen, mit der Folge, dass das entsprechende Plakat entweder gar nicht oder nur ohne die rechtsverletzenden Passagen vertrieben wird. Im schlechtesten Fall verliert er nicht nur den Prozess. Vielmehr wird er über die mediale Berichterstattung, deren Archivierung und Publizierung sowie Ausstellungen des Plakats, der Urteile oder sogar Schriftsätze durch den Künstler zu einem weit über die Tagesaktualität hinaus präsenten satirischen Gegenstand im Schaffen des Künstlers.

\section{F. Zwischenfazit}

Im fünften Kapitel wurde herausgearbeitet:

Die gegen die Plakate Klaus Staecks angeführten rechtlichen Verfahren waren Teil seines künstlerischen Schaffens. Als engagierter Künstler, der es sich zum Ziel gesetzt hat, die Meinungsfreiheit zu verteidigen, gehören auch Verfahren, die er selbst angestrengt hat. Auch diese werden von ihm als ein Beitrag zum Ausloten der Grenzen der Meinungsfreiheit verstanden. Er setzt sich nicht für eine grenzenlose Meinungsfreiheit des Künstlers ein, denn für ihn muss auch jede satirische Übertreibung, Verkürzung, Re-Kontextualisierung auf Tatsachen und so einem wahrhaftig zu kritisierendem Umstand beruhen. Die Prozesse sind, wie in den zehn Abschnitten dieses Kapitels dargelegt wurde, zu einem wesentlichen Teil seiner Künstlerfigur geworden, deren Ziel die politische Einmischung ist.

Eine besondere Virulenz besaßen diejenigen Plakate, in denen der oder das Angegriffene nicht nur mit Namen oder Kennzeichen benannt wurden, sondern auf Abbildungen zurückgegriffen wurde. Dem eigenen Bild, ein besonderer Ausfluss des allgemeinen Persönlichkeitsrechts, lässt sich in dieser, wenn auch kleinen Stichprobe eine besondere Wirkung zuschreiben, denn letztlich waren es die Bilder, die in den beiden größten Verfahren („Alle reden vom Frieden. Wir nicht“ und „Alle reden vom Klima. Wir ruinieren es") mehrfach dazu führten, dass die Abgebildeten die Gerichte angerufen haben. 
Die rechtliche Beurteilung der als künstlerische Politsatire einzustufenden Plakate Klaus Staecks erfolgt lediglich unter Bezugnahme auf das Grundrecht der Meinungsfreiheit nach Art. 5 Abs. 1 GG. Insofern fügt sich auch das satirische Plakat eines politischen Künstlers in die Rechtsprechungs-Leitlinie des BVerfG. In der letztlich maßgeblichen Abwägung der kollidierenden Verfassungsgüter nach dem Prinzip der praktischen Konkordanz kommen so auch im künstlerischen Politsatire-Plakat die gleichen Kriterien zum Tragen wie in sonstigen äußerungsrechtlichen Fällen, wobei die Besonderheiten der Kunstform miteinzubeziehen sind. Eine Auseinandersetzung mit der Satire als Begriff, mit dem Satirischen im Plakat oder der Satire als künstlerischer Ausdrucksform erfolgt in den gerichtlichen Entscheidungen kaum. Das ließe sich als grundlegender Kritikpunkt an der rechtlichen Würdigung werten, doch wird in der überwiegenden Zahl der Verfahren durchaus Wert auf eine kontextuelle Einordnung des Plakats und einer Untersuchung der Bedeutung der Text-Bild-Kombinationen gelegt. Für eine rechtliche Würdigung muss das Satirische weder als solches benannt werden, noch bedarf es einer Auseinandersetzung mit dem literaturwissenschaftlichen Satirebegriff oder notwendiger Definitionsmerkmale des Satirebegriffs. Dennoch bleibt auch bei der satirischen Äußerung zu fragen, warum, unter welchen Umständen, gegen wen und wie sich die Äußerung richtet. In den Plakaten von Klaus Staeck wird das "gegen wen“ mit den Verantwortlichen des anzugreifenden Ungleichgewichts, das „unter welchen Umständen“ mit dem zu Grunde gelegten Kontext, das „wie“ mit auf ein Lachen ausgerichteten meist antithetisch aufgebauten Verkürzung oder Übertreibung und das „warum“ mit einer politischen oder gesellschaftlichen Veränderung beantwortet. 
- Dritter Teil - 


\section{Sechstes Kapitel: Satirerechtsprechung nach Staeck}

Nachdem im fünften Kapitel die Rechtsstreitigkeiten untersucht wurden, die durch die Politsatire-Plakate des Klaus Staeck ausgelöst worden waren, sollen in diesem Kapitel andere satirische Medien, die ebenfalls vor Gericht verhandelt wurden, beleuchtet werden. Damit wird bezweckt, die verschiedenen möglichen juristischen Verfahrensweisen im Umgang mit Satire beispielhaft aufzuzeigen und so den Blick von einem neuen Standpunkt aus auf das Politsatire-Plakat zu schärfen. Die herausgegriffenen Entscheidungen behandeln satirische Äußerungen in einer Satirezeitschrift (A.) und in Satire-Fernsehshows (B.).

\section{A. Die Satire in der Satirezeitschrift}

Die Satirezeitschrift „Titanic - Das endgültige Satiremagazin“ löste seit seiner Gründung 1979 diverse anwaltliche Schreiben, Unterlassungserklärungen, gerichtliche Verfahren und sogar auch einige Verbote ganzer Ausgaben aus. Nicht ohne Grund bezeichnet sich daher das Magazin als die „verbotenste Zeitung Deutschlands“. ${ }^{818}$ Ein Rechtsstreit führte auch zu einer für die Zeitschrift Titanic erfolgreichen Verfassungsbeschwerde und so zu einer Auseinandersetzung durch das BVerfG mit der Satire allgemein. Dieses Urteil wurde bereits im dritten Kapitel dieser Arbeit und zwar in Bezug auf den Satirebegriff angesprochen, insofern kann verwiesen werden. ${ }^{819}$ In diesem Fall ging es um eine als Leserbrief bezeichnete Glosse in der Zeitschrift. In vielen anderen Fällen waren Fotomontagen Gegenstand der rechtlichen Auseinandersetzungen. Als Beispiel soll in diesem Kontext eine Fotomontage in der April-Ausgabe der Titanic von 1993 ausgewählt werden: Anlässlich des Rücktritts Björn Engholms (SPD) vom Amt des Ministerpräsidenten des Landes Schleswig-Holstein - der Endpunkt der sogenannten Barschel-Affäre - setzte die Redaktion der Titanic eine Fotografie des Gesichts des grinsenden Björn Engholm auf ein Bild, das weltweite Verbreitung fand und den Leichnam des CDU-Poli-

818 Schmidt, Titanic. Die verbotenste Zeitschrift Deutschlands, in: Folckers/Solms (Hrsg.), Risiken und Nebenwirkungen. Komik in Deutschland, 1996, S. 176.

819 Vgl. Kap. 3, B., I. 
tikers Uwe Barschel in der Badewanne des Genfer Hotels „Beau Rivage“ zeigt, und unterschrieb die Montage mit den Worten „Sehr komisch, Herr Engholm!“. Björn Engholm war damals auf Grund einer Falschaussage vor dem parlamentarischen Untersuchungsausschuss zur Aufklärung der Barschel-Affäre 1987 von allen politischen Ämtern zurückgetreten. Es hatte sich nämlich der Eindruck erhärtet, dass er selbst in die Affäre verwickelt sei. Engholm klagte dennoch gegen die Titanic wegen Verletzung seines Persönlichkeitsrechts. Sowohl das LG Hamburg als auch das OLG Hamburg entschieden zulasten der beklagten Titanic. ${ }^{820}$ Für die damaligen Verhältnisse und vor allem für ein Magazin mit einer nur kleinen Druckauflage fiel das angesetzte Schmerzensgeld von DM 40.000,- hoch aus. ${ }^{821}$ Diese - die Existenz der Titanic gefährdende - Entscheidung mag gerade vor dem Hintergrund der Tatsache überraschen, dass es sich bei der Fotomontage um eine Satire in einem als solchen ausgewiesenen Satire-Kontext handelt.

Die Titanic weist sich selbst - bereits durch den Untertitel der Zeitschrift - in eindeutiger Weise als Satiremagazin aus, der Leser rechnet also schon im Vorfeld mit Beiträgen satirischen Inhalts. Hier liegt ein gravierender Unterschied zu den Werken von Klaus Staeck, dessen Plakate mit ihrer Präsentation im öffentlichen Raum nicht für einen eindeutigen Satire-Kontext geschaffen wurden. Da die Wirkung von Satire unmittelbar vom Rezipienten abhängt, ist also die Fehleranfälligkeit des Satireverständnis in der Titanic weitaus niedriger. Auch die für die Satire typischen Formen der Übertreibung, Überzeichnung oder Zuspitzung sollten in einem Magazin, in dem ausnahmslos jeder Beitrag mit diesen Stilmitteln arbeitet, nicht überraschen.

Allerdings zeigt der Vergleich der Arbeiten von Staeck und den Beiträgen in der Titanic auch Gemeinsamkeiten auf: Ähnlich wie das Werk von

820 OLG Hamburg, 9.12.1993, 3 U 170/93, NJW-RR 1994, S. 1373-1375; LG Hamburg, 26.12.1993, 324 O 511/93, AfP 1994, S. 64-68; OLG Hamburg, 15.9.1994, 3 U 296/93, WRP 1994, S. 889-895. Es ist auf die - wie es im Urheber-, Medienund Presserecht bekannt ist - Strenge der Hamburger Gerichte zu verweisen. Viele der äußerungsrechtlichen Entscheidungen der Hamburger Gerichte wurden vom BGH aufgehoben. So z.B. BGH, 5.6.2008, I ZR 96/07, NJW 2008, S. 3782 - zerknitterte Zigarettenschachtel; BGH, 12.11.2009, VI ZR 226/08, GRUR 2010, S. 458 - heute wird offen gelogen; BGH, 16.1.2018, VI ZR 498/16, NJW 2018, S. 2882.

$821 \mathrm{Zu}$ dem zu zahlenden Schmerzensgeld kamen noch die gerichtlichen und außergerichtlichen Kosten hinzu. Das zugesprochene Schmerzensgeld zählte damals zu den höchsten im Äußerungsrecht, vgl. auch N.N., Björn Engholm, Der Spiegel, 23.10.1995, https://www.spiegel.de/spiegel/print/d-9224278.html. 
Staeck mit den gegen ihn angestrengten Prozessen von ihm zu einem Gesamtkunstwerk verwoben wurde, sind die Gerichtsverfahren gegen die Titanic auch zu einem maßgeblichen Teil der Geschichte des Magazins geworden. So waren die rechtlichen Streitigkeiten u.a. auch Gegenstand der Ausstellung „40 Jahre TITANIC“ von 2019, die anlässlich des 40-jährigen Bestehens der Satirezeitschrift im Frankfurter Caricatura Museum für komische Kunst ausgerichtet wurde. ${ }^{822}$

\section{B. Die Satire-Fernsehshow}

Ein ähnlich eindeutig der Satire zugeschriebenes Medium ist das der Satire-Fernsehshow. Aus diesem Kontext stammen die drei im Folgenden aufgeführten Beispiele rechtlicher Auseinandersetzungen, deren nähere Betrachtung sich auch insofern als weiterführend darstellen, da die Verfahren aktuell sind, bzw. nur wenige Jahre zurückliegen.

I. Das „Schmähgedicht“: Die Satire um der Satire willen

Dieses von dem Satiriker Jan Böhmermann vorgetragene Gedicht besteht aus einer Aneinanderreihung vulgärer Ausdrücke aus dem Fäkalbereich mit starken sexuellen Bezügen und Gewaltbegriffen, die in Bezug zu Recep Tayyip Erdoğan, dem Präsidenten der Republik Türkei, gesetzt werden. Das Gedicht war in einem Teil der ZDFneo-Show „Neo Magazin Royale“ über den türkischen Präsidenten und dessen Verhältnis zur Meinungsfreiheit eingebettet. Darin wollte Böhmermann veranschaulichen, dass unter der Präsidentschaft Erdoğans eine freie Meinungsäußerung nicht mehr möglich sei. Ferner war das Gedicht aber auch Antwort auf das Lied „Erdowie, Erdowo, Erdogan“. Dieser Song, zwei Wochen zuvor in der Satiresendung Extra 3 des NDR vom 17. März 2016 ausgestrahlt, hatte bereits diplomatische Auseinandersetzungen mit der Türkei, die eine Löschung des Liedes aus der Mediathek des öffentlich-rechtlichen Senders einforderte, ausgelöst. Jan Böhmermann wertete diese erste Reaktion der Türkei als stark übertrieben, da ihm der Text des Extra 3-Lieds als harmlos erschien, und setzte mit dem Schmähgedicht nach. Eingeleitet und wiederholt unterbrochen wurde der Vortrag des Gedichts mit Ausführungen, dass man

82240 Jahre TITANIC. Die endgültige Titel-Ausstellung, Caricatura Museum für komische Kunst Frankfurt, 3.10.2019-2.2.2020. 
mit diesem Gedicht zeigen wolle, wie in Deutschland eine unzulässige Schmähkritik aussehen könnte.

Unüblicher Weise kam es im Wege der mittlerweile aufgehobenen Strafverfolgungsermächtigungsnorm $\$ 103$ StGB auch zu einem Strafprozess wegen Beleidung, der parallel zum Zivilprozess gegen Jan Böhmermann in Sachen des Schmähgedichts angestrengt wurde. ${ }^{823}$ Letztlich hatte die Staatsanwaltschaft das Verfahren aber nach $\mathbb{\$} 170$ Abs. 2 StPO eingestellt, da fraglich war, ob überhaupt der objektive Tatbestand erfüllt ist, aber vor allem ein Vorsatz Böhmermanns nicht nachgewiesen werden konnte. ${ }^{824}$ Im zivilrechtlichen Prozess musste in Bezug auf die Satire entschieden werden, ob es sich bloß um eine Aneinanderreihung von Formalbeleidigungen handele, die zu einer nicht gerechtfertigten Persönlichkeitsrechtsverletzung führen würde, oder, ob das Gedicht auch im Wege dieser „quasi-edukatorischen" 825 Einbettung eine geschützte Meinung äußere. Im Beschluss der einstweiligen Verfügung heißt es noch, dass das Gedicht „zweifelsohne eine Satire“826, aber auch „zweifelsohne schmähend und ehrverletzend“827 sei. Im Hauptsacheverfahren war das Gericht zwar dann nicht mehr ganz ohne Zweifel, nahm zwischen der Kunst- und Meinungsfreiheit auf der einen Seite und dem Persönlichkeitsrecht auf der anderen Seite eine Abwägung vor und kam trotzdem zu dem gleichen Ergebnis: Das Gedicht beinhalte teilweise rechtswidrige Passagen ${ }^{828}$ Solche wären gerade diese mit besonders starken sexuellen Bezügen. Für die getrennte Prüfung der einzelnen Verse des Gedichts, für das Offenlassen, welches Grundrecht zugunsten Böhmermanns eingreife, und für ein vermeintliches Verkennen der starken Fiktionalität und Absurdität, steht diese Entscheidung in Kritik. ${ }^{829}$ Darüber hinaus wird dem Gericht vorgeworfen, den angelegten Maßstab von Entkleiden des Aussagekerns und der getrennten Prüfung von Aussagekern und Einkleidung sowie die Kriterien, die für die Abwä-

823 Der Fall löste neben der Frage nach der Satire auch eine Diskussion um die Frage, ob sich Böhmermann der Beleidigung strafbar gemacht hat, um die Strafverfolgungsermächtigungsnorm $₫ 103$ StGB und die generelle rechtspolitische Frage, ob der Staat an einer Rechtsnorm festhalten soll, die er für obsolet und nicht mehr erforderlich hält. Vgl. zur rechtspolitischen Frage den Aufsatz Heinke, ZRP 2016, S. 121-122.

824 StA Mainz, 4.10.2016, 3113 Js 10220/16. Vgl. zur strafrechtlichen Bewertung Kühling, FS Kirchberg 2017, S. 111-126 m.w.N.

825 Fahl, ZUM 2016, S. 313, 316; Kühling, ebd., S. 115 m.w.N.

826 LG Hamburg, 17.5.2016, 324 O 255/16, ZUM 2016, S. 774, 775.

827 LG Hamburg, ebd., S. 775.

828 LG Hamburg, 10.2.2017, 324 O 402/16, BeckRS 2017, 101443, Rn. 33-42.

829 so z.B. Hoßbach, ZUM-RD 2017, S. 417 f.; Hermann, AfP 2017, S. 177, 181. 
gung von Meinungsfreiheit und Persönlichkeitsrecht entwickelt wurden, entweder nicht gerecht zu werden oder wie beispielsweise die Idee der Reizüberflutung vollständig unbeachtet zu lassen. ${ }^{830}$

Trotz aller gesellschaftlicher und in den juristischen Fachzeitschriften geäußerten Kritik wurde das Urteil des LG und so auch dessen getrennte Prüfung, die eine teilweise ungerechtfertigte Persönlichkeitsrechtsverletzung feststellte, vom OLG Hamburg bestätigt. ${ }^{831}$ Das Gericht will auch aus der edukatorischen Einbettung heraus die Persönlichkeitsrechtsverletzung mit dem Argument nicht rechtfertigen, denn es handele sich nicht um eine „vorlesungs- oder seminarähnliche Demonstration möglicher Arten von Meinungsäußerungen, sondern [um] eine konkret auf den Kläger bezogene Kritik an dessen Person, die in Form einer Anhäufung zuvor als unerlaubt charakterisierter Beschimpfungen erfolgt. " ${ }^{\text {"832 }}$ Für eine ausführliche Besprechung dieser Entscheidungen kann auf die entsprechenden Aufsätze verwiesen werden. ${ }^{83}$

Die Revision zum BGH war nicht zugelassen worden, die Nichtzulassungsbeschwerde am BGH wurde abgewiesen. ${ }^{834}$ Eine Verfassungsbeschwerde Böhmermanns ist laut der Presseberichterstattung hingegen am BVerfG anhängig. ${ }^{835}$ Für diesen Fall, in dem Satire genutzt wird, um zu zeigen, was Satire und deren Grenze - die Schmähkritik - ausmacht, bleibt insofern auf die Klärung durch das BVerfG zu warten.

\section{II. „Nazi-Schlampe“: Die Satire als Argument}

Alice Weidel wurde am 23. April 2017 zur Spitzenkandidatin der Partei "Alternative für Deutschland“ (AfD) gewählt. In ihrer Dankesrede forderte die Politikerin, dass die Mitglieder der AfD sich als „Demokraten und

830 Hoßbach, ebd; Vgl. zu den Kriterien hier Kap. 3, E., III.

Es ließe sich auf die Form der Satire ein Blick werfen. Ein Gedicht ist eine literarische Ausdrucksform und es darauf hingewiesen, dass gerade ein Schmähgedicht geschichtlich mit der Satire verbunden ist, bedenkt man, dass das römische Spottgedicht von der Wissenschaft als eine historische Grundlage der Satire begriffen wird. Vgl. dazu Kap. 2, D., I.

831 OLG Hamburg, 15.5.2018, 7 U 34/17, BeckRS 2018, S. 8374.

832 OLG Hamburg, ebd., Rn. 33.

833 Götting/Schertz/Seitz/Hösch, Handbuch Persönlichkeitsrecht, $\mathbb{2 1}$, Rn. 10; Fahl, NStZ 2016, S. 313, 318; Faßbender, NJW 2019, S. 705, 709; Rusch/Becker, AfP 2016, S. 201, 204; Hoßbach, ZUM-RD 2017, S. 417-419, jeweils m.w.N.

834 BGH, 30.7.2019, VI ZR 231/18.

835 BVerfG, 1 BvR 2026/19. 
Patrioten nicht den Mund verbieten lassen“ sollten und „politische Korrektheit auf den Müllhaufen der Geschichte“ gehöre. "836 Darauf reagierte Christian Ehring in der Sendung „extra 3“ vom NDR am 27. April 2017 mit den Worten: „Jawoll, Schluss mit der politischen Korrektheit. Lasst uns alle unkorrekt sein. Da hat die Nazi-Schlampe doch recht. War das unkorrekt genug? Ich hoffe. “837

Alice Weidel wendete sich gegen die Äußerung „Nazi-Schlampe“ und machte einen Unterlassungsanspruch geltend. ${ }^{838}$

Diese umstrittene Äußerung enthält zum einen das Wort „Nazi“ und zum anderen den Begriff „Schlampe“, zwei Ausdrücke, die für sich genommen und erst recht in der Kombination geeignet sind, jemanden in seiner Persönlichkeit herabzusetzen. Erst wenn die mehrminütige Sendungssequenz, also der Gesamtzusammenhang in der Wertung berücksichtigt wird, lässt sich die Aussage einordnen. Wie das LG Hamburg dann auch ausführt, nimmt der Moderator Christian Ehring ausdrücklich Bezug auf die Äußerung von Alice Weidel, dass politische Korrektheit auf den Müllhaufen der Geschichte gehöre. Er wählt gezielt eine bereits wegen der besonders scharfen Wortwahl im Allgemeinen politisch - und auch allgemein in der Gesellschaft - nicht akzeptierte Formulierung, um zu zeigen, wohin eine solche Forderung der Antragstellerin führen könne. ${ }^{839}$ Dem Zuschauer wird auch deutlich, dass sie keinen Anlass für die Bezeichnung als „Schlampe“ gegeben hatte. Ganz im Gegenteil wurde vor dem umstrittenen Satz in der Sendung betont, dass Frau Weidel in einer festen Partnerschaft mit zwei Kindern lebe. Gerade der promiskuitiven Konnotation des Begriffs wurde insofern entgegengesteuert. Einen Vergleich mit der Entscheidung zum „Schmähgedicht" von Jan Böhmermann lehnt das Gericht jedoch in einer knapp gehaltenen Formulierung ab, die besagt, dass die beiden Fälle sich in ihrer Schwere erheblich unterscheiden würden. ${ }^{840}$

Der Fall Alice Weidel ist ein gutes Beispiel für die Möglichkeit, dass eine satirische Äußerung selbst zu einem Argument werden kann, das gegen die Aussage des Klägers, hier die AFD-Politikerin Alice Weidel, vorgebracht werden kann. Wie eine detaillierte Betrachtung zeigt, nutzt der Satiriker nämlich nichts anderes als ein argumentum ad absurdum, um der

836 Rede von Dr. Alice Weidel zum 6. ordentlichen Bundesparteitag, 26.4.2017, ab

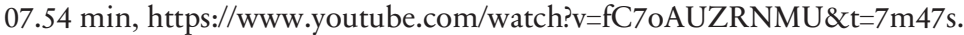

837 https://www.youtube.com/watch?v=R5ZcZZF--Vg.

838 Vgl. LG Hamburg, 11.5.2017, 324 O 217/17, ZUM-RD 2017, S. 630.

839 LG Hamburg, ebd., Rn.11. Vgl. auch für eine etwas ausführlichere Besprechung des Urteils die Anmerkung Klobusch, ZUM-RD 2017, 631-633.

840 LG Hamburg, 11.5.2017, 324 O 217/17, ZUM-RD 2017, S. 631, Rn. 19. 
- für ihn aberwitzig anmutenden - Forderung, die politische Korrektheit abzuschaffen, zu begegnen. So ließe sich auch vertreten, dass die Ansicht des Satirikers durch die Klage der Politikerin eher bekräftigt wurde. Denn ohne politische Korrektheit käme es zu einer unerwünschten Verrohung der Sprache, die zutiefst beleidigende Ausdrücke, wie zum Beispiel „NaziSchlampe“ erst ermögliche.

\section{III. „Darf ich zuspitzen“: Der Kontextbezug}

In der Satiresendung „Die Anstalt“ des ZDF vom 29. April 2014 beschäftigten sich die Kabarettisten Max Uthoff und Claus von Wagner mit dem Thema Sicherheitspolitik und hinterfragten die Unabhängigkeit der journalistischen Meinungsbildung. In einem Dialog verwendeten sie zur Veranschaulichung - wie es im Laufe der vorhergehenden Folgen dieser Sendung bereits zu einem festen Format geworden war - ein Whiteboard, auf welchem die Teilhabe von Journalisten an NATO-freundlichen, sicherheitspolitischen Netzwerken, Thinktanks, Organisationen wie der Atlantik-Brücke oder des German Marshall Fund of the United States und insofern die mangelnde Unabhängigkeit der in Frage stehenden Journalisten, grafisch veranschaulicht wurde. Am unteren Rand der Schautafel befanden sich Bilder einer Reihe bekannter Journalisten, unter anderem die Fotografien eines Mitherausgebers sowie eines Journalisten der deutschen Wochenzeitung „Die Zeit“. Der Herausgeber wurde auf dem Whiteboard mit acht der zwölf genannten Organisationen in Verbindung gebracht, der Journalist mit drei Netzwerken. Im dialogischen Rednerwechsel wurden die abgebildeten Journalisten und Organisationen knapp vorgestellt und die jeweilige Teilhabe angerissen.

Die beiden „ZEIT"-Mitarbeiter gingen gegen die Verbreitung im einstweiligen Rechtsschutzverfahren vor. In den beiden parallellaufenden Verfahren erwirkten die Journalisten jeweils, dass das ZDF nicht mehr verbreiten durfte, dass der Herausgeber mit acht der genannten Organisationen verbunden sei. ${ }^{841}$ Die Organisationszugehörigkeit von acht bzw. drei Organisationen ergaben sich aus der Anzahl der Linien, mit denen auf dem Whiteboard die Personen mit den Organisationen in verbunden wurden. Im Falle des Journalisten ging es im Kern um die Teilhabe an dem Projekt „Elemente einer außenpolitischen Strategie für Deutschland“, welches durch den German Marshall Fund of the United States (GMF) und

841 Vgl. BGH, 10.1.2017, VI ZR 561/15. 
der Stiftung Wissenschaft und Politik (SWP) initiiert sowie durchgeführt wurde und in welchem ein Strategiepapier erarbeitetet wurde. Am 31. Januar 2014 hielt der ehemalige Bundespräsident Joachim Gauck eine Rede vor der Münchner Sicherheitskonferenz, in welche die Gedanken des Strategiepapiers einflossen. Über diese Rede schrieb der benannte Journalist in einem gemeinsam mit einem weiteren Autor verfassten Artikel für die „ZEIT“. Darin befasste er sich wohlwollend mit der Rede und berichtete - zur Erläuterung der Vorgeschichte des „Kurswechsels“ - über die Arbeit der Strategiegruppe. Seine eigene Teilnahme an dem Projekt legte er in diesem Artikel nicht offen. ${ }^{842}$ Dies führte letztlich zu einer bundesweiten Diskussion über die journalistische Berufsethik und die Grenzziehung zwischen politisch-beratender und journalistischer Tätigkeit. ${ }^{843}$ Der Journalist strengte die Klage insofern wegen der Aussagen der Kabarettisten an, dass er Mitglied, Beirat oder Vorstand von drei Organisationen sei und dass er „im Zusammenhang mit der Rede des Bundespräsidenten Gauck vor der Münchner Sicherheitskonferenz für den Bundespräsidenten geschrieben [habe]“. 844

Nachdem das LG Hamburg der Klage des Journalisten gegen die Satiresendung nur teilweise stattgab und die Klage des Herausgebers abwies, entschied das Hamburger OLG in beiden Fällen vollständig zulasten des Satireformats des ZDF. Der BGH hingegen hob in beiden Fällen die Berufungsurteile in allen Punkten auf ${ }^{845}$ und bezog sich in beiden Entscheidungen zunächst auf die für die satirische Äußerung herausgearbeitete Herangehensweise, nach der der zugrundeliegende Aussagekern von seiner satirischen Verzerrung, Verfremdung und Überspitzung zu befreien sei. ${ }^{846}$ Dieser gewonnene Aussagekern und die satirische Einkleidung sind anschließend getrennt und mit entsprechend unterschiedlichen Maßstäben zu überprüfen, wobei gerade die Bewertung der Einkleidung unter weniger strengen Prämissen zu erfolgen habe als die Bewertung des Aussagekerns. ${ }^{847}$ Dieses Vorgehen des BGH steht mit der ständigen

842 BGH, 10.1.2017, VI ZR 561/15; BGH, 10.1.2017, VI ZR 562/15, NJW 2017, S. 1617.

843 S. BGH, 10.1.2017, VI ZR 562/15, NJW 2017, S.1618. Vgl. zur gesellschaftlichen Diskussion beispielsweise zusammenfassend: Klöckner, Leitartikler und Machteliten, Telepolis, 23.5.2014.

844 BGH, 10.1.2017, VI ZR 562/15, NJW 2017, S. 1618.

845 Vgl. auch zur Prozessgeschichte BGH, 10.1.2017, VI ZR 561/15; BGH, 10.1.2017, VI ZR 562/15, NJW 2017, S. 1617, 1618.

846 BGH, ebd., S. 1618, Rn. 14; BGH, 10.1.2017, VI ZR 561/15, Rn. 12.

847 BGH, ebd.; BGH, ebd. 
Rechtsprechung, wie es schon im dritten Kapitel ausgeführt wurde, im Einklang.

Ferner stellt der BGH klar, dass es für die rechtliche Beurteilung, sofern der satirische Beitrag eine unrichtige Tatsachenbehauptung enthält, zu berücksichtigen sei, ob für den Empfänger erkennbar sei, dass es sich dabei um eine für die Satire typische Verfremdung oder Übertreibung handele, er sie also für seine Meinungsbildung bewertend einordnen könne, oder ob er vielmehr zu der irrigen Einschätzung kommen könne, die Aussage sei tatsächlich wahr. ${ }^{848}$ Nur eine Satire, die man als solche zuordnet, kann verstanden werden. Hier machen die Kabarettisten gerade durch die Einleitung „Darf ich zuspitzen“ den Rezipienten auf die Verfremdung in Form der Verkürzung auf die satirische Einkleidung aufmerksam. Auch lassen sich einzelne Aussagen des Dialogs nicht isoliert betrachten. In der Zusammenschau der Dialogteile wird die Kritik deutlich, der einzelne Satz kann dabei verkürzt oder eben zugespitzt sein. ${ }^{849}$

Die Stärke dieser Entscheidungen wird darin gesehen, dass der BGH den Gerichten für künftige Verfahren relativ klare Anknüpfungspunkte zur Erfassung des objektiven Sinngehalts von Äußerungen im Rahmen eines satirischen Beitrags an die Hand gebe. ${ }^{850}$

\section{Zwischenfazit}

Dem unterschiedlichen Medium geschuldet, ergeben sich auch Unterschiede in der Wirkung der Satire, die bei einer Beachtung von werk- bzw. satirebezogenen Maßstäben durchaus relevant werden.

Erstens handelt es sich bei einer Satirezeitschrift und einer Satiresendung um ein eindeutiges der Satire zugeschriebenes Medium. Der Rezipient erwartet eine satirisch eingekleidete und so eben auch überzeichnete Kritik an einem bestehenden Missstand oder Ungleichgewicht. Damit eng verwandt ist die Tatsache, dass die genannten Fernsehshows und das ge-

848 BGH, ebd. und BGH, 10.1.2017, VI ZR 561/15, Rn.12, jeweils mit Verweis auf BVerfG, 14.2.2005, 1 BvR 240/04, GRUR 2005, S. 500, 501 - satirische Fotomontage, vgl. dazu auch Kap. 3, B., I.

849 BGH, 10.1.2017, VI ZR 562/15, NJW 2017, S. 1617, 1619, Rn. 17.

850 So z.B. die beiden Münchner Richter am Landgericht Grau und Bose in ihrer Entscheidungsanmerkung zum besprochenen Fall, Anm. zu BGH NJW 2017, S. 1617, 1620. Von der Literatur wird der Entscheidung jedoch vorgeworfen, dass die werkspezifischen Besonderheiten dieser Satire zu kurz kommen. Brauneck, ZUM 2017, S. 432 f. 
druckte Satiremagazin in der Regel auch nur von einem „satirewilligen“ Rezipienten konsumiert wird. Dieser setzt sich der Satire bewusst und voller Neugier und Erwartung aus. Ein homogenes Zusammenspiel von Satire und Publikum dieser Art findet bei der Rezeption der Politsatire-Plakate von Staeck nicht statt. Seine Satire agiert im öffentlichen Raum: Die konkurrierenden Plakate bewerben Produkte, die vorbeilaufenden Passanten reagieren und rezipieren eher zufällig, wahrscheinlich sogar irritiert, da sie sich ja gar nicht auf Satire eingestellt haben.

Zweitens steht bei satirischen Fernsehformaten das gesprochene Wort im Vordergrund. Dieses ist flüchtig, kurzweilig und durch die Vielzahl an audiovisuellen Sinneseindrücken, die durch einen Schnitt von Ton und Bild, der meistens in knappen Sequenzen durchgeführt wird, verstärkt werden, für den Rezipienten auch deutlich schwieriger aufzunehmen als das statische und allein mit dem Auge wahrzunehmende Plakat. Der durchschnittliche Betrachter eines Plakats wird insofern nicht alle Details in der Schnelle wahrnehmen.

In dem Fall zur Kabarettsendung „Die Anstalt“ 29. April 2014 stellt der BGH ganz in diesem Sinne klar, dass der durchschnittliche und verständige Zuschauer, wenn man die satirische Verkürzung außer Acht lasse, erkenne, worin die Kritik liege. Angesichts der Vielzahl der auf einen Moment verdichteten Eindrücke entnehme der verständige Zuschauer der von ihrer satirischen Einkleidung befreiten Darstellung nur die - als solche ja zutreffende - Aussage, es bestünden überhaupt wie auch immer geartete Verbindungen zwischen den Abgebildeten und den in der Sendung genannten Organisationen. ${ }^{851}$

Wurden die erstgenannten Entscheidungen („Schmähgedicht“ und „Nazi-Schlampe") mit dem Argument kritisiert, dass die Prüfung der Satire nach dem Maßstab der Entkleidung des Aussagekerns und der anschließenden getrennten Prüfung von Aussagekern und Einkleidung nicht gerecht wurde, gilt die letztgenannte Entscheidung zur Sendung „Die Anstalt" eher als hilfreich für die Prüfung von satirischen Äußerungen.

851 Vgl. BGH, 10.1.2017, VI ZR 561/15; BGH, 10.1.2017, VI ZR 562/15, NJW 2017, S. $1617,1618$. 


\section{Siebtes Kapitel: Ausblick: Neue Problemfelder des Plakats und der Satire}

\section{A. Die Zukunft des Plakats}

\section{Das Plakat ist tot}

Man könnte meinen, dass das reine Werbeplakat, das auf Papier gedruckt auf öffentliche Werbeflächen geklebt wird, bald nicht mehr existieren wird. Inzwischen arbeitet, recherchiert und konsumiert beinahe jeder an seinem Computer mit Hilfe des Internets. Das Verhalten des einzelnen Nutzers generiert dabei im Hintergrund personenbezogene Daten. Diese Nutzerdaten werden intelligent verknüpft und kommerzialisiert, um für personalisierte Produktwerbung eingesetzt zu werden, die nicht nur auf das individuelle Konsumverhalten, sondern zuweilen auch auf die individuelle Kaufkraft abgestimmt ist. Eine denkbare Folge dieser Entwicklung könnte also tatsächlich sein, dass das werbende Warenplakat in gedruckter und plakatierter Form bald nur noch im Museum als Dokument der Zeitgeschichte oder der historischen Werbegrafik zu finden sein wird.

Das künstlerische Politsatire-Plakat würde in diesem Fall kaum noch eine Zukunft haben, denn es lebt naturgemäß vom Spiel mit den Inhalten, Mechanismen und Stilmitteln des Werbeplakats. Auch muss in diesem Zusammenhang bedacht werden, dass das satirisch-politische Plakat in seiner Wirkungsmöglichkeit zeitlich beschränkt ist: Die Aussage des politischen Plakats, das sich naturgemäß auf aktuelle Ereignisse bezieht, verliert nach einer gewissen Zeit, nämlich ab dem Moment, an dem der Betrachter den politischen Bezug nicht mehr herstellen kann und damit die Satire nicht mehr verstehen kann, ihre Wirkung: Das satirische Werk wandelt sich zu einem historischen Zeitzeugnis.

Ist die Annahme, das Plakat würde sich im digitalen Zeitalter überleben, also wirklich berechtigt? Trägt im Zusammenhang dieser Annahme die Behauptung, dass die bewerbenden Aussagen zu einem Produkt, die auch die Grundlage für die Gestaltung eines traditionellen Plakats bilden, in viel einfacher, variabler und schnellerer Form digital verbreitet werden könnten?

Vielleicht nein: denn gerade im digitalen Raum lebt die innere, nämlich konzeptuelle Struktur des Plakats weiter. So erleichtern der Rechner und 
die Ressourcen des Internets die Re-Kombination und Neu-Kontextualisierung von Bildern. Digitale Werkzeuge wie beispielsweise das Bildbearbeitungsprogramm Photoshop in Verbindung mit der im Netz stetig wachsenden und somit nahezu unerschöpflichen Bildersammlung vereinfachen die Herstellungsverfahren von Bild-Text-Montagen, die ja ganz im Sinne der Arbeiten Heartfields oder der Staeck-Plakate gestaltet sein können.

So können im Bereich der digitalen satirischen Bildmontage gewisse Merkmale herausgearbeitet werden, die in ihrer Regelhaftigkeit mit dem Aufbau der Staeck-Plakate vergleichbar sind. Denn auch in den digitalen Medien muss Satire als solche erkannt werden. Dies ist besonders einfach, sobald die Merkmale, die sich im Rahmen der analogen Text-Bildsprache zur Kennzeichnung von Satire etabliert haben, unmittelbar in die digitale Form übernommen werden. Formale Gestaltungsprinzipien der analogen Welt werden im Rechner häufig in annähernd mimetischem Sinne kopiert, so wie beispielsweise das Bildschirm-Layout einer Nachrichten-Seite und insbesondere einer E-Paper-Ausgabe der Tageszeitungen und Zeitschriften in vielen Fällen dem Layout der Druckversion angeglichen wird. ${ }^{852}$ Ganz in diesem Sinne entsprechen die sogenannten Memes ${ }^{853}$ einem einfachen, mit Text- und Bildbestandteilen gestalteten analogen Plakat. Unabhängig von der Gestaltung des Layouts lassen sich darüber hinaus Memes in überzeugender Form das Verhältnis von Text- zu Bildelementen analysieren und einordnen, d.h. mit der gleichen Methode untersuchen, wie sie hier in Kapitel vier vorgeführt wurde. Auch im Bereich der Politik lässt sich übrigens beobachten, dass sich die digitale Wahlwerbung - und zwar über die Parteigrenzen hinweg - überwiegend der Text- und Bildsprache des traditionellen Plakats bedient.

II. Es lebe das Plakat

1. Das Wahlplakat der Satire-Partei

Der Inbegriff des satirischen politischen Wahlplakats sind sicherlich die Wahlplakate der Satire-Partei „Die PARTEI“, die zwar in der Text- und

852 Vgl. dazu z.B. die Print-Version der New York Times mit der Website www.nytimes.com, in der neben dem typografisch entsprechenden Titel („New York Times"), der Datumsangabe am linken Rand auch die jeweiligen Nachrichtenberichte mit Längs- und Querbalken gesetzt werden.

853 Vgl. zu Memes auch Kap. 7, B., II. 
Bildsprache ihrer Pendants aus Papier konzipiert, jedoch digital verbreitet werden. Auf diese Partei kann hier nicht eigens eingegangen werden, denn damit würde eine neue Kategorie eröffnet: Einer auf Satire angelegten politischen Partei. ${ }^{854}$ Doch es sei zumindest angemerkt, dass ihre Wahlplakate einen den Plakaten von Klaus Staeck verwandten strukturellen Aufbau besitzen. Für den Europawahlkampf 2019, in dem Klimaschutzbelange eine maßgebliche Bedeutung hatten, wurde ein Plakat von der Partei „Die PARTEI“ verbreitet, in dem zwischen den Textteilen „Alle reden vom Klima“ und "Wir machen es“ die Fotografie eines vierstrahligen Flugzeugs montiert ist, das am Himmel einen langen Kondensstreifen hinterlässt. ${ }^{855}$ Und so lebt - angestoßen durch zwei Plakate von Klaus Staeck aus den Jahren 1981 und 1990 - ein weiteres Mal die Werbekampagne der Bundesbahn von 1966 auf.

\section{Adbusting und Street Art in der Tradition Staecks}

Wurde zuvor die Frage erörtert, ob das Plakat im öffentlichen Raum womöglich durch rein digitale Werbeangebote abgelöst werden könne, ist dieser Überlegung darüber hinaus entgegen zu halten, dass es trotz des Internets immer noch Plakatwerbung im öffentlichen Raum gibt. Dem Plakat wird weiterhin gewichtige Vorteile zugeschreiben. Vor allem - und das darf nicht unterschätzt werden - lässt sich die Plakatwerbung im öffentlichen Raum nicht filtern, blocken oder überhören. Es kann ihr kaum aus dem Weg gegangen werden. So verwundert es nicht, dass Künstler, Kollektive und Bürgerinitiativen mit ganz unterschiedlicher Ausrichtung Außenwerbung als „visuelle Umweltverschmutzung“ 856 bezeichnen, sich gegen Werbung aussprechen oder sogar Werbeverbote im öffentlichen Raum fordern. ${ }^{857}$

Mit diesen Initiativen verwandt ist das sogenannte Adbusting. Bei diesem steht weniger ein werbefreies Stadtbild im Vordergrund als vielmehr

854 Siehe dazu Podskalsky, Jan Böhmermann und Die Partei, 2017.

855 Siehe https:/www.facebook.com/dieparteikarlsruhe/photos/a.284674978340910 /1438262112982185/?type=3\&theater.

856 https://www.instagram.com/p/BgcCx4Nj98s/?igshid=uf8s4tfja381; Plakat „Werbung ist visuelle Umweltverschmutzung“ im Schaukasten war auch Teil der Ausstellung des ZK/U Zentrum für Kunst und Urbanistik Berlin, Hacking Urban Furniture, 16.3.2018-25.3.2018, Berlin.

857 Vgl. die Initiative „Berlin werbefrei“, https://berlin-werbefrei.de. 
ein kritischer Umgang mit Werbeinhalten. Nur zwei Beispiele sollen die Bewegung des „Adbusting“ zunächst veranschaulichen:

Als erstes Beispiel dient eine Aktion von 2012. Der US-amerikanische Künstler Daniel Soares hatte die Werkzeugleiste des Bildbearbeitungsprogramms Photoshop der kalifornischen Firma Adobe als großen Aufkleber auf die Werbeplakate des schwedischen Textilunternehmens H\&M, auf welchen stark gebräunte und magere Models zu sehen waren, geklebt. ${ }^{858}$ Indem Soares die Werbefläche zum Abbild eines Bildschirms mit aktiviertem Bildbearbeitungsprogramm umdeutet, macht der Künstler subtil und zugleich pointiert auf die irreführende Makellosigkeit der Werbegesichter und auf das damit verbreitete unrealistische Schönheitsideal aufmerksam.

Das zweite Beispiel stammt aus dem Jahr 2017. Das bekannte Design der Zigarettenmarke Marlboro, das von Frank Gianninoto bereits 1955 entworfen worden war und ein rotes Markendach vor weißen Grund zeigt, wurde von dem Künstlerkollektiv „dies irae“ um $180 \mathrm{Grad}$ gedreht und mit der Aufschrift „Tabakwerbung ködert Kinder. Volker Kauder will, dass es so bleibt." versehen. Darunter erscheint in derselben Schrifttype der Verweis auf die Webseite „www.bit.ly/kauder“. ${ }^{859}$ Dieser Link führt zu dem Artikel „Schöner qualmen auf deutschen Litfaßsäulen“ des Nachrichtenmagazins „Der Spiegel“, der vom Streit um das Tabakwerbeverbot handelt, in welchem der langjährige CDU-Politiker Volker Kauder als die maßgebliche Kraft, die einen Gesetzesentwurf zum Bann von Zigarettenwerbung blockiert hat, genannt wird. ${ }^{860}$

Ziel des Adbustings ist, wie die genannten Beispiele gezeigt haben, die künstlerische Bearbeitung von Werbeplakaten, die dahingehend in ihren Aussagen verfremdet werden, dass sie die von den Werbemachern beabsichtigte Wirkung verfehlen oder sogar ins Gegenteil verkehren. 861 Das Adbusting wird als eine „subversive Dekonstruktionstechnik, die sich

858 http://danielsoares.me/work/hm-photoshop-adbusting.

859 Die Plakate waren 2017 in diversen Bahnhaltestellen in u.a. den Städten Hamburg und Marburg angebracht. Als Beispiel ein Foto von der Haltestelle Landungsbrücken abrufbar unter https://www.facebook.com/nervtjeden/photos/a.3 $52851681566644 / 662821490569660 /$ type $=3 \&$ theater.

860 http://www.spiegel.de/wirtschaft/service/zigarettenlobby-volker-kauder-blockiert -gesetz-gegen-tabakwerbung-a-1137549.html.

861 Vgl. zu den Definitionen BT.-Drucks. 19/16887, S. 1; Beaugrand, Adbusts, Kunst und Kommunikation, in: Beaugrand/Smolarski (Hrsg.), Adbusting. Ein designrhetorisches Strategiehandbuch, 2016, S. 8 f. 
in ihrer rhetorischen Dimension am Gebrauch rhetorischer Strategien der Werbung selbst orientiert" bezeichnet. ${ }^{862}$

Entweder handelt es sich um eine einfache Überarbeitung, wie sie durch den Aufkleber in dem ersten Beispiel erzielt wurde, oder um ganz neu geschaffene Plakate im Stil eines verfremdeten Werbeplakats, wie das zweite Beispiel zeigt. Gemein haben sie, dass sie häufig satirisch sind, da sie ein gesellschaftlich anerkanntes Ungleichgewicht - bei den hier vorgestellten Beispielen manipulierte Schönheitsideale und staatlich geschützte Tabakwerbung - mit Hilfe der Montage geistreich und gewitzt aufzeigen.

Ähnlich aufgebaute Plakatkampagnen waren auch Gegenstand des Verfassungsschutzberichts von 2018, in dem Adbusting-Aktionen unter „II. Gewaltorientierter Linksextremismus“ gelistet wurden. ${ }^{863}$ Als Beispiel einer solcher Form des Linksextremismus werden Plakate gegen die Berliner Polizei benannt. Laut diesem Bericht sind die zugrunde liegenden Plakate, mit welchen die Berliner Polizei für sich selbst wirbt, „so verfremdet, dass damit der Polizei willkürliche Gewaltausübung, „institutioneller Rassismus“ und die Absicherung bestehender „Ausbeutungsverhältnisse“ unterstellt werden würde. ${ }^{864}$ Diese Einschätzung wird mit einem Plakatbeispiel untermauert, auf dem zu lesen ist „Da für 5003 Schlagstockeinsätze und die beste G20-Party. Da für Gewalt.". 865 Adbusting dient dem politischen Protest. Es wird „phänomenologisch [...] dem Bereich der gewaltfrei operierenden Kommunikationsguerrilla" zugeordnet. ${ }^{866}$ Das Adbusting wird in dem Verfassungsschutzbericht dem linken Spektrum der politischen Meinungsbildung zugeordnet. Diese eindeutig linke politische Ausrichtung mag im Einzelfall vorliegen, aber es werden im Zusammenhang des Adbusting ebenso Themen angesprochen, die im politischen Meinungsspektrum nicht formuliert werden und damit eine eindeutige parteipolitische Zuordnung nicht erkennen lassen.

Die genannten Adbusting-Beispiele bedienen sich also der Werbesprache, um im Wege eines Anti-Werbeplakats ihre Botschaft zu verbreiten. Genau darin liegt eine große Gemeinsamkeit zu den Plakaten Staecks. Ähnlich wie bei den Staeck-Plakaten mit der satirischen Wahlwerbung ${ }^{867}$

862 Smolarski, Werbeparasiten und Designrhetorik. Eine Einleitung, in: Beaugrand/Smolarski (Hrsg.), Adbusting. Ein designrhetorisches Strategiehandbuch, 2016, S. 37.

863 Verfassungsschutzbericht 2018, S. 118, $126 \mathrm{f}$.

864 Verfassungsschutzbericht 2018, S. 127.

865 Verfassungsschutzbericht 2018, S. 127.

866 BT.-Drucks. 19/16887, S. 1.

867 Vgl. dazu Kap. 5, B., I. 
kann es auch im ersten Moment unklar bleiben, wer der Urheber ist. Nichtsdestotrotz gibt es offenkundig - auch bei aller struktureller Ähnlichkeit zwischen Staeck und den genannten Beispielen - einen gravierenden Unterschied. Staeck mietete Werbefläche für die Verbreitung seiner Plakate offiziell an, Adbusting-Plakate zeichnen sich ganz elementar dadurch aus, dass sie bestehende Plakate überkleben, verfremden oder sich sonst, ohne für die Werbefläche ein Entgelt zu zahlen, dieser bedienen. Ein wirtschaftlicher Schaden kann so unter Umständen bei dem überklebten werbenden Unternehmen als auch bei dem Unternehmen, das die Werbeflächen unterhält, eintreten. Aus strafrechtlicher Sicht kann das Adbusting unter $\$ 303$ StGB und, sofern ein Werbeplakatschaukasten mit einem Steckschlüssel geöffnet wird und das darin befestigte Plakat nicht nur überklebt, sondern mitgenommen wird, auch der Diebstahl in einem besonders schweren Fall nach $\$ 242$ Abs. 1 i.V.m. $\$ 243$ Abs. 1 S. 2 Nr. 2 StGB fallen. Das gegen einen der Künstler aus dem Kollektiv „dies irae“ geführte Strafverfahren wegen u.a. des besonders schweren Falls des Diebstahls wurde jedoch gegen eine Auflage eingestellt. ${ }^{868}$

\section{B. Ausblick: politische Satire und politische Manipulation}

Die Satire oder das Satirische ist nicht nur als Gegenstand der wissenschaftlichen Bewertung interdisziplinär angelegt, sondern auch in ihren Erscheinungsformen selbst. Wurden in den vorangegangenen Kapiteln immer wieder auch andere Medien als das Politsatire-Plakat angesprochen, stan-

868 Der Tatvorwurf bezog sich auf das Anbringen von Plakaten in Werbeschaukästen eines Unternehmens, die mittels eines Steckschlüssels geöffnet wurden. Die Plakate "Nazis essen heimlich Falafel“, „lieber solidarisch als solide arisch“, „wer kein Selbstbewusstsein hat, braucht ein Nationalbewusstsein“ (jeweils in Großbuchstaben) und „Der Fuchs ist schlau und stellt sich dumm. Der Nazi macht es andersrum" wurden gegen Werbeplakate ausgetauscht, die in keiner inhaltlichen Beziehung zu den angebrachten Plakaten standen. Vor der türkischen Botschaft wurde das Plakat „\#mimimimimi \#freeboehmi \#satiredarfalles \#humorlose kackbratze“ während der sogenannten Böhmermann-Affäre angebracht. Das Verfahren stand in öffentlicher Kritik, da die vierjährige polizeiliche Ermittlung mit Hausdurchsuchungen und Beschlagnahmungen, gerade weil das Werbeschaukasten-Unternehmen keinen Strafantrag stellte, als überzogen eingeschätzt wurde. Vgl. https://www.instagram.com/p/B3Rdfxrn9Z0/?igshid=2 h0j8ge480f2; https://www.facebook.com/nervtjeden/photos/a.35285168156664 4/1175677405950730/?type=1\&theater; Nowak, Satire oder Sachbestätigung, taz, 8.10.2019; ders., Gefährdet Adbusting die Grundordnung, telepolis, 9.10.2019. 
den aber dann - wie im sechsten Kapitel - hauptsächlich die rechtlichen Aspekte im Vordergrund. Im Rahmen dieses Kapitels wird die Satire in aktuellen Erscheinungsformen untersucht. Dazu werden knapp satirische Fernsehformate aus einem medienwissenschaftlichen Blick heraus betrachtet (I.), um anschließend das Feld der nutzergenerierten satirischen Inhalte anzureißen (II.). Zuletzt wird ein weiterer Fall zum Problem der Erkennbarkeit der Satire besprochen, der zu der Frage nach der Abgrenzung von satirischen Nachrichten und Fake News führt (III.).

\section{Die Satire im Fernsehformat}

Genauso wie die Literaturwissenschaft die Elemente der Satire in den schriftlich und mündlich fixierten Sprachzeugnissen untersucht, findet mittlerweile eine umfangreiche Forschungsarbeit ebenso zur Satireform in anderen Medien statt. ${ }^{869}$ In Bezug auf satirische Fernsehformate ist die US-amerikanische Forschung federführend, da in den USA seit den 1990er Jahren eine Vielzahl an humoristischen bzw. satirischen politischen Kommentatoren und Sendungen existieren, deren Formate mit zeitlicher Verzögerung in andere Märkte, so auch in Deutschland, übernommen wurden..$^{870}$

Die politische Satire setzt aber zunächst politisches Wissen voraus. Je größer und damit heterogener die angesprochene Zielgruppe ist, desto weniger Wissen kann vorausgesetzt werden. Während die Anzahl der Rezipienten satirisch-politischer Plakate im öffentlichen Raum schwer einzuschätzen ist, ist die Größe der Zielgruppe bei Auftragsarbeiten, expliziten Satire-Fernsehnischen-Programmen oder Satirezeitschriften eindeutig zu benennen. Deutsche Satirezeitschriften wie „pardon“ (1962-1982) und "TITANIC“ (seit 1979) oder auch das schweizerische, deutschsprachige Satiremagazin „Nebelspalter“ (seit 1875) weisen einen konstanten jedoch überschaubaren Leserstamm auf. ${ }^{871}$ Die entsprechenden Fernsehprogram-

869 Vgl. dazu z.B. Behrmann, Politische Satire im deutschen und französischen Rundfunk, 2002.

870 Beispielsweise genannt seien „Daily Show with Trevor Noah“, „Last Week Tonight with John Oliver“; „The Late Show with Stephen Colbert“ oder „Full Frontal with Samantha Bee“.

871 So hat die Titanic eine Auflage von 100.000 Stück. Vgl. https://runze-casper.de/a nzeigenservice/193-titanic-verlag-titanic-satiremagazin.html?ml=0. Als Vergleich: der fünfminütige Ausschnitt der Sendung „extra 3“ hat über 150.000 Aufrufe. Vgl. https://www.youtube.com/watch?v=R5ZcZZF--Vg. Der Song „Erdowie, 
me - seien es Kabarettsendungen („Die Anstalt" seit 2014, Nachfolger der Sendung „Neues aus der Anstalt“ 1979-2013), Late-Night-Shows („Neo Magazin Royale“ 2013-2019872) oder Formate der Nachrichtensatire („heute show" seit 2009 oder die bereits genannten US-amerikanischen Programme) sprechen - bedingt durch das Medium - ein weitaus größeres Publikum an. ${ }^{873}$

Die Ansicht, dass die Satire gerade in Form der Fernsehformate einen erheblichen Einfluss auf den Rezipienten und damit auch auf seine politische Meinungsbildung hat, ist vorherrschend. In der US-amerikanischen Forschung wird diese Annahme zum einem damit begründet, dass satirische Formate sehr präsent seien und durch ein erhöhtes Misstrauen gegenüber den klassischen Medien- und Nachrichtenformaten als eher vertrauenswürdig erachtet werden würden. ${ }^{874}$ Diesen Satireshows wird zugutegehalten, für eine große Öffentlichkeit Ereignisse und deren Hintergründe einerseits humorvoll, andererseits auf intellektuell anspruchsvollem Niveau aufzuarbeiten und auf diese Weise das kritische Denken zu fördern. ${ }^{875}$ Darüber hinaus wird der Satire eine ganz zentrale gesellschaftspolitische Rolle zugesprochen. So wird in einer Arbeit mit dem Titel „Is Satire Saving our Nation?" argumentiert, dass sich die Krise, in der sich die Demokratie in den USA seit 2001 befinde, erst mit der Hilfe des satirischen Kommentars überwunden werden könne: „Satire is shaping a new version of democracy“. ${ }^{876}$ Die Gegenposition befürchtet jedoch, dass die satirischen Fernsehformate zu einem zynischen Politikverständnis führen und dieses festigen könnte. 877 Mag gerade für die letztgenannte These ein empirischer Nachweis fehlen, ist beiden Ansichten gemein, dass sie von einem erheblichen Einfluss der Satire auf die politische Meinungsbildung ausgehen. Ausgehend von der Frage nach dem Einfluss der Satire wurde in Bezug auf die relevanten Fernsehformate eine wertende Unterscheidung der Satire angestrengt. Als Erweiterung dessen soll demnach zwischen

Erdowo, Erdogan“ fast 15 Millionen Aufrufe. Vgl. https:/www.youtube.com/wa tch? $\mathrm{v}=\mathrm{R} 2 \mathrm{e} 2 \mathrm{yHj}$ _.mc.

872 Weiterführung der Show ab Herbst 2020 im ZDF Hauptprogramm.

873 Hinzukommt, dass teilweise ganz oder in Ausschnitten die Fernsehshows über das Internet auf Videoplattformen verbreitet werden.

874 McClennen/Maisel, Is Satire Saving our Nation?, 2014, S. 11.

875 McClennen/Maisel, ebd., S. 4.

876 McClennen/Maisel, ebd.

877 Baumgartner/Morris, American Politics Research, 34 (3), S. 362, 363. 
produktiver Satire, die aktuelles Geschehen hinterfragt, ${ }^{878}$ und pseudo-kritischer Satire, die vordergründig belustigen will, ${ }^{879}$ unterschieden werden.

\section{Formen der partizipativen Satire}

Die genannten Satireshows erlangen in der Form von kurzen Ausschnitten von einzelnen themenbezogenen Sequenzen, die im Nachgang zur Erst-Ausstrahlung im Fernsehen aus einer vollständigen Episode herausgenommen und in den Videoplattformen des Internets bereitgestellt werden, nicht zuletzt durch die Erwähnungen in den sozialen Netzwerken eine enorme Reichweite. So sind beispielsweise die US-amerikanischen Satireshows in Teilen global und so auch in Deutschland über Plattformen wie YouTube abrufbar. Aber auch das Adbusting oder andere satirische Plakate werden über das Internet von ihrer örtlichen Begrenzung befreit und erfahren so durch die Verlinkung in den Posts der sozialen Netzwerke eine große Verbreitung. ${ }^{880}$ In den Strukturen des Internets hat sich ein weiteres, für die Perspektive dieser Arbeit erwähnenswertes Phänomen entwickelt, nämlich die Verbreitung von Satireformen, die von nicht professionellen Nutzern gestaltet wird. Diese Satireformen zeichnen sich insbesondere dadurch aus, dass sich die klassische Verteilung der Rollen zwischen Anbieter und Rezipient auflöst. Ist es in der klassischen politischen Satire - wie im Falle Klaus Staecks - der Satiriker, der das Augenmerk des Rezipienten und damit der Öffentlichkeit auf einen bestimmten Aspekt richtet, sind es im Rahmen der hier partizipativ genannten Satire (auch User-generated satire - in Anlehnung an den Begriff des User-generated content - oder citizen satire bezeichnet) die Rezipienten und damit die Öffentlichkeit selbst, die Satire für ein häufig vergleichsweise kleines Publikum, also eine Mikro-Öffentlichkeit, schaffen. ${ }^{881}$ Diese werden über das Internet - sei es in sozialen Netzwerken, Chaträumen, Messenger-Diensten oder Foren verbreitet und können in ihrer Erscheinung sehr unterschiedlich ausfallen.

878 Vgl. dazu Lichtenstein/Nitsch, M\&K 2018, S. 5-21.

879 Vgl. auch die Untersuchung der Otto Brenner Stiftung von Gäbler, Quatsch oder Aufklärung, 2016.

880 Vgl. dazu die Instagram, Facebook und Twitter Accounts von „dies irae“ (beispielsweise https://www.facebook.com/nervtjeden/) oder auch der Partei „Die PARTEI“.

881 Vgl. dazu insbesondere zu User-generated satire im Rahmen von Fake Accounts in Italien die Untersuchung von Ferrari, new media \& society 2018, S. 22082223. 
Eine dieser Formen ist die Imitation des Internetauftritts von bekannten Persönlichkeiten, zumeist Politikern, durch die Einrichtung falscher Konten in den sozialen Medien wie augenblicklich „Twitter“ oder „Facebook“. Diese sogenannten „fake accounts“ sind aktuell beispielsweise in Italien sehr beliebt. ${ }^{882}$ Ein anderes, für die Perspektive der satirischen Ausdrucksformen hochrelevantes Internetphänom stellt das sogenannte Meme dar. Ein Meme (auch Mem) bezieht sich zunächst auf die besondere Art der viralen, also ungewöhnlich schnellen Ausbreitung. ${ }^{883}$ Der Begriff „Meme“ wird aber auch häufig synonym mit einer besonderen Erscheinungsform der Kombination (Montage) von Text- und Bildelementen verwendet. ${ }^{884}$ In dieser Bedeutung ist das Meme, vereinfacht gesprochen, die digitale Form des Plakats, auch wenn neben statischen Bildern nun ebenso Bewegtbild- und Tonsequenzen benutzt werden können. In dieser Arbeit wurde in Bezug auf die künstlerischen Politsatire-Plakate Klaus Staecks die Kombination von Bild und Wort bereits untersucht. ${ }^{885}$ Mit Hilfe der hier im 4. Kapitel gewonnenen Kriterien lassen sich in gleicher Weise Text-Bild-basierte Memes analysieren. Ein solches Meme arbeitet meist mit einer humoristischen Pointe, kann aber auch satirisch, politisch oder unpolitisch sein. Dabei entstehen häufig durch die Beteiligung weiterer Nutzer in kurzer Zeit eine ganze Reihe von Memes zum selben Thema. Zusammengehalten werden diese Beiträge durch den einheitlichen Hashtag. Als ein Internet-Phänomen dient das Meme allgemein der sehr schnell rezipierbaren, kurzweiligen Unterhaltung, da es von seiner zügigen Vermehrung und kreativen „Fortpflanzung“ lebt. ${ }^{886}$

882 Ferrari, new media \& society 2018, S. 2208-2223.

883 Erlehmann/Plomlompom, Internet-Meme, 2013, S. 8-14, v.a. S. 11. Die Autoren arbeiten als Ausnahme beispielsweise den sogenannten Computer-Virus heraus, da es an einem eigenen, bewussten Handeln fehlt; vgl. ferner auch Sava, Germanistische Beiträge, Bd. 43, 2018, S. 151-174.

884 In diesem Verständnis beispielsweise bei Bogerts/Fielitz, "Do You Want Meme War?" Understanding the Visual Memes of the German Far Right: Online Actions and Offline Consequences in Europe and the US, in: Fielitz/Thruston (Hrsg.), Post-digital Cultures of the Far Right. Online Actions and Offline Consequences in Europe and the US, 2019, S. 137-153. Auch wird der Begriff Meme so hauptsächlich in der rechtswissenschaftlichen Literatur verwendet, siehe Maier, GRUR-Prax 2016, S. 397; Wandtke, MMR 2019, S. 142.

885 Vgl. Kap. 4, C., II., 2.

886 Deswegen wird hier auf eine Besprechung von Beispielen verzichtet. 
Rechtlich relevant werden Memes einerseits bezüglich Fragen des Urheberrechts, wenn sich der Ersteller einer geschützten Vorlage bedient, ${ }^{887}$ und andererseits im Rahmen des Schutzes der Persönlichkeit, wenn z.B. Fotos einer Person verwendet werden. ${ }^{888}$ Auch in Rechtsstreitigkeiten bezüglich der satirischen Memes müssen die betroffenen Grundrechte im Falle der Kollision, immer auf den einzelnen Fall bezogen, abgewogen werden.

Politisch-satirische Memes haben ähnliche Funktionen wie die Satire im Allgemeinen, so wird auch diesem neuen Kulturphänomen eine zur politischen Teilhabe anregende Wirkung zugesprochen. ${ }^{889}$ Memes sind aufgrund ihrer Verbreitung und kreativen Fortpflanzung weitaus partizipativer ausgerichtet als ein Plakat im öffentlichen Raum. Aus diesem Grund ermöglicht eine Analyse der von unterschiedlichen Nutzern geschaffenen und verbreiteten Ketten politischer Memes auch Rückschlüsse auf die öffentliche Meinung. Das politische Satireplakat formuliert die Aussage einer einzelnen benennbaren Person, das Meme entwickelt sich hingegen zu einem Zusammenklang, der aus vielen Stimmen einer heterogenen Personengruppe, die sich spontan herausbildet, besteht. Wie bereits angesprochen wurde, kann die erschwerte Gleichsetzung einer Meinung mit

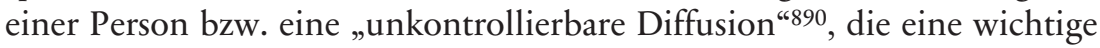
Eigenschaft der Viralität ausmacht, auch zur Verbreitung von „Fake News“ führen. ${ }^{891}$ Das Phänomen der Fake News und deren Abgrenzung zur Satire wird im Folgenden behandelt.

887 Vgl. Bauer, Die Aneignung von Bildern. Eine urheberrechtliche Betrachtung von der Appropriation Art bis hin zu Memes, 2020, S. 152 ff., $167 \mathrm{ff}$.

888 Vgl. Wandtke, MMR 2019, S. 143 f.

889 Johann/Bülow, Die Verbreitung von Internet-Memes: empirische Befunde zur Diffusion von Bild- Sprache-Texten in den sozialen Medien, kommunikation @ gesellschaft 19 (2018), S. 1-24, vgl. v.a. S. 19 f.

890 Johann/Bülow, ebd. S. 19.

891 Johann/Bülow, ebd.; vgl. auch Bogerts/Fielitz, "Do You Want Meme War?" Understanding the Visual Memes of the German Far Right: Online Actions and Offline Consequences in Europe and the US, in: Fielitz/Thruston (Hrsg.), Postdigital Cultures of the Far Right. Online Actions and Offline Consequences in Europe and the US, 2019, S. 137-153; Marwick, Georgetown Law Tech. Rev., 2018, S. 474-512. 
III. Satire und „Fake News“

Zunächst soll geklärt werden, um was es sich bei „Fake News“ handelt, um anschließend die Notwendigkeit einer Abgrenzung zwischen „Fake News" und Satire aufzuzeigen. Anschließend folgen anhand eines Beispiels Überlegungen zu Abgrenzungskriterien.

\section{Schritt 1: „Fake News“ und „Hate Speech“}

Mit dem Begriff der „Fake News“ werden zunächst Desinformationen allgemeiner Art bezeichnet. „Fake News“ sind unter anderem eng verwandt aber nicht zu verwechseln - mit den Phänomenen der sogenannten „Hate Speech" bzw. der "Social Bots“ und sie sind abzugrenzen von der versehentlichen, bzw. aus mangelnder Sorgfalt entstandenen Falschmeldung. Ebenso ist der Begriff „Fake News“ im hiesigen Verständnis von dem gleichnamigen US-amerikanischen politischen Schlagwort und Kampfbegriff zu unterscheiden. Nach dem US-amerikanischen Verständnis geht es um die Diffamierung der Presse, die ihr deutsches Äquivalent am ehesten in dem Ausdruck „Lügenpresse“ findet.

In der internationalen Forschung werden unter „Fake News“ Informationen verstanden, die als Nachrichtenartikel präsentiert werden, aber sowohl faktisch falsch sind als auch darauf abzielen, den Rezipienten in der Weise zu täuschen, dass er die Informationen für wahr hält. ${ }^{892}$ Diese Definition wird zuweilen enger gefasst. In einer empirischen Studie zu „Fake News“ im Rahmen des Bundestagswahlkampf 2017 wird für den Begriff die Absicht einen Schaden herbeizuführen vorausgesetzt: „Fake News“ sind danach „gezielt verbreitete falsche oder irreführende Informationen, die ,jemandem (Person, Gruppe oder Organisation“ Schaden zufügen sollen. ${ }^{893}$ Sie zeichnen sich durch Dekontextualiserung oder bewusst falscher Interpretation wahrer Informationen (misinterpreted content), Manipulation eigentlich wahrer Informationen (manipulated content) und völlig frei erfundener Inhalte (fabricated content) aus. ${ }^{894}$ Dem hinzuzufügen bleibt lediglich, dass der Anlass für solche „Fake News“ längst nicht oder

892 „Fake News is information, presented as a news story that is factually incorrect and designed to deceive the consumer into believing it is true" Golbeck/Mauriello/Auxier et al, Fake News vs Satire: Dataset and Analysis, WebSci' 18, S. 18.

893 Sängerlaub/Meier/Rübl, Fakten statt Fakes, 2018, S. 11.

894 Sängerlaub/Meier/Rübl, ebd. 
nicht nur in einem politischen Kalkül liegen muss, sondern meist eher durch wirtschaftliche Interessen ausgelöst wird. ${ }^{895}$ Mit Werbung verbundene „Fake News“ können mit den entsprechenden Aufrufen („Klick-Zahlen"), d.h. mit der entsprechend großen Zahl an Lesern im Internet, nicht unerhebliche Summen einspielen, so dass „Fake News" nicht in erster Linie politisch, sondern häufig kommerziell motiviert sind. ${ }^{896}$

Die Flut an „Fake News" und die damit verbundene Angst vor politischer Einflussnahme vor allem im Zusammenhang politischer Wahlen hat eine Reihe von Mechanismen zur Überprüfung von Nachrichtenangeboten ins Leben gerufen. So sind Fakten-Check-Seiten ${ }^{897}$ oder sogenannte „News Verification Browser“898 entstanden. ${ }^{899}$ Von Seiten des deutschen Gesetzgebers wurde in Bezug auf soziale Netzwerke mit dem NetzDG reagiert. ${ }^{900}$ In Bezug auf „Fake News“ ist auch die Sorgfaltspflicht der Presse, die im Grundgesetz in der Pressefreiheit verankert ist ${ }^{901}$ und in den jeweiligen Landesgesetzen seine Ausführung findet, zu beachten. Die Presse hat alle Nachrichten vor ihrer Verbreitung mit der nach den Umständen gebotenen Sorgfalt auf Wahrheit, Inhalt und Herkunft zu prüfen, statuiert beispielsweise $\$ 6$ LPresseG BW. Der Maßstab an die Sorgfaltspflicht - der wegen des Aktualitätsdrucks ${ }^{902}$ nicht zu hoch anzusetzen ist - ist in den Grenzen des Rechts der persönlichen Ehre zu halten. ${ }^{903}$

895 Vgl. Morawietz Alternative Fakten, Fake-News und Lügen, in: Kürschner (Hrsg.), Alternative Fakten, Fake News und Verwandtes, 2019, S. 57-82.

896 Vgl. dazu Braun/Eklund, Digital Journalism 2019, 7:1, S. 1-21.

897 ARD-Faktencheck; gemeinnützige GmbH correctiv.org; politifact für US-amerikanische Politik und Medien; mimikama.at Verein zur Aufklärung über Internetmissbrauch.

898 Rubin/Brogly/Conroy/Chen/Cornwell/Asubiaro, Journal of Open Source Software, 2019, 4 (35), S. 1208.

899 Ein Schwerpunkt in vor allem der computerlinguistischen Forschung ist die Unterscheidung zwischen Fake News und „echten“ Nachrichten. So wird die Aufgabe der „Fake news detection“ beschrieben als „die Vorhersage der Wahrscheinlichkeit, dass ein bestimmter Nachrichtenartikel absichtlich trügerisch ist (gefälschte, fabrizierte, inszenierte Nachrichten oder ein Hoax). Rubin/Chen/ Conroy, Deception detection for News: Three Types of Fakes, Proceedings of the ASIST Annual Meeting 2015, S. 1.

900 So wurde schon in dem Entwurf des Gesetzes „Fake News“ auch als Grund für dieses Gesetz genannt. Vgl. BT-Drucks. 18/12356, S. 1, 11, 12.

901 Vgl. zur Tragweite BVerfG, 9.10.1991, 1 BvR 1555/88, NJW 1992, S. 1439, 1142 - Bayer-Aktionäre.

902 Mangoldt/Klein/Starck/Starck/Paulus, GG, Art. 5, Rn. 141.

903 Mangoldt/Klein/Starck/Starck/Paulus, ebd. 
Von Falschmeldungen durch mangelnde Sorgfalt sind „Fake News“ über das subjektive Merkmal der Intention abzugrenzen. Bei mangelnder Berichtigung - auch nach erfolgter Nachfrage - wird eine solche Intention unterstellt. ${ }^{904}$ Landläufig werden auch „Fake News“ und Satire insofern über das Merkmal der Absicht unterschieden, da bei der Satire keine Böswilligkeit vorliegt. ${ }^{905}$ Die Schwierigkeit in der begrifflichen Definition von „Fake News" liegt auch darin begründet, dass der Begriff im Englischen anfänglich verwendet wurde, um satirische Nachrichtenformate (mock news programs) zu bezeichnen. .06

Die Abgrenzung der Satire zu „Fake News“ ist notwendig, aber gleichzeitig problematisch, wie im nächsten Abschnitt gezeigt werden soll.

\section{Schritt 2: Unter dem Deckmantel der Satire}

Die hier vorgestellten Überlegungen beruhen auf der Hypothese, dass sich „Fake News“ und „Hate Speech“ mitunter als Satire ausgeben. Satire wird so als eine Form von "Schutzschirm" oder „Generalablass" verwendet, „grauenhaftes Zeug zu reden, ohne Widerworte erwarten zu müssen“.907 Das kann dazu führen, dass radikale, aber auch falsche Tatsachenbehauptungen unter dem Deckmantel einer humoristischen Gesellschaftskritik in den sozialen Netzwerken eine größere Verbreitung erfahren und dadurch auch in zunehmendem Umfang akzeptiert werden.

Als Beispiel sei ein „Bericht“ auf der Internet-Seite mmnews.de unter der Rubrik „Vermischtes“ vom 02. September 2018 genannt, der unter dem Titel „Sachsen: Kiosk-Besitzer stoppen SPIEGEL-Verkauf“ erschienen war. ${ }^{908}$

Laut „Berichterstattung“ sei der Verkaufsstopp damit zu begründen, dass die Zeitschrift „Der Spiegel“ alle Bewohner Sachsens „als Nazis hinstelle“ und dann noch erwarte, dass das Magazin dort verkauft werde. Dabei soll es um die Ausgabe 36/2018 der Wochenzeitschrift gehen, deren Cover den Titel trägt „Sachsen. Wenn Rechte nach der Macht greifen“.

904 Sängerlaub/Meier/Rühl, Fakten statt Fakes, 2018, S. 12.

905 So z.B. bei Sängerlaub/Meier/Rübl, ebd.

906 Vgl. Tandoc Jr./Lim/Ling, Digital Journalism 2018, 6:2, S. 141.

907 Fischer, Macht euch Schmutzig! Oder soll man es lassen? Über die Schmerzgrenzen der Satire, in: Berendsen/Cheema/Mendel (Hrsg.), Trigger Warnung, 2019, S. 235.

908 https://www.mmnews.de/vermischtes/87687-sachsen-kiosk-besitzer-stoppen-spie gel-verkauf. 
Dabei ist das Wort "Sachsen“ in der ersten Hälfte in einer serifenlosen weißen Schrift und in der zweiten Hälfte in altdeutscher Schrift in brauner Farbe dargestellt.

Nach der Überschrift folgt in dem „Bericht“ der Teaser: „Wegen SPIEGEL-Cover: Kioskbetreiber in Sachsen stoppen den Verkauf der aktuellen Auflage. Claudia Roth: ,gefährliche Zensur'. Göring Eckhardt: ,BoykottAktion wie Nazi-Deutschland'. Grüne Jugend (GJ) plant SPIEGEL-Notverkauf über Bürgerbüros. “909

Der „Bericht“ ist in seiner Aussage - wie in Blogs besprochen wurde erfunden, so fanden bspw. weder dieser Verkaufsstopp der Kiosk-Besitzer noch die Reaktionen der im Teaser genannten Politiker statt. ${ }^{910}$ Doch besteht der „Bericht“ nicht nur aus solchen Teilen. In einem Abschnitt heißt es: „Das weckt auch Erinnerungen an die von der AfD-Fraktionsvorsitzenden Alice Weidel bereits am 29.8.2018 erstattete Strafanzeige gegen Reiner Woop, der mit Napalm nicht nur die Sachsen, sondern auch die AfD in den Feuertod schicken wollte: “911 Darauf folgt als Screenshot ein Tweet von Alice Weidel. ${ }^{912}$ Nach diesem echten Tweet schließt sich ein Abschnitt zu einer vermeintlichen Reaktion einer Grünen-Politikerin an. Unter der Zwischenüberschrift: „Katrin Göring-Eckardt: ,Der Verkaufsstopp [...] bedroht unsere Demokratie!' Vergleich mit Boykott-Aktionen in Nazi-Deutschland heißt es: Ganz anders dagegen sehen es etwa die Grünen, Katrin Göring-Eckardt, die selbst in Leipzig studiert hat, sieht Demokratie und Pressefreiheit bedroht: ,Der Verkaufsstopp des Spiegels in Sachsen ist wider die Pressefreiheit und bedroht unsere Demokratie! Solche Boykott-Aktionen erinnern schmerzhaft an ein Deutschland, das es nie wieder geben darf.“ “ Diese Aussage wird noch einmal als vermeintlicher Tweet der Politikerin dargestellt. ${ }^{913}$ Der „Bericht“ fährt dann mit vermeintlichen Aussagen der Politikerin Claudia Roth fort. Für diese Aus-

909 https://www.mmnews.de/vermischtes/87687-sachsen-kiosk-besitzer-stoppen-spie gel-verkauf.

910 Vgl. Besprechung bei https://www.volksverpetzer.de/hintergrund/pseudo-satire/; https://meedia.de/2018/09/03/trending-erfundene-kiosk-besitzer-in-sachsen-noch -mehr-luegen-hans-soellner-childish-gambino-und-george-w-bush/; https:/www. flurfunk-dresden.de/2018/09/07/fake-news-iii-polizei-sachsen-korrigiert-maximili an-krah/;

911 https://www.mmnews.de/vermischtes/87687-sachsen-kiosk-besitzer-stoppen-spie gel-verkauf.

912 Alice Weidel, Tweet vom 30.8.2018, 11:35 Uhr, https://twitter.com/Alice_Weide 1/status/1035098550831599616.

913 https://www.mmnews.de/vermischtes/87687-sachsen-kiosk-besitzer-stoppen-spie gel-verkauf. 
sagen der Politikerin habe es dann laut „Bericht“ nicht nur Zuspruch gegeben und es wird als Screenshot ein Tweet mit dem Inhalt „Diese \#ClaudiaRoth von den \#Grünen [...] kann man doch eh nicht mehr ernst nehmen! [...]“ angefügt. Der Tweet wurde von diesem Account auch getätigt, doch in einem ganz anderen Zusammenhang. ${ }^{914} \mathrm{Im}$ „Bericht“ folgen dann wieder völlig erfundene Absätze bis am Ende Aussagen des Politikwissenschaftlers Vorländer zitiert werden. Dieses Zitat stammt aus einem Interview des Wissenschaftlers mit der Frankfurter Allgemeinen Zeitung und ist insofern ein „echtes“ Zitat. ${ }^{915}$ Das Fazit des „Berichts“ ist wiederum erfunden.

Der „Bericht“ besteht aus wahren Teilen, aus durch Dekontextualisierung bewusst falsch interpretierten wahren Informationen, aus manipulierten eigentlich wahren Informationen und völlig frei erfundenen Inhalten.

In erheblich kleinerer Schriftgröße befindet sich am rechten äußeren Rand des Artikels in hellgrauer Schrift das Wort "Satire“.916 Dieser Zusatz war nur schwer zu erkennen, so dass der „Bericht" als „wahrhaftig“ angenommen und im Internet häufig weiterverbreitet wurde. Nicht zuletzt führten die Re-Posts des Artikels, die von AFD-Politikern in den sozialen Netzwerken eingestellt wurden, zu einer Ausweitung der Bekanntheit. ${ }^{917}$ Wegen der zahlreichen Schritte innerhalb der Verbreitungswege der sozialen Netzwerke konnte der Hinweis auf die Satire nicht mehr nachvollzogen werden. In weitergeleiteten Meldungen wurden so z.B. nur die Header übernommen, während der Link, der typischerweise die Quelle, in diesem Fall www.mmnews.de, noch angezeigt hätte, im URL Shortener „versteckt“ war. Da der Satire-Hinweis auch nicht in der Überschrift beinhaltet war, wurde gerade von denjenigen, die nur die Snippets oder nur die Überschrift lasen, ${ }^{918}$ der Satire-Disclaimer nicht gesehen. Bevor

914 BB12_DE, Tweet vom 1.9.2018, 16:38 Uhr, https://twitter.com/BB12_DE/status/ 1035899790633193474.

915 Bender, „Viele fühlen sich heimatlos, ausgesetzt und abgehängt“ Interview mit Hans Vorländer, FAZ, 23.2.2015.

916 https://www.mmnews.de/vermischtes/87687-sachsen-kiosk-besitzer-stoppen-spie gel-verkauf.

917 So z.B. Erika Steinbach über facebook (https://www.facebook.com/erika.steinba $\mathrm{ch} /$ posts/1776476239138312?utm_campaign $=$ nl_Trending\&utm_source=nl_Tre nding\&utm_medium=email) oder Petr Bystron über twitter (https://twitter.com /PetrBystronAfD/status/1036250686948880384?utm_campaign=nl_Trending\&ut m_source=nl_Trending\&utm_medium=email).

918 Laut einer US-amerikanischen Studie von 2014 lesen nur $60 \%$ mehr als die Überschrift. The Media Insight Project, 2014 zit. nach Rubin/Conroy/Chen/Corn- 
sich im dritten Schritt einer Abgrenzung zwischen Satire und „Fake News“ genähert wird, sei angemerkt, dass die politische Ausrichtung einer Satire unschädlich für den Satirebegriff ist. Das sei hier betont, da das Nachrichtenportal mmnews.de wohl eher politisch dem rechten Spektrum zuzuordnen ist ${ }^{919}$, während die in dieser Arbeit bisher ausführlicher besprochenen Fälle, allen voran die politischen Satireplakate des Klaus Staeck, im Spektrum politischer Meinungen eher im linken Bereich einzuordnen sind.

\section{Schritt 3: Die notwendige Abgrenzung}

„Fake News“ und Satire werden - wie im ersten Schritt benannt - häufig über die Intention des Urhebers abgegrenzt. Dieses zunächst einleuchtende Vorgehen kann im Einzelfall durch das Subjektive aber mit Problemen in der Beweisführung einhergehen, weswegen nach objektiveren Kriterien zu suchen ist, um in belastbarer Form auf die Intention schließen zu können.

Dazu scheint der Versuch vielversprechend, unter Zugrundelegung des Satirebegriffs aus Kapitel 2 zu prüfen, ob es sich bei dem genannten „Bericht" um eine Satire handeln kann.

Wie im zweiten Kapitel dargelegt, operiert die Satire mit den Mitteln der Provokation, der Aggression oder der Kritik und wendet sich auf diese Weise gegen ein, für den Satiriker tatsächlich bestehendes Ungleichgewicht. Die Satire kann unter Hinzunahme einer Vielzahl von Stilmitteln, wie beispielsweise der Übertreibung, auf ein, durchaus auch bedrücktes Lachen beim Rezipienten ausgelegt sein und dabei ein weiterführendes Ziel verfolgen. ${ }^{920}$ Für die rechtliche Bewertung muss die Satire ihrer satirischen Einkleidung entkleidet werden, so dass dann der Aussagekern und die satirische Einkleidung getrennt voneinander überprüft werden können. ${ }^{921}$ Diese Auslegungsmethodik der Rechtsprechung befreit aber nicht von der Aufgabe, zu untersuchen, ob es sich überhaupt um eine Satire handelt.

well, Fake News or Truth? Using Satirical Cues to detect Potentially Misleading News, Proceedings of NAACL-HLT 2016, S. 9.

919 Stefan Kaiser beschreibt es im Spiegel als europafeindlich, Kaiser, Das Geschäft mit der Angst, Spiegel 22.5.2014.

920 Vgl. Kap. 2, E.

921 Vgl. Kap. 3, E., IV., 1. 
Auf das obige Beispiel angewendet bedeutet das, dass die typischen Stilmittel wie Übertreibung, Verzerrung oder Verfremdung sich in dem Beispiel nur dann herauslösen lassen würden, wenn die Erfindung einer Nachricht als eine Form der Verfremdung erkennbar wird. Das vermeintliche Ungleichgewicht, das gerügt wird, mag höchstens in dem Bericht oder Cover der entsprechenden Spiegel-Ausgabe oder in dem grundlegenden Vorwurf, dass die Politiker der Partei Bündnis 90/Die Grünen vorschnell von "Zensur" sprechen, liegen. Diese Argumentation erscheint jedoch konstruiert und wenig plausibel. Deshalb wird hier im Ergebnis nicht davon ausgegangen, dass es sich um Satire handelt. Die Formulierung der Nachricht lässt vielmehr jede Form eines humoristischen Umgangs mit Tatsachen, der Verzerrung oder scharfe Kritik rechtfertigen würde, vermissen.

Geht man dennoch hilfsweise davon aus, dass es sich bei dem „Bericht“ um eine für die Satire typische Verfremdung oder Übertreibung handelt, dann ist danach zu fragen, ob für den Rezipienten erkennbar ist, dass es sich um eine satirische Verfremdung handelt, und ob er sie für seine Meinungsbildung bewertend einordnen kann; oder ob der Rezipient zu der irrigen Einschätzung kommen kann, die Aussage sei tatsächlich wahr. ${ }^{922}$

Zunächst ließe sich dafür auf den Satire-Disclaimer verweisen, der für eine Erkennbarkeit der Satire spreche. Doch stellt sich die Sachlage als komplexer dar, wenn man berücksichtigt, dass, einerseits, die Plakate „Die Reichen müssen reicher werden“ oder „Die SPD will euch eure Villen im Tessin wegnehmen“ von Klaus Staeck, die nicht explizit als Satire gekennzeichnet wurden, von einzelnen Rezipienten nicht als satirische Arbeiten erkannt wurden. ${ }^{923}$ Andererseits, im Fall der Pseudosatire ist der „Bericht" über den Verkaufsstopp des Spiegels in Sachsen - wenn auch versteckt so doch eindeutig als Satire gekennzeichnet worden. Die beiden diametral entgegengesetzten Beispiele belegen, dass die Kennzeichnung als Satire nicht notwendig ist, sondern sogar fehlleitend sein kann; in beiden Fällen jedoch kann es sein, dass der satirische Charakter nicht erkannt wird. Demnach kann der versteckte Satire-Hinweis nicht generell als Argument für oder gegen eine Erkennbarkeit oder böswilligen Intention verwendet werden. Der „Bericht“ zeigt jedenfalls, dass die Kennzeichnung einer Nachricht als Satire diese nicht automatisch zu einer Satire werden lässt.

Darüber hinaus ist zu fragen, ob der diesen „Bericht“ umgebende Kontext Auswirkungen auf die Erkennbarkeit hat. Der „Bericht“ ist auf einem

922 Vgl. Kap. 3, B., I.

923 Siehe dazu Kap. 5., B., I., 1. 
Internet-Portal zu finden, bei welchem es sich explizit um ein Nachrichten-Portal handelt und gerade nicht um eine Plattform für Satire. Auch dies ist zunächst nicht schädlich, da eine satirische Äußerung nicht zwingend ein satirisches Umfeld benötigt.

Hilfreich ist in diesem Kontext auch wieder Klaus Staecks Verständnis der Satire: Für ihn müsse die Satire, mag sie noch so übertreiben, immer auf Wahrheit fußen. ${ }^{924}$ Verfolgt man diesen Ansatz, ergibt sich, dass die Satire auf wahren und bestehenden Tatsachen, d.h. auf Bestehendem aufbaut und fiktive Elemente wie eben eine Überzeichnung oder Verfremdung nur als Mittel zur Verdeutlichung der Kritik verwendet. „Fake News“ hingegen beruhen nicht auf wahren und bestehenden Tatsachen, sondern schaffen Neues, können als Mittel zur Glaubhaftmachung ihrer falschen Aussage jedoch Wahres bzw. Bestehendes verwenden. In dem hier angeführten Beispiel vermischen sich Wahres und Falsches, bzw. Bestehendes und Neues, ${ }^{925}$ doch wird das Neue oder Fiktive nicht zur Überzeichnung genutzt, sondern als (unwahres) Fundament der Nachricht verwendet.

Im Rahmen dieser Arbeit muss im Kontext des Phänomens „Fake News" die Betrachtung eines einzelnen Beispiels genügen anhand dessen sich die vorherigen Teilaspekte zur präziseren Auslegung der Intention des Verfassers des „Berichts“ ableiten bzw. anwenden lassen. Für einen letzten Aspekt sei aber noch angefügt, dass die Kommunikationswissenschaftler Schwarzenegger und Wagner in einer qualitativen Untersuchung zu Posts auf Facebook herausgefunden haben, dass die Satire-Kennzeichnung - sei es im Rahmen von Satiregruppen und Satireseiten - gezielt genutzt wurde, um eine zumeist radikale politische Positionen zu kaschieren, bzw. Satire ganz generell genutzt wurde, um solche extremen politischen Meinungen bis hin zur der Diskriminierung von Minderheiten zu verschleiern. ${ }^{926}$ Zudem diskutieren die Autoren ein weiteres Merkmal, welches bei der Unterscheidung von Satire und „Fake News“ hilfreich sein kann: die „ganzheitliche Analyse“. Unter einer ganzheitlichen Analyse wird die Bezugnahme auf „das diskursive Ensemble der Beiträge und Kommentare in Kombination "927 verstanden. In dem oben angeführten Beispiel zeigt gerade die Verbreitung über die sozialen Netzwerke, dass dieser „Bericht“

924 Vgl. Kap. 2, D., V., 1.

925 In dem hier besprochenen Beispiel ist der mit „Das weckt auch Erinnerungen“ beginnende Abschnitt sowie der folgende Tweet wahr. Vgl. https://www.mmne ws.de/vermischtes/87687-sachsen-kiosk-besitzer-stoppen-spiegel-verkauf.

926 Schwarzenegger/Wagner, Studies in Communication and Media 2018, S. $484 \mathrm{f}$.

927 Schwarzenegger/Wagner, ebd. 
als eine wahre Berichterstattung kommentiert und verbreitet wurde. Ein weiteres Mal wird so die Abhängigkeit einer Einordnung von dem Wahrnehmungsprozess deutlich.

Fehlt es an einer satirischen Einkleidung, bedarf es auch keiner getrennten Prüfung von satirischer Einkleidung und Aussagekern, sondern es bleibt bei der Prüfung der Äußerung selbst. Wenn es sich dann nicht um eine Meinung, sondern um unwahre Tatsachenbehauptungen handelt, ist auch ein Schutz über die Meinungsfreiheit ausgeschlossen. ${ }^{928}$

Zusammenfassend lässt sich festhalten: Wird das unterscheidende Merkmal für hinter Satire versteckter „Fake News“ und „echter" Satire in der Intention gesehen, dann erweisen sich drei Aspekte, nämlich die Definition der Satire, die Frage nach der Erkennbarkeit des satirischen Charakters, ganz unabhängig von einem etwaigen „Satire-Disclaimer“, und schließlich die ganzheitliche Analyse der Interaktionsmechanismen als hilfreich für eine belastbare Auslegung der Intention.

\section{Zwischenfazit}

Im siebten Kapitel wurde im Rahmen eines Ausblicks besprochen, dass das Plakat in seinen Strukturmerkmalen auch in digitaler Form weiterlebt, wie z.B. in der Form des Memes. Das sogenannte Adbusting greift hingegen in die Plakatwerbung im öffentlichen Raum ein und ist damit auch einer analogen Form der Text-Bild-Kombination verpflichtet, auch wenn die Ergebnisse der Adbusting-Aktionen maßgeblich über Fotografien in den sozialen Netzen verbreitet werden. Adbusting und die Plakate Klaus Staecks ähneln sich als Formen der Antiwerbung, unterscheiden sich jedoch maßgeblich darin, dass das Adbusting Bestehendes unautorisiert überklebt. Klaus Staeck hingegen mietete die Flächen für seine Plakate offiziell bei den entsprechenden Unternehmen. Der Vergleich mit dem Adbusting unterstreicht noch einmal, wie sehr Klaus Staeck auf die Einhaltung von gesetzlichen Normen bei seiner als „Plakatanschläge“ bezeichneten Aktionen bedacht ist.

Nur angerissen wurde das Problemfeld zwischen satirischen Äußerungen im Internet und den sogenannten „Fake News“. Das angeführte Beispiel zur erfundenen und vorgeblich satirischen Berichterstattung hat gezeigt, wie schwierig im Grenzfall die Prüfung sein kann, ob eine satirische Äußerung vorliegt oder eben nicht.

928 Vgl. Kap. 3, C., I., 2. 


\section{Schlussgedanke}

„Betroffen von der Satire fühlen sich [...] jene, die auf dem absteigenden Ast sitzen“929. So beschreibt die langjährige Titanic-Anwältin Gabriele Rittig ihre Erfahrungen mit satirischen Äußerungen vor Gericht. Einige der Kläger, welche das Satiremagazin Titanic in Gerichtsverfahren verwickelt haben, legen diesen Schluss durchaus nahe. So trat Björn Engholm von allen politischen Ämtern zurück, nachdem seine Verwicklung in die sogenannte Barschel-Affäre sichtbar wurde. Dieses Beispiel zeigt, dass ein juristisches Vorgehen gegen satirische Inhalte durchaus mit einem allgemeinen Bedeutungsverlust der Kläger einhergehen kann. Ebenfalls wurde das Verhalten der in den Staeck-Verfahren klagenden Unternehmen Höchst AG und Rheinmetall AG in der Öffentlichkeit zuweilen überaus kritisch bewertet. Das Image von beiden Unternehmen hat als Folge der Auseinandersetzungen zumindest zeitweise gelitten. Für Personen der unmittelbaren Zeitgeschichte, wie beispielsweise den türkischen Präsident Recep Tayyip Erdoğan oder die Politikerin Alice Weidel, lässt sich die Beobachtung der Rechtsanwältin Rittig nicht oder noch nicht objektiv überprüfen.

Offensichtlich ist jedoch, dass die Betroffenen einer Satire die Öffentlichkeit verstärkt zu einer Beschäftigung mit den Themen, Institutionen und Personen, die in der Form der Satire angegriffen wurden, anregen, sobald sie wegen Persönlichkeitsrechtsverletzung vor Gericht gehen. Deshalb sollten die Betroffenen sorgfältig abwägen, ob es für sie jeweils ratsam ist, durch einen Rechtsstreit den öffentlichen Diskurs anzuregen und damit eine über die Satire hinausgehende negative Beurteilung zu riskieren. Ein Blick auf die juristischen Verfahren gegen Klaus Staeck kann in diesem Zusammenhang sehr hilfreich sein, da diese zur Genüge belegen, dass Rechtsverfahren, gerade wenn satirische Äußerungen der Auslöser waren, gewöhnlich zu einer großen medialen Aufmerksamkeit führen. Diese Überlegung soll aber keinesfalls die Notwendigkeit eines Rechtsschutzes für die Betroffenen untergraben.

Die Verfahren belegen den unauflösbaren Widerspruch, der in der Satire selbst liegt. Will die Satire in ihrer Aggressivität und Bissigkeit aufde-

929 Rittig, Preis der Satire, in: Folckers/Solms (Hrsg.), Was kostet der Spaß? Wie Staat und Bürger die Satire bekämpfen, 1997, S. 66. 
cken, angreifen, kritisieren, entblößen, ist sie doch notwendigerweise von dem Verständnis des Rezipienten abhängig. Denn unabhängig davon, ob sie den Rezipienten in seiner Ansicht bestärkt oder kritisiert, möchte sie ihn auf alle Fälle durch die humorvolle Pointe überraschen. So bewegt sich die Satire zwischen Provokation und Bestätigung, zwischen Irritation und Affirmation, zwischen Ausgrenzung und Konsens, zwischen Verletzung und Unterhaltung. Eine Äußerung, die nur provoziert, irritiert, ausgrenzt und verletzt, ist ebenso wenig eine Satire, wie eine Äußerung, die nur bestätigt, affirmiert, vereinigt und unterhält. Insofern analysieren und bewerten der Gerichtsprozess und all die ihn vorbereitenden juristischen Handlungen dieses notwendige Spannungsverhältnis. So kommt man zu dem Ergebnis, dass eine juristische Auseinandersetzung unter Berücksichtigung kommunikationswissenschaftlicher Aspekte zeigen kann, ob es sich bei einer vom Urheber als Satire bezeichneten Äußerung tatsächlich um Satire handelt. Zur gelungenen politischen Satire passt das Bild der bissigen Bulldogge und nicht der Vergleich mit einem zahmen Schoßhündchen, dem der Rezipient nur ein müdes Lächeln schenkt.

Klaus Staeck hat diesen Grenzgang, dieses Spannungsverhältnis, diesen Kampf für die satirische Äußerung zu seinem Lebenswerk gemacht. Er nutzt das öffentlich angebrachte Plakat als Medium, für das er ein neues ästhetisches Konzept entwickelt hat. Die in der künstlerischen Bewegung des Dada zu Beginn des 20. Jahrhunderts erfundene Bildkollage wird zu seinem Werkzeug. Auch wenn die Plakate Klaus Staecks heute niemanden mehr empören, haben die meisten der von ihm satirisch ins Bild gesetzten Themen ihre Relevanz nicht verloren. Waffenexporte sind weiterhin umstritten, eine Geschlechterparität bei Führungskräften ist nicht erreicht, und die Kenntnis über den schädigenden Einfluss von menschlich erzeugten Giften auf die Umwelt ist so groß wie noch nie zuvor. ${ }^{930}$

„Satire boomt." "931 ist das Ergebnis einer Studie von 2016 und dazu hat Klaus Staeck mit seinen künstlerischen Politsatire-Plakaten, die einen Zeitraum von 50 Jahren überspannen und von Rechtsstreitigkeiten begleitet waren, ganz wesentlich beigetragen. Wie kaum ein anderer Künstler der

930 Wurde die FCKW-Verwendung mittlerweile verboten, weiß man heute, dass der Ersatzstoff FKW, wenn nicht ozonabbauende Wirkung, dennoch durch den Treibhauseffekt klimaschädigende Wirkung hat. Nach der Kigali-Änderung von 2016 des Montreal-Protokolls die Industrieländer bis 2036 die FKW-Produktion und Verwendung um $85 \%$ reduzieren. Bis 2047 soll dieses Ziel weltweit erreicht sein.

931 Gäbler, Quatsch oder Aufklärung, 2016, S. 84. 
Nachkriegszeit hat Klaus Staeck das Muster geprägt, das politsatirischen Meinungsäußerungen auch heute noch zugrunde liegt. 


\section{Anhang}

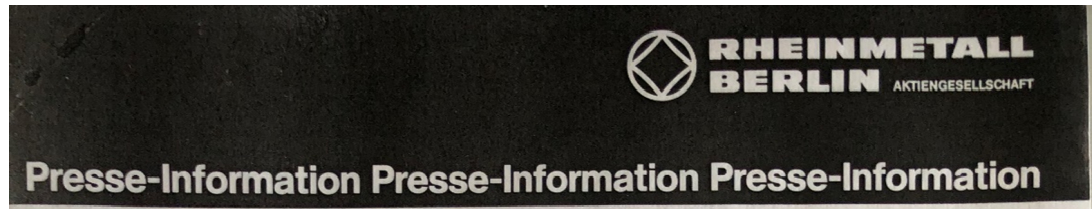

Rheinmetall Berlin Aktiengesellschaft Ulmenstrabe 125, Postfach 6609 D-4000 Düsseldorf 1

Pressestelle Telefon $0211 / 4472123$ Telex 8584963 a rhmt d

Düsseldorf

$$
\text { 21. 12. } 1981
$$

Rheinmetall contra Staeck

Rheinmetall, bzw. der Vorstandsvorsitzende des Unternehmens haben die juristischen Aktivitäten gegen Herrn Staeck eingestellt.

In verschiedenen juristischen Instanzen war dem sogenannten künstlerischen Interesse des Herrn Staeck eine übergeordnete Bedeutung gegenüber den im Grundgesetz gesicherten Persönlichkeitsrechten der von inm auf einem Poster abgebildeten Mitglieder der Geschäftsführung der Rheinmetall $\mathrm{GmbH}$ und des Vorstandsvorsitzenden beigemessen vorden. Das Unternehmen sah in dem nach Meinung des Herrn Staeck in den Bereich Kunst gehörenden Plakates, das neben der Personendarstellung den Text "Alle reden vom Frieden - Wir nicht" enthält, eine Diskriminierung der Mitarbeiter der Rheinmetall-Wehrtechnik.

Rheinmetall stellt fest, daß die Mitarbeiter des Unternehmensbereiches Wehrtechnik einen wesentlichen Beitrag zur wehrtechnischen Ausrüstung von Bundeswehr und Bündnis - und insofern zur Friedenssicherung leisten.

Rheinmetall hat deutlich gemacht, daß das Unternehmen Mitarbeiter und Management vor Diffamierung und Diskriminierung zu schützen sucht.

Eine veitere Auseinandersetzung mit Herrn Staeck - in jüngster Zeit durch mehrere große Ausstellungen in der DDR und Ost-Berlin ausgezeichnet - führt ausschließlich zu einer unnötigen Aufuertung dieser nunmehr unzweideutig politisch qualifizierten "Kunst". 
B. Leserbrief des Bundestagsabgeordneten Wilfried Böhm, Hersfelder Zeitung, 26.5.1976 $6^{932}$

Staecks „Kunst“ politische Hetze

Die neueste Masche der Sozialisten im Kampf gegen die CDU/CSU ist es, dass sie ihre politischen Kampfplakate zu „Kunstwerken“ hochstilisieren und dafür allgemein gültigen Aussagewert beanspruchen. Der politische Agitator Staeck ist ein Musterbeispiel für diese zu „Kunst“ verklärte Hetze gegen politisch Andersdenkende.

Drei „Werke“ des „Künstlers“ seien kurz beschrieben:

1. Da wird der Vorsitzende der CSU, Franz Josef Strauß, als Metzger blutverschmiert dargestellt, lange Messer in der Hand, auf der Brust steht: „Wählt christlich“ und über dem „Kunstwerk“: „Entmannt alle Wüstlinge!"

2. Da werden Strauß, Axel Springer und der Journalist Löwenthal waffenstarrend karikiert und die Überschrift lautet: „Der kalte Krieg macht uns erst richtig heiß“ - so als ob der Kalte Krieg nicht von Moskau und den Kommunisten, sondern von demokratischen Politikern, Verlegern und Journalisten ausginge.

3. Da werden Opfer der Konzentrationslager in Chile dargestellt und dem Betrachter des „Kunstwerks“ suggeriert, dass die CDU die Verschleppung in faschistische Konzentrationslager billige.

Die Agitation Staecks ist typisch faschistisch. Wenn sie „Kunst“ ist, dann sind auch die Hetzkarikaturen der Nazis, mit denen sie im "Stürmer" unsere jüdischen Mitbürger verächtlich machten, nachträglich als „Kunstwerke" anzusehen. Wenn die CDU in derselben Art antworten würde und solcherart „Kunst“ produzieren und in den politischen Kampf einbeziehen ließe, würde sie zum Beispiel folgende Plakate herausbringen.

1. Ein Opfer des kommunistischen Schießbefehls verblutet an der Mauer und daneben steht Bundeskanzler Schmidt - natürlich als Karikatur entstellt - und spricht: „Die Kosten für die Munition übernimmt der westdeutsche Steuerzahler!“

2. Brandt und Wehner - natürlich zur Karikatur verunstaltet - stehen vor dem Kreml in Moskau und melden in militärisch strammer Haltung: „Befehl ausgeführt - Deutschland kommunistisch!“

Welcher Aufschrei des Entsetzens würde durch die deutsche Öffentlichkeit gehen bei solcherart Plakaten! Das wäre „Staeck umgekehrt“ und trüge

932 Vgl. OLG Frankfurt/Main, 7.6.1977, 14 U 216/76, S. 3 f. 
zur Verwilderung der politischen Sitten bei - an der sich die CDU nicht beteiligt und auch nicht beteiligen wird. Es ist beschämend, dass sich die SPD dieser Staeck-Plakate bedient und „Kunst“ als Schlagwaffe gegen die CDU/CSU benutzt.

In die Parlamentarische Gesellschaft in Bonn, den Club der Abgeordneten aller Fraktionen, in dem - Gott sei Dank! - bisher noch das kollegiale Gespräch über Parteigrenzen hinweg, ungezwungen und offen möglich war, schleppten einige SPD-Abgeordnete als Provokation diese die CDUMitglieder des Clubs beleidigenden Polit-Plakate. Viele SPD-Kollegen waren über dieses Vorgehen entsetzt und billigten es keineswegs.

Man stelle sich vor, Plakate gegen Schmidt, Brandt und Wehner, wie ich sie oben beschrieben habe, würden in den Wohnungen oder Vereinslokalen angebracht, in denen SPD-Mitglieder wohnen oder Mitglied sind. Auch sie würden sich diese Provokation nicht bieten lassen. Mit einem Angriff auf die Meinungsfreiheit hat die Verteidigung gegen diese unerhörten Beleidigungen, begangen in privaten Clubräumen, aber auch nicht das Geringste zu tun.

Nun mag der eine oder andere vielleicht sagen, die hässlichsten StaeckPlakate seien in Bad Hersfeld nicht gezeigt worden. Diese Staeck-Freunde müssen sich sagen lassen, dass sie dann unter dem Gesichtspunkt der politischen Opportunität das „Werk“ ihres verehrten „Künstlers“ manipulieren und in der Öffentlichkeit den Blick auf die Gesamtpersönlichkeit Staecks verwehren. Und das grenzt ja wohl nach dieser Denkart wieder an Zensur!

Ich meine, dass alle Demokraten Schluss mit der hässlichen Agitation machen sollten, die die Atmosphäre vergiftet und letztlich nur auf die SPD zurückfällt, die sich solcher Methoden leider bedient.

\section{Zeitungsartikel mit Erklärung des CDU-Fraktionsvorsitzenden im Gemeinderat, Dr. Raban von der Malsburg, Rhein-Neckar Zeitung vom 28.3.1994}

In der Nachverdichtungs-Diskussion

CDU wirft OB Vetternwirtschaft vor. Statt Wohnungsbau „alten Schuppen an Klaus Staeck vermietet“

Im Zusammenhang mit dem Thema „Nachverdichtung“ hat jetzt der CDU-Fraktionsvorsitzende im Gemeinderat, Dr. Raban von der Malsburg, nicht nur heftige Kritik an SPD und GAL geübt, denen er vorwirft, wichtige Flächen für den Wohnungsbau gestrichen zu haben. Er greift auch Oberbürgermeisterin Beate Weber an, der er wegen der Vermietung eines 
Schuppens auf dem Gelände der ehemaligen Glockengießerei Schilling an ihren Parteifreund Klaus Staeck „Vetternwirtschaft“ vorhält. In der Erklärung des CDU-Fraktionschefs heißt es:

„Das Thema „Nachverdichtung' wird von einigen Mitgliedern des Gemeinderates mit sehr kurzem Gedächtnis geführt. Es ist noch gar nicht lange her, da haben SPD und GAL Flächen für den Wohnungsbau gestrichen mit der Begründung, es gebe genug Wohnungen. Daraufhin sind die Wohnungen knapp und teuer geworden. Als SPD und GAL ihren Fehler bemerkten, haben sie aber nicht ausreichend Wohnbauflächen wieder zur Verfügung gestellt, sondern sie haben ein ,Baulückenprogramm` erfunden mit der These, der notwendige Baubedarf könne in den Baulücken befriedigt werden. Auf die Veraltung wurde starker Druck ausgeübt, für die Schließung der Baulücken zu sorgen. Es wurde sogar Baugebote ausgesprochen und in einem Fall war auch von Enteignung die Rede.

Jetzt regte sich der Widerstand der Nachbarn dieser Grundstücke. In vielen Fällen wurden auch wirklich Bauanträge vorgelegt, die den Bogen entschieden überspannten. Aber nun machten SPD und GAL unter dem Druck der betroffenen Bürger eine radikale Kehrtwende und kritisierten dieselbe Verwaltung, die sie eben noch zur verstärkten Schließung der Baulücken angetrieben hatten, sie genehmige zu viel.

Aus Baulücken wurden jetzt wieder Biotope. Eine höchst seltsame Wandlung. Nur in einem sind sich SPD und GAL ganz treu geblieben. Die zuvor gestrichenen Wohnbauflächen soll es nicht mehr geben. 800 Wohnungen pro Jahr wurden versprochen. Das Ziel ist zu niedrig angesetzt, wie auch die GAL zugibt - und es wurde nicht erreicht. Die Mieten steigen weiter.

Die Krönung dieser Politik leistete sicher aber kürzlich die Mehrheit des Bauausschusses: Für eine unserer größten Reserveflächen, das Gelände der ehemaligen Glockengießerei Schilling in Bergheim, hat er beschlossen einen wesentlichen Teil von der Bebauung auszunehmen und einen dort vorhandenen Schuppen stehen zu lassen. Der Schuppen wurde kürzlich von Oberbürgermeisterin Beate Weber (SPD) an Herrn Klaus Staeck (SPD) vermietet. Dieser obskure Beschluss, der Herrn Staeck begünstigt, verhindert 35 Wohnungen. Er wurde mit den Stimmen von SPD und GAL und - soviel ich weiß - auch der LD gefasst. Vetternwirtschaft ist für sowas ein noch zu freundlicher Ausdruck." 
Abbildungen

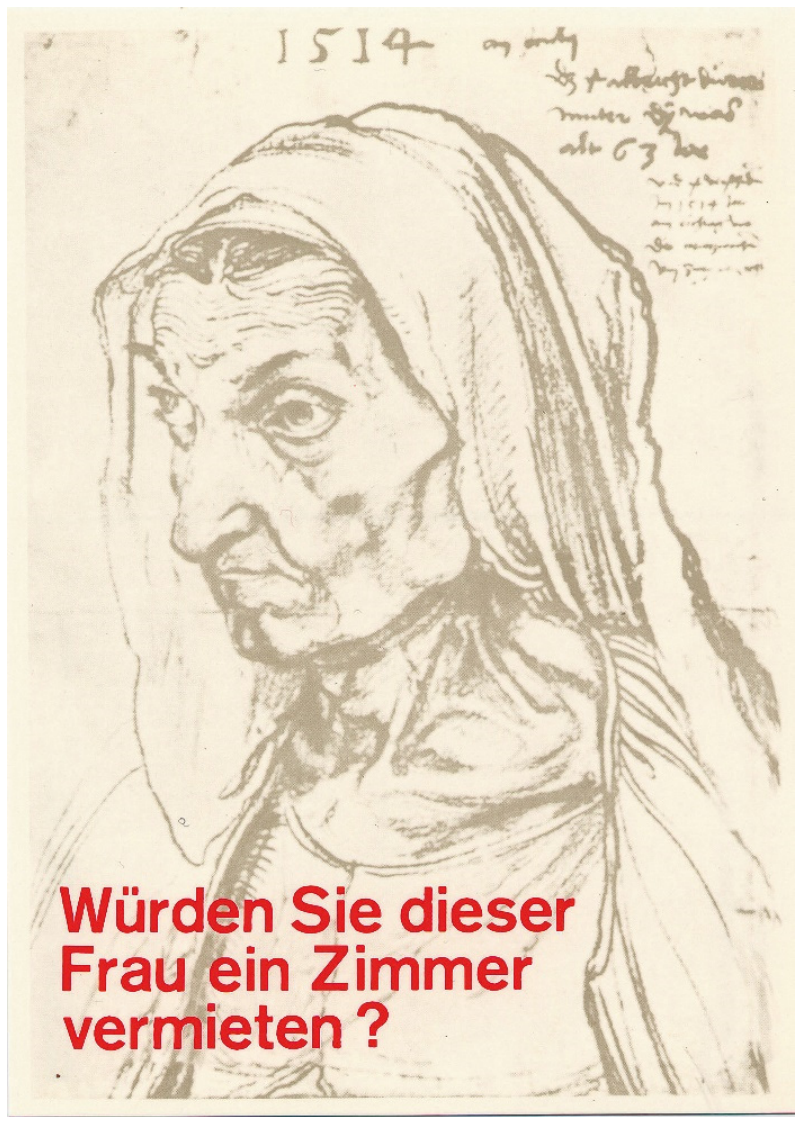

Abb. 1: Klaus Staeck, Sozialfall, 1971 
Abbildungen

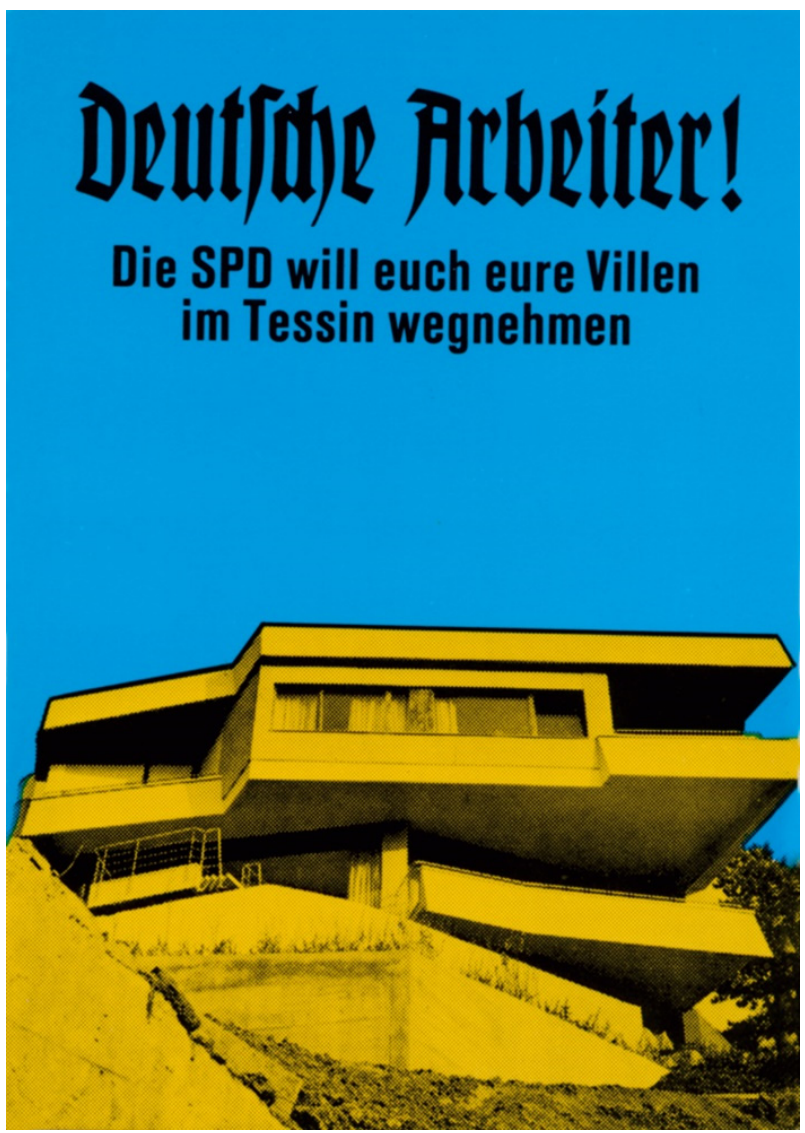

Abb. 2: Klaus Staeck, Deutsche Arbeiter, 1972 


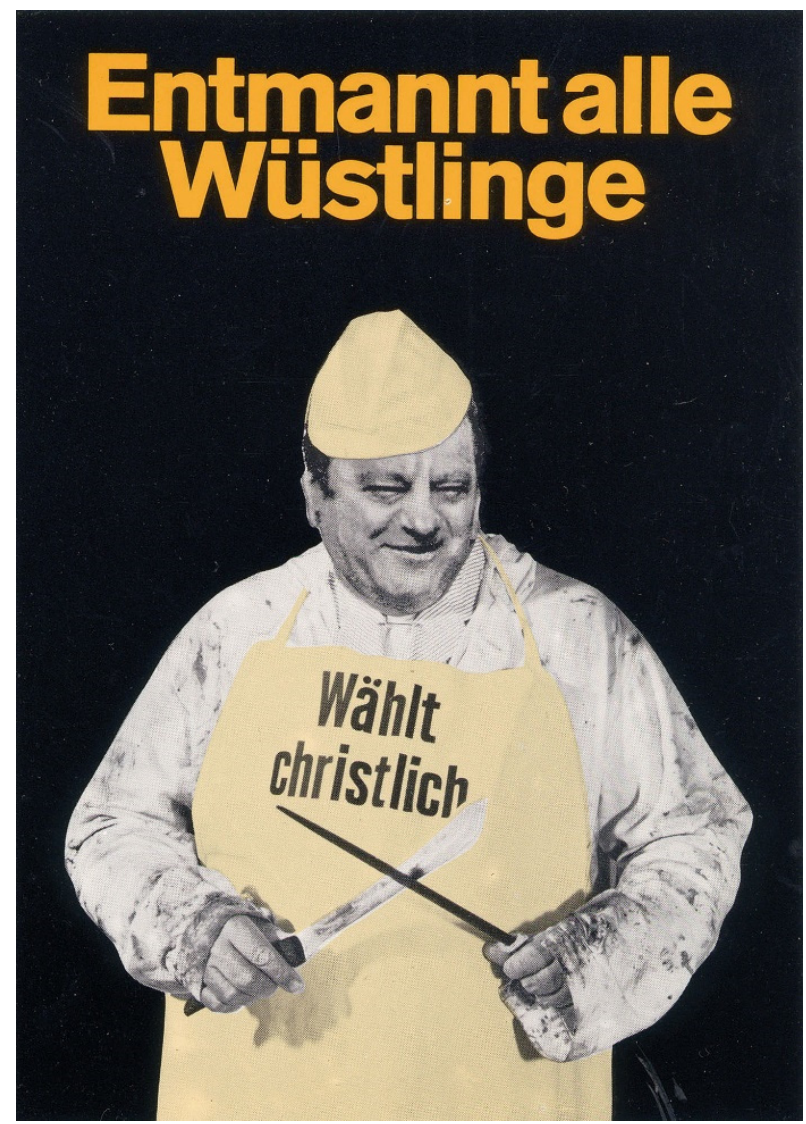

Abb. 3: Klaus Staeck, Entmannt alle Wüstlinge, 1972 


\section{Die Reichen müssen noch reicher werden}

\section{Wählt christdemokratisch}

Abb. 4: Klaus Staeck, Die Reichen, 1972 


\section{In Niedersachsen läuft alles wie geschmiert}

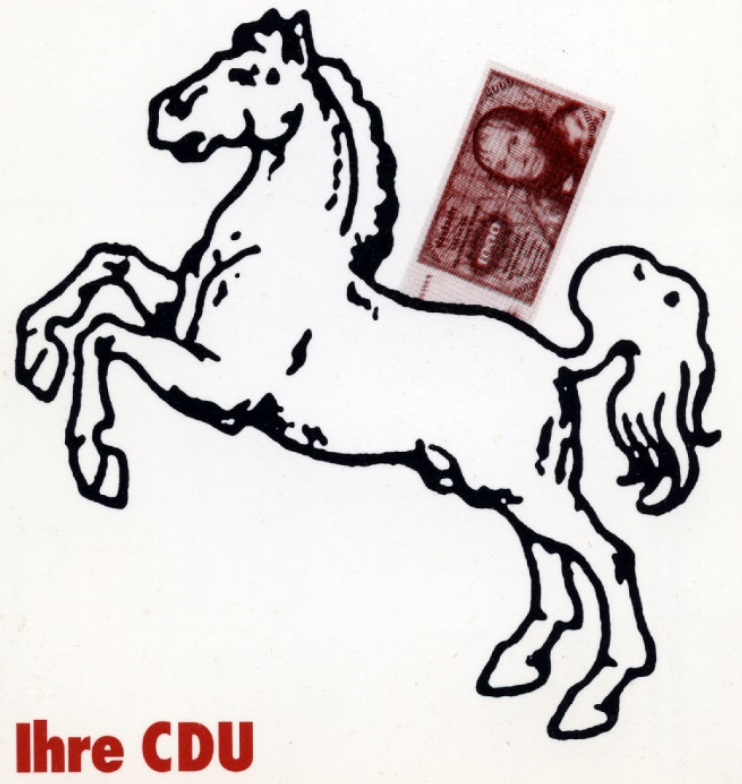

Abb. 5: Klaus Staeck, Niedersachsen, 1989 
Dahinter steckt immer ein kluger Kopf

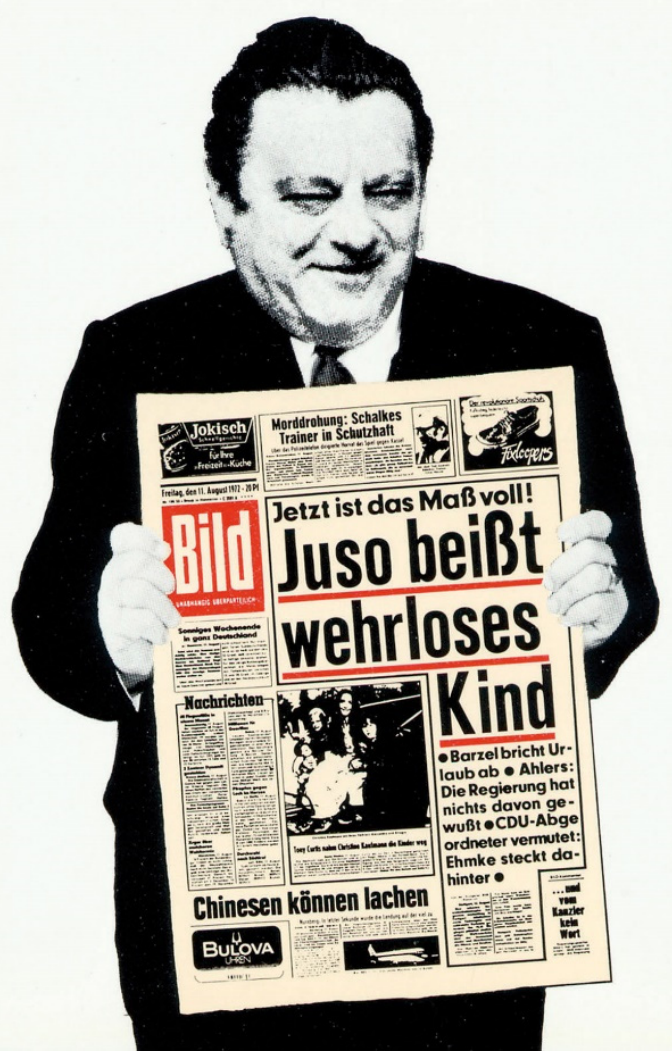

Abb. 6: Klaus Staeck, Juso beißt webrloses Kind, 1972 


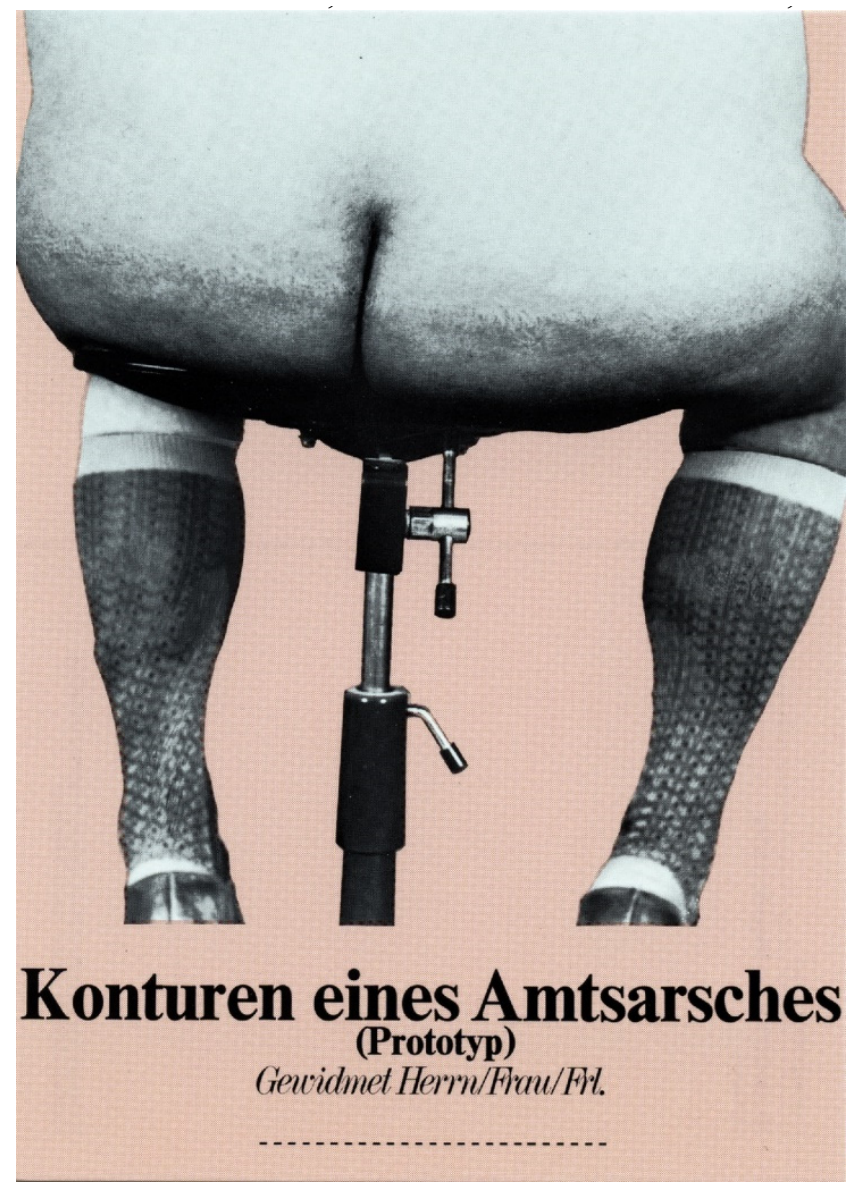

Abb. 7: Klaus Staeck, Amtsarsch, 1974 
Abbildungen

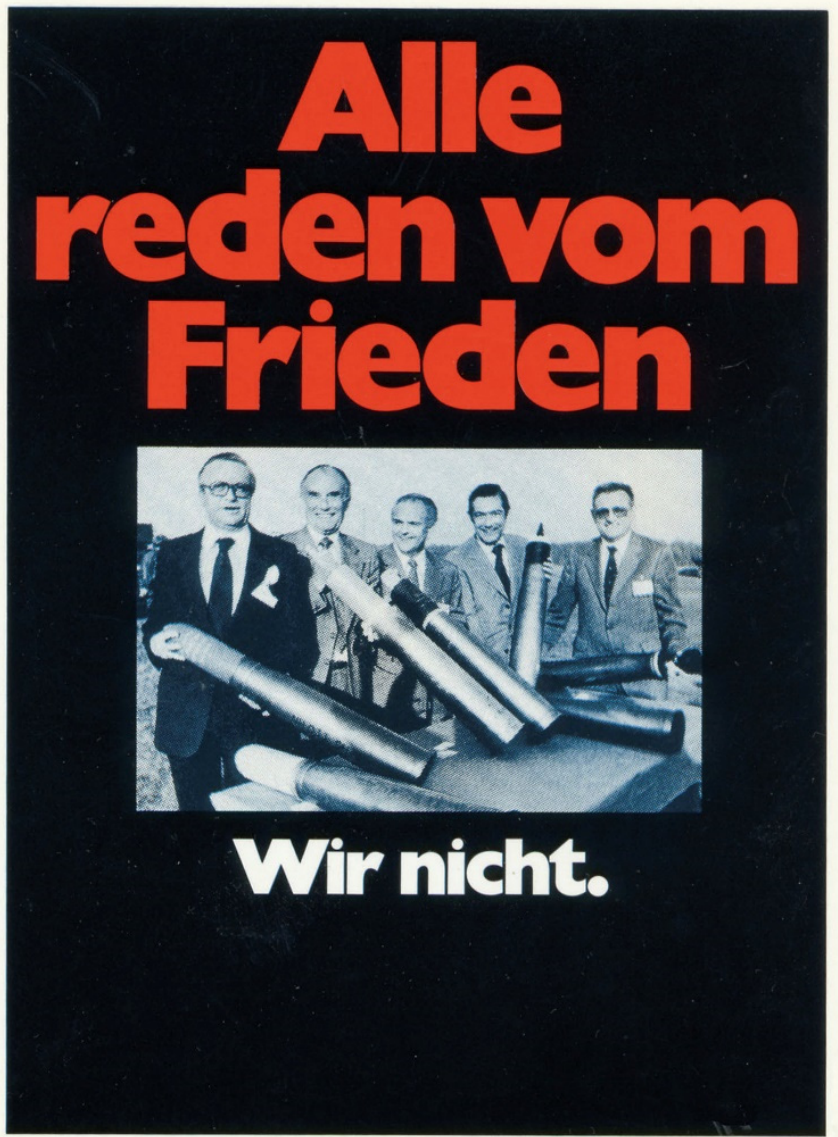

Zweckverband der Rüstungsindustrie

Abb. 8: Klaus Staeck, Alle reden vom Frieden, 1981 
Abbildungen

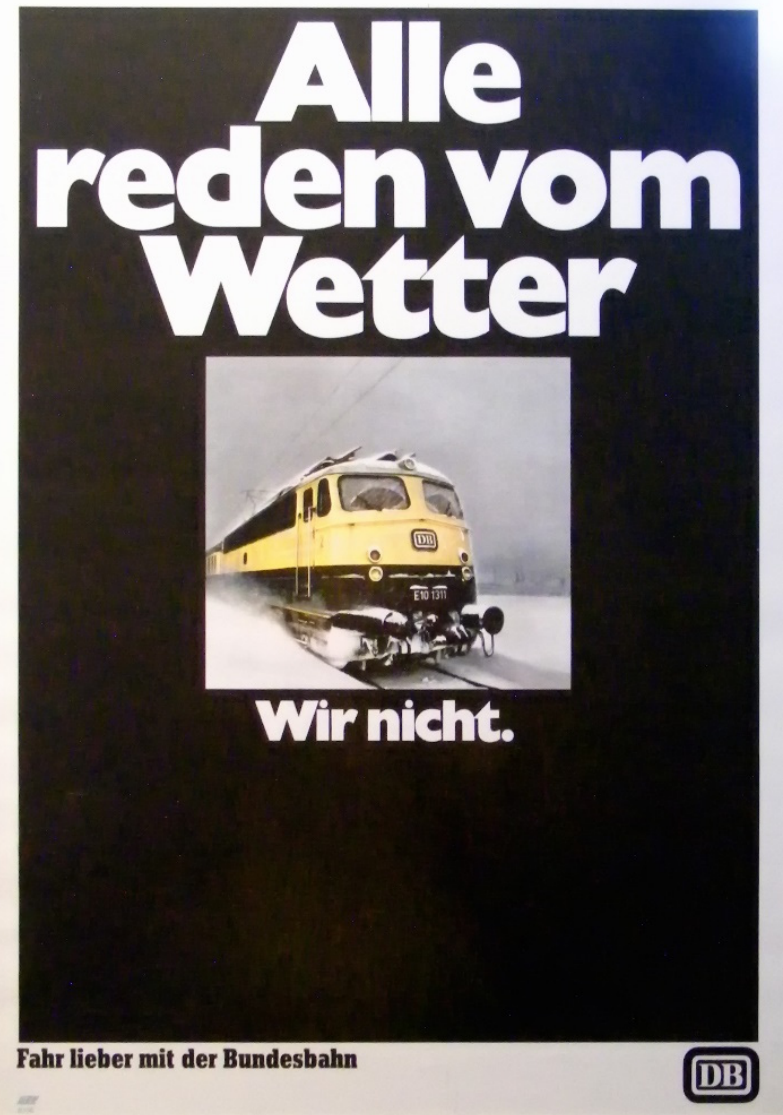

Abb. 09: Bundesbahn, Werbekampagne, 1966 
Abbildungen
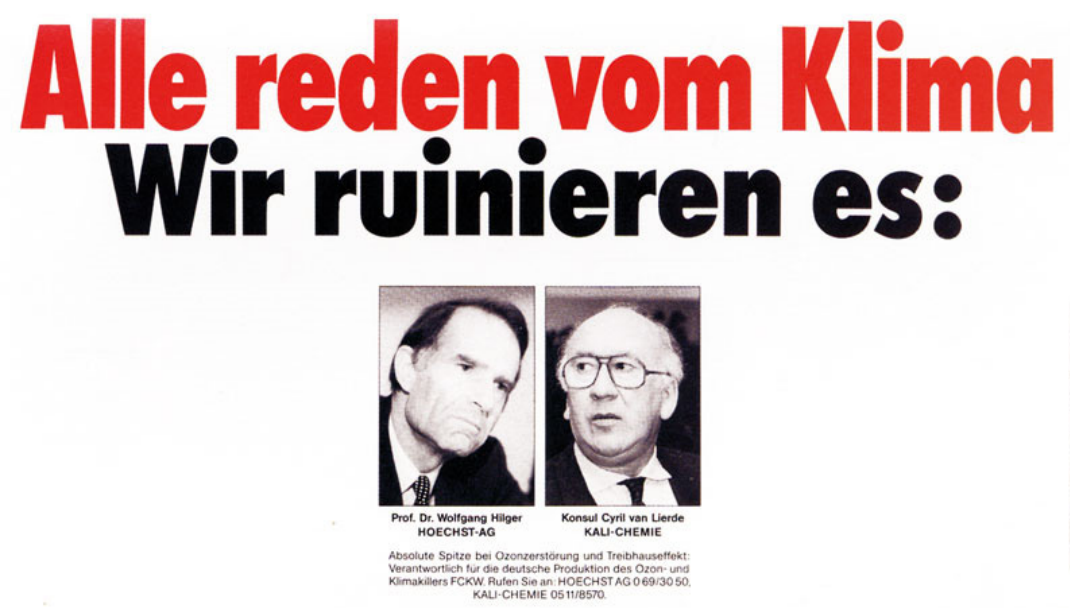

Eine Information von GREENPEACE

Bundesumweltminister Klaus Töpfer weigert sich immer noch, die Produktion von FCKW zu verbieten. $\mathbb{W}$

Abb. 10: Klaus Staeck, Alle reden vom Klima, 1990 


\section{Der größte Schwindel seit der Farbe Grön}
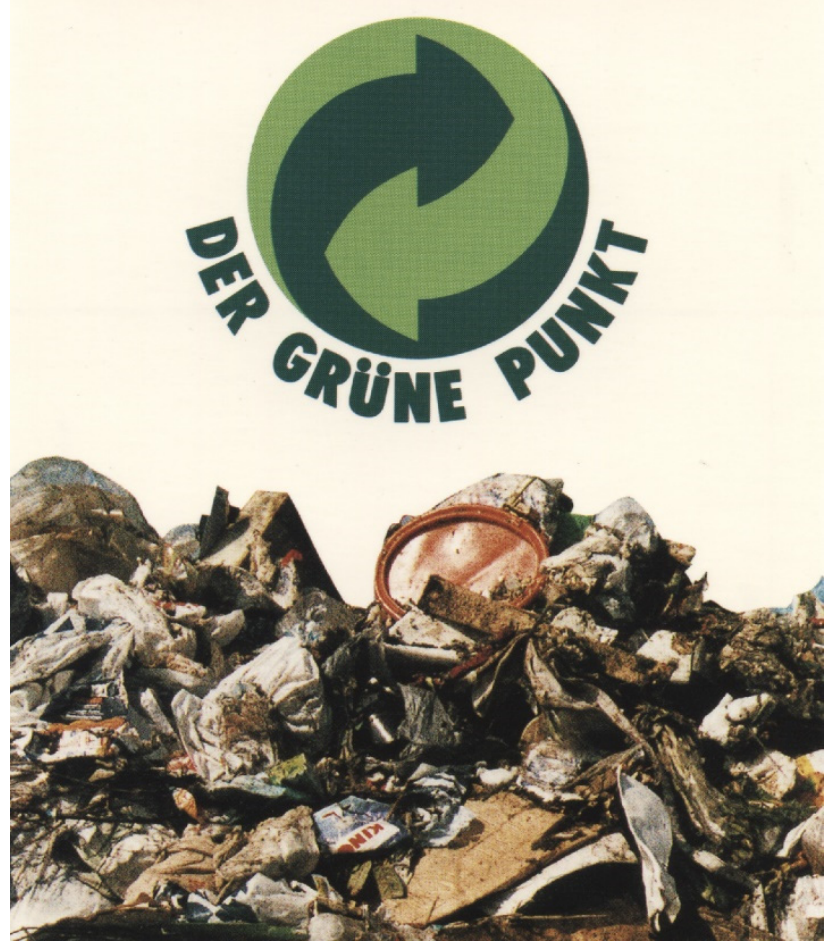

Abb. 11: Klaus Staeck, Grüner Punkt, 1992 


\section{Literaturverzeichnis}

Abromeit, Heidrun, Das Politische in der Werbung. Wahlwerbung und Wirtschaftswerbung in der Bundesrepublik, Opladen 1972

Adorno, Theodor, Minima Moralia, Reflexionen aus dem beschädigten Leben, Gesammelte Schriften in 20 Bänden, Bd. 4, Berlin 2003

- ders., Negative Dialektik. Jargon der Eigentlichkeit, Gesammelte Schriften in 20 Bänden, Bd. 6, Frankfurt am Main 1973

Albertz, Heinrich, Klaus Staeck, Sand fürs Getriebe, Göttingen 1989

Albrecht, Michael von, Horaz, in: Adamietz, Joachim (Hrsg.), Die römische Satire, Darmstadt 1986, S. 123-178

Amann, Klaus, Ironie im Dienste politischer Agitation. Walthers von der Vogelweide „Opferstock“-Strophe und das Spottgedicht auf Kaiser Ludwig den Bayern (1346/47), in: ders./Hackl, Wolfgang (Hrsg.), Satire - Ironie - Parodie. Aspekte des Komischen in der deutschen Sprache und Literatur, Innsbruck 2016, S. $95-$ 115

Aristoteles, Nikomachische Ethik, hrsg. v. Bien, Günther, übers. auf Grundlage v. Rolfes, Eugen, Hamburg 1985.

— ders., Rhetorik, übers. v. Heinrich Huebel, Stuttgart 1838

Arntzen, Helmut, Satirischer Stil zur Satire Robert Musils im „Mann ohne Eigenschaften“, 3. Aufl., Bonn 1983

— ders., Deutsche Satire im 20. Jahrhundert, Heidelberg 1964

August-Bebel-Stiftung (Hrsg.), Demokratie stärken. Die Verleihung des August-BebelPreises an Günter Wallraff, Klaus Staeck und Gesine Schwan, Berlin 2017

Bamberger, Georg/Roth, Herbert/Hau, Wolfgang/Poseck, Roman, Beck'scher OnlineKommentar Bürgerliches Gesetzbuch, 53 Ed. München 2020 [zit.: BeckOK $\mathrm{BGB} /$ Bearbeiter]

Bauer, Eva-Maria, Die Aneignung von Bildern. Eine urheberrechtliche Betrachtung von der Appropriation Art bis hin zu Memes, Baden-Baden 2020

Baumgartner, Jody/Morris, Jonathan S., The Daily Show effect: Candidate evaluations, efficacy, and American youth, American Politics Research, 34 (3), S. 341367

Beaucamp, Eduard, Der neue Bildersturm, Frankfurter Allgemeine Zeitung, 7.9.2001

Beaugrand, Andreas, Adbusts, Kunst und Kommunikation. Über den kulturgeschichtlichen Kontext eines Kunstphänomens, in: Beaugrand, Andreas/Smolarski, Pierre (Hrsg.), Adbusting. Ein designrhetorisches Strategiehandbuch, Bielefeld 2016, S. 6-23 


\section{Literaturverzeichnis}

Becker, Bernhard von, Rechtsfragen der Satire, GRUR 2004, S. 908-913

Behler, Ernst, „Ironie“, in: Ueding, Gert (Hrsg.), Historisches Wörterbuch der Rhetorik, Bd. 4, Hu-K, Tübingen 1998, Sp. 599-624

Behrmann, Sven, Politische Satire im deutschen und französischen Rundfunk, Würzburg 2002

Beisel, Daniel, Die Kunstfreiheitsgarantie des Grundgesetzes und ihre strafrechtlichen Grenzen, Heidelberg 1997

Bender, Justus, „Viele fühlen sich heimatlos, ausgesetzt und abgehängt“ Interview mit Hans Vorländer, FAZ, 23.2.2015, https:/www.faz.net/aktuell/politik/inland/ rechtsextremismus/hans-vorlaender-zu-fremdenfeindlichkeit-in-sachsen-1408491 1.html?printPagedArticle=true\#pageIndex_2\&service=printPreview\&service=pri ntPreview

Blum, Gerd, „Vorsicht Kunst“. Die Fotomontagen von Klaus Staeck, in: Paul, Gerhard (Hrsg.), Das Jahrhundert der Bilder, Band 2, Göttingen 2008, S. 418-425

Bogerts, Lisa/Fielitz, Maik, "Do You Want Meme War?” Understanding the Visual Memes of the German Far Right: Online Actions and Offline Consequences in Europe and the US, in: Fielitz, Maik/Thruston, Nick (Hrsg.), Post-digital Cultures of the Far Right. Online Actions and Offline Consequences in Europe and the US, Bielefeld 2019, S. 137-153

Bobrmann, Hans (Hrsg.), Politische Plakate, Dortmund 1984

Böll, Heinrich, Wie man eine Sache hochspielen kann, in: Karst, Ingeborg (Hrsg.), Der Fall Staeck oder: wie politisch darf die Kunst sein?, Göttingen 1975, S. 9-11

—ders./Kopelev, Lev/Staeck, Klaus, Wir kommen weit her - Gedichte, Göttingen 1986

Bott, Hermann, Die Volksfeind-Ideologie: Zur Kritik rechtsradikaler Propaganda, Stuttgart 1969

Bowen, Claire, „Pastiche“, in: Greene, Ronald (Hrsg.), The Princeton Encyclopedia of Poetry and Poetics, 4. Aufl., Princeton 2012, S. 1005

Braun, Joshua A./Eklund, Jessica L., Fake News, Real Money: Ad Tech Platforms, Profit-Driven Hoaxes, and the Business of Journalism, Digital Journalism 2019, 7:1, S. 1-21 https://doi.org/10.1080/21670811.2018.1556314

Brauneck, Anja, Das allgemeine Persönlichkeitsrecht im Konflikt mit dem verfassungsrechtlichen Freiheitsanspruch der Satire, ZUM 2000, S. 137-142

- dies., Das Problem der Authentizität in der Dokumentarsatire - Anm. zu BGH ZUM 2017, 429, ZUM 2017, S. 432-434

Brinkmann, Franziska, Formen der Kopie von der Fälschung bis zur Hommage eine Begriffsbestimmung und ihre Grenzen, in: Dreier, Thomas/Jehle, Oliver (Hrsg.), Original - Kopie - Fälschung, Baden-Baden 2020, S. 57-104

Brzoska, Michael/Wulf, Herbert, In aller Stille ist die Bundesrepublik Deutschland zu einem Hauptexporteur für Rüstung geworden, Deutsches Allgemeines Sonntagsblatt, 30.11.1980, S. 10 
Brummack, Jürgen, Zu Begriff und Theorie der Satire, Deutsche Vierteljahresschrift für Literaturwissenschaft und Geistesgeschichte 45 (1971), S. 275-377 [zit.: Brummack, DVjs 45]

Brummack, Jürgen, Satirische Dichtung. Studien zu Friedrich Schlegel, Tieck, Jean Paul und Heine, München 1979

Bundesministerium des Innern, für Bau und Heimat, Verfassungsschutzbericht 2018, Berlin 2019 https://www.verfassungsschutz.de/embed/vsbericht-2018.pdf

Burg, Tobias, Von Warhol bis Richter - Grafik zwischen Foto und Druck, in: Museum Folkwang (Hrsg.), Klaus Staeck. Sand fürs Getriebe, Ausst. Kat. Museum Folkwang, Göttingen 2018, S. 23-26

Burke, Kenneth, Attitudes Towards History, Berkeley 1987

Castorp, Claus, „Nimmt Springer noch am öffentlichen Leben teil?“, Deutsches Allgemeines Sonntagsblatt, 7.3.1976, o. Seitenangabe

Chen, Hsuan-Ting/Gan, Chen/Sun, Ping, How does Political Satire Influence Political Participation? Examining the Role of Counter-and Proattitudinal Exposure, Anger, and Personal Issue Importance, International Journal of Communication Bd. 11, 2017, S. 3011-3029

Christoph, Stephan, Die Strafbarkeit satirisch überzeichneter Schmähkritik, JuS 2016, S. 599-603

Condren, Conal, Satire and definition, HUMOR International Journal of Humor Research, 25,4, 2012, S. 375-399

Creusere, Marlena A., A Developmental Test of Theoretical Perspectives on the Understanding of Verbal Irony: Children's Recognition of Allusion and Pragmatic Insincerity, in: Gibbs, Raymond W. Jr./Colston, Herbert L. (Hrsg.), Irony in Language and Thought. A Cognitive Science Reader, New York, London 2007, S. 409-424

Cueni, Raphaela, Schutz von Satire im Rahmen der Meinungsfreiheit, Zürich, St. Gallen 2019

Deiters, Franz-Josef, Bilder ohne Rahmen - Zur Rhetorik des Plakats, in: Knape, Joachim (Hrsg.), Medienrhetorik, Tübingen 2005, S. 81-112

Deiters, Franz-Josef, „Plakat“, in: Ueding, Gert (Hrsg.), Historisches Wörterbuch der Rhetorik, Bd. 6, Must-Pop, Tübingen 2003, Sp. 1230-1239

Declercq, Dieter, A Definition of Satire (and why a definition matters), Journal of Aesthetics and Art Criticism 2018, 319-330

Dieckmannshenke, Hajo/Klemm, Michael/Stöckl, Hartmut (Hrsg.), Bildlinguistik. Theorien - Methoden - Fallbeispiele, Berlin 2011

Diekmannshenke, Hajo, ,Schlagbilder', in: Dieckmannshenke/Klemm/Stöckl (Hrsg.), Bildlinguistik. Theorien - Methoden - Fallbeispiele, 2011, S. 161-184

Di Fabio, Udo, Grundrechte als Werteordnung, JZ 2004, S. 1-8

Döring, Jürgen, Plakatkunst. Von Toulouse-Lautrec bis Benetton, Ausst. Kat. Museum für Kunst und Gewerbe Hamburg, Heidelberg 1994 
Dörr, Julian, Böhmermann, kein Ziel, keine Agenda, kein Herz - Flexitarier-WGs von Münster bis Tübingen jubeln dem Satiriker zu. Dabei ist er nicht mehr als ein kalter Zyniker auf Ego-Trip, Süddeutsche Zeitung 26.8.2016

Dreier, Thomas, Schulze, Gernot, Urheberrechtsgesetz. Verwertungsgesellschaftengesetz. Kunsturhebergesetz. Kommentar, 6. Auflage, München 2018

Dyer, Richard, Pastiche, London 2007

Eckel, Jan, Die Ambivalenz des Guten. Menschenrechte in der internationalen Politik seit den 1940ern, 2. Auflage, Göttingen 2015

Eilers, Tobias, Robert Gernhardt: Theorie und Lyrik. Erfolgreiche komische Literatur in ihrem gesellschaftlichen und medialen Kontext, Münster u.a. 2011

Elliot, Robert C., The Power of Satire. Magic, Ritual, Art, Princeton 1960

Epping, Volker/Hillgruber, Christian (Hrsg.), Beck'scher Online-Kommentar Grundgesetz, 42. Ed., München 2019 [zit.: BeckOK GG/Bearbeiter]

Erlehmann (Nils Dagsson Moskopp)/Plomlompom (Christian Heller), Internet-Meme, Köln 2013

Erhardt, Elmar, Kunstfreiheit und Strafrecht - Zur Problematik satirischer Ehrverletzungen, Heidelberg 1989

Faßbender, Kurt, Was darf die Satire, NJW 2019, S. 705-710

Fahl, Christian, Böhmermanns Schmähkritik als Beleidigung, NStZ 2016, 313-318

Faulstich, Werner, Die bürgerliche Mediengesellschaft, 1700-1830, Göttingen 2002

Feinberg, Leonard, The Satirist, Ames (Iowa Sate Univ. Press) 1963

— ders., Introduction to Satire, Santa Fe 1967

Ferrari, Elisabetta, Fake accounts, real activism: Political faking and user-generated satire as activist intervention, new media \& society 2018, S. 2208-2223

Fetscher, Iring, Kritik, Aufklärung und Sichtbarmachen des Verdrängten, in: Staeck, Klaus/Bussmann, Georg/Frankfurter Kunstverein, Klaus Staeck - Rückblick in Sachen Kunst und Politik, Ausst. Kat. Frankfurter Kunstverein, Heidelberger Kunstverein, Kunstamt Tiergarten Berlin u.a., 2. Aufl., Göttingen 1980, S. 61-63

— ders., Politische Satire in der Bundesrepublik Deutschland - Anmerkungen eines Sozialwissenschaftlers, in: Münkler, Herfried/Saage, Richard (Hg,), Kultur und Politik. Brechungen der Fortschrittsperspektive heute, Opladen 1990, S. 19-32

Feuchtinger, Heinz-Werner, Plakatkunst des 19. und 20. Jahrhunderts, Hannover 1977

Fischer, Leo, Macht euch Schmutzig! Oder soll man es lassen? Über die Schmerzgrenzen der Satire, in: Berendsen, Eva/Cheema, Saba-Nur/Mendel, Meron (Hrsg.), Trigger Warnung. Identitätspolitik zwischen Abwehr und Abschottung und Allianzen, Berlin 2019, S. 235-239

Fleischhack, Marianne, Deutsche Mütter, Zeulenroda 1942

Foerster, Uly, „Der Mist muss unbedingt rausgetragen werden“, Nürnberger Nachrichten, 1.4.1976

Freud, Sigmund, Gesammelte Werke. Chronologisch geordnet, hrsg. v. Freud, Anna, Bd. 6, Frankfurt am Main 1999 
Freund, Winfried, Die literarische Parodie, Stuttgart 1981

Friedrich, Jesko, Was darf Satire? - Versuch einer Definition und Abgrenzung, ARDJahrbuch 09, S. 76-81

Frye, Northrop, Anatomy of Criticism. Four Essays, Princeton 1957

Gäbler, Bernd, Quatsch oder Aufklärung? Witz und Politik in heute show und Co., Eine Studie der Otto Brenner Stiftung, Frankfurt am Main 2006.

Gadamer, Hans-Georg, Hegel-Tage Royaumont 1964: Beiträge zur Deutung der Phänomenologie des Geistes, Nachdruck, Hamburg 2016

Gaede, Werner, Abweichen von der Norm. Enzyklopädie kreativer Werbung, München 2002

Gärtner, Sebastian, Was die Satire darf - Eine Gesamtbetrachtung zu den rechtlichen Grenzen einer Kunstform, Berlin 2009

Gaier, Ulrich, Satire. Studien zu Neidhart, Wittenwiler, Brant und zur satirischen Schreibart, Tübingen 1967.

Gernhardt, Robert, Was gibt's denn da zu lachen? Kritik der Komiker. Kritik der Kritiker. Kritik der Komik, Zürich 1988

Gerold-Tucholsky, Mary/Raddatz, FritzJ. (Hrsg), Kurt Tucholsky. Gesammelte Werke in 10 Bänden, Bd. 2, Hamburg 1960

Goethe, Johann Wolfgang von, Goethes poetische und prosaische Werke, hrsg. v. Riemer, Friedrich Wilhelm, Eckermann, Johann Peter, Bd. 1, Ausgabe 2, Stuttgart/Tübingen 1837

Goetze, Jochen/Staeck, Klaus/Gerling, Friedrich (Hrsg.), Intermedia '69, Ausst. Kat. Heidelberg, 2. Auflage, Heidelberg 1969

Gold, Helmut (Hrsg.), "wer nicht denken will fliegt raus" - Joseph Beuys Postkarten Sammlung Neuhaus, Ausst. Kat. Museum für Post und Kommunikation Frankfurt am Main, Museum für Post und Kommunikation Berlin, Heidelberg 1998

Gold, Helmut/Heuberger, Georg, Abgestempelt. Judenfeindliche Postkarten. Auf der Grundlage der Sammlung Wolfgang Haney, Ausst. Kat., Heidelberg 1999

Golbeck, Jennifer/Mauriello, Matthew/Auxier, Brooke et al, Fake News vs Satire: Dataset and Analysis, WebSci‘ 18, Amsterdam, http://web.stanford.edu/ mattm401/d ocs/2018-Golbeck-WebSci-FakeNewsVsSatire.pdf

Gosche, Anna, Das Spannungsverhältnis zwischen Meinungsfreiheit und Ehrenschutz in der fragmentierten Öffentlichkeit, Baden-Baden 2008 [zit. Gosche, Spannungsverhältnis, 2008]

Götting, Horst-Peter/Schertz, Christian/Seitz, Walter, Handbuch des Persönlichkeitsrechts, München 2008 [zit. Götting/Schertz/Seitz/Autor, Handbuch des Persönlichkeitsrechts]

Grabenwarter, Christoph/Pabel, Katharina, Europäische Menschenrechtskonvention, 6. Aufl., München 2016 [Grabenwarter/Pabel, EMRK]

Grabitz, Eberhard/Hilf, Meinhard/Nettesheim, Martin, Das Recht der Europäischen Union, Bd. I EUV/AEUV, 68. EL, München 2019 [zit.: Grabitz/Hilf/Nettesheim/Bearbeiter] 
Griffin, Dustin, Satire. A Critical Reintroduction, Univ. Press of Kentucky, Lexington (Kentucky) 1993

Greenberg, Jonathan, The Cambridge Introduction to Satire, Cambridge 2018

Große, Franziska, Bild-Linguistik. Grundbegriffe und Methoden der linguistischen Bildanalyse in Text- und Diskursumgebungen, Frankfurt am Main u.a. 2011

Gsell, Beate/Krüger, Wolfgang/Lorenz, Stephan/Reymann, Christoph (Hrsg.), BeckOnline. Großkommentar, München 2019 [zit.: BeckOGK/Bearbeiter]

Hasselmann, Jörn, Aufruf zum Bildersturm, Tagesspiegel, 15.4.2004, S. 11

Harris, David J./O'Boyle, Michael u.a. (Hrsg.), Harris, O'Boyle, Warbick, Law of the European Convention of Human Rights, 3. Aufl., New York 2014 [zit.: Harris/O'Boyle/Warbick, Law oft he ECHR, $\left.{ }^{3} 2014\right]$

Hauschild, Annette/Lorscheid, Helmut/Kampagne „Produzieren für das Leben: Rüstungsexporte stoppen" (Hrsg.), Ermittlungen gegen Rheinmetall. Rüstungsexporte vor Gericht, Bonn 1987

Heesen, Kerstin te, Das illustrierte Flugblatt als Wissensmedium der Frühen Neuzeit, Opladen 2011

Hegel, Georg Wilhelm Friedrich, Vorlesungen über die Ästhetik Erster Teil, 2. Aufl., Berlin 1842

Heinke, Daniel H., Unzulässiges Festhalten an einer überkommenden Strafnorm. $\$ 103$ StGB - wenn abschaffen, dann sofort, ZRP 2016, S. 121-122

Heißerer, Dirk, Das „beste Witzblatt der Welt“: Thomas Mann und der „Simplicissimus“, Bad Schwartau 2005

Heller, Sven/Goldbeck, Nino, Mohammed zu Gast in Popetown. Religiöse (Bild-)Satire im Spannungsfeld von medienrechtlicher Fremdkontrolle und medienethischer Selbstregulierung, ZUM 2007, S. 628-641

Henscheid, Eckhard, Satire und Begriffsverwirrung. Eine Kurzgeschichte, in: Folckers, Nils/Solms, Wilhem (Hrsg.), Was kostet der Spaß? Wie Staat und Bürger die Satire bekämpfen, Marburg 1997, S. 60-61

Henschel, Johann Friedrich, Kunstfreiheit als Grundrecht, Stuttgart u.a. 1993

Hermann, Tobias, Persönlichkeitsverletzende Passagen einer Satire - Schmähgedicht, AfO 2017, S. 177-182

Herzog, Roman (Hrsg.), Grundgesetz. Kommentar, 79. Aufl., München 2016

Heuer, Claudia, Satire und Postmoderne - unvereinbare Gegensätze? - Aktualisierungsmöglichkeiten und -notwendigkeiten des Satirebegriffs im Kontext des postmodernen Romans, Heidelberg 2014

Highet, Gilbert, The Anatomy of Satire, Princeton 1962

Hiepe, Richard, Die Fotomontage, Geschichte und Wesen einer Kunstform, in: Feuchtinger, Heinz-Werner, Plakatkunst des 19. und 20. Jahrhunderts, Hannover u.a. 1977, S. 20-25

Hoesterey, Ingeborg, Pastiche. Cultural Memory in Art, Film, Literature, Bloomington u.a. 2001 
Hofmann, Werner, "Die grellsten Erfindungen sind Zitate", in: Staeck, Klaus/Falckenberg, Harald/Seyfarth, Ludwig (Hrsg.), Nichts ist erledigt - Klaus Staeck; eine Retrospektive, Ausst. Kat. Sammlung Falckenberg in den Phoenix-Fabrikhallen Hamburg-Harburg, Göttingen 2004, S. 45-51

Hofmann, Wilhelm (Hrsg.), Kunst und Macht - Politik und Herrschaft im Medium der bildenden Kunst, Münster 2005

Hong, Mathias, Hassrede und rassistische Meinungsäußerungen in der Rechtsprechung EGMR und nach dem Wunsiedel-Beschluss des BVerfG, ZaöRV 2010, S. 73-126

Honisch, Dieter (Hrsg.), Kunst in der Bundesrepublik Deutschland - 1945-1985, Ausst. Kat. Nationalgalerie, Berlin 1985

Hörisch, Jochen (Hrsg.), Organisierte Phantasie - Medienwelten im 21. Jahrhundert - 30 Positionen, Paderborn 2014

Hoßbach, Niklas, Böhmermanns „Schmähkritik“ als Grenzfall schützenswerter Kommunikation - Anmerkung zu LG Hamburg ZUM-RD 2017, S. 412, ZUMRD 2017, S. 417-419.

Horvat-Pintarić, Vera, Das politische Plakat, in: Feuchtinger, Heinz-Werner, Plakatkunst des 19. und 20. Jahrhunderts, Hannover, Dortmund, Darmstadt, Berlin 1977, S. 99-104

Hume, Kathryn, Diffused Satire in Contemporary American fiction, Modern Philology 2007, S. 300-325

Huntington, Heide E., Affect and effect of internet memes: assessing perceptions and influence of online user-generated political discouse as media, Fort collins, Colorado 2017, https://mountainscholar.org/handle/10217/183936

Isensee, Josef/Kirchhof, Paul, Handbuch des Staatsrechts der Bundesrepublik Deutschland, Bd. VII, 3. Auflage, Heidelberg 2009 (zit.: Isensee/Kirchhof/Autor, HStR VII)

Jameson, Fredric, The Political Unconscious, Postmodernism: The Cultural Logic of Late Capitalism, Duke University Press 1991

Johann, Michael/Bülow, Lars, Die Verbreitung von Internet-Memes: empirische Befunde zur Diffusion von Bild- Sprache-Texten in den sozialen Medien, kommunikation@ gesellschaft 19 (2018), S. 1-24, https://nbn-resolving.org/urn:nbn:de: 0168-ssoar-56037-8

Kaiser, Stefan, Das Geschäft mit der Angst, Der Spiegel 22.5.2014, https://www.spie gel.de/wirtschaft/verschwoerungstheorien-der-kopp-verlag-macht-geschaefte-mit -der-angst-a-967704.html

Kämpfer, Frank, „Der rote Keil“. Das politische Plakat. Theorie und Geschichte, Berlin 1985

Karst, Ingeborg (Hrsg.), Die Reichen müssen noch reicher werden - politische Plakate, Reinbek bei Hamburg 1973

— dies. (Hrsg.), Der Fall Staeck oder wie politisch darf die Kunst sein?, Göttingen 1975

— dies. (Hrsg.), Die Reichen müssen noch reicher werden. Politische Plakate, Reinbek bei Hamburg 1977 
Kassing, Katja, Ehrverletzende Personalsatire in Deutschland, Österreich, der Schweiz und England, Frankfurt am Main 2004

Kellner, Douglas, Media Culture. Cultural studies, Identity and Politics between the Modern and the Postmodern, London u.a. 1995

Kindt, Tom, „Humor“, in: Wirth, Uwe (Hrsg.), Komik. Ein interdisziplinäres Handbuch, Stuttgart 2017, S. 7-11

—ders., „Komik“, in: Wirth, Uwe (Hrsg.), Komik. Ein interdisziplinäres Handbuch, Stuttgart 2017, S. 2-6

Klass, Nadine, Satire im Spannungsfeld von Kunstfreiheitsgarantie und Persönlichkeitsrechtsschutz - Zur rechtlichen Beurteilung der "Böhmermann-Performance" im Lichte verfassungsrechtlicher Vorgaben, AfP 2016, S. 477-495

— dies., Rechtliche Grenzen des Realitätsfernsehens. Ein Beitrag zur Dogmatik des Menschenwürdeschutzes und des allgemeinen Persönlichkeitsrechts, Tübingen 2004

Klobusch, Maximilian, Zulässigkeit und Grenzen politischer Satire am Beispiel der Bezeichnung einer Politikerin als „Nazi-Schlampe“, Anmerkung zu LG Hamburg ZUM-RD 2017, 630, ZUM-RD 2017, S. 631-633

Klöckner, Marcus, Leitartikler und Machteliten, Telepolis, 23.5.2014, https:/www.h eise.de/tp /features/Leitartikler-und-Machteliten-3365501.html.

Knape, Joachim (Hrsg.), Medienrhetorik, Tübingen 2005

Knies, Wolfgang, Schranken der Kunstfreiheit als verfassungsrechtliches Problem, München 1967

Knight, Charles A., Satire, Speech and Genre, Comparative Literature 1992 (Vol. 44, Nr. 1), S. 22-41

Knoche, Ulrich, Die römische Satire, 4. Aufl., Göttingen 1982

Köhler, Peter, Der Spaßmacher und Ernstmacher Robert Gernhardt, Der Rabe. Magazin für jede Art von Literatur. Bd. 50, Robert Gernhardt zum 60. Geburtstag 1997, S. 171-203

Kohlhammer, Siegfried, Resignation und Revolte. Immermanns „Münchhausen“: Satire und Zeitroman der Restaurationsepoche, Stuttgart 1973

Kollwitz, Käthe, Bekenntnisse, 3. Aufl., Leipzig 1987

Kosthorst, Daniel, "In lustiger Gesellschaft?" Politischer Humor als Spiegel der Zeit, in: Stiftung Haus der Geschichte der Bundesrepublik Deutschland (Hrsg.), Spaß beiseite - Politik und Humor in Deutschland, Ausst. Begleitbuch Zeitgeschichtliches Forum Leipzig der Stiftung Haus der Geschichte der Bundesrepublik Deutschland, im Haus der Geschichte der Bundesrepublik Deutschland, Bonn, Leipzig 2010, S. 11-23

Kriele, Martin, Ehrenschutz und Meinungsfreiheit, NJW 1994, S. 1897-1905

Kroeber-Riel, Werner, Bildkommunikation. Immagery-Strategien für die Werbung, München 1993

Kröncke, Gerd, Gruppenbild mit Zündstoff, SZ, 23.11.1981, S. 3

Kube Ventura, Holger, Politische Kunst Begriffe in den 1990er Jahren im deutschsprachigen Raum, Wien 2002 
Kühling, Jürgen, Was darf Satire? Eine rechtliche Annäherung in Form eines „Ringmodells“, in: Herrmann, Dirk/Krämer, Achim (Hrsg.), Festschrift für Christian Kirchberg zum 70. Geburtstag am 05. September 2017, Stuttgart 2017, S. 111126 [zit.: Kühling, FS Kirchberg 2017]

Kürschner, Wilfried (Hrsg.), Alternative Fakten, Fake News und Verwandtes: Wissenschaft und Öffentlichkeit, Berlin 2019

Ladeur, Karl-Heinz, Persönlichkeitsschutz und „Comedy“ - Das Beispiel der Fälle SAT 1/Stahnke und RTL 2/Schröder, NJW 2000, S. 1977-1982

Lange, Paul, Marken- und Kennzeichenrecht, München 2012.

Lanius, Karima, Ist „Satire [...] ästhetisch sozialisierte Aggression“? Überlegung zu einer möglichen Satiredefinition, sic 4/2019, S. 239-244

Lazarowicz, Klaus, Verkehrte Welt. Vorstudien zu einer Geschichte der deutschen Satire, Tübingen 1963

Levin, Andrej, Die lauterkeitsrechtlichen Möglichkeiten und Grenzen der humorvollen und satirischen vergleichenden Werbung, Berlin 2013

Lichtenstein, Dennis/ Nitsch, Cordula, Informativ und kritisch? Die Politikdarstellung in deutschen Satiresendungen, M\&K Medien und Kommunikation 2018, S. 5-21

Lindner, Irene, Die Persönlichkeitsverletzung durch Kunst, Baden-Baden 2015

Lipps, Theodor, Komik und Humor. Eine psychologisch-ästhetische Untersuchung, Hamburg, Leipzig 1898

Locher, Horst, Das Recht der bildenden Kunst, München 1970

Lohr, Steve, New York Times's Global Edition Is Ending Daily Political Cartoons, New York Times 10.6.2019, https:/www.nytimes.com/2019/06/10/business/inter national-new-york-times-political-cartoons.html.

Luhmann, Niklas, Die Realität der Massenmedien, Opladen 1996

Lüthy, Edwin, Das künstlerische politische Plakat in der Schweiz. Mit Äußerungen plakatschaffender Künstler und 32 originalgetreuen Wiedergaben, Basel 1920

Maier, Henrike, Meme und Urheberrecht, GRUR-Prax 2016, S. 397-398

Maier, Henrike, Remixe auf Hostingplattformen. Eine urheberrechtliche Untersuchung filmischer Remixe zwischen grundrechtsrelevanten Schranken und Inhaltefiltern, Tübingen 2018

Malhotra, Ruth, Künstler und politisches Plakat, in: Bohrmann, Hans (Hrsg.), Politische Plakate, Dortmund 1984, S. 11-48

v. Mangoldt, Hermann/Klein, Friedrich/Starck, Christian, Kommentar zum Grundgesetz, 7. Auflage, München 2018 [zit.: Mangoldt/Klein/Starck/Bearbeiter, GG]

Marwick, Alice E., Why Do People Share Fake News? A Sociotechnical Model Of Media Effects, Georgetown Law Technology Review, 2018, S. 474-512

Maunz, Theodor/Dürig, Günter, Grundgesetz. Kommentar, 85. Lieferung, München 2018 (zit.: Maunz/Dürig/Bearbeiter)

McClennen, Sophia A./Maisel, Remy M., Is Satire Saving our Nation? Mockery and American Politics, New York 2014 
Merkert, Jörn (Hrsg.), Klaus Staeck - Schöne Aussichten - eine Retrospektive, Ausst. Kat. Berlinische Galerie, Landesmuseum für Moderne Kunst, Fotografie und Architektur, Berlin, Göttingen 2009

Merten, Detlef/Papier, Hans-Jürgen (Hrsg.), Handbuch der Grundrechte in 12 Bänden, Bd. 4, Heidelberg 2011 [zit.: Merten/Papier/Bearbeiter, HGR]

Meyer-Sickendieck, Burkhard, „Sarkasmus“, in: Ueding, Gert (Hrsg.), Historisches Wörterbuch der Rhetorik, Bd. 8, Rhet-St, Tübingen 2007, Sp. 436-447

Mohr, Reinhard, Schluss mit lustig? Alte und neue Tabus, in: Stiftung Haus der Geschichte der Bundesrepublik Deutschland (Hrsg.), Spass beiseite - Politik und Humor in Deutschland, Ausst. Begleitbuch Zeitgeschichtliches Forum Leipzig der Stiftung Haus der Geschichte der Bundesrepublik Deutschland, im Haus der Geschichte der Bundesrepublik Deutschland, Bonn, Leipzig 2010, S. 139-149

Morawietz, Holger, Alternative Fakten, Fake-News und Lügen mit dem Internet einfach enttarnen. Definitionen, Beispiele, Strategien, in: Kürschner, Wilfried (Hrsg.), Alternative Fakten, Fake News und Verwandtes: Wissenschaft und Öffentlichkeit, Berlin 2019, S. 57-82

Moritz, Angela, Das Plakat als Mittel der politischen Provokation. Klaus Staecks Werk in der BRD und der DDR, in: Hofmann, Wilhelm (Hrsg.), Kunst und Macht - Politik und Herrschaft im Medium der bildenden Kunst, Münster 2005, S. 236-249

Moroni, Manuela Caterina, Ironie und Intonation im privaten Gespräch, in: Amann, Klaus, Hackl, Wolfgang (Hrsg.), Satire - Ironie - Parodie. Aspekte des Komischen in der deutschen Sprache und Literatur, Innsbruck 2016, S. 167-185

Muckenhaupt, Manfred, Text und Bild. Grundfragen der Beschreibung von TextBild-Kommunikation aus sprachwissenschaftlicher Sicht, Tübingen 1986

Museum Folkwang (Hrsg.), Klaus Staeck. Sand fürs Getriebe, Ausst. Kat. Museum Folkwang, Göttingen 2018

Mübleisen, Hans-Otto (Hrsg.), Grenzen politischer Kunst, München 1982

Müller, Beate, Komische Intertextualität: Die literarische Parodie, Trier 1994

Müller, Gerd, Das Wahlplakat - Pragmatische Untersuchungen zur Sprache in der Politik am Beispiel von Wahlplakaten aus der Weimarer Republik und der Bundesrepublik, Tübingen 1978

Müller-Brockmann, Shizuko/Müller-Brockmann, Josef, Geschichte des Plakats, Zürich 1971

Müller-Riemenschneider, Severin, Pressefreiheit und Persönlichkeitsschutz. Zur Rechtsprechung von Bundesverfassungsgericht und Europäischem Gerichtshof für Menschenrechte, Hamburg 2013

Nekula, Marek, Ironiesignal. Beschreibung der Ironie in Handlung und Text, in: Brünner Beiträge zur Germanistik und Nordistik, 1996, 41-53

Neumann-Duesberg, Horst, Bildberichterstattung über absolute und relative Personen der Zeitgeschichte, JZ 1960, S. 114-118

Nowak, Peter, Satire oder Sachbestätigung, taz, 8.10.2019, https://taz.de/Adbusting -Prozes/!5628427/ 
— ders., Gefährdet Adbusting die Grundordnung, telepolis, 9.10.2019, https://www. heise.de/tp/features/Gefaehrdet-Adbusting-die-Grundordnung-4549401.html

Nöth, Winfried, Der Zusammenhang von Text und Bild, in: Antos, Gerd/Brinker, Klaus/Heinemann, Wolfgang/Sager, Sven, Text- und Gesprächslinguistik. Ein internationales Handbuch zeitgenössischer Forschung, 1. Halbband, Berlin 2001, S. 489-496.

Ohly, Ansgar, HipHop und die Zukunft der „freien Benutzung“ im EU-Urheberrecht. Anmerkungen zum Vorlagebeschluss des BGH „Metall auf Metall III“, GRUR 2017, 964-969

Oppermann, Gregor, Ehrensache Satire: Zur Frage satirischer Ehrbeeinträchtigungen im Strafrecht, Berlin 2015

Ossenbühl, Fritz, Medienfreiheit und Persönlichkeitsschutz, ZUM 1999, S. 505-513

Paul, Gerhard (Hrsg.), Das Jahrhundert der Bilder, Band 2, Göttingen 2008

Paul, Jean, Vorschule der Ästhetik nebst einigen Vorlesungen in Leipzig über die Parteien der Zeit, in: Pfotenhauer, Helmut/Hunfeld, Barbara (Hrsg.), Werke. Historisch-Kritische Ausgabe, Bd. 2, Berlin, München 2015

Podskalsky, Vera, Jan Böhmermann und Die Partei. Neue Formen der Satire im 21. Jahrhundert und ihre ethische (Un-)Begrenztheit, Würzburg 2017

Preisendanz, Wolfgang/Warning, Rainer (Hrsg.), Das Komische, München 1976

Rabener, Gottlieb Wilhelm, Gottliebt Wilhelm Rabeners Satire. Vierter und letzter Theil, Leipzig 1763

Referat Öffentlichkeitsarbeit der CSU-Landesleitung (Hrsg.), Der Mann., München 1979, o. Seitenangaben

Ridder, Helmut, Freiheit der Kunst nach dem Grundgesetz, Berlin u.a. 1963

Riedl, Rita, „AIDA-Formel“, in: Ueding, Gert (Hrsg.), Historisches Wörterbuch der Rhetorik Band 1, A-Bib, Tübingen 1992, Sp. 285-295

Rittig, Gabriele, Preis der Satire, in: Folckers, Nils/Solms, Wilhem (Hrsg.), Was kostet der Spaß? Wie Staat und Bürger die Satire bekämpfen, Marburg 1997, S. $62-83$

Romain, Lothar, Kunst die auf die Straße geht. Anmerkungen zu den Plakaten von Klaus Staeck, in: Staeck, Klaus/Adelmann, Dieter, Der Bonner Bildersturm oder: was die CDU von Demokratie hält, 2. Aufl., Göttingen 1976, S. 15-33

— ders., Die alltägliche Kunstfeindlichkeit, in: Staatliche Museen Preußischer Kulturbesitz (Hrsg.), 1945-1985. Kunst in der Bundesrepublik, Ausst. Kat. Nationalgalerie Berlin, Berlin 1985, S. 630-637

—ders., Die Montage zur Demontage - Der Künstler Klaus Staeck von 1956 bis heute, in: Staeck, Klaus/Falckenberg, Harald/Seyfarth, Ludwig (Hrsg.), Nichts ist erledigt - Klaus Staeck; eine Retrospektive, Ausst. Kat. Sammlung Falckenberg in den Phoenix-Fabrikhallen Hamburg-Harburg, Göttingen 2004, S. 27-32

Rösch, „Karikatur“, in: Fricke, Harald et al. (Hrsg.), Reallexikon der deutschen Literaturwissenschaft. Neubearbeitung des Reallexikons der deutschen Literaturgeschichte, Bd. II H-O, Berlin/New York 2007 
Rose, Margaret A., Parodie, Intertextualität, Interbildlichkeit, Bielefeld 2006

Rosenberger, Sebastian, Satire und Sprachgeschichtsschreibung. Theoretische und methodische Überlegungen, Jahrbuch für Germanistische Sprachgeschichte, Bd. 5, 2014, S. 266-280

Rosenheim, Edward W., Swift and the Satirist's Art, Chicago 1963

Rother, Bernd, "Jetzt wächst zusammen, was zusammengehört" Oder: Warum Historiker Rundfunkarchive nutzen sollten, in: Bundeskanzler-Willy-Brandt-Stiftung (Hrsg.), Wächst zusammen, was zusammengehört?, Potsdam 2001, S. 25.

Rubin, Victoria L./Brogly, Chris/Conroy, Nadia/Chen, Yimin/Cornwell, Sarah E./Asubiaro, Toluwase V., A News Verification Browser for the detection of Clickbait, Satire, and Falsified News, Journal of Open Source Software, 2019, 4 (35), S. 1208

—dies./Conroy Niall J./Chen, Yimin/Cornwell, Sarah, Fake News or Truth? Using Satirical Cues to detect Potentially Misleading News, Proceedings of NAACL-HLT 2016, Proceedings of the Second Workshop on Computational Approaches to Deception Detection, S. 7-17

-dies./Chen, Yimin/Conroy Niall J., Deception detection for News: Three Types of Fakes, Proceedings of the ASIST Annual Meeting 2015, S. 1-4

Rühl, Ulli F.H., Tatsachen - Interpretationen - Wertungen: Grundfragen einer anwendungsorientierten Grundrechtsdogmatik, Baden-Baden 1998

Rusch, Roman/Becker, Thomas G., Warum Satire eben doch fast alles darf, AfP 2016, S. 201-205

Säcker, Franz Jürgen/Rixecker, Roland/Oetker, Hartmut/Limperg, Bettina, Münchner Kommentar zum Bürgerlichen Gesetzbuch, Bd. 1, 8. Auflage, München 2018 [zit.: MüKoBGB/Bearbeiter]

Sängerlaub, Alexander/Meier, Miriam/Rühl, Wolf-Dieter, Fakten statt Fakes. Verursacher, Verbreitungswege und Wirkungen von Fake News im Bundestagswahlkampf 2017, Studie der Stiftung Neue Verantwortung 2018, https:/www.stiftun g-nv.de/sites/default/files/snv_fakten_statt_fakes.pdf

Sava, Doris, Scherz, Satire \& Ironie - Internet-Meme als öffentliche Kritikform, in: Germanistische Beiträge, Bd. 43, Editura Universităţii „Lucian Blaga” din Sibiu, Sibiu 2018, S. 151-174

Schiller, Friedrich, Über naive und sentimentalische Dichtung, Berlin 2013

Schindler, Herbert, Monografie des Plakats. Entwicklung, Stil, Design, München 1972

Schertz, Christian, Bildnisse die einem höheren Interesse der Kunst dienen - die Ausnahmevorschrift des $₫ 23$ Abs. 1 Nr. 4 KUG, GRUR 2007, S. 558-565

Schmidt, Christian, Titanic. Die verbotenste Zeitschrift Deutschlands, in: Folckers, Nils/Solms, Wilhelm (Hrsg.), Risiken und Nebenwirkungen. Komik in Deutschland, Berlin 1996, S. 176-190

Schmitz, Christine, Das Satirische in Juvenals Satiren, Berlin, New York 2000

Schmolck, H. C. (Hrsg.), Staeck: Pornografie, Steinbach 1971 
Schopenhauer, Arthur, Wille und Vorstellung, Bd. 1, 4. Aufl., Leipzig, 1873

Schönert, Jörg, Roman und Satire im 18. Jahrhundert. Ein Beitrag zur Poetik, Stuttgart 1969

Schultz-Gerstein, Christian, Satire nicht erwünscht, Die Zeit, 5.3.1976, S. 37

Schwarzenegger, Christian/Wagner, Anna, Can it be hate if it is fun? Discursive ensembles of hatred and laughter in extrem right satire on Facebook, Studies in Communication and Media, (Bd, 4) 2018, S. 473-498

Schweinebraden v. Wichmann-Eichhorn, Jürgen, Kunst und Politik, in: Staatliche Museen Preußischer Kulturbesitz (Hrsg.), 1945-1985. Kunst in der Bundesrepublik, Ausst. Kat. Nationalgalerie Berlin, Berlin 1985, S. 300-307

—ders. (Hrsg.), Klaus Staeck - Umwelt auf dem Prüfstand - Plakate 1971-2001, Niedenstein 2001

Schwind, Klaus, Satire in funktionalen Kontexten. Theoretische Überlegungen zu einer semiotisch orientierten Textanalyse, Tübingen 1988

Schwind, Klaus, „Komisch“, in: Barck, Karlheinz/Fontius, Martin/Schlenstedt, Dieter/Steinwachs, Burkhart/Wolfzettel, Friedrich (Hrsg.), Ästhetische Grundbegriffe. Historisches Wörterbuch in sieben Bänden, Bd. 3. Stuttgart u.a. 2001, S. 332383

Sellin, Wolfgang (Hrsg.), Die Gedanken sind frei - Plakate, 2. Aufl., Berlin 1981

Senefelder, Alois, Vollständiges Lehrbuch der Steindruckerey. enthaltend eine richtige und deutliche Anweisung zu den verschiedenen Manipulations-Arten derselben in allen ihren Zweigen und Manieren belegt mit den nöthigen Musterblättern nebst einer vorangehenden ausführlichen Geschichte dieser Kunst von ihrem Entstehen bis auf gegenwärtige Zeit, München/Wien 1818

Senn, Mischa, Satire und Persönlichkeitsschutz - Zur rechtlichen Beurteilung satirischer Äußerungen auf der Grundlage der Literatur- und Rezeptionsforschung, Bern 1998

Seyfarth, Ludwig, Die Macht der Bilder und Worte - Klaus Staeck und die zeitgenössische Kunst, in: Staeck, Klaus/Falckenberg, Harald/Seyfarth, Ludwig (Hrsg.), Nichts ist erledigt - Klaus Staeck. Eine Retrospektive, Ausst. Kat. Sammlung Falckenberg in den Phoenix-Fabrikhallen Hamburg-Harburg, Göttingen 2004, S. 147-153

Siegle, Miriam, Das Spannungsverhältnis von Kunstfreiheit und Persönlichkeitsrecht - zur Problematik der Darstellung realer Personen in Kunstwerken, Baden-Baden 2012

Simpson, Paul, On the Discourse of Satire, Amsterdam/Philadelphia 2003

Sindermann, Thorsten, Über praktischen Humor. Oder eine Tugend epistemischer Selbstdistanz, Würzburg 2009

Sloterdijk, Peter, Kritik der zynischen Vernunft, Frankfurt am Main 1983

Smolarski, Werbeparasiten und Designrhetorik. Eine Einleitung, in: Beaugrand/Smolarski (Hrsg.), Adbusting. Ein designrhetorisches Strategiehandbuch, 2016, S. 32-45 


\section{Literaturverzeichnis}

Solms, Wilhelm, Warum stehen Satiriker in den 90er Jahren so oft vor Gericht?, in: Folckers, Nils/Solms, Wilhem (Hrsg.), Was kostet der Spaß? Wie Staat und Bürger die Satire bekämpfen, Marburg 1997, S. 9-32

Spielmann, Heinz, Kunsthistorische Aspekte des frühen Plakats in England und den Vereinigten Staaten, in: Malhotra, Ruth/Thon, Christina/Kunstbibliothek Staatliche Museen Preußischer Kulturbesitz Berlin/Museum für Kunst und Gewerbe Hamburg (Hrsg.), Das frühe Plakat in Europa und den USA, Bd. 1, Berlin 1973, S. 14-39

Stark, Ralf, Ehrenschutz in Deutschland, Berlin 1996

Staeck, Klaus, Reichen müssen reicher werden. Politische Plakate, Reinbek bei Hamburg 1973

- ders., Plakate abreißen verboten! Politische Plakate im Bundestagswahlkampf 72, 2. Aufl., Göttingen 1975

— ders., Plakate, Düsseldorf 1988

— ders., Brauchen wir eine neue Regierung?, Göttingen 1990

— ders., Bericht zur Schieflage der Nation, Göttingen 1991

- ders., Ohne Auftrag - Unterwegs in Sachen Kunst und Politik, 2. Aufl., Göttingen 2001

— ders, Frohe Zukunft, Göttingen 2004

- ders., „Demokratie kommt nicht aus der Steckdose“, Monte Packham im Gespräch mit Klaus Staeck, in: Museum Folkwang (Hrsg.), Klaus Staeck. Sand fürs Getriebe, Ausst. Kat. Museum Folkwang, Göttingen 2018, S. 8-19

- ders./Adelmann, Dieter, Die Kunst findet nicht im Saale statt. Politische Plakate, Reinbek bei Hamburg 1976

— ders. - _ ders., Der Bonner Bildersturm oder: was die CDU von Demokratie hält, 2. Aufl., Göttingen 1976

- ders./Bussmann, Georg/ Frankfurter Kunstverein, Klaus Staeck - Rückblick in Sachen Kunst und Politik, Ausst. Kat. Frankfurter Kunstverein, Heidelberger Kunstverein, Kunstamt Tiergarten Berlin u.a., 2. Aufl. Göttingen 1980

- ders./Falckenberg, Harald/Seyfarth, Ludwig (Hrsg.), Nichts ist erledigt - Klaus Staeck. Eine Retrospektive, Ausst. Kat. Sammlung Falckenberg in den PhoenixFabrikhallen Hamburg-Harburg, Göttingen 2004

— ders./Steidl, Gerhard, Beuys in Amerika, Heidelberg 1987

Stäcker, Dieter, „Juso beißt wehrloses Kind“-Plakat darf verbreitet werden, Frankfurter Rundschau, 28.2.1976, S. 1

— ders, Juso darf wehrloses Kind weiterbeißen, Badische Zeitung, 28.2.1976, S. 12

Steidl, Gerhard, Before Photoshop, in: Merkert (Hrsg.), Klaus Staeck. Schöne Aussichten. Eine Retrospektive, Ausst. Kat. Berlinische Galerie, Göttingen 2009, S. $180-187$

- ders., Plakate drucken für Staeck, in: Museum Folkwang (Hrsg.), Klaus Staeck. Sand fürs Getriebe, Ausst. Kat. Museum Folkwang, Göttingen 2018, S. 233-241 
Stelmach, Nathalie/Wegner, Ludwig, Kunst in der politischen Diskussion. Der Vorwurf der „politischen Pornographie“, Hypotheses, 8.10.2017, https://kstreit.hypo theses.org/554\#more-554

Stern, Klaus, Staatsrecht, Die einzelnen Grundrechte, Bd. IV/2, München 2011

Stieper, Malte, Fan Fiction als moderne Form der Pastiche. Zur Abgrenzung von Vervielfältigung, Bearbeitung und freier Benutzung im Lichte des Unionsrechts, AfP 2015, S. 301-305

Stöckl, Hartmut, Sprache-Bild-Texte lesen. Bausteine zur Methodik einer Grundkompetenz, in: Dieckmannshenke, Hajo/Klemm, Michael/Stöckl, Hartmut (Hrsg.), Bildlinguistik. Theorien - Methoden - Fallbeispiele, Berlin 2011, S. 4570

Stauffer, „Polemik“, in: Ueding, Gert (Hrsg.), Historisches Wörterbuch der Rhetorik, Bd. 6, Must-Pop, Tübingen 2003, Sp. 1403-1415

Tandoc Jr., Edson C./Lim, Zheng Wei/Ling, Richard, Defining „Fake News“, Digital Journalism 2018, 6:2, S. 137-153, https://doi.org/10.1080/21670811.2017.136014 3

Tannert, Christoph, Stolperstein und Anstifter sein. Über die Fotografien und Collagen von Klaus Staeck, in: Staeck, Klaus/Falckenberg, Harald/Seyfarth, Ludwig (Hrsg.), Nichts ist erledigt - Klaus Staeck; eine Retrospektive, Ausst. Kat., Sammlung Falckenberg in den Phoenix-Fabrikhallen Hamburg-Harburg, Göttingen 2004, S. 103-109

Teichmann, Christoph, Abschied von der absoluten Person der Zeitgeschichte, NJW 2007, S. 1917-1920

Test, George A., Satire. Spirit and Art, Tampa 1991

Teuber, Dirk, Klaus Staeck, in: Holten (Hrsg.), Bilderbedarf. Braucht Gesellschaft Kunst?, Ausst. Kat., Staatliche Kunsthalle Baden-Baden, Köln 2012, S. 69-73

Thomas, Karin, Formen einer Kommunikation von Kunst und Gesellschaft, in Feuchtinger, Heinz-Werner, Plakatkunst des 19. und 20. Jahrhunderts, Hannover u.a. 1977 , S. $70-72$

Toscani, Oliviero, Die Werbung ist ein lächelndes Aas, 7. Aufl., Frankfurt am Main 1997

Ullrich, Anna Valentina, Gebaute Zitate: Formen und Funktionen des Zitierens in Musik, Bild und Architektur, Bielefeld 2015

Ullrich, Wolfgang, Hier wache ich! Warum Klaus Staeck der nützlichste Künstler der Bundesrepublik ist, Art 2014/12, S. 52-56

— ders., Die Tabubrecher. Wie moralisch soll Kunst sein?, in: SWR 2 Wissen: Aula, Sendung vom 10.5.2018, Manuskript abrufbar unter https://www.swr.de/-/id=21 434428/property=download/nid=660374/1oypahl/swr2-wissen-20180510.pdf

Vinsor, Thomas, In Hamburg lächelte das Gericht, Neue Rhein-Zeitung, 28.2.1976, o. Seitenangaben

Vlah, Tudor, Parodie, Pastiche und Karikatur - Urheberrechte und ihre Grenzen. Eine rechtsvergleichende Untersuchung des deutschen und spanischen Urheberrechts, Frankfurt am Main 2015 
Voegtle, Simone, Graffiti und Karikaturen als Medien der Kommunikation im städtischen Raum, in: v. Mundt, Felix (Hrsg.), Kommunikationsräume im kaiserzeitlichen Rom, Berlin 2012, S. 105-121

Walker, John A., Left Shift. Radical Art in 1970s Britain, London u.a. 2002

Wallraff, Günter/Hagen, Jens, Was wollt ihr denn, ihr lebt ja noch - Chronik einer Industrieansiedlung, Reinbek b. Hamburg 1976

—dies.Jungk, Robert, Was wollt ihr denn, ihr lebt ja noch - Chronik einer Industrieansiedlung, München 1985

Wandtke, Arthur Axel, Persönlichkeitsschutz versus Internet, MMR 2019, 142-147

—ders./Bullinger, Winfried, Praxiskommentar Urheberrecht, 5. Auflage, München 2019

Weart, Spencer R., The Discovery of Global Warming, Cambridge/London 2004

Wetzel, Jakob, Satire - das unbekannte Stilprinzip. Wesen und Grenzen im Journalismus, Communicatio Socialis 45 (2012), S. 276-291

Willer, Stefan, „Witz“, in: Wirth, Uwe (Hrsg.), Komik. Ein interdisziplinäres Handbuch, Stuttgart 2017, S. 11-16

Winkler, Markus, „Komik“, in: Ueding, Gert (Hrsg.), Historisches Wörterbuch der Rhetorik, Bd. 4, Hu-K, Tübingen 1998, Sp. 1166-1176

Wirth, Uwe, „Parodie“, in: Wirth, Uwe (Hrsg.), Komik. Ein interdisziplinäres Handbuch, Tübingen 2017, S. 26-30

Wölfflin, Heinrich, Die Kunst Albrecht Dürers, München 1971

Worcester, David, The Art of Satire, New York 1960

Würtenberger, Thomas, Karikatur und Satire aus strafrechtlicher Sicht, NJW 1982, S. 610-616

— ders., Satire und Karikatur in der Rechtsprechung, NJW 1983, S. 1144-1151

Wüst-Kralowetz, Elke, John Heartfield und die politische Fotomontage: drei Werke aus dem Jahr 1932 für die Arbeiter Illustrierte Zeitung (AIZ), in: Hemingway, Andrew/Schneider, Norbert (Hrsg.), Schwerpunkt: Hauptwerke politischer Kunst im 20. Jahrhundert, Göttingen 2016, S. 45-56

Zechlin, Lothar, Kunstfreiheit, Strafrecht und Satire, NJW 1984, 1091-1093

Zehrer, Klaus Cäsar, Dialektik der Satire. Zur Komik von Robert Gernhardt und der „Neuen Frankfurter Schule“, Osnabrück 2002

Zeller, Ursula, Die Frühzeit des politischen Bildplakats in Deutschland (1848-1918), Stuttgart 1988

Zentralarchiv des internationalen Kunsthandels e.V. ZADIK (Hrsg.), Joseph Beuys. Wir betreten den Kunstmarkt, sediment. Mitteilungen zur Geschichte des Kunsthandels, Nürnberg 2009

Zimmer, Dieter E., Wie liberal wollen wir sein?, Die Zeit 1975/5 (24.1.1975), https:// www.zeit.de/1975/05/wie-liberal-wollen-wie-sein/komplettansicht

Zinsmaier, Thomas, „Zynismus“, in: Historisches Wörterbuch der Rhetorik, Band 9, St-Z, Tübingen 2009, Sp. 1594-1606 
Zymner, Rüdiger, „Satire“, in: Wirth, Uwe (Hrsg.), Komik. Ein interdisziplinäres Handbuch, Stuttgart 2017, S. 21-25

N.N., Die Kunst findet nicht im Saale statt - Der Plakatkünstler Klaus Staeck, 2020, Fernsehreportage, SWR, 16.4.2020, 22:45 Ubr, $60 \mathrm{~min}$, https://www.ardmediathek. de/swr/player/Y3JpZDovL3N3ci5kZS9hZXgvbzEyMjg0MjY/die-kunst-findet-nic ht-im-saale-statt---der-plakatk-nstler-klaus-staeck

Zitierte Tagesberichterstattung ohne Autorenangabe oder nur mit Autorenkürzel, Entscheidungen, Schriftsätze, Bundestags-Drucksachen und Pressemitteilungen wurden nicht in das Literaturverzeichnis aufgenommen. 


\section{Abbildungsverzeichnis}

Abb. 1-8, 10-11: Klaus Staeck

Abb. 09: Bundesbahn, https://deecee.de/wp-content/uploads/werbung-db-wetter.jpg 